CONTRACTOR REPORT

SAND96-1179

Unlimited Release

UC-523
RECEIVTD

JUH 19 Ty40

OSTI

\title{
An Investigation of Temperature Measurement Methods in Nuclear Power Plant Reactor Pressure Vessel Annealing
}

DOE

Commercial Operating

Light Water Reactor Program

Off. of Eng. \& Tech. Dev.

19901 Germantown Rd.

Germantown, Maryland 20874
EPRI

System and Component Integrity

Technology Group

1300 Harris Blvd.

Charlotte, NC 28262

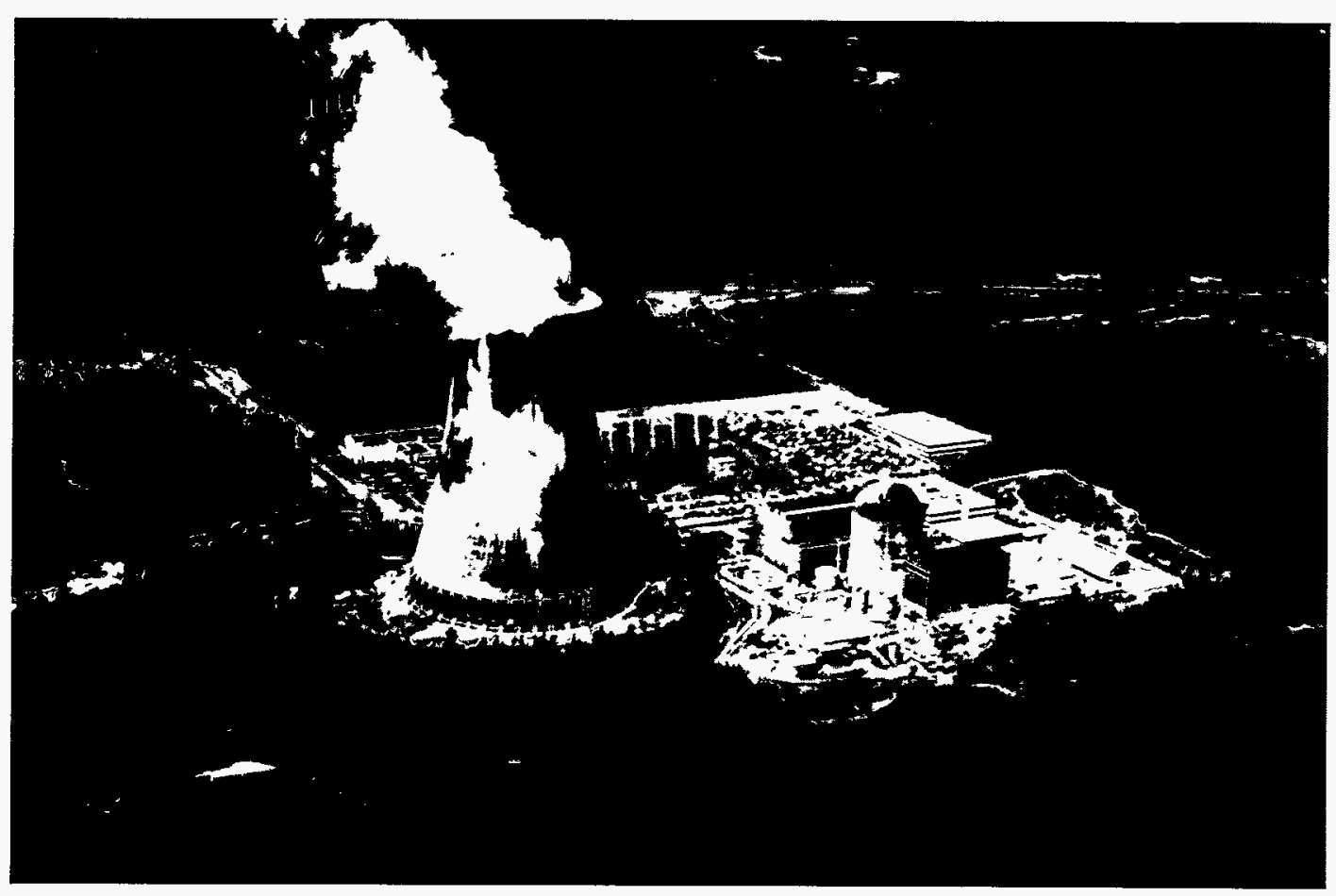

Printed May 1996

Funded by the U.S. Department of Energy under Contract DE-AC04-94AL85000. 
Issued by Sandia National Laboratories, operated for the United States Department of Energy by Sandia Corporation.

NOTICE: This report was prepared as an account of work sponsored by an agency of the United States Government. Neither the United States Government nor any agency thereof, nor any of their employees, nor any of their contractors, subcontractors, or their employees, makes any warranty, express or implied, or assumes any legal liability or responsibility for the accuracy, completeness, or usefulness of any information, apparatus, product, or process disclosed, or represents that its use would not infringe privately owned rights. Reference herein to any specific commercial product, process, or service by trade name, trademark, manufacturer, or otherwise, does not necessarily constitute or imply its endorsement, recommendation, or favoring by the United States

Government, any agency thereof or any of their contractors or subcontractors. The views and opinions expressed herein do not necessarily state or reflect those of the United States Government, any agency thereof or any of their contractors.

Printed in the United States of America. This report has been reproduced directly from the best available copy.

Available to DOE and DOE contractors from Office of Scientific and Technical Information PO Box 62

Oak Ridge, TN 37831

Prices available from (615) 576-8401, FTS 626-8401

Available to the public from

National Technical Information Service

US Department of Commerce

5285 Port Royal Rd

Springfield, VA 22161

NTIS price codes

Printed copy: A07

Microfiche copy: A01 
SAND96-1179

Distribution

Unlimited Release

Printed May 1996

Category UC-523

\title{
An Investigation of Temperature Measurement Methods in Nuclear Power Plant Reactor Pressure Vessel Annealing
}

\author{
R.U. Acton, ${ }^{1}$ W. Gill, D.J. Sais, and D.H. Schulze \\ Thermal Characterization and Simulation Department \\ Sandia National Laboratories \\ and \\ J.T. Nakos \\ DOE's Light Water Reactor Technology Center \\ Advanced Nuclear Power Technology Department \\ Sandia National Laboratories \\ Albuquerque, NM 87185
}

\begin{abstract}
The objective of this project was to provide an assessment of several methods by which the temperature of a commercial nuclear power plant reactor pressure vessel (RPV) could be measured during an annealing process. This project was a coordinated effort between DOE's Office of Nuclear Energy, Science and Technology; DOE's Light Water Reactor Technology Center at Sandia National Laboratories; and the Electric Power Research Institute's NonDestructive Evaluation Center.

Ball-thermocouple probes similar to those described in NUREG/CR-5760, spring-loaded, metalsheathed thermocouple probes, and air-suspended thermocouples were investigated in experiments that heated a section of an RPV wall to simulate a thermal annealing treatment. A parametric study of ball material, emissivity, thermal conductivity, and thermocouple function locations was conducted. Also investigated was a sheathed thermocouple failure mode known as "shunting" (electrical breakdown of insulation separating the thermocouple wires).

Large errors were found between the temperature as measured by the probes and the true RPV wall temperature during heat-up and cool-down. At the annealing soak temperature, in this case $454^{\circ} \mathrm{C}\left[850^{\circ} \mathrm{F}\right]$, all sensors measured the same temperature within about $\pm 5 \%\left(23.6^{\circ} \mathrm{C}\left[42.5^{\circ} \mathrm{F}\right]\right)$. Because of these errors, actual RPV wall heating and cooling rates differed from those prescribed (by up to 29\%). Shunting does not appear to be a problem under these conditions.

The large temperature measurement errors led to the development of a thermal model that predicts the RPV wall temperature from the temperature of a ball-probe. Comparisons between the model and the experimental data for ball-probes indicate that the model could be a useful tool in predicting the actual RPV temperature based on the indicated ball-probe temperature. The model does not predict the temperatures as well for the spring-loaded and air-suspended probes.
\end{abstract}

\footnotetext{
${ }^{1}$ Retired.
} 


\section{Investigation of RPV Temperature Measurement Methods}

\section{Acknowledgments}

This work was performed at Sandia National Laboratories, Albuquerque, New Mexico, by personnel from the Department of Energy's Light Water Reactor Technology Center, Advanced Nuclear Power Technology Department (6471), and the Thermal Characterization and Simulation Department (9735). Funding and support for this work was provided by the U.S. Department of Energy, Commercial Operating Light Water Reactor Program, NE-50, Dennis Harrison, Program Director. The authors acknowledge the work of Bill Jacoby during the instrumentation fabrication and T.Y. Chu for thoughtful comments and improvements to the final report. They would also like to acknowledge the support of Larry Becker of the Electric Power Research Institute's (EPRI) Non-Destructive Evaluation Center in Charlotte, NC, who lent the reactor pressure vessel wall section to Sandia, and to Bob Carter of EPRI's System and Component Integrity Technologies group, who arranged for us to keep the wall section for these tests. 


\section{Investigation of RPV Temperature Measurement Methods}

\section{Contents}

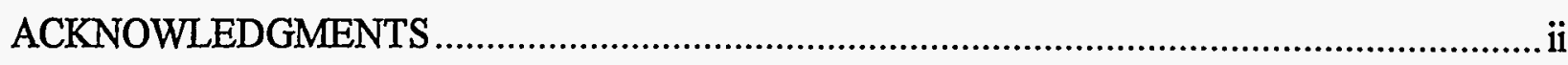

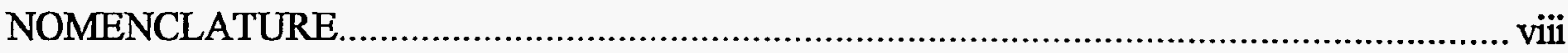

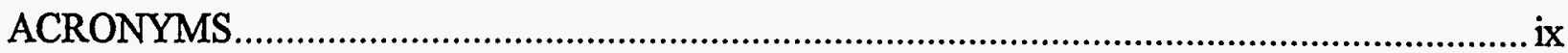

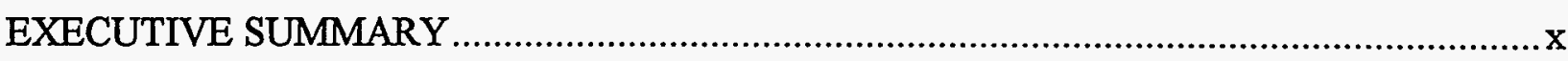

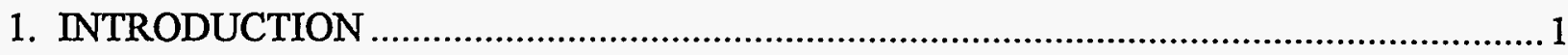

2. EXPERIMENTAL SETUP ..............................................................................

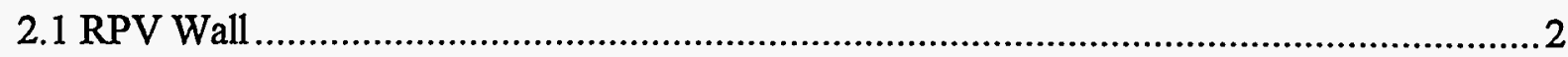

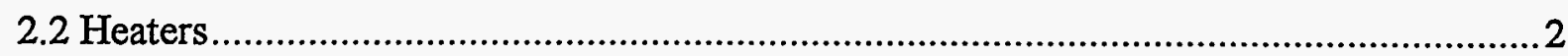

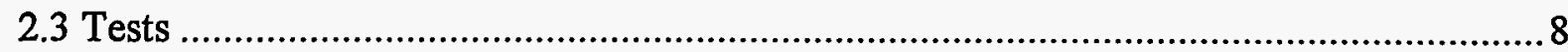

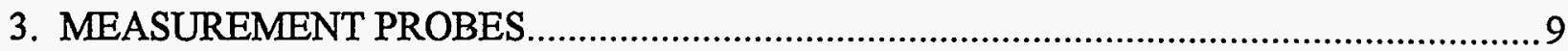

3.1 Ball-Thermocouple Probe Variables..................................................................

3.2 Spot-Welded Wall Thermocouples.............................................................. 14

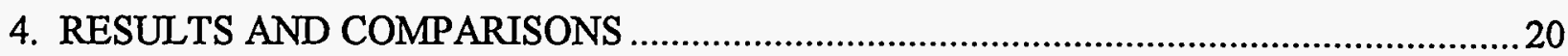

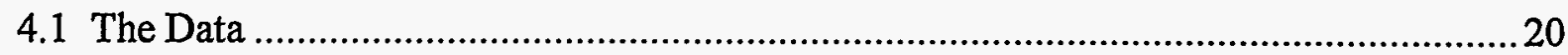

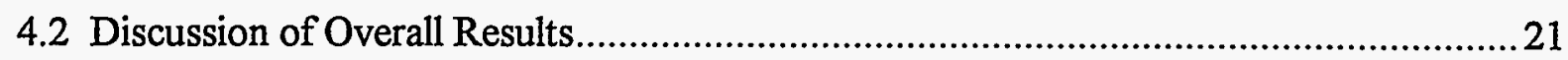

4.3 Summary and Discussion of Results.......................................................... 110

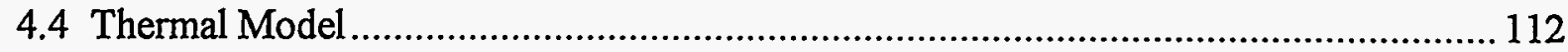

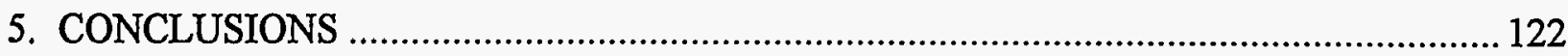

6. SUGGESTIONS FOR FURTHER INVESTIGATIONS .......................................... 124

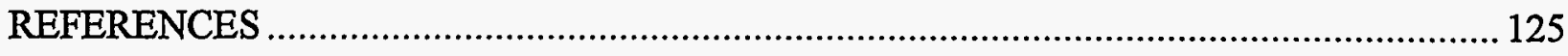

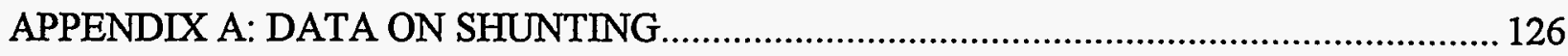

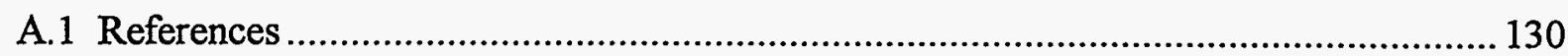

APPENDIX B: THERMAL MODEL ENHANCEMENTS ............................................ 131 


\section{Investigation of RPV Temperature Measurement Methods}

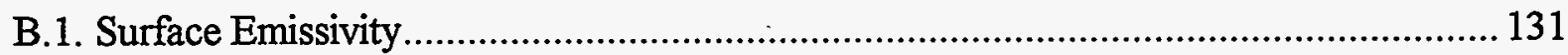

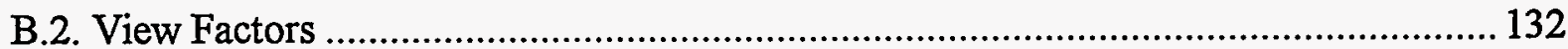

B.3. Conduction and Convection Heat Loss Terms ....................................................... 134

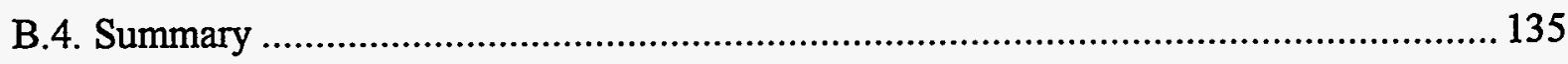

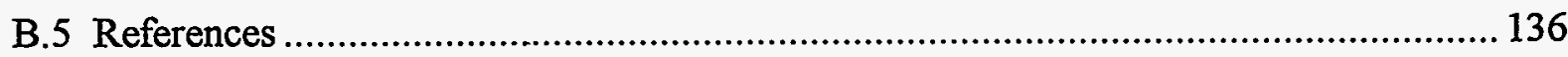


Tables

Table 1: Experimental Matrix for Ball-Probe ............................................................. 13

Table 2. Probe Descriptions.................................................................................. 14

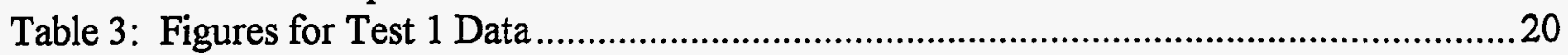

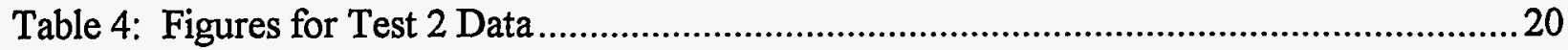

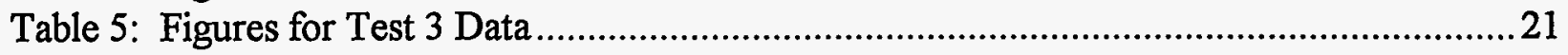

Table 6. Typical Material Properties ...................................................................... 112

Table 7: Test Matrix Probe Identification Numbers....................................................... 120

Table 8: Maximum Temperature Error, ${ }^{\circ} \mathrm{C}\left[{ }^{\circ} \mathrm{F}\right]$............................................................. 120

Table 9: Maximum Temperature Error after Radiation Model Correction, ${ }^{\circ} \mathrm{C}\left[{ }^{\circ} \mathrm{F}\right]$................. 121

Table Al Thermocouple Locations in Shunting Experiments ........................................... 128

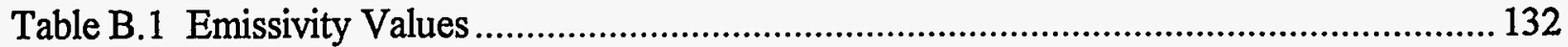

\section{Figures}

Figure 1. Unheated Side of RPV Wall Section ............................................................

Figure 2. Side View of Setup Showing Heaters and Probes ............................................. 4

Figure 3. Overall View of Test Setup ...................................................................... 5

Figure 4. Orientation of RPV Wall Section with Respect to Heaters ......................................6

Figure 5. Side View of Test Setup ............................................................................ 7

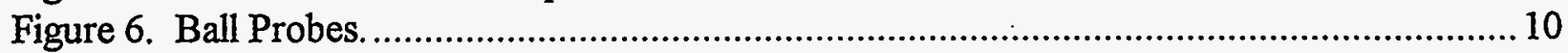

Figure 7. Locations of Thermocouple Measuring Junction in Ball-Probes ............................... 11

Figure 8. Spring-Loaded and Air-Suspended Probes...................................................... 12

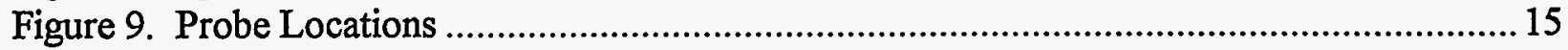

Figure 10. Wall Thermocouple Locations ................................................................. 17

Figure 11. Ball-Probes and Companion Wall Thermocouples............................................. 18

Figure 12. Intrinsic and Sheathed Thermocouples........................................................... 19

Figure 13. Test $1,28^{\circ} \mathrm{C} / \mathrm{hr}\left[50^{\circ} \mathrm{F} / \mathrm{hr}\right]$ Heat-up Rate, Plot of Wall Control.............................26

Figure 14. Test 1, Comparison of Wall TC and Probe Responses, 2.5-cm SS Probes..............27

Figure 15. Test 1, Comparison of Wall TC and Probe Responses, 2.5-cm SS Probes..............28

Figure 16. Test 1, Comparison of Wall TC and Probe Responses, 1.9-cm SS Probes. .............29

Figure 17. Test 1, Comparison of Wall TC and Probe Responses, 1.9-cm SS Probes.............. 30

Figure 18. Test 1, Comparison of Wall TC and Probe Responses, 2.5-cm Brass Probes........... 31

Figure 19. Test 1, Comparison of Wall TC and Probe Responses, 2.5-cm Brass Probes. .......... 32

Figure 20. Test 1, Comparison of Wall TC and Probe Responses, 1.9-cm Brass Probes............ 33

Figure 21. Test 1, Comparison of Wall TC and Probe Responses, 2.5-cm Brass Probes........... 34

Figure 22. Test 1, Comparison of Wall TC and Spring-Loaded Probes ................................35

Figure 23. Test 1, Comparison of Wall TC, Closest Ball-Probe, and Infrared

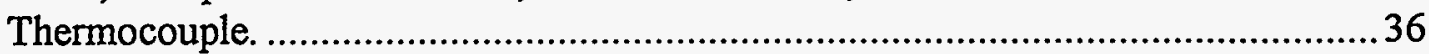

Figure 24. Test 1, Effect of Ball Emissivity on Errors, 2.5-cm SS Probes..............................37

Figure 25. Test 1, Effect of Ball Emissivity on Errors, 1.9-cm SS Probes............................... 38

Figure 26. Test 1, Effect of Ball Emissivity on Errors, 2.5-cm Brass Probes.............................39 


\section{Investigation of RPV Temperature Measurement Methods}

\section{Figures (continued)}

Figure 27. Test 1, Effect of Ball Emissivity on Errors, 1.9-cm Brass Probes............................ 40

Figure 28. Test 1, Effect of Material on Errors, 2.5-cm SS and Brass Probes......................... 41

Figure 29. Test 1, Effect of Material on Errors, 1.9-cm SS and Brass Probes......................... 42

Figure 30. Test 1, Effect of Material on Errors, 2.5-cm SS and Brass Probes.......................... 43

Figure 31. Test 1, Effect of Material on Errors, 1.9-cm SS and Brass Probes......................... 44

Figure 32. Test 1, Effect of Ball Size and Thermocouple Location on Errors, 1.9-cm and

2.5-cm SS Probes. ................................................................................. 45

Figure 33. Test 1, Effect of Ball Size and Thermocouple Location on Errors, 1.9-cm and

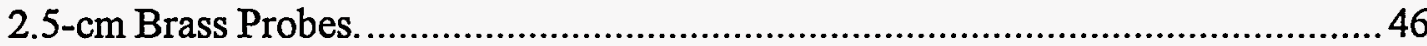

Figure 34. Test 1, Effect of Ball Size and Thermocouple Location on Errors, 1.9-cm and 2.5-cm SS Probes. ............................................................................... 47

Figure 35. Test 1, Effect of Ball Size and Thermocouple Location on Errors, 1.9-cm and

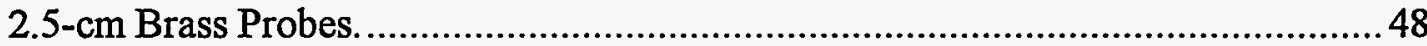

Figure 36. Test 1, Errors Associated with Spring-Loaded Probes. ..................................... 49

Figure 37. Test 1, Check for Shunting Errors. ........................................................ 50

Figure 38. Test 1, Total Electrical Power to Control Zones. ................................................5 51

Figure 39. Test 2, Plot of Control Probes and Heat-up Rate. ............................................ 56

Figure 40. Test 2, Comparison of Wall TC and Probe Responses, 2.5-cm SS Probes. .............57

Figure 41. Test 2, Comparison of Wall TC and Probe Responses, 2.5-cm SS Probes.............. 58

Figure 42. Test 2, Comparison of Wall TC and Probe Responses, 1.9-cm SS Probes. ..............59

Figure 43. Test 2, Comparison of Wall TC and Probe Responses, 1.9-cm SS Probes. ............. 60

Figure 44. Test 2, Comparison of Wall TC and Probe Responses, 2.5-cm Brass Probes. ..........61

Figure 45. Test 2, Comparison of Wall TC and Probe Responses, 2.5-cm Brass Probes. ..........62

Figure 46. Test 2, Comparison of Wall TC and Probe Responses, 1.9-cm Brass Probes. ..........63

Figure 47. Test 2, Comparison of Wall TC and Probe Responses, 1.9-cm Brass Probes. ..........64

Figure 48. Test 2, Comparison of Spring-Loaded Probes and Wall TCs..............................65

Figure 49. Test 2, Effect of Ball Emissivity on Errors, 2.5-cm SS Probes.............................66

Figure 50. Test 2, Effect of Ball Emissivity on Errors, 1.9-cm SS Probes..............................67

Figure 51. Test 2, Effect of Ball Emissivity on Errors, 2.5-cm Brass Probes............................ 68

Figure 52. Test 2, Effect of Ball Emissivity on Errors, 1.9-cm Brass Probes............................69

Figure 53. Test 2, Effect of Material on Errors, 2.5-cm Brass and SS Probes........................... 70

Figure 54. Test 2, Effect of Material on Errors, 1.9-cm Brass and SS Probes........................... 71

Figure 55. Test 2, Effect of Material on Errors, 2.5-cm Brass and SS Probes.......................... 72

Figure 56. Test 2, Effect of Material on Errors, 1.9-cm Brass and SS Probes.......................... 73

Figure 57. Test 2, Effect of Ball Size and Thermocouple Location on Errors, 1.9-cm and

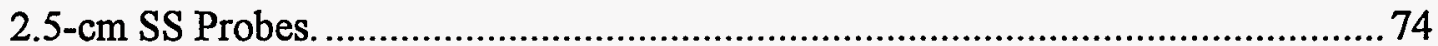

Figure 58. Test 2, Effect of Ball Size and Thermocouple Location on Errors, 1.9-cm and 2.5-cm Brass Probes..................................................................................... 75

Figure 59. Test 2, Effect of Ball Size and Thermocouple Location on Errors, 1.9-cm and 2.5-cm SS Probes. ............................................................................... 76

Figure 60. Test 2, Effect of Ball Size and Thermocouple Location on Errors, 1.9-cm and 2.5-cm Brass Probes. 77 
Figures (continued)

Figure 61. Test 2, Errors Associated with Spring-Loaded Probes. .................................. 78

Figure 62. Test 2, Check for Shunting Errors. .................................................................. 79

Figure 63. Test 2, Total Electrical Power to Control Zones. .............................................. 80

Figure 64. Test 3, Plot of Control Probes and Heat-up Rate. ............................................ 85

Figure 65. Test 3, Comparison of Wall TC and Probe Responses, 2.5-cm SS Probes. ............. 86

Figure 66. Test 3, Comparison of Wall TC and Probe Responses, 2.5-cm SS Probes. ..............87

Figure 67. Test 3, Comparison of Wall TC and Probe Responses, 1.9-cm SS Probes. ............. 88

Figure 68. Test 3, Comparison of Wall TC and Probe Responses, 1.9-cm SS Probes. ..............89

Figure 69. Test 3, Comparison of Wall TC and Probe Responses, 2.5-cm Brass Probes........... 90

Figure 70. Test 3, Comparison of Wall TC and Probe Responses, 2.5-cm Brass Probes.......... 91

Figure 71. Test 3, Comparison of Wall TC and Probe Responses, 1.9-cm Brass Probes.......... 92

Figure 72. Test 3, Comparison of Wall TC and Probe Responses, 1.9-cm Brass Probes........... 93

Figure 73. Test 3, Comparison of Spring-Loaded Probes and Wall TCs................................. 94

Figure 74. Test 3, Effect of Ball Emissivity on Errors, 2.5-cm SS Probes.............................. 95

Figure 75. Test 3, Effect of Ball Emissivity on Errors, 1.9-cm SS Probes.............................. 96

Figure 76. Test 3, Effect of Ball Emissivity on Errors, 2.5-cm Brass Probes...........................97

Figure 77. Test 3, Effect of Ball Emissivity on Errors, 1.9-cm Brass Probes............................98

Figure 78. Test 3, Effect of Material on Errors, 2.5-cm SS and Brass Probes.........................99

Figure 79. Test 3, Effect of Material on Errors, 1.9-cm Brass and SS Probes....................... 100

Figure 80. Test 3, Effect of Material on Errors, 2.5-cm Brass and SS Probes........................ 101

Figure 81. Test 3, Effect of Material on Errors, 1.9-cm Brass and SS Probes........................ 102

Figure 82. Test 3, Effect of Ball Size and Thermocouple Location on Errors, $1.9-\mathrm{cm}$ and 2.5-cm SS Probes. ................................................................................... 103

Figure 83. Test 3, Effect of Ball Size and Thermocouple Location on Errors, $1.9-\mathrm{cm}$ and 2.5-cm Brass Probes. .

Figure 84. Test 3, Effect of Ball Size and Thermocouple Location on Errors, 1.9-cm and 2.5-cm SS Probes.

Figure 85. Test 3, Effect of Ball Size and Thermocouple Location on 1.9-cm and $2.5-\mathrm{cm}$ Brass Probes.

Figure 86. Test 3, Errors Associated with Spring-Loaded Probes. ..................................... 107

Figure 87. Test 3, Check for Shunting Errors. ............................................................. 108

Figure 88. Test 3, Total Electrical Power to Control Zones. ............................................... 109

Figure 89. Test 1 Data and Corrective Model Results for a Ball-Probe ................................ 117

Figure 90. Test 1 Data and Corrective Model Results for a Spring-Loaded Probe.................. 118

Figure 91. Test 1 Data and Corrective Model Results for an Air-Probe................................. 119

Figure A1. Thermocouple Shunting Experiment ..................................................... 127

Figure A2. Results of Sheathed Thermocouple Shunting Experiments.................................. 129 


\section{Investigation of RPV Temperature Measurement Methods}

\section{Nomenclature}

A area, $\mathrm{m}^{2}\left[\mathrm{ft}^{2}\right]$

$c_{p}$

specific heat at constant pressure, $\mathrm{W} \cdot \mathrm{sec} / \mathrm{kg} /{ }^{\circ} \mathrm{C}\left[\mathrm{Btu} / \mathrm{lbm} /{ }^{\circ} \mathrm{F}\right]$

$\mathrm{D} \quad$ diameter, $\mathrm{m}$ [ft]

$\mathrm{f}$ function of

F view factor or shape factor or configuration factor

$\mathrm{h}_{\mathrm{tc}} \quad$ thermal contact conductance, $\mathrm{W} / \mathrm{m}^{2}-^{\circ} \mathrm{C}\left[\mathrm{Btu} / \mathrm{hr} / \mathrm{ft}^{2} /{ }^{\circ} \mathrm{F}\right]$

hr time, hours

$\mathrm{H}$ hardness

I intrinsically mounted thermocouple

Ir $r / \mathrm{tc}^{\circledR} \quad$ infrared thermocouple

$\mathrm{J} \quad$ radiosity

$\mathrm{k}$ thermal conductivity, $\mathrm{W} / \mathrm{m}-{ }^{\circ} \mathrm{C}\left[\mathrm{Btu} / \mathrm{hr} / \mathrm{ft} /{ }^{\circ} \mathrm{F}\right]$

$\mathrm{L} \quad$ length, $\mathrm{m}[\mathrm{ft}]$

q heat flux, W/cm $\mathrm{cm}^{2}\left[\mathrm{Btu} / \mathrm{hr} / \mathrm{ft}^{2}\right]$

$r \quad$ surface roughness

ss stainless steel

$\mathrm{T} \quad$ temperature, ${ }^{\circ} \mathrm{C}\left[{ }^{\circ} \mathrm{F}\right]$

$t$ time

W Wall (spot-welded) thermocouple

Subscripts

$\mathrm{w} \quad$ wall

$\mathrm{p} \quad$ probe

h heater

Greek Symbols

$\sigma$

$\alpha$

$\varepsilon$

$\rho$

Stefan-Boltzmann constant absorptivity of surface emissivity density 


\section{Investigation of RPV Temperature Measurement Methods}

\section{Acronyms}

$\begin{array}{ll}\text { ANSI } & \text { American National Standards Institute } \\ \text { ASTM } & \text { American Society for Testing and Materials } \\ \text { DOE } & \text { Department of Energy } \\ \text { EPRI } & \text { Electric Power Research Institute } \\ \text { MgO } & \text { magnesium oxide insulation } \\ \text { RPV } & \text { Reactor pressure vessel } \\ \text { PTS } & \text { Pressurized thermal shock } \\ \text { FSU } & \text { Former Soviet Union } \\ \text { TCs } & \text { thermocouples }\end{array}$




\section{Executive Summary}

Neutron exposure in the beltline region of a reactor pressure vessel (RPV) causes the steel to become less ductile, lowering its resistance to fracture and making the RPV more susceptible to pressurized thermal shock (PTS). PTS occurs when an RPV is depressurized, then repressurized at a lower temperature. Annealing is the only known embrittlement management technique that restores material properties to the RPV steel. Thermal annealing returns the embrittled portions of the RPV (e.g., beltline welds) to a more ductile state and may be used to extend the service life of the plant. This investigation was undertaken to determine how accurately various methods measure the true temperature of an RPV wall during a thermal annealing procedure.

Commercial nuclear power plant RPVs in the United States have not yet undergone annealing. However, at least 12 Russian-designed VVER 440 RPVs have been successfully annealed in the former Soviet Union. The RPV temperature measuring device used in Russian anneals as described by Cole and Friderichs (1991) was a thermocouple probe that pressed against the reactor wall after the furnace was placed inside the RPV. The probe consisted of a spherical ball (about $1.3 \mathrm{~cm}$ [0.5 in.] diameter) on the end of a $1 \mathrm{~cm}$ [0.38 in.] diameter metal rod. A thermocouple was routed through the rod into the ball. This assembly was hinged so that it could be pivoted against the RPV wall. We fabricated "ball-probes" based on this brief description and investigated this technique with variations in the ball material, size, emissivity, and location of the thermocouple measuring junction inside the ball. Unfortunately, it was not possible to duplicate the Russian measurement technique because not enough detailed information was available. Therefore the ball-probe used in this investigation is not totally representative of the Russian design and the results would differ. It is now known that the ball sizes used in these experiments were much larger than those used in the Russian design.

Other techniques of temperature measurement investigated were (1) spring-loaded, commercial, metal-sheathed thermocouples with a hemispherical tip; (2) metal-sheathed thermocouples freely suspended in the air space between the heater and the wall; and (3) a device called an infrared thermocouple.

A failure phenomenon known as shunting in metal-sheathed thermocouples was also investigated to determine if this failure mode could be a problem in annealing applications. Shunting is caused by the loss of insulation resistance of the magnesium oxide packing insulation at elevated temperatures.

The experimental setup consisted a section of the Phipps Bend RPV. A $3 \times 3$ array of electrical resistance heaters faced the concave (interior) face of the wall section. Programmable controllers regulated the power to the heaters. The probes were inserted through gaps between the heaters and pressed against the wall. A thermocouple was spot-welded to the wall next to each probe being investigated. This spot-welded thermocouple was considered to provide the true RPV wall temperature for its companion probe. 


\section{Investigation of RPV Temperature Measurement Methods}

Three experiments were conducted in which the temperature of the RPV wall was raised to $454^{\circ} \mathrm{C}\left[850^{\circ} \mathrm{F}\right]$ at a prescribed rate, held for a time at the "soak" temperature, and then passively cooled. The tests were

- Test 1 , with spot-welded thermocouples (henceforth called 'wall') controlling at a heat-up rate of $28^{\circ} \mathrm{C} / \mathrm{hr}\left[50^{\circ} \mathrm{F} / \mathrm{hr}\right]$ per hour,

- Test 2 , with ball-probe thermocouples controlling at a heat-up rate of $28^{\circ} \mathrm{C} / \mathrm{hr}$ $\left[50^{\circ} \mathrm{F} / \mathrm{hr}\right]$ per hour,

- Test 3 , with ball-probe thermocouples controlling at a heat-up rate of $14^{\circ} \mathrm{C} / \mathrm{hr}$ $\left[25^{\circ} \mathrm{F} / \mathrm{hr}\right]$ per hour.

Conclusions reached from these three tests are

- All of the probe sensors responded much more rapidly than the RPV wall.

- There were large differences between the RPV wall temperature and the probe temperatures during the heat-up and cool-down phases. These differences (errors) were as large as $150^{\circ} \mathrm{C}\left[270^{\circ} \mathrm{F}\right]$.

- At the soak temperature, all sensors gave the same reading within about $\pm 5 \%$.

- RPV wall heating rates also differed; the probes indicated one rate while the wall was responding at a different rate. Since the heating rate was set to control thermal stresses within the RPV wall, the difference between measured and actual rates may be significant.

- Variations in the ball thermocouple probe construction (material, size, emissivity, and junction location) caused different probe responses. These differences are summarized as:

- Ball material: In all three tests during the heat-up, the brass ball-probes showed smaller errors than the stainless steel ball-probes. Therefore, a higher thermal conductivity is desirable. In two of the tests during the soak, there was no clear distinction as to which probe had smaller errors; during the third test's soak period, the brass probes showed slightly lower errors. During the cool-down there was no clear distinction as to which probe material showed the lower errors.

- Ball emissivity: In all three tests during the heat-up, polished ball-probes had smaller errors than blackened probes, i.e., a low emissivity is desirable. During the soak, polished probes showed slightly less error but during the cool-down there was no clear distinction. 


\section{Investigation of RPV Temperature Measurement Methods}

- Ball size: During Test 1 , the smaller ball size (1.9 $\mathrm{cm}$ [0.75 in.]) had the lowest error during the heat-up, but on all tests the data were inconclusive during the soak. During the heat-up and cool-down in Tests 2 and 3, the larger balls $(2.5 \mathrm{~cm}$ [1.0 in.]) showed slightly lower errors.

- Location of thermocouple measuring junction within the ball: In Test 1 , the junction located closest to the wall had the lowest errors during the heat-up, but in Test 2, the junction in the center of the ball showed the lowest errors. During the soak in all three tests there was no clear distinction. During the cool-down in Tests 2 and 3, the junction located in the center of the ball again showed the lowest errors.

- Sheathed thermocouple shunting does not appear to be a problem under the conditions tested. However, if heaters used in an actual anneal operate at a significantly higher temperature than the heaters in this investigation and metal-sheathed thermocouples are used, this failure mode should be investigated further.

- A thermal model was developed that can be used to predict more accurately the true RPV wall temperature using ball-probe measurements. The model worked best with ball-probes.

- Probe errors were very different in magnitude and character, depending on how the heaters were controlled, i.e., with wall thermocouples (Test 1) or with ball-probes (Tests 2 and 3 ).

- Probe errors were very different in magnitude and character during the heat-up, soak, and cool-down, i.e., errors were negative during the heat-up, smaller than the heat-up or cool-down errors during the soak, and positive during the cool-down. 


\section{Investigation of RPV Temperature Measurement Methods}

\section{Introduction}

Neutron exposure in the beltline region of a reactor pressure vessel (RPV) causes the steel to become less ductile, lowering its resistance to fracture and making the RPV more susceptible to pressurized thermal shock (PTS). PTS occurs when an RPV is depressurized, then repressurized at a lower temperature. Annealing is the only known embrittlement management technique that restores material properties to the RPV steel. Thermal annealing returns the embrittled portions of the RPV (e.g., beltline welds) to a more ductile state and may be used to extend the service life of the plant. This investigation was undertaken to determine how accurately various methods measure the true temperature of an RPV wall during a thermal annealing procedure.

Commercial nuclear power plant RPVs in the United States have not yet undergone annealing. However, at least 12 Russian-designed VVER 440 RPVs have been successfully annealed in the former Soviet Union. The RPV temperature measuring device used in Russian anneals as described by Cole and Friderichs (1991) was a thermocouple probe that pressed against the reactor wall after the furnace was placed inside the RPV. The probe consisted of a spherical ball (about $1.3 \mathrm{~cm}$ [0.5 in.] diameter) on the end of a $1 \mathrm{~cm}$ [0.38 in.] diameter metal rod. A thermocouple was routed through the rod into the ball. This assembly was hinged so that it could be pivoted against the RPV wall. We fabricated "ball-probes" based on this brief description and investigated this technique with variations in the ball material, size, emissivity, and location of the thermocouple measuring junction inside the ball. Unfortunately, it was not possible to duplicate the Russian measurement technique because not enough detailed information was available. Therefore the ball-probe used in this investigation is not totally representative of the Russian design and the results would differ. It is now known that the ball sizes used in these experiments were much larger than those used in the Russian design.

Temperature and time at a specific temperature are two critical parameters in thermal annealing. Heating rates must be accurately known and followed so that RPV thermal stresses are controlled. The soak temperature and time must also be accurately known to ensure that the anneal is complete and the annealing recipe has been followed. The process is complicated by the fact that the outside wall of an RPV is sometimes inaccessible and therefore it may not be possible to attach thermal sensors directly to the RPV wall. The inside is a hostile environment and attachment may not be possible or, if possible, may not be allowed.

The question then is: How closely do temperature measuring techniques determine the true RPV wall temperature? 


\section{Investigation of RPV Temperature Measurement Methods}

\section{Experimental Setup}

\subsection{RPV Wall}

An experimental setup was fabricated using a $1.2 \mathrm{~m} \times 1.2 \mathrm{~m} \times 17.1 \mathrm{~cm}$ [ $4 \mathrm{ft} \times 4 \mathrm{ft} \times 6.75 \mathrm{in}$.] section of the Phipps Bend reactor pressure vessel wall. The section was to Sandia by the Electric Power Research Institute's Non-Destructive Evaluation Center. The radius of curvature of the section is $279.4 \mathrm{~cm}$ [110 in.]. The base material is ASTM A533 Grade B steel with a $3.2-4.8 \mathrm{~mm}$ [0.13-0.19 in.] thick stainless steel cladding on the inside (concave) face. The cladding was applied by a welding process and, consequently, this surface has a somewhat rough texture (see Figure 8). The RPV wall section was previously used in a one-dimensional heat transfer experiment (Nakos et al., 1994) and the instrumentation shown in Figure 1 was reconfigured for this study. The back side of the RPV wall, instrumented from a previous test series, can be seen in Figure 1.

\subsection{Heaters}

An array of electrical resistance heaters faced the concave surface of the RPV wall section at a nominal distance of $25.4 \mathrm{~cm} \mathrm{[10} \mathrm{in.],} \mathrm{nominal} \mathrm{because} \mathrm{the} \mathrm{wall} \mathrm{section} \mathrm{was} \mathrm{curved} \mathrm{and} \mathrm{the} \mathrm{heaters}$

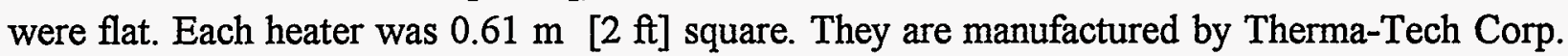
under the name "Type B infrared panel heaters." The heaters have a maximum output of $3.1 \mathrm{~W} / \mathrm{cm}^{2}\left[2.7 \mathrm{Btu} / \mathrm{ft}^{2} \mathrm{sec}\right]$. Nine heaters were used in a $3 \times 3$ array. A side view of the heaters (closeup) can be seen in Figure 2; another view farther away can be seen in Figure 3. Each of the three horizontal rows constituted a control zone. The output of a control thermocouple was used by a programmable controller to regulate the power to that control zone. The RPV wall section was heated at a prescribed rate, held at a soak temperature of $454^{\circ} \mathrm{C}\left[850^{\circ} \mathrm{F}\right]$, and then passively cooled at the same rate as the heat-up. Heat-up rates of $14^{\circ} \mathrm{C} / \mathrm{hr}\left[25^{\circ} \mathrm{F} / \mathrm{hr}\right]$ and $28^{\circ} \mathrm{C} / \mathrm{hr}\left[50^{\circ} \mathrm{F} / \mathrm{hr}\right]$ were used in this investigation. The cool-down rate was the same as the heat-up only to the point at which forced cooling would have been needed to maintain the rate.

In an actual anneal of an RPV using electric resistance heaters, one likely access to the RPV wall will be between the gaps in the heaters. Therefore, in these experiments, all of the RPV temperature measurement probes were placed through the gaps in the heater array. Wall thermocouples (which were not routed between the heaters) were placed next to the probe thermocouples.

Figure 4 shows the relationship between the RPV wall and the heaters. The figure depicts the setup when looking at the back side of the heaters. The heaters extended beyond the edges of the RPV wall approximately 34-41 cm [13-16 in.] in each direction. Figure 5 shows a side view schematic of the setup. The heaters are separated from the RPV wall by a $25-\mathrm{cm}$ [10 in.] air space. The RPV wall was placed on a steel frame; the RPV wall bottom was insulated from the frame using a rigid ceramic-fiber insulation block. Directly behind the RPV wall was a 1.3-1.9 
Investigation of RPV Temperature Measurement Methods

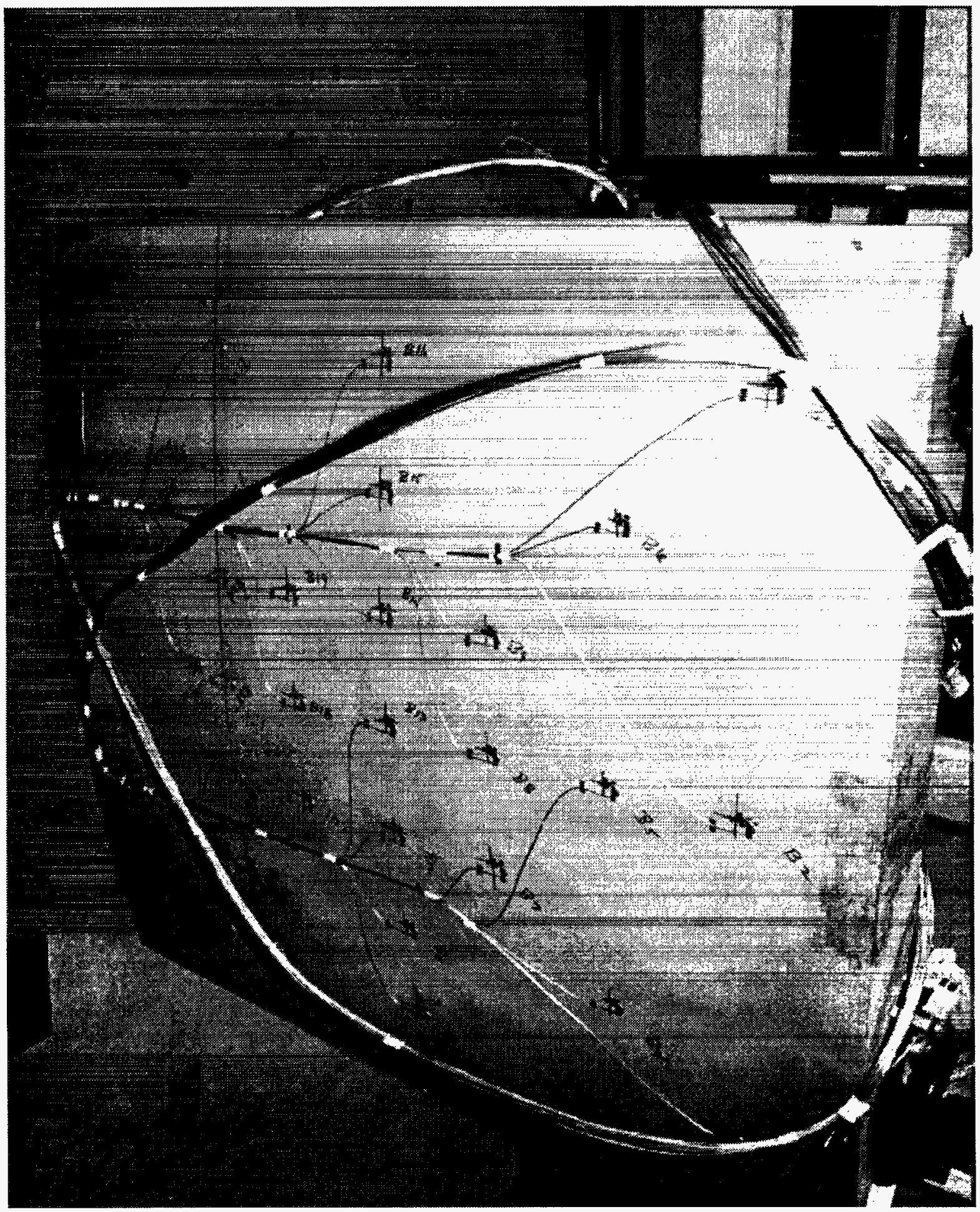

Figure 1. Unheated Side of RPV Wall Section. 
Investigation of RPV Temperature Measurement Methods

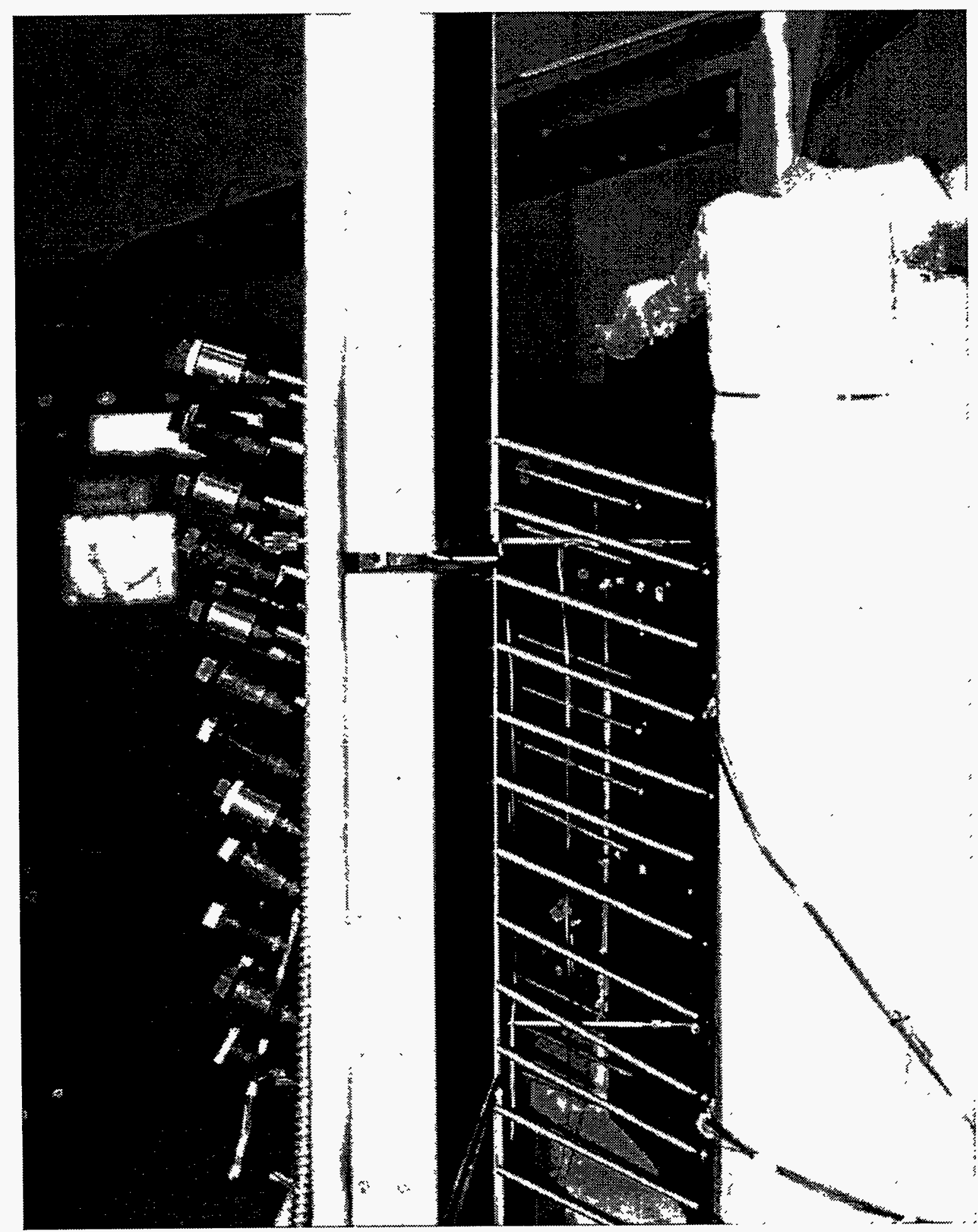

Figure 2. Side View of Setup Showing Heaters and Probes. 
Investigation of RPV Temperature Measurement Methods

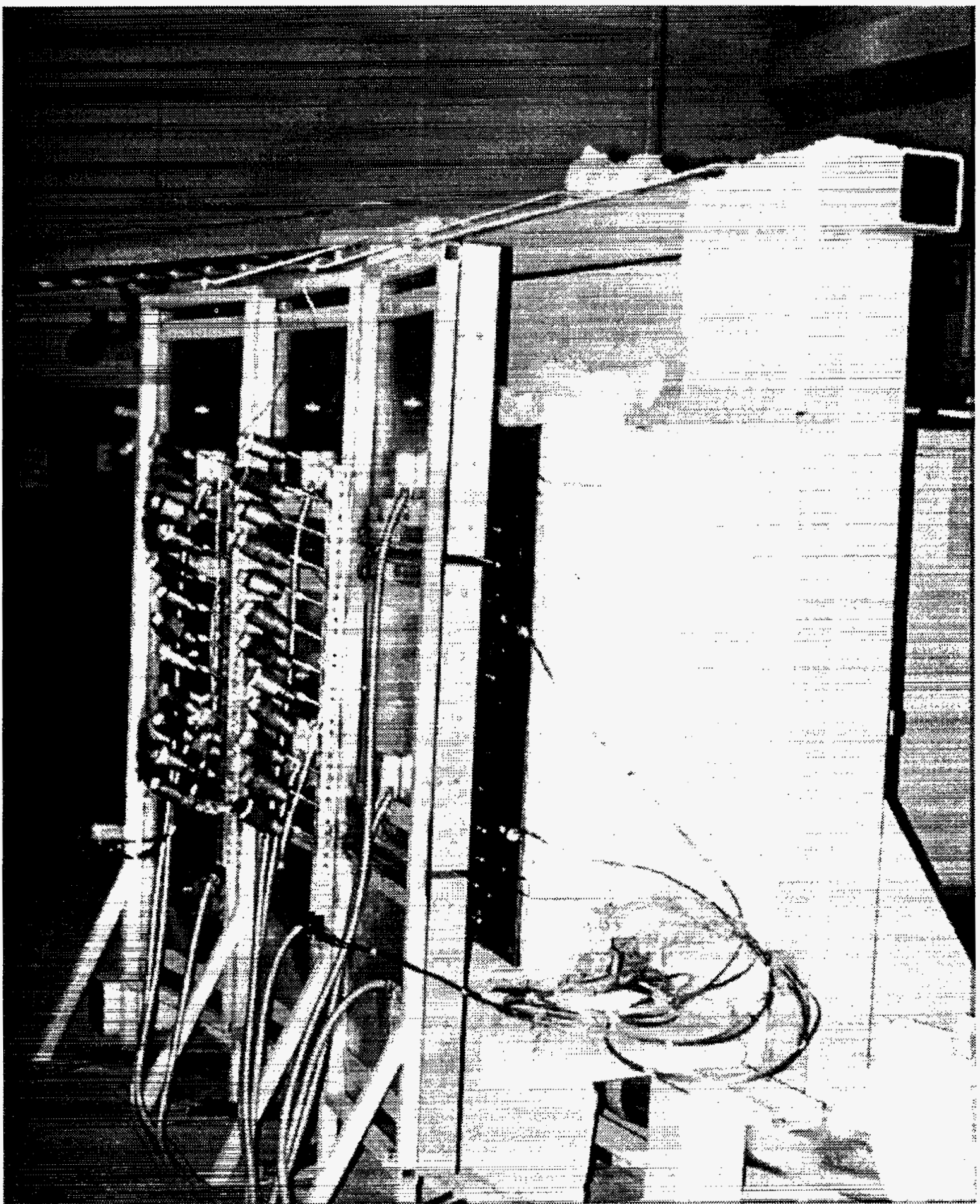

Figure 3. Overall View of Test Setup. 


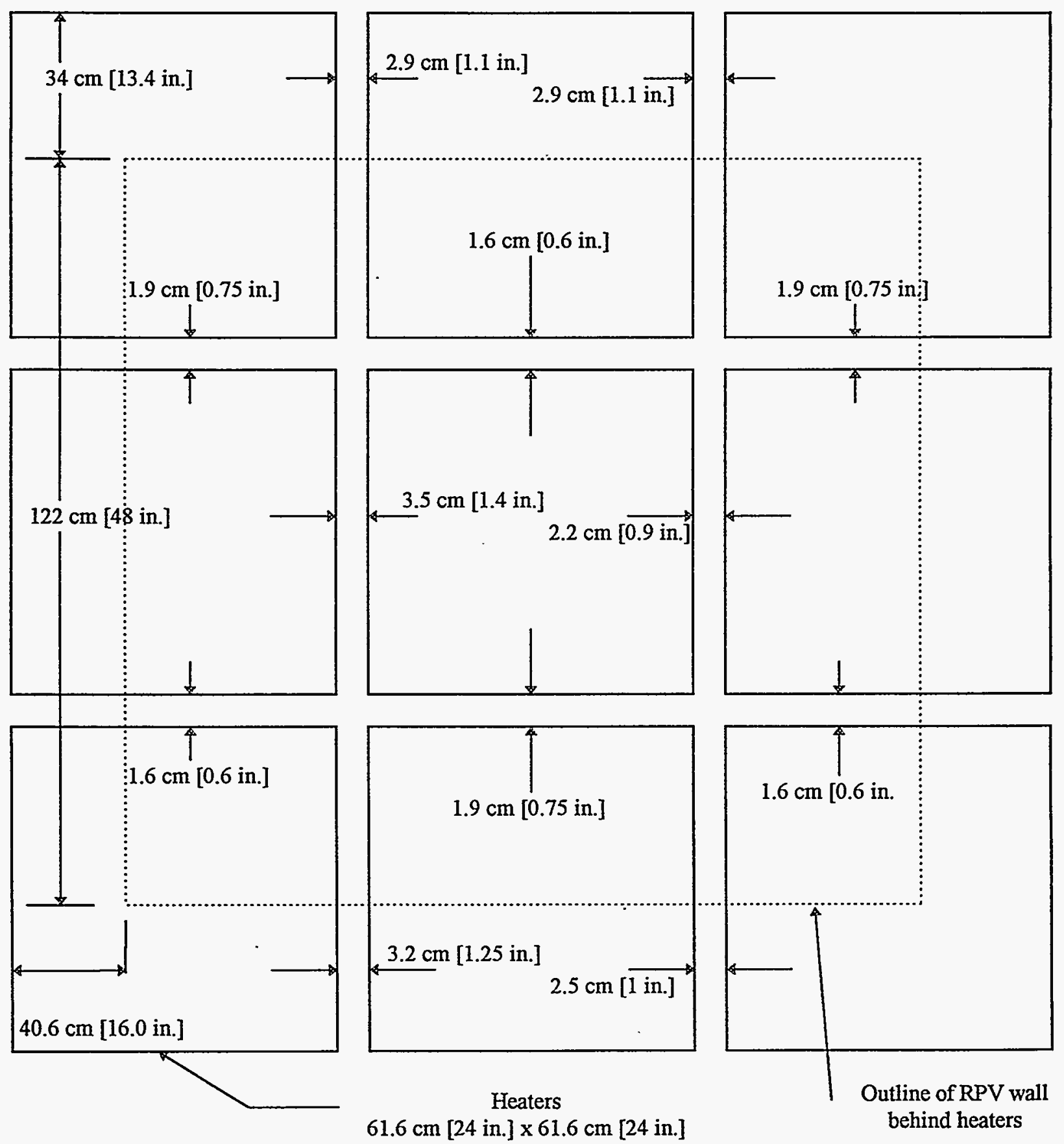

Typ.

Figure 4. Orientation of RPV Wall Section with Respect to Heaters. 
$5.1 \mathrm{~cm}[2 \mathrm{in}] \mathrm{min}$, $10.2 \mathrm{~cm}[4 \mathrm{in}] \max$ gop between concrete wall and insulation

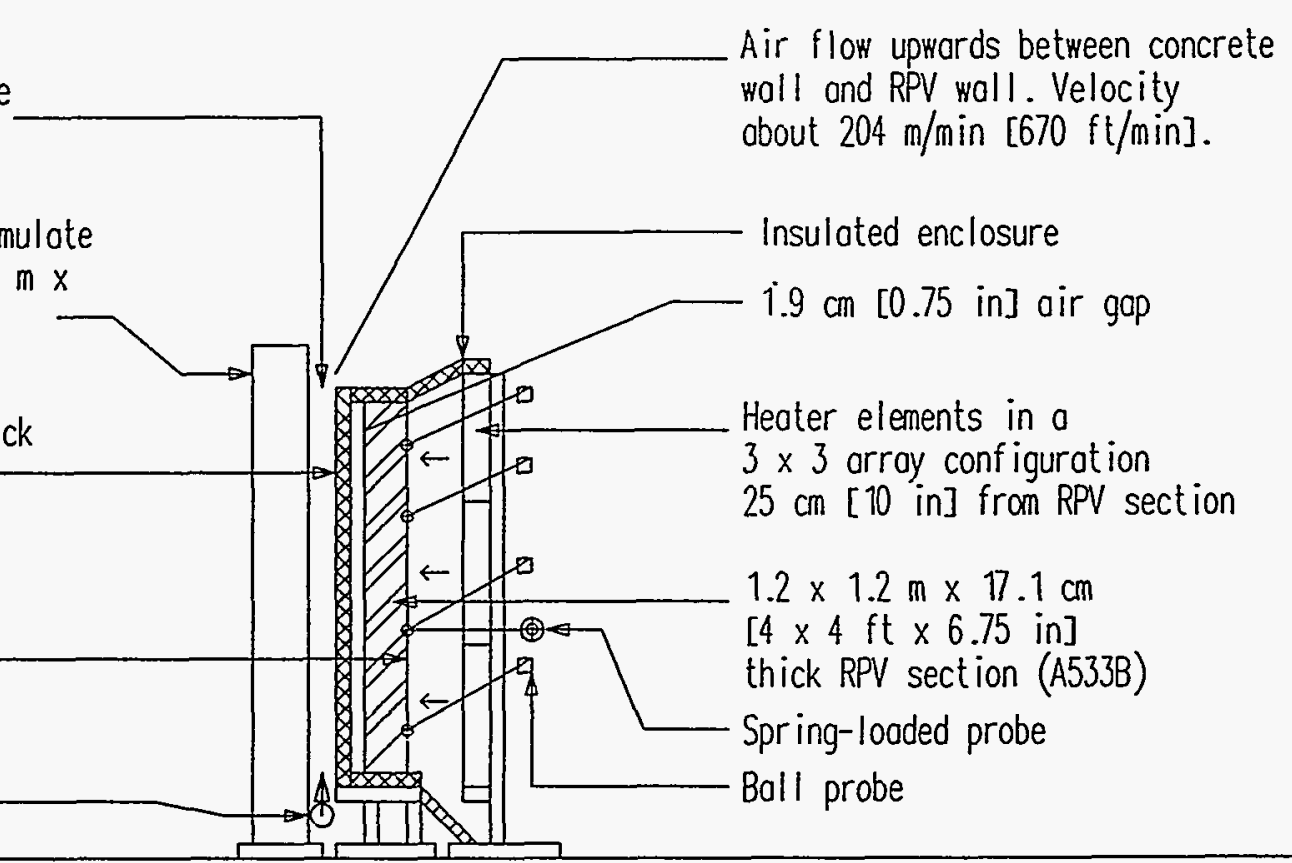

Figure 5. Side View of Test Setup. 


\section{Investigation of RPV Temperature Measurement Methods}

cm [0.5-0.75 in.] air gap. Adjacent to the unheated side of the RPV wall was an insulation assembly composed of a ceramic fiber insulator of $3.8 \mathrm{~cm}$ [1.5 in.] "sandwiched" between two polished aluminum sheets. This "sandwich" insulation approximated a "mirror" insulation typically used in power plants. Behind the insulation assembly was a $2.1 \mathrm{~m} \times 2.1 \mathrm{~m} \times 25.4 \mathrm{~cm}$ thick [ $7 \mathrm{ft} \times 7 \mathrm{ft} \times 10 \mathrm{in}$.] concrete wall to simulate the biological shield wall. The air gap between the concrete wall and the insulation was nominally about $5 \mathrm{~cm}$ [2 in.] (the concrete was flat while the insulation was curved to match the RPV wall).

\subsection{Tests}

Three tests were run with this experimental setup:

Test 1 was run with wall thermocouples as the controlling element for each heater control zone and a heat-up rate of $28^{\circ} \mathrm{C}$ [ $\left.50^{\circ} \mathrm{F}\right]$ per hour. Control thermocouples were wall TCs W27, W28 and W29. Test 1 was not carried through the cooling portion of the cycle,

Test 2 was run with ball-probe thermocouples controlling (PR4, PR14, and PR26) and a heat-up rate of $28^{\circ} \mathrm{C}\left[50^{\circ} \mathrm{F}\right]$ per hour,

Test 3 was run with ball-probe thermocouples controlling (PR4, PR14, and PR26) and a heat-up rate of $14^{\circ} \mathrm{C}\left[25^{\circ} \mathrm{F}\right]$ per hour.

Test 1 used thermocouples attached to the RPV wall section to control the heaters rather than ball-probes. Tests 2 and 3 used ball-probes as control thermocouples to simulate what would occur in an actual anneal. All thermocouples were recorded on all tests. The only difference among the tests was the kind of TC used to control the heater banks. 


\section{Investigation of RPV Temperature Measurement Methods}

\section{Measurement Probes}

Four types of RPV temperature measurement probes were investigated. They are

1. Ball-thermocouple probes contacting the RPV wall at an angle.

2. Spring-loaded thermocouple probes rigid, hemispherically tipped, and mounted perpendicular to the RPV wall.

3. Metal-sheathed thermocouples, suspended in the air space between the heaters and the RPV wall section.

4. A noncontact measurement device called an/infrared thermocouple ( $\left.\mathrm{Ir} / \mathrm{tc} \mathrm{C}^{8}\right)$.

The method described in NUREG/CR-5760 (Cole and Friderichs, 1991) of measuring the RPV wall temperature was used to construct a thermocouple probe that pivoted out from the heater assembly and pressed against the wall after the furnace assembly was lowered into the RPV. The probe consisted of a steel ball on the end of a steel tube. A thermocouple was inserted through the tube into the ball. The probe was hinged so that it could be moved into contact with the wall after the furnace assembly was in place (see Figures 6 and 7). Note that the probe was not attached to the RPV wall but rather pressed against it.

Another concept for measuring the RPV wall temperature is similar to that described above, but uses a rigid, commercially available, spring-loaded metal-sheathed thermocouple with a hemispherical tip that would push against the RPV wall at $90^{\circ}$ (see Figure 8).

The third type was a metal-sheathed thermocouple suspended in the air space between the RPV wall and the heaters. The air-suspended thermocouples were mounted on and suspended from the shafts of the spring-loaded thermocouple probes. At the midpoint between the heaters and the RPV wall, these air-suspended thermocouples were bent so they ran parallel to the wall and heaters and had a free span of about $5 \mathrm{~cm}$ [2 in.] (see Figure 8).

The noncontact device was mounted to "look" directly at the RPV wall. Infrared energy, a function of the RPV wall temperature, was intercepted by the Ir/tc ${ }^{\circledR}$ and the measurement converted to read a temperature value.

Finally, a metal-sheathed, $\mathrm{MgO}$-insulated thermocouple failure phenomenon called "shunting" was studied. The failure phenomenon is described in the next section and in Appendix A.

\subsection{Ball-Thermocouple Probe Variables}

To investigate the ball-thermocouple probe, we developed the experimental matrix shown in Table 1. 


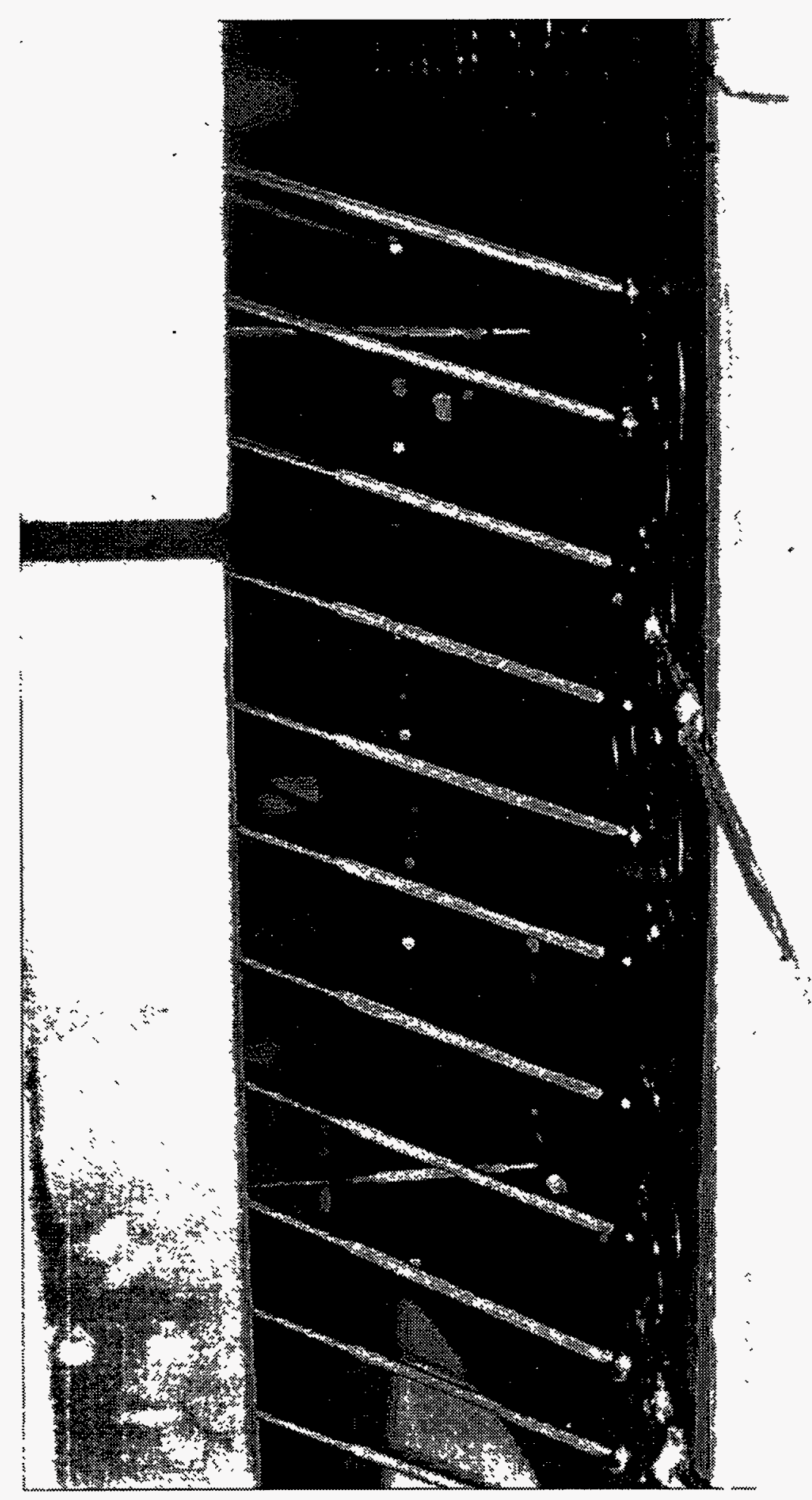

-

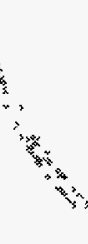

Figure 6. Ball-Probes. 


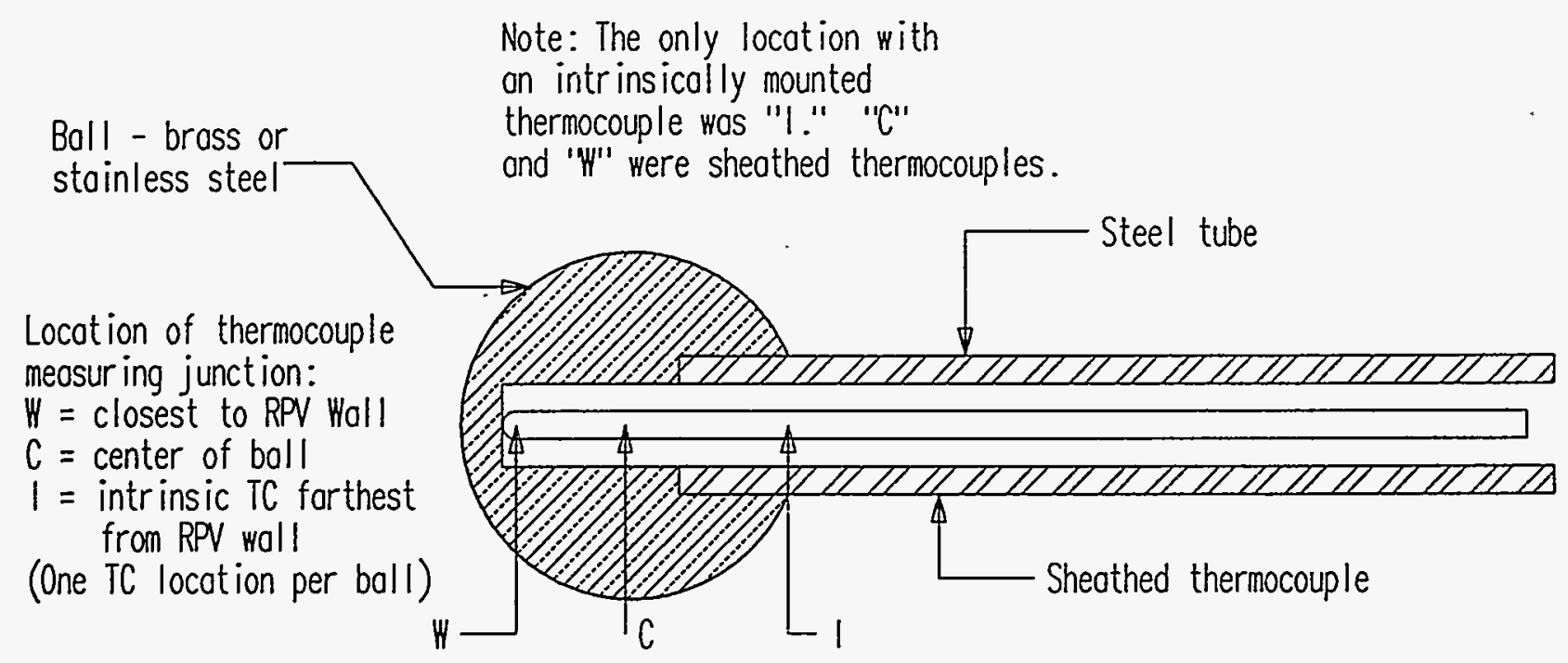

Figure 7. Locations of Thermocouple Measuring Junction in BallProbes. 


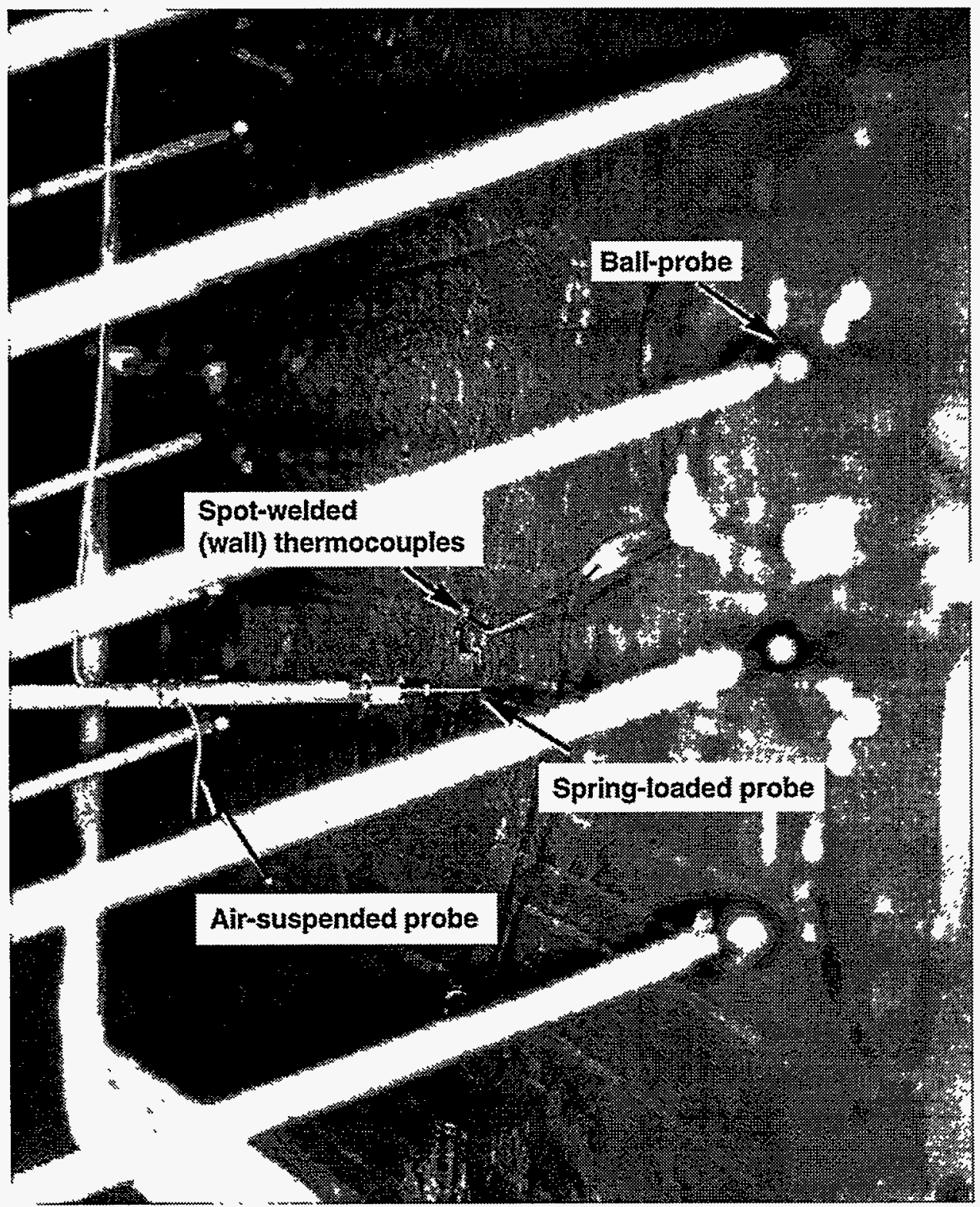

Figure 8. Spring-Loaded and Air-Suspended Probes. 
Table 1: Experimental Matrix for Ball-Probe

\begin{tabular}{|c|c|c|}
\hline Variable & Variations & Comments \\
\hline Material & $\begin{array}{l}\text { 1. Stainless steel } \\
\text { 2. Brass }\end{array}$ & $\begin{array}{l}\text { Thermal conductivity ratio of } \\
\text { about } 9 \text { to } 1\end{array}$ \\
\hline Size & $\begin{array}{l}\text { 1. } 2.54 \mathrm{~cm} \text { diameter [1 inch] } \\
\text { 2. } 1.91 \mathrm{~cm} \text { diameter [3/4 inch] }\end{array}$ & Volume ratio of 2.4 to 1 \\
\hline Emissivity & $\begin{array}{l}\text { 1. Polished }(\varepsilon=0.1) \\
\text { 2. Blackened }(\varepsilon=0.85) \\
\text { (Pyromark }^{\otimes} \text { coating) }\end{array}$ & $\begin{array}{l}\text { Emissivity ratio of } \\
\sim 8.5 \text { to } 1\end{array}$ \\
\hline $\begin{array}{l}\text { Placement of thermocouple } \\
\text { measuring junction within ball }\end{array}$ & $\begin{array}{l}\text { 1. Through ball to near the RPV } \\
\text { wall } \\
\text { 2. Centerline of ball } \\
\text { 3. Intrinsic at tube-ball junction }\end{array}$ & $\begin{array}{l}\text { Nearest to RPV wall } \\
\text { Farthest from RPV wall }\end{array}$ \\
\hline
\end{tabular}

A 4-digit code was used to describe the ball-probes:

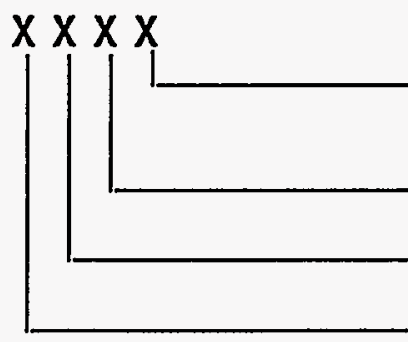

$\mathrm{B}$ or $\mathrm{P}$ for black or polished (polished before first test, no subsequent repolish)

$\mathrm{W}, \mathrm{C}$ or I for wall, centerline or intrinsic

$\mathrm{B}$ or $\mathrm{S}$ for brass or stainless steel

1 or 3 for $1 \mathrm{in}$. [2.54 cm] or $3 / 4 \mathrm{in}$. [1.91 cm] diameter

These codes are used to identify individual curves on the results. For example, a plot of $3 \mathrm{SXX}$ would identify all ball-probes that are $1.9 \mathrm{~cm}$ [0.75 in.] in diameter, made from stainless steel, and that show 6 curves with variations on emissivity and junction placement.

The test matrix yielded 24 ball-probes; 2 spring-loaded, hemispherical-tipped probes; 2 airsuspended probes; and 3 shunt probes. Ball-probe 5 was replaced with the infrared thermocouple in Test 1. After the infrared thermocouple failed in Test 1, ball-probe 5 was reinstalled in place of the $\mathrm{Ir} / \mathrm{tc}{ }^{\otimes}$. Table 2 gives a description of each probe; Figure 9 shows a sketch of the probe locations.

The ball-probes were routed through sleeves that pivot at the back plane of the heaters. Weights (about $0.45 \mathrm{~kg}[1.01 \mathrm{lb}]$ ) were placed over the ends of the portion of the probe tubes that extended backward away from the heaters; they were needed to provide the weight necessary to pivot the probe balls into contact with the RPV wall section. The angle of the probes with the horizontal was about 20 degrees, or the probes were 20 degrees from being perpendicular to the vertical plane of the wall section. 


\section{Investigation of RPV Temperature Measurement Methods}

\section{Table 2. Probe Descriptions}

\begin{tabular}{|c|c|c|c|c|c|c|}
\hline Probes & $\begin{array}{l}\text { Diameter: } \mathrm{cm} . \\
1.91 \mathrm{~cm}[0.75 \mathrm{in} .] \\
2.54 \mathrm{~cm}[1.0 \mathrm{in} .]\end{array}$ & $\begin{array}{c}\text { Material: } \\
\text { Stainless Steel } \\
\text { (SS) Brass (Br) }\end{array}$ & $\begin{array}{c}\text { Thermocouple } \\
\text { Placement }\end{array}$ & $\begin{array}{c}\text { Surface: } \\
\text { polished (P) } \\
\text { Black (B) }\end{array}$ & $\begin{array}{l}\text { Contact Angle } \\
\text { with Wall: } \\
\text { Degree }\end{array}$ & Code \\
\hline 1 & 2.54 & Ss & Intrinsic (I) & $\mathbf{P}$ & 17 & ISIP \\
\hline 2 & 1.91 & SS & I & $\mathrm{P}$ & 12 & 3SIP \\
\hline 3 & 1.91 & SS & I & B & 17 & 3 SIB \\
\hline 4 & 2.54 & ss & Centerline (C) & $\mathbf{P}$ & 14 & ISCP \\
\hline 5 & 1.91 & SS & $\mathrm{C}$ & $\bar{P}$ & 18 & $3 \mathrm{SCP}$ \\
\hline 6 & $*$ & & & & 0 & \\
\hline 7 & 1.91 & $\mathrm{Br}$ & I & B & 16 & 3BIB \\
\hline 8 & 1.91 & $\mathrm{Br}$ & C & B & 21 & $3 \mathrm{BCB}$ \\
\hline 9 & 2.54 & SS & C & $\bar{B}$ & 20 & 1SCB \\
\hline 10 & 2.54 & $\mathrm{Br}$ & C & $P$ & 19 & IBCP \\
\hline 11 & 1.91 & SS & Wall (W) & $\mathrm{P}$ & 18 & 3SWP \\
\hline 12 & 1.91 & $\overline{\mathrm{Br}}$ & $\mathrm{W}$ & $\bar{P}$ & 20 & 3BWP \\
\hline 13 & 2.54 & $\mathrm{Br}$ & I & $\overline{\mathrm{B}}$ & 18 & IBIB \\
\hline 14 & 2.54 & $\mathrm{Br}$ & $\mathrm{W}$ & $\bar{B}$ & 23 & 1BWB \\
\hline 15 & 2.54 & SS & $\mathrm{W}$ & $\mathrm{B}$ & 21 & 1SWB \\
\hline 16 & 1.91 & $\mathrm{Br}$ & C & $\mathrm{P}$ & 23 & $3 \mathrm{BCP}$ \\
\hline 17 & 1.91 & SS & $\mathrm{C}$ & $\mathrm{B}$ & 23 & $3 \mathrm{SCB}$ \\
\hline 18 & 2.54 & $\mathrm{Br}$ & $\mathrm{C}$ & $\mathrm{B}$ & 24 & $1 B C B$ \\
\hline 19 & 2.54 & $\mathrm{Br}$ & $I$ & $\mathbf{P}$ & 25 & 1BIP \\
\hline 20 & 2.54 & SS & $I$ & $\mathrm{~B}$ & 26 & ISIB \\
\hline 21 & 2.54 & SS & $\mathrm{W}$ & $\mathbf{P}$ & 26 & 1SWP \\
\hline 22 & 1.91 & SS & $\mathrm{W}$ & B & 23 & 3SWB \\
\hline 23 & $*$ & & & & 0 & \\
\hline 24 & 1.91 & $\mathrm{Br}$ & W & B & 24 & 3BWB \\
\hline 25 & 1.91 & $\mathrm{Br}$ & I & $P$ & 21 & 3BIP \\
\hline 26 & 2.54 & $\mathrm{Br}$ & $\mathrm{W}$ & $\mathrm{P}$ & 25 & 1BWP \\
\hline
\end{tabular}

\subsection{Spot-Welded Wall Thermocouples}

All thermocouples used in this investigation were type $\mathrm{K}$, chromel-alumel, $1.59 \mathrm{~mm}$ diameter [1/16 in.], stainless steel sheathed and magnesium oxide $(\mathrm{MgO})$ insulated except for the springloaded probes, which were $3.2 \mathrm{~mm}$ [1/8 in.] in diameter. The thermocouple measuring junctions were ungrounded. Thermocouples of this type are manufactured to American National Standards Institute (ANSI) specifications. The specifications for temperature uncertainties are (1) $\pm 2.2^{\circ} \mathrm{C}$ $\left[4^{\circ} \mathrm{F}\right]$ between $0^{\circ} \mathrm{C}$ and $293^{\circ} \mathrm{C}\left[32^{\circ}\right.$ and $\left.559^{\circ} \mathrm{F}\right]$ and (2) $\pm 3 / 4 \%$ of the reading between $293^{\circ}$ and $1256^{\circ} \mathrm{C}$ [559 ${ }^{\circ}$ and $2282^{\circ} \mathrm{F}$ ]. These uncertainties were sufficiently small for this investigation, therefore the thermocouples were not individually calibrated.

A sheathed thermocouple failure mode known as shunting occurs in certain applications. This phenomenon is caused by degradation of the electrical insulating property of the $\mathrm{MgO}$ insulation with temperature. False hot junctions may form in regions where the thermocouple traverses temperatures that are hotter (e.g., $540^{\circ} \mathrm{C}\left[1000^{\circ} \mathrm{F}\right]$, see Appendix A) than the measuring junction. To investigate whether shunting may be a problem in RPV annealing, several thermocouples were 


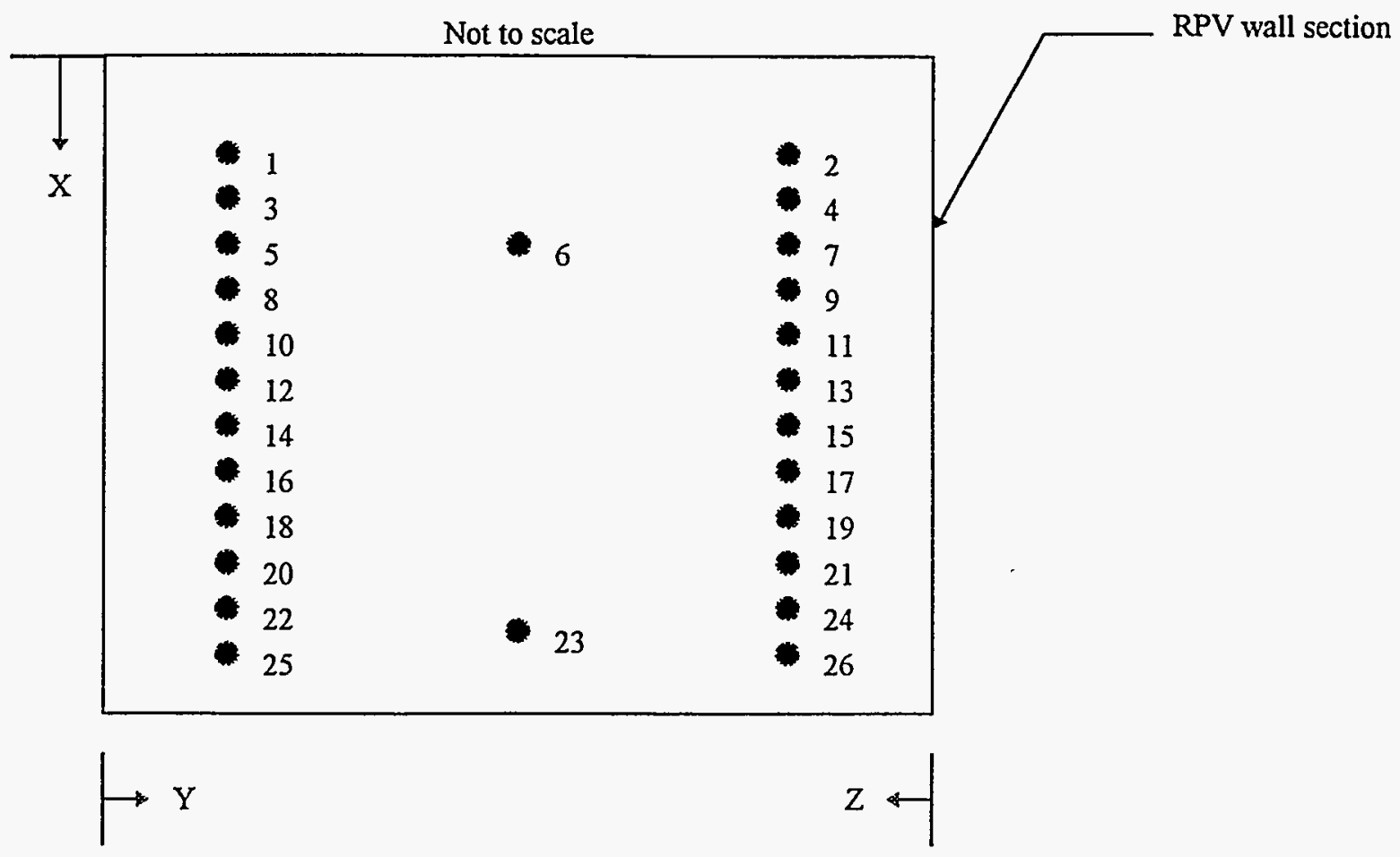

Unit of measure

\begin{tabular}{cllllcllll} 
Probe & $\mathrm{X}(\mathrm{cm})$ & {$[\mathrm{in}]$.} & \multicolumn{2}{c}{$\mathrm{Y}(\mathrm{cm})[$ in.] } & Probe & $\mathrm{X}(\mathrm{cm})[\mathrm{in}]$. & $\mathrm{Z}$ (cm) [in.] \\
\hline 1 & 22.7 & {$[8.9]$} & 21.3 & {$[8.4]$} & 2 & 20.9 & {$[8.2]$} & 25.4 & {$[10.0]$} \\
3 & 31.4 & {$[12.4]$} & 22.5 & {$[8.9]$} & 4 & 29.5 & {$[11.6]$} & 22.5 & {$[8.9]$} \\
5 & 40.3 & {$[15.9]$} & 25.1 & {$[9.9]$} & 7 & 39.5 & {$[15.6]$} & 22.9 & {$[9.0]$} \\
8 & 48.9 & {$[19.3]$} & 22.2 & {$[8.8]$} & 9 & 47.9 & {$[18.9]$} & 22.9 & {$[9.0]$} \\
10 & 55.9 & {$[22.0]$} & 23.2 & {$[9.1]$} & 11 & 56.8 & {$[22.4]$} & 23.2 & {$[9.1]$} \\
12 & 65.1 & {$[25.6]$} & 24.8 & {$[9.8]$} & 13 & 64.8 & {$[25.5]$} & 22.9 & {$[9.0]$} \\
14 & 74.8 & {$[29.4]$} & 26.0 & {$[10.3]$} & 15 & 74.3 & {$[29.3]$} & 22.5 & {$[8.9]$} \\
16 & 84.5 & {$[33.3]$} & 26.4 & {$[10.4]$} & 17 & 84.0 & {$[33.1]$} & 22.5 & {$[8.9]$} \\
18 & 94.5 & {$[37.2[$} & 26.0 & {$[10.3]$} & 19 & 93.0 & {$[36.6]$} & 21.9 & {$[8.6]$} \\
20 & 102.2 & {$[40.3]$} & 24.1 & {$[9.5]$} & 21 & 100.0 & {$[39.4]$} & 21.9 & {$[8.6]$} \\
22 & 108.9 & {$[42.9]$} & 26.0 & {$[10.3]$} & 24 & 107.7 & {$[42.2]$} & 22.9 & {$[9.0]$} \\
25 & 115.3 & {$[45.4]$} & 26.4 & {$[10.4]$} & 26 & 114.6 & {$[45.1]$} & 22.9 & {$[9.0]$} \\
6 & 29.2 & {$[11.5]$} & 58.1 & {$[22.9]$} & & & & & \\
23 & 93.0 & {$[36.6]$} & 58.6 & {$[23.1]$} & & & & &
\end{tabular}

Figure 9. Probe Locations. 


\section{Investigation of RPV Temperature Measurement Methods}

routed along the faces of the electrical heaters before the measuring junction terminated in the air space midway between the heaters and the RPV wall section. One thermocouple was routed this way but was spot welded to the "cold" frame of the experimental setup. See Appendix A for more data on the shunting problem.

The sheathed thermocouples spot-welded to the RPV wall section were considered to give the true RPV wall temperature. Their locations are shown in Figure 10 and were designated W1W32. For every probe, there was a comparison wall thermocouple within $2.5 \mathrm{~cm}$ [ $1 \mathrm{in}$.] (see Figure 11). Three thermocouple locations within the ball-probes were studied. In two of the 3 (wall and center locations) metal-sheathed thermocouples were used, but in the third (farthest from the RPV wall) an "intrinsically" mounted thermocouple was used.

An intrinsic thermocouple uses the material being measured as part of the thermocouple measuring junction, and thus gives readings that are closest to the true temperature (see Figure 12). The intrinsic thermocouples were made by removing the metal sheathing and $\mathrm{MgO}$ insulation from the thermocouple tip. The original junction was cut off, leaving the two thermocouple wires exposed and separated. The chromel and alumel wires were individually spot welded to the tube. This arrangement gives a chromel-steel-steel-alumel junction. By keeping the separation small, one can be sure that the junction is isothermal and that spurious signals are not generated. However, intrinsic thermocouples are delicate and unreliable, and several failed during the test series.

It was demonstrated in an earlier investigation (Nakos et al., 1994) that when RPV temperature was measured, spot-mounted and intrinsic thermocouples gave temperature readings that were within $5^{\circ} \mathrm{C}\left[9^{\circ} \mathrm{F}\right]$ of each other over the entire temperature range used in this investigation; the spot-mounted thermocouples gave the hotter reading during the heat-up. At $454^{\circ} \mathrm{C}\left[850^{\circ} \mathrm{F}\right]$ this difference is about $1 \%$. 


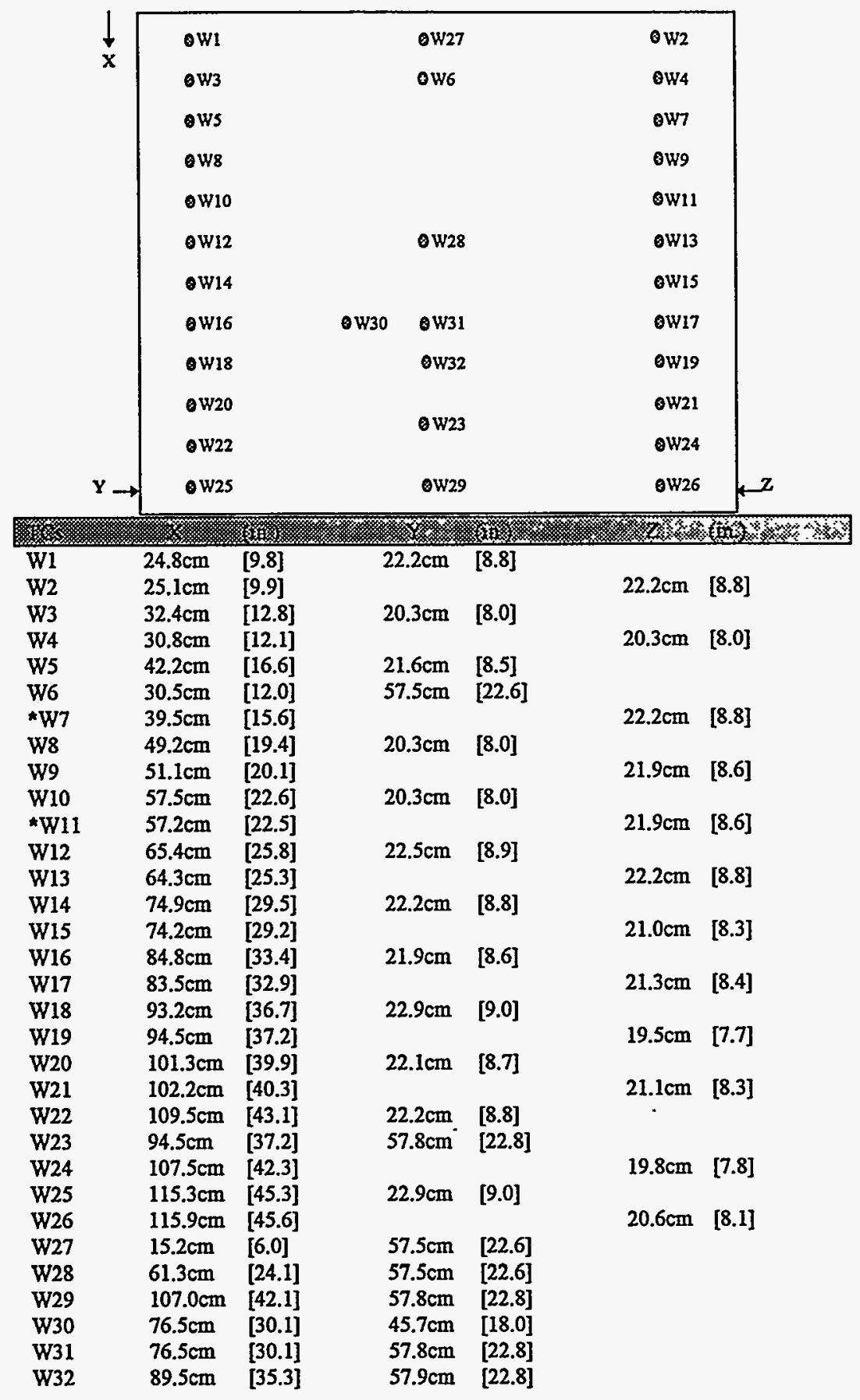

Figure 10. Wall Thermocouple Locations. (*Note that these two thermocouples have probes resting on them.) 


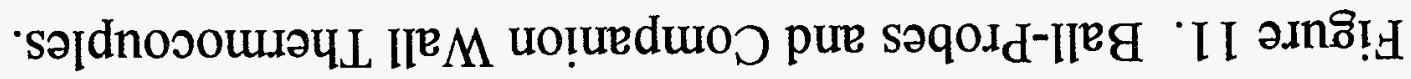

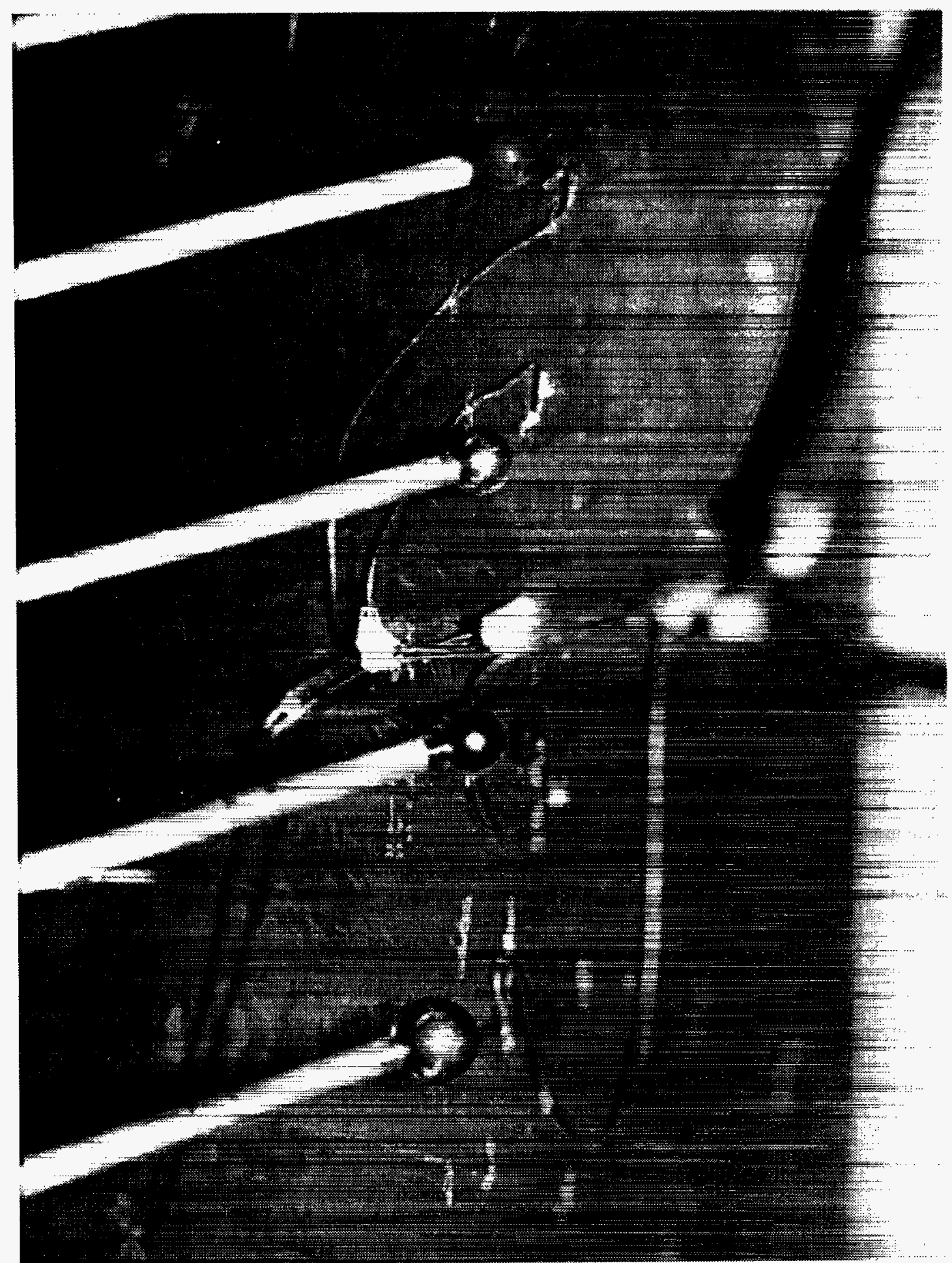




\section{Investigation of RPV Temperature Measurement Methods}

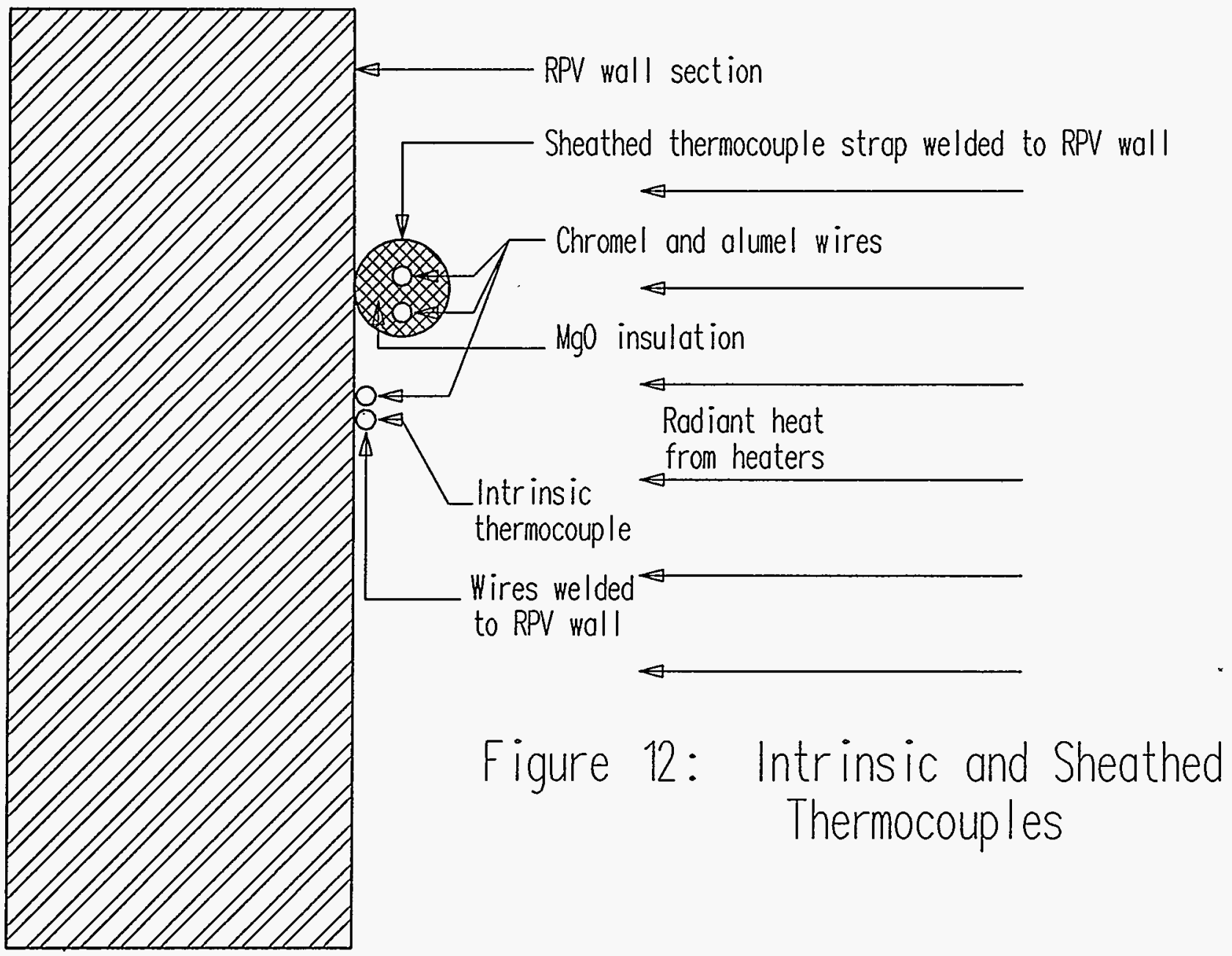

Figure 12. Intrinsic and Sheathed Thermocouples. 


\section{Results and Comparisons}

\subsection{The Data}

The data collected from all of the thermocouples during these tests are shown in the figures as described in the tables below.

Table 3: Figures for Test 1 Data

\begin{tabular}{||l|l|l||}
\hline \hline Figure & \multicolumn{1}{|c|}{ Data in Figure } & \multicolumn{1}{c|}{ Comments } \\
\hline \hline 13 & control thermocouple temperatures & spot-welded thermocouples \\
\hline $14-22$ & $\begin{array}{l}\text { wall and companion probe thermocouple } \\
\text { temperatures }\end{array}$ & grouped by size \& material \\
\hline 23 & Ir/tc ${ }^{\circledR}$, wall \& probe temperatures & $\begin{array}{l}\text { wall \& probe sensors in area } \\
\text { where Ir/tc }{ }^{\circledR} \text { looking }\end{array}$ \\
\hline $24-27$ & ball-probe errors & ball emissivity effect \\
\hline $28-31$ & ball-probe errors & ball material effect \\
\hline $32-35$ & ball-probe errors & TC location and ball size effect \\
\hline 36 & spring-loaded probe errors & spring-loaded probes \\
\hline 37 & air and shunt thermocouple temperatures & $\begin{array}{l}\text { looking for evidence of } \\
\text { shunting errors }\end{array}$ \\
\hline 38 & electrical power & power to 3 control zones \\
\hline
\end{tabular}

Table 4: Figures for Test 2 Data

\begin{tabular}{||l|l|l||}
\hline Figure & \multicolumn{1}{|c|}{ Data in Figure } & \multicolumn{1}{c|}{ Comments } \\
\hline \hline 39 & control thermocouple temperatures & probes PR4, PR14 and PR26 \\
\hline $40-48$ & $\begin{array}{l}\text { wall and companion probe thermocouple } \\
\text { temperatures }\end{array}$ & grouped by size \& material \\
\hline $49-52$ & ball-probe errors & ball emissivity effect \\
\hline $53-56$ & ball-probe errors & ball material effect \\
\hline $57-60$ & ball-probe errors & TC location and ball size effect \\
\hline 61 & spring-loaded probe errors & spring-loaded probes \\
\hline 62 & air and shunt thermocouples temperatures & look for evidence of shunting \\
\hline 63 & electrical power & power to 3 control zones \\
\hline
\end{tabular}




\section{Investigation of RPV Temperature Measurement Methods}

Table 5: Figures for Test 3 Data

\begin{tabular}{||l|l|l||}
\hline Figure & \multicolumn{1}{|c|}{ Data in Figure } & \multicolumn{1}{c|}{ Comments } \\
\hline \hline 64 & control thermocouple temperatures & probes PR4, PR14 and PR26 \\
\hline $65-73$ & $\begin{array}{l}\text { wall and companion probe thermocouple } \\
\text { temperatures }\end{array}$ & grouped by size \& material \\
\hline $74-77$ & ball-probe errors & ball emissivity effect \\
\hline $78-81$ & ball-probe errors & ball material effect \\
\hline $82-85$ & ball-probe errors & TC location and ball size effect \\
\hline 86 & spring-loaded probe errors & spring-loaded probes \\
\hline 87 & air and shunt thermocouples temperatures & look for evidence of shunting \\
\hline 88 & electrical power & power to 3 control zones \\
\hline
\end{tabular}

Test 1 is the only test to show data for the Ir/tc ${ }^{\circledR}$ because the device failed about 14 hours into the test. The cause of failure has not been determined. The output of the Ir/tc ${ }^{\otimes}$ is shown in Figure 23 along with wall thermocouple W5 and ball-probe PR3. These latter two sensors are in the same area at which the $\operatorname{Ir} / \mathrm{tc}^{\circledR}$ was aimed. As can be seen, the $\mathrm{Ir} / \mathrm{tc}^{\circledR}$ had an appreciable error, similar to PR3.

\subsection{Discussion of Overall Results}

\subsubsection{Test 1 Data}

\section{Control Thermocouples}

Figure 13 shows a plot of the three control thermocouples (TCs), W27-W29. As can be seen, they closely follow a linear rise from ambient to $454^{\circ} \mathrm{C}\left[850^{\circ} \mathrm{F}\right]$ at a heat-up rate of $28^{\circ} \mathrm{C} / \mathrm{hr}$ $\left[50^{\circ} \mathrm{F} / \mathrm{hr}\right.$ ]. W27 controlled the top heater bank, W28 the middle heater bank and W29 the bottom heater bank.

\section{Comparison of Wall and Probe Responses}

Figures 14-22 show comparisons of the wall and companion probe responses for all of the probe-wall TC combinations. Figures 14 and 15 show plots for pairs (e.g., W1 and PR1) of $2.5 \mathrm{~cm}$ [1 in.]-diameter, stainless steel (SS) ball-probes. Figures 16 and 17 are for pairs of $1.9 \mathrm{~cm}$ [0.75 in.]-diameter SS ball-probes; Figures 18 and 19 are for $2.5 \mathrm{~cm}$ [1 in.]-diameter brass ballprobes; and Figures 20 and 21 are for $1.9 \mathrm{~cm}$ [0.75 in.]-diameter brass ball-probes. Figure 22 shows pairs of spring-loaded probes and their companion wall TCs. 
In all cases during the heat-up it can be seen that the probes read higher than their companion wall TCs, by a larger amount during the early stages of the heat-up, but by a lesser amount during the later stages of the heat-up. During the soak portion at $454^{\circ} \mathrm{C}\left[850^{\circ} \mathrm{F}\right]$, most of the probes read close to their companion wall TCs. In all cases, the ball-probes probes read within $\pm 23^{\circ} \mathrm{C}$ $\left[ \pm 41^{\circ} \mathrm{F}\right]$ or $\pm 5 \%$ of the soak (i.e., annealing) temperature. The spring-loaded probes (Figure 22) were as much as $27^{\circ} \mathrm{C}$ [ $49^{\circ} \mathrm{F}$ ] (about $6 \%$ ) below the wall temperature. As a result, ball-probe designs read within $\pm 5 \%$ of the actual RPV wall temperature during the soak. However, the probe errors were substantial, as high as $150^{\circ} \mathrm{C}\left[270^{\circ} \mathrm{F}\right]$, during the early part of the heat-up.

\section{Infrared Thermocouple}

Figure 23 shows a comparison of the infrared TC $\left(\mathrm{Ir}_{\mathrm{rtc}} \mathrm{t}^{8}\right)$ and its companion TC on the wall (W5) and the ball-probe (PR3). The Ir $/ \mathrm{tc}^{\otimes}$ failed at about 14 hours. Before that time, its error was similar, but slightly less than that of probe PR3. There is little to conclude from this limited amount of data; however, it may be that the $\operatorname{Ir} / \mathrm{tcs}^{\otimes}$ are not very reliable and not very accurate in this type of application. There will be no further discussion of the Ir/tc ${ }^{\circledR}$.

\section{Data Not Shown}

Plots of wall TCs W30, W31, and W32 are not shown for any of the tests because the results were not useful.

\section{Error Plots: Differences between the Wall Thermocouples and Probes}

Figures 24-36 show plots of the difference between the wall TCs and their companion probes. A typical curve goes sharply negative soon after the heat-up begins, then slowly rises with time until the soak begins, at which time the curve approaches a steady-state value close to zero. Stated differently, a typical probe measurement error goes sharply negative at the beginning of the heat-up, slowly decreases with time until the end of the heat-up, and rapidly drops to a steadystate value (usually small) during the soak. In a majority of the cases, the probes located in the lower third of Figure 9 had the least error, the probes located in the top third in Figure 9 had the most error, and the middle third had errors in between. It is not clear why this trend occurred.

\section{The Effect of Ball-Probe Emissivity (Absorptivity)}

Figures 24-27 show the effect of the ball emissivity (or absorptivity) on the error. (Emissivity and absorptivity are assumed to be equal.) "Polished" probes were clean and unpainted; "blackened" probes were painted with a high-absorptivity black paint called "Pyromark black®." Figure 24 shows $2.5 \mathrm{~cm}$ [1 in.]-diameter SS probes; Figure 25 shows $1.9 \mathrm{~cm}$ [0.75 in.]-diameter SS probes; Figure 26 shows $2.5 \mathrm{~cm}$ [1 in.]-diameter brass probes; and Figure 27 shows $1.9 \mathrm{~cm}$ [0.75 in.]-diameter brass probes.

In all cases during the heat-up, one can see that the polished probes had the lowest errors. During the soak, in almost all cases, the polished probes showed lower errors. The overall errors 


\section{Investigation of RPV Temperature Measurement Methods}

were very large during the initial part of the rise, then dropped to less than $\pm 23^{\circ} \mathrm{C}\left[ \pm 41^{\circ} \mathrm{F}\right]$, about $\pm 5 \%$, during the soak.

This behavior may be explained by noting that, during the heat-up, a significant amount of radiant energy is impinging on both the wall and the probes. Contact resistance between the probes and the RPV wall prevented the ball-probes from reaching the same temperature as the wall. The blackened probes absorbed more energy than the polished probes, thus generating a larger error. However, during the soak, there is almost no net heat transfer between the heaters and the RPV wall. Therefore, errors for all probes are lower during the soak, but the polished probes are still more accurate.

\section{The Effect of Ball-Probe Material}

Figures 28-31 show the differences in errors due to ball-probe material: stainless steel or brass. Figure 28 shows temperature differences between wall TCs and $2.5 \mathrm{~cm}$ [1 in.]-diameter polished SS or brass ball-probes for three different TC measuring junction locations (see Figure 7). Figure 29 shows temperature differences between wall $\mathrm{TCs}$ and $1.9 \mathrm{~cm}$ [0.75 in.]-diameter polished SS or brass ball-probes for two different TC measuring junction locations. Figure 30 shows temperature differences between wall TCs and $2.5 \mathrm{~cm}$ [1.0 in.]-diameter blackened SS or brass ball-probes, and Figure 31 shows temperature differences between wall $\mathrm{TCs}$ and $1.9 \mathrm{~cm}$ [0.75 in.]-diameter blackened SS or brass ball-probes.

In all cases, the brass probes, with a higher thermal conductivity, had lower errors than similar SS probes during the heat-up portion. During the soak, all errors were much smaller, but only in some cases were the brass probe errors smallest. In many cases it was not possible to distinguish which probe material had the lower error. It is believed that this behavior is due to the brass probes having lower contact resistance (see Section 4.3 for more information). During the soak there was little radiant heat exchange and therefore the conductivity of the ball material was not as important to the error.

\section{The Effect of Ball Size}

Figures 32-35 show error plots associated with ball size and thermocouple location within the ball. The effect of ball size will be discussed here; the effect of TC location will be discussed in the next subsection. Figure 32 shows errors of both $1.9 \mathrm{~cm}$ [0.75 in.] and $2.5 \mathrm{~cm}$ [1.0 in.]diameter polished stainless steel (SS) probes; Figure 33 shows errors of both $1.9 \mathrm{~cm}$ [0.75 in.] and $2.5 \mathrm{~cm}$ [1.0 in.]-diameter polished brass probes; Figure 34 shows errors of both $1.9 \mathrm{~cm}$ [0.75 in.] and $2.5 \mathrm{~cm}$ [1.0 in.]-diameter blackened SS probes; Figure 35 shows errors of both $1.9 \mathrm{~cm}$ [0.75 in.] and $2.5 \mathrm{~cm}$ [1.0 in.]-diameter blackened brass probes.

In most cases during the heat-up, the $1.9 \mathrm{~cm}$ [0.75 in.]-diameter (smaller diameter) probes had the lowest error. However, the data are inconclusive for the soak period. 


\section{Investigation of RPV Temperature Measurement Methods}

One may explain the smaller ball size having the lower error by noting that a smaller size ball is less affected by the radiative heat transfer from the heater. During the soak there was little net radiant heat exchange (i.e., the heaters required much less power during the soak period) and therefore the ball size was not as important to the error.

\section{The Effect of Thermocouple Placement in the Ball}

Figures 32-35 show plots of the errors associated with the location of the TCs in the ball. Figure 32 shows errors of both $1.9 \mathrm{~cm}$ [0.75 in.] and $2.5 \mathrm{~cm}$ [1.0 in.]-diameter polished SS balls. Figure 33 shows errors of both $1.9 \mathrm{~cm}$ [0.75 in.] and $2.5 \mathrm{~cm}$ [1.0 in.]-diameter polished brass balls; Figure 34 shows errors for both $1.9 \mathrm{~cm}$ [0.75 in.] and $2.5 \mathrm{~cm}$ [1.0 in.]-diameter blackened SS balls; and Figure 35 shows both $1.9 \mathrm{~cm}$ [0.75 in.] and $2.5 \mathrm{~cm}$ [1.0 in.]-diameter blackened brass balls.

In a majority of cases, the errors associated with TCs located closest to the RPV wall were the lowest during the heat-up. In a few cases, the other locations showed lower error. During the soak, no clear distinction could be determined.

One possible explanation for the lower error of the location within the ball closest to the RPV wall may be that the location closest to the RPV wall is likely to have a temperature more like the RPV wall temperature than the other two locations because there is likely some temperature gradient in the ball, and the locations touching the wall may be closer to the RPV temperature.

\section{Spring-Loaded Probes}

Figure 36 shows the errors associated with the spring-loaded probes for Test 1 . The shapes of the curves are similar to those in the ball-probe plots and the magnitude of the errors during the heat-up is in the same range as those of the ball-probes. However, for PR23 during the soak, the error was larger than for ball-probes $\left(28^{\circ} \mathrm{C}\left[50^{\circ}\right]\right)$ or about $6 \%$. The error for PR6 was smaller than for some ball-probes $\left(11^{\circ} \mathrm{C}\left[20^{\circ} \mathrm{F}\right], 2.4 \%\right)$ during the soak. Although the errors during the soak were not very large, a design of this type would not be used without a radiation shield; shields were not used on these tests because we wanted to obtain a baseline for the errors with the simplest design.

\section{The "Air" Temperature and Shunting Error Thermocouples}

Figure 37 shows the response of the air temperature measurements (W33, W34, W35 and W36) and the TCs that were used to check for shunting errors (W35, W36 and W37). W35 and W36 acted as both air temperature measurements and TCs used to check for shunting. W33 W36 responded in a similar manner to a typical ball-probe, but had larger absolute errors. W37 showed very little change in temperature and showed no evidence of shunting errors. W35 and W36 responded in a manner very similar to W33 and W34, also with no evidence of shunting. The large difference between W33 and W34 was a result of position, not shunting. If shunting were to 


\section{Investigation of RPV Temperature Measurement Methods}

occur, the result would be an unexplained "hump" in the data during the heat-up (see Appendix A).

\section{Electrical Power to Heater Zones}

Figure 38 shows a plot of the total electrical power supplied to each of the three control zones (top, middle, and bottom). During the heat-up, the bottom required the greatest power, followed by the middle and the top; the top and bottom zones required increasing power while the middle zone was almost constant. This plot is consistent with those presented previously (Nakos et al., 1994), and indicates that the mounting frame near the bottom heater bank absorbs a considerable amount of energy, thus requiring more power on the bottom zone than either the middle or top zones. Convection heating also contributed to a lower power requirement for the middle and upper zones than for the lower zone.

During the soak portion beginning at about 15-16 hours, all three power channels showed a reduction in power, with the middle zone showing the largest decrease.

An item of note when data from Tests 2 and 3 are presented is the relative stability of the power in Figure 38 - the curves are relatively stable except for the first few hours. 


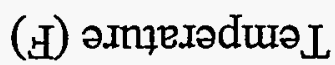

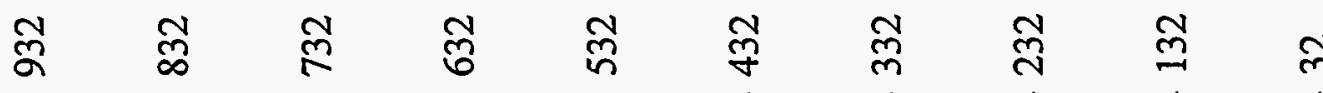

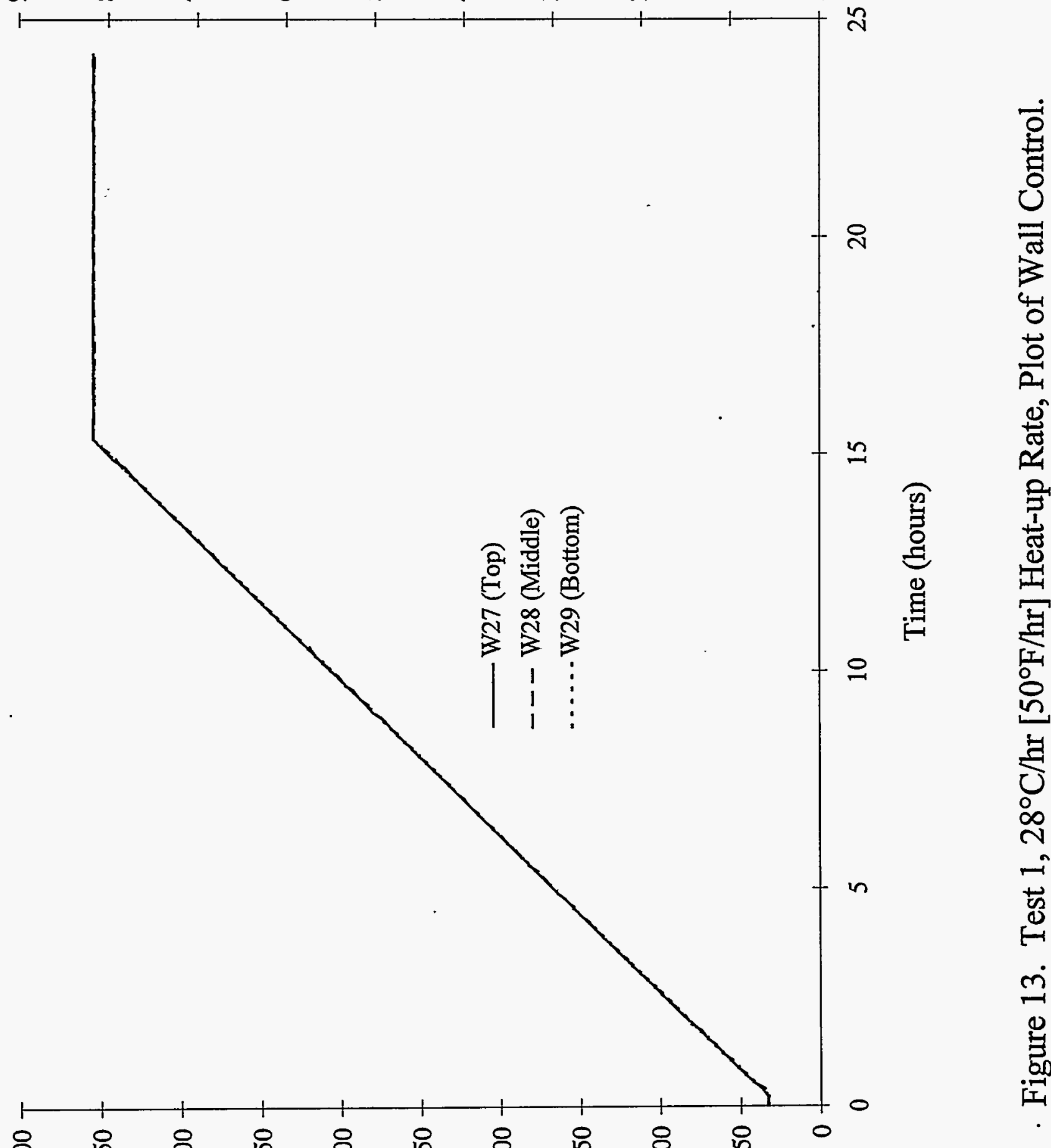

유 \& \&

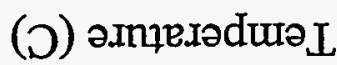




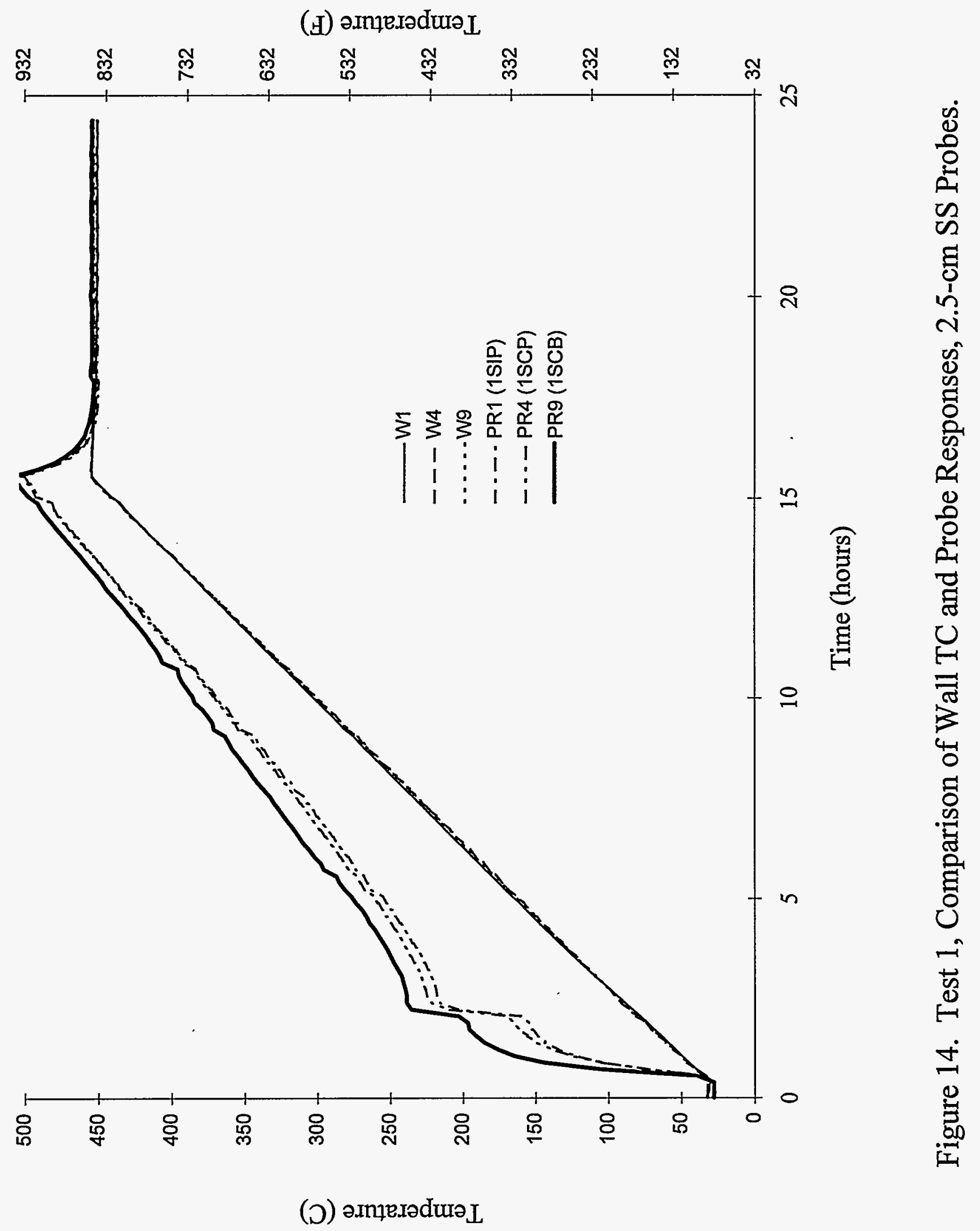




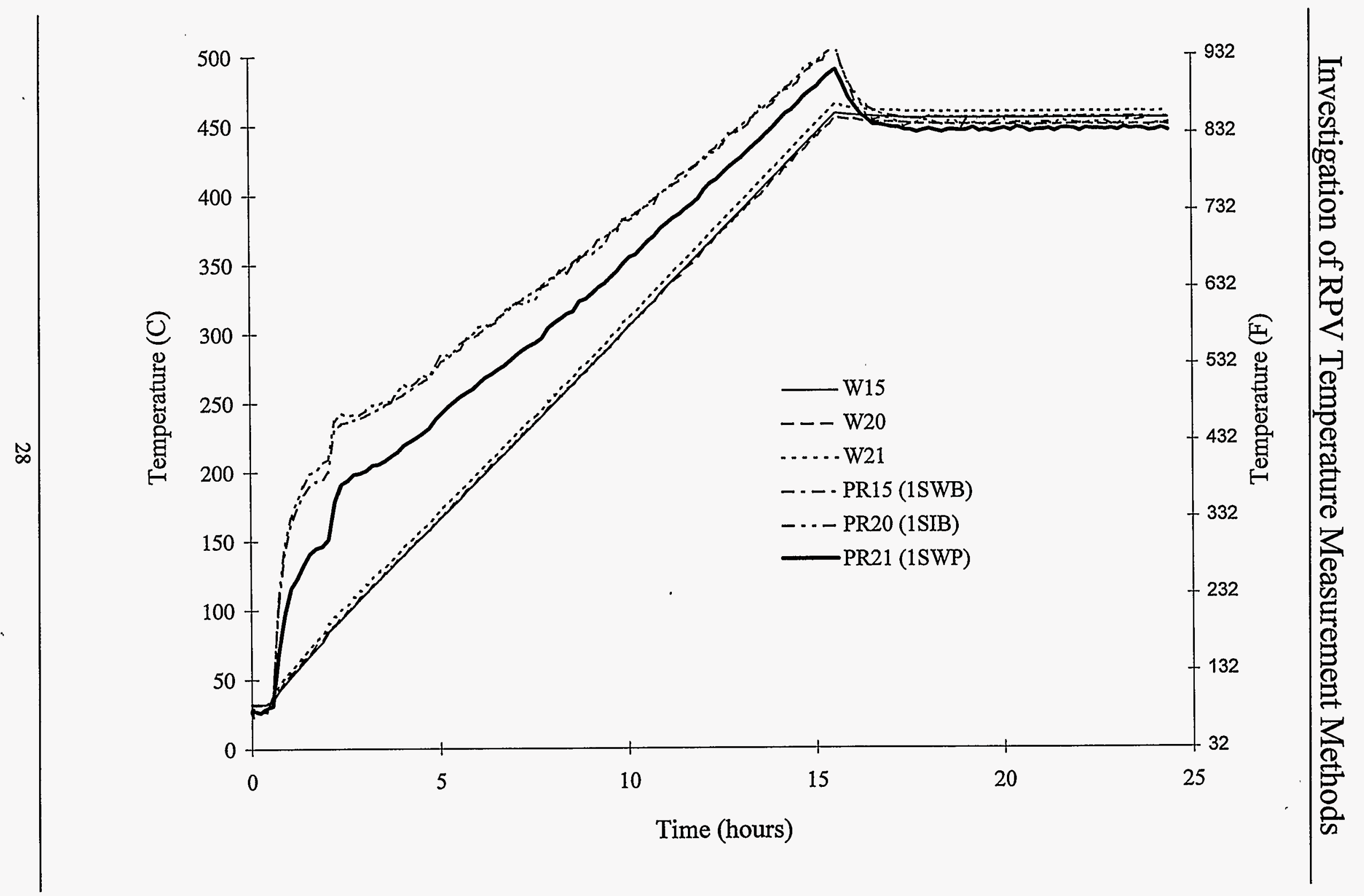

Figure 15. Test 1, Comparison of Wall TC and Probe Responses, 2.5-cm SS Probes. 
(A) əxпุеxəduีว $L$

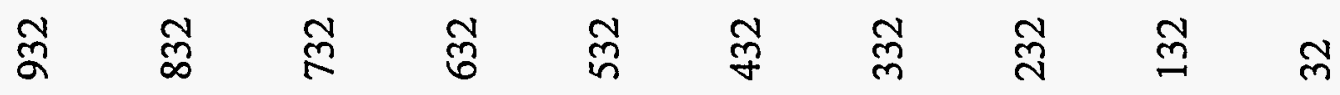

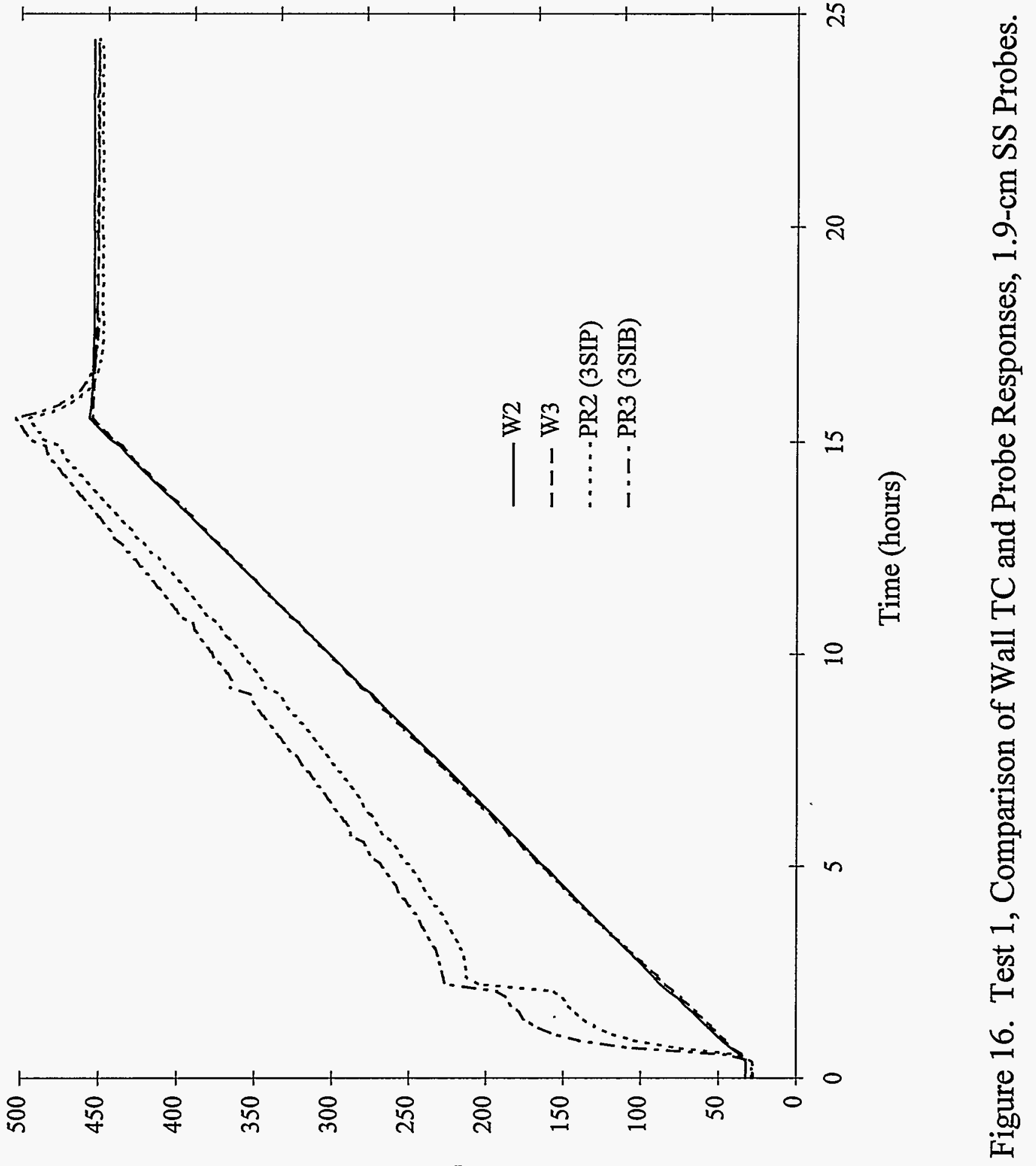

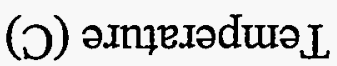




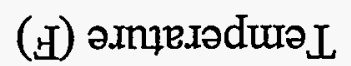

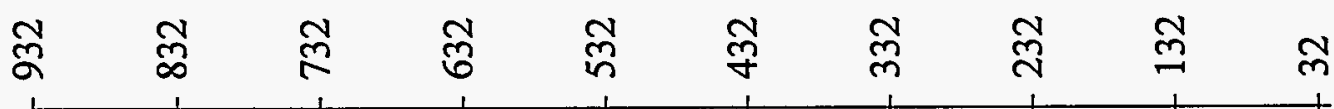

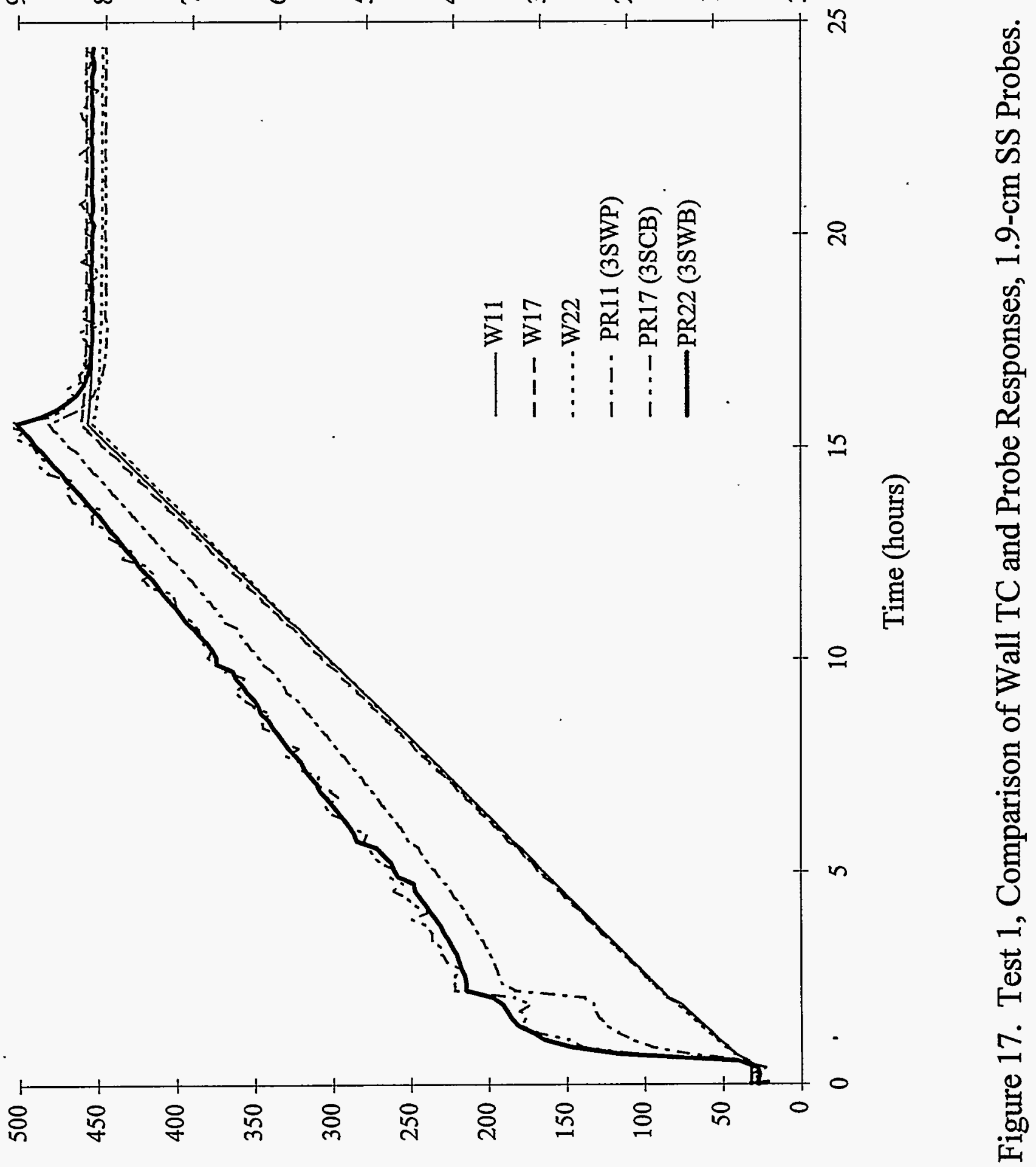

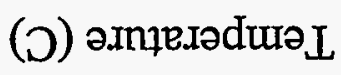




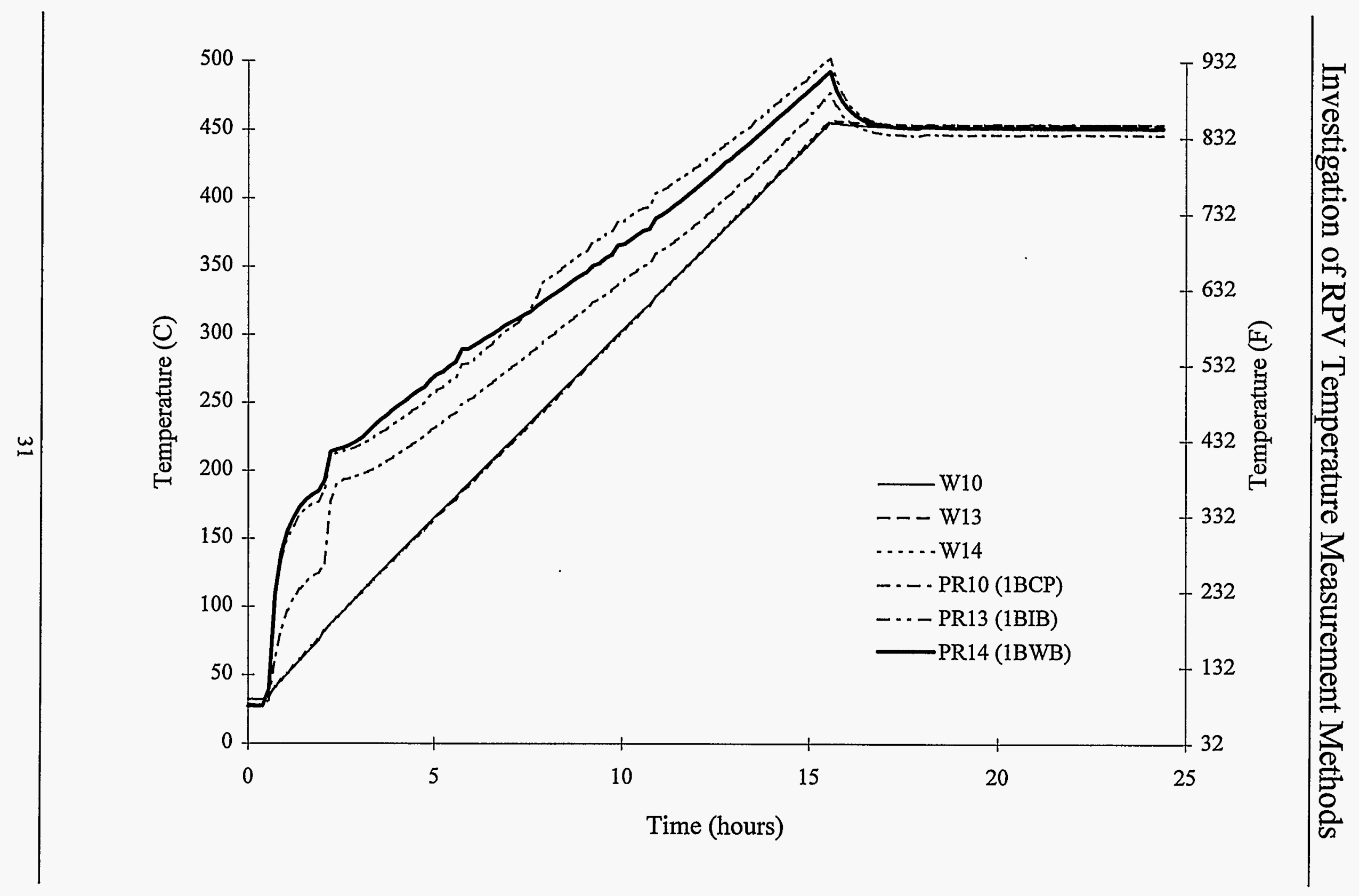

Figure 18. Test 1, Comparison of Wall TC and Probe Responses, 2.5-cm Brass Probes. 


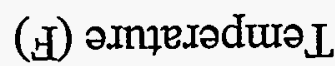
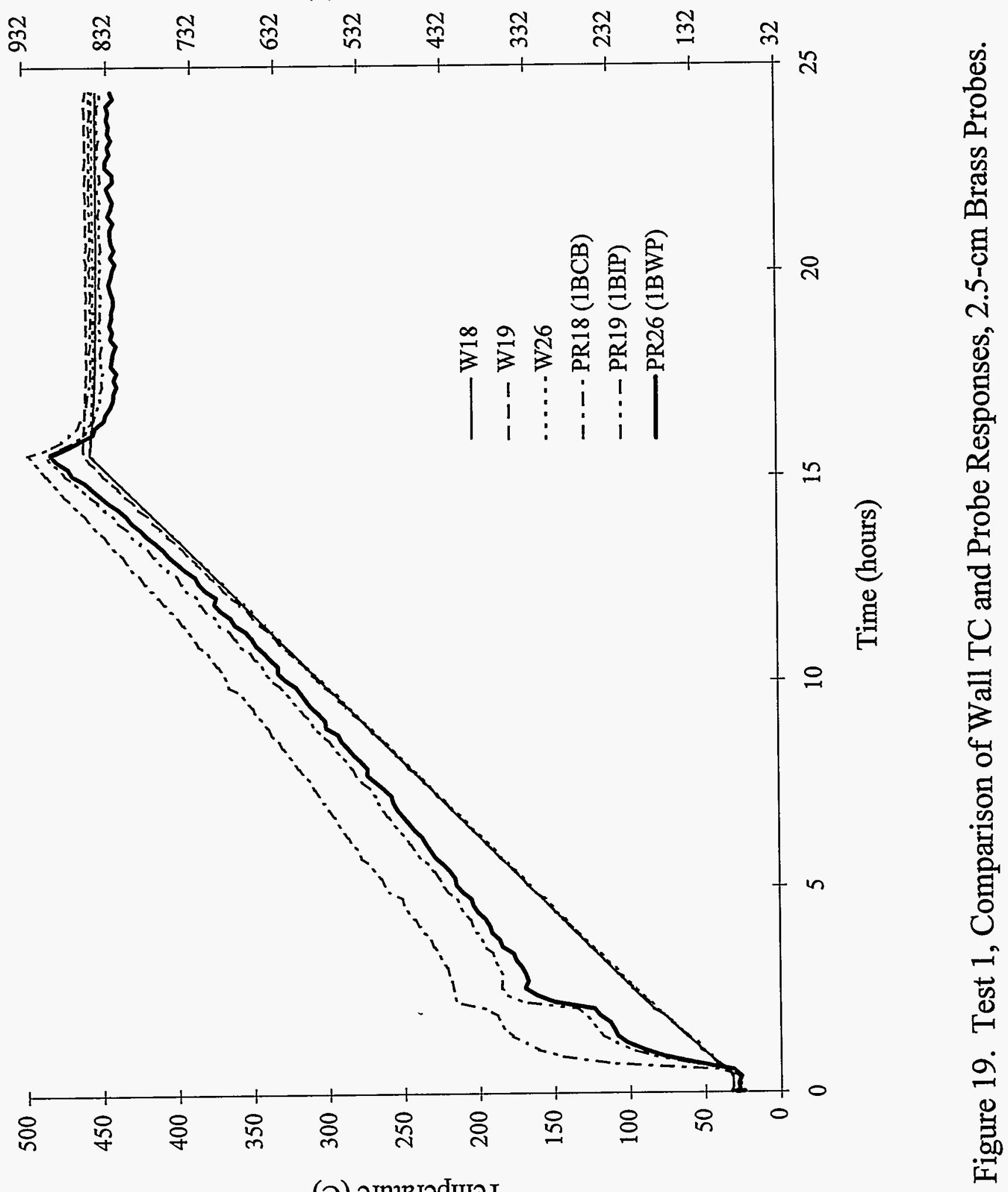

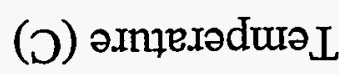




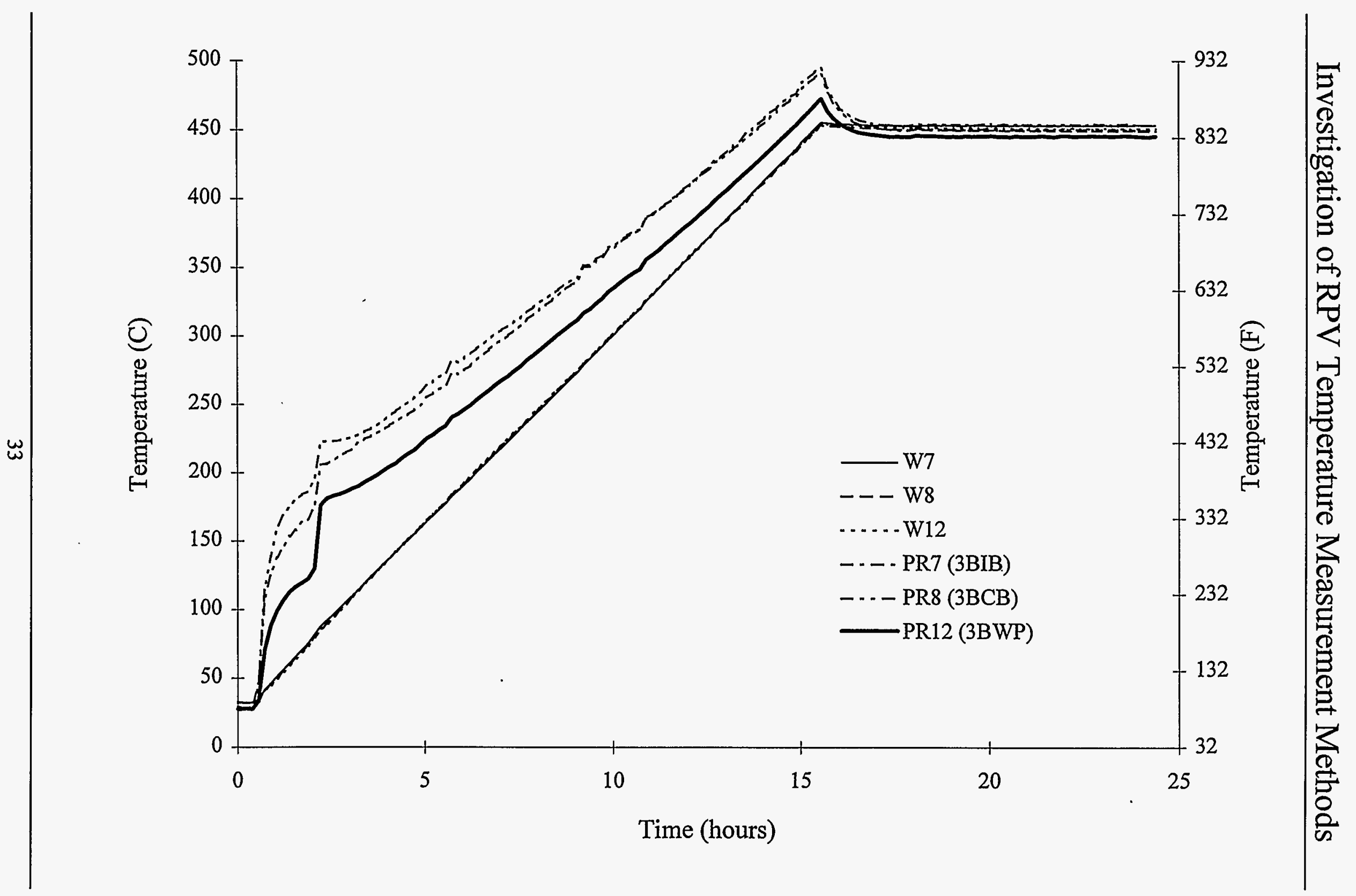

Figure 20. Test 1, Comparison of Wall and TC Probe Responses, 1.9-cm Brass Probes. 


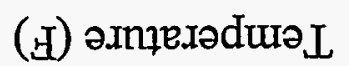

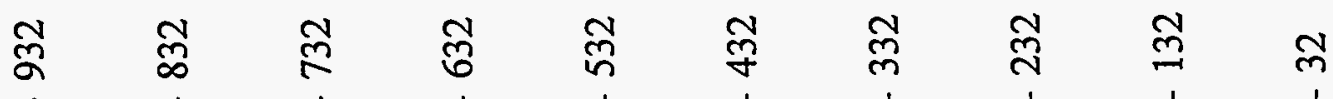

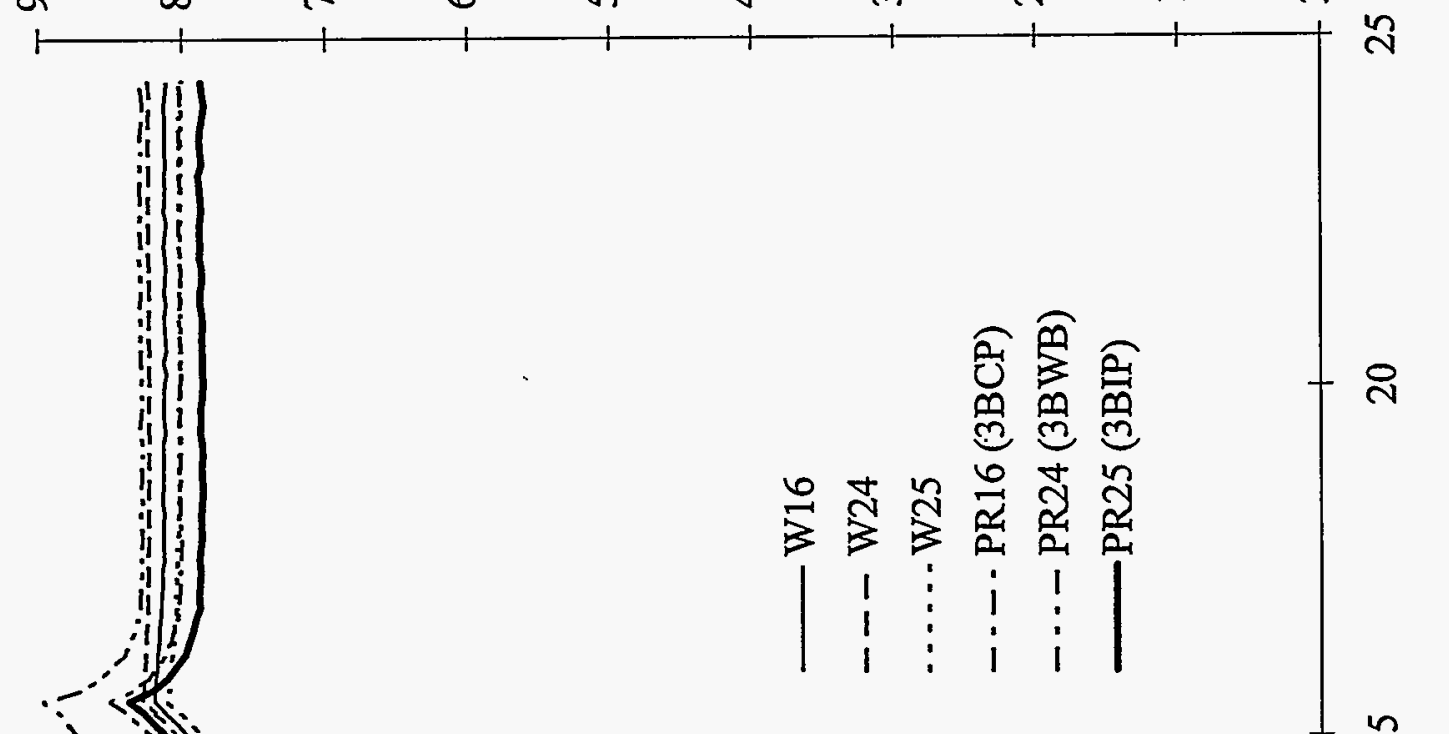

กิ

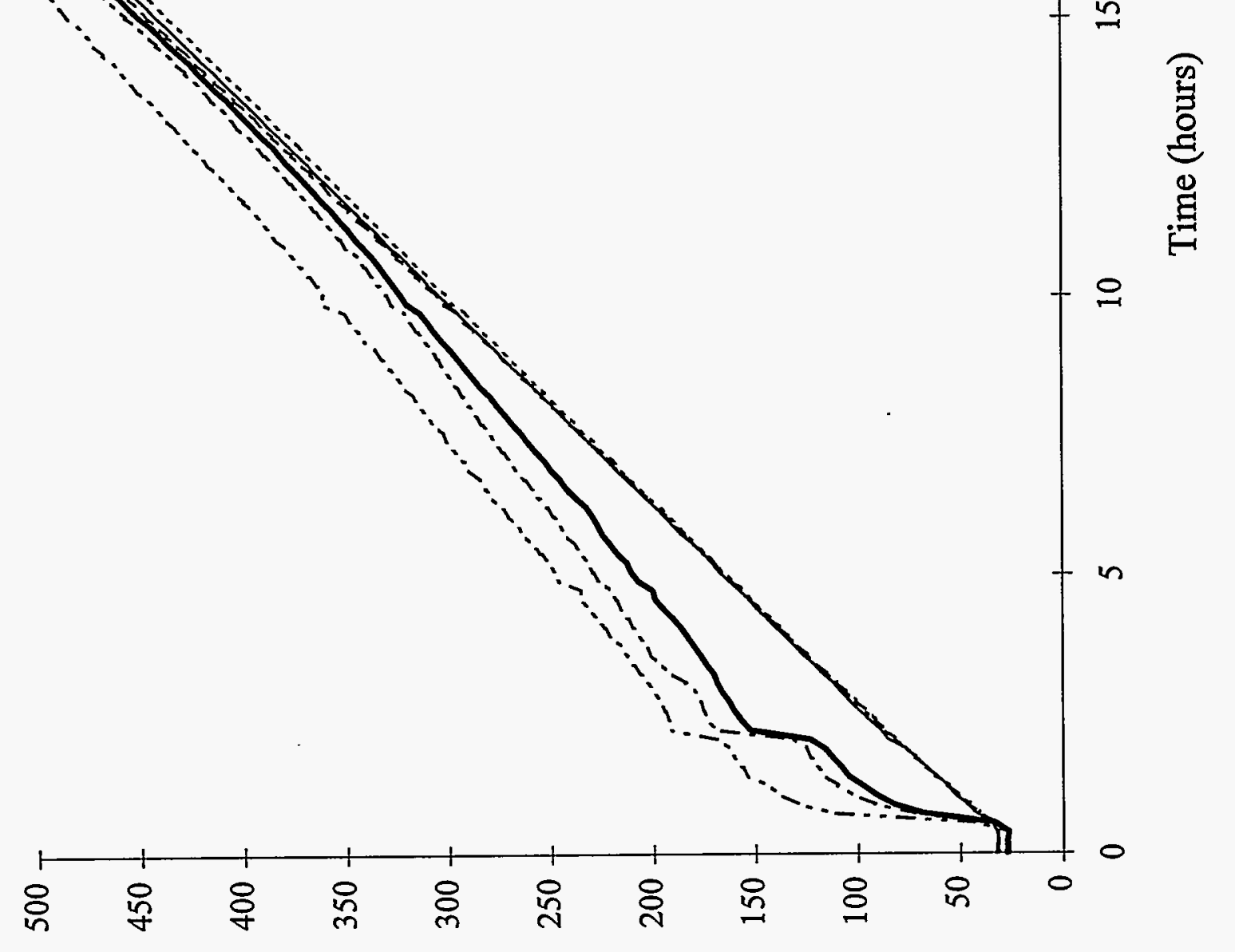

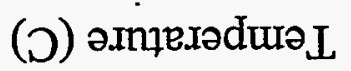




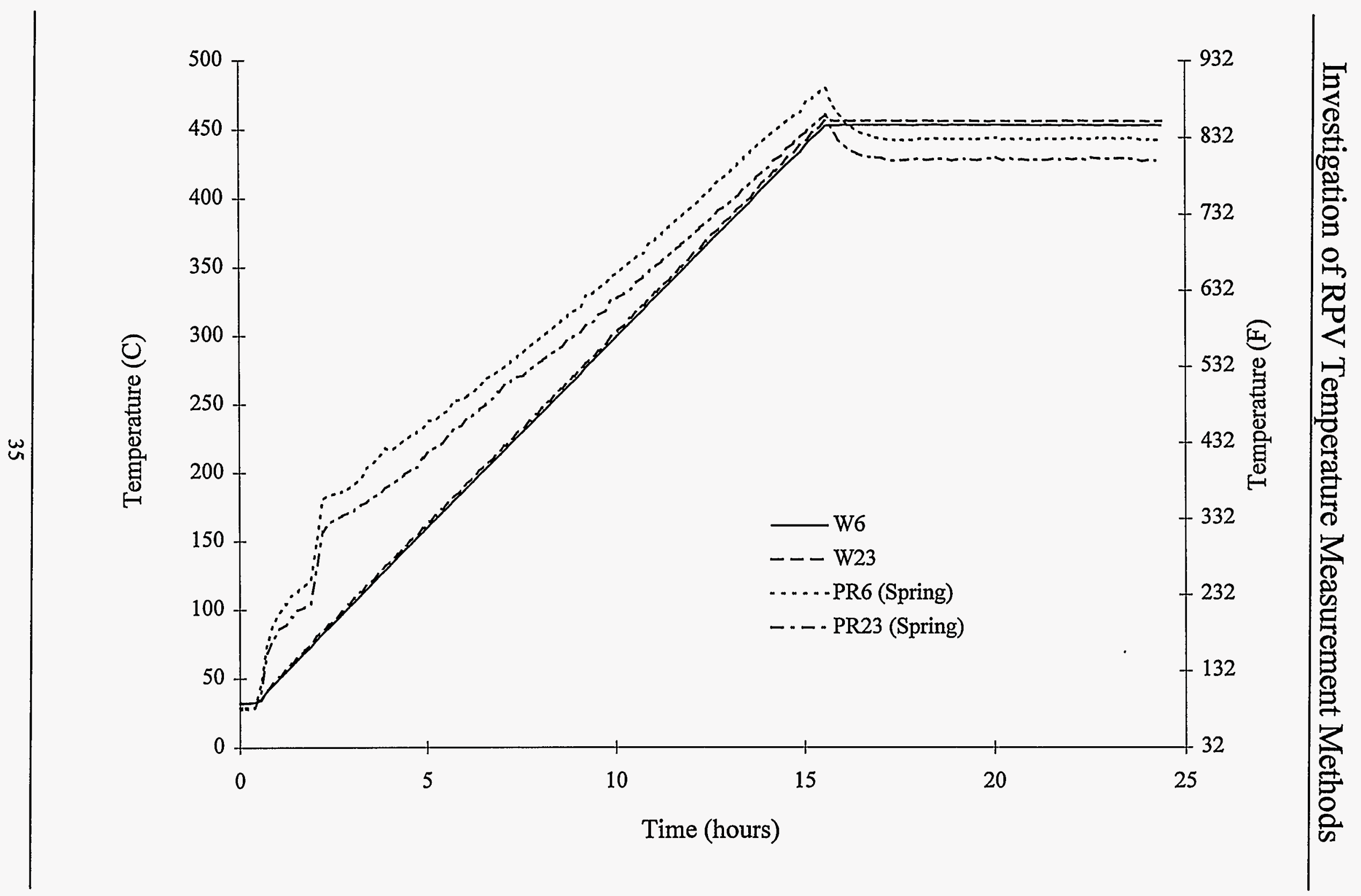

Figure 22. Test 1, Comparison of Wall TC and Spring-Loaded Probes. 


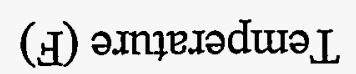

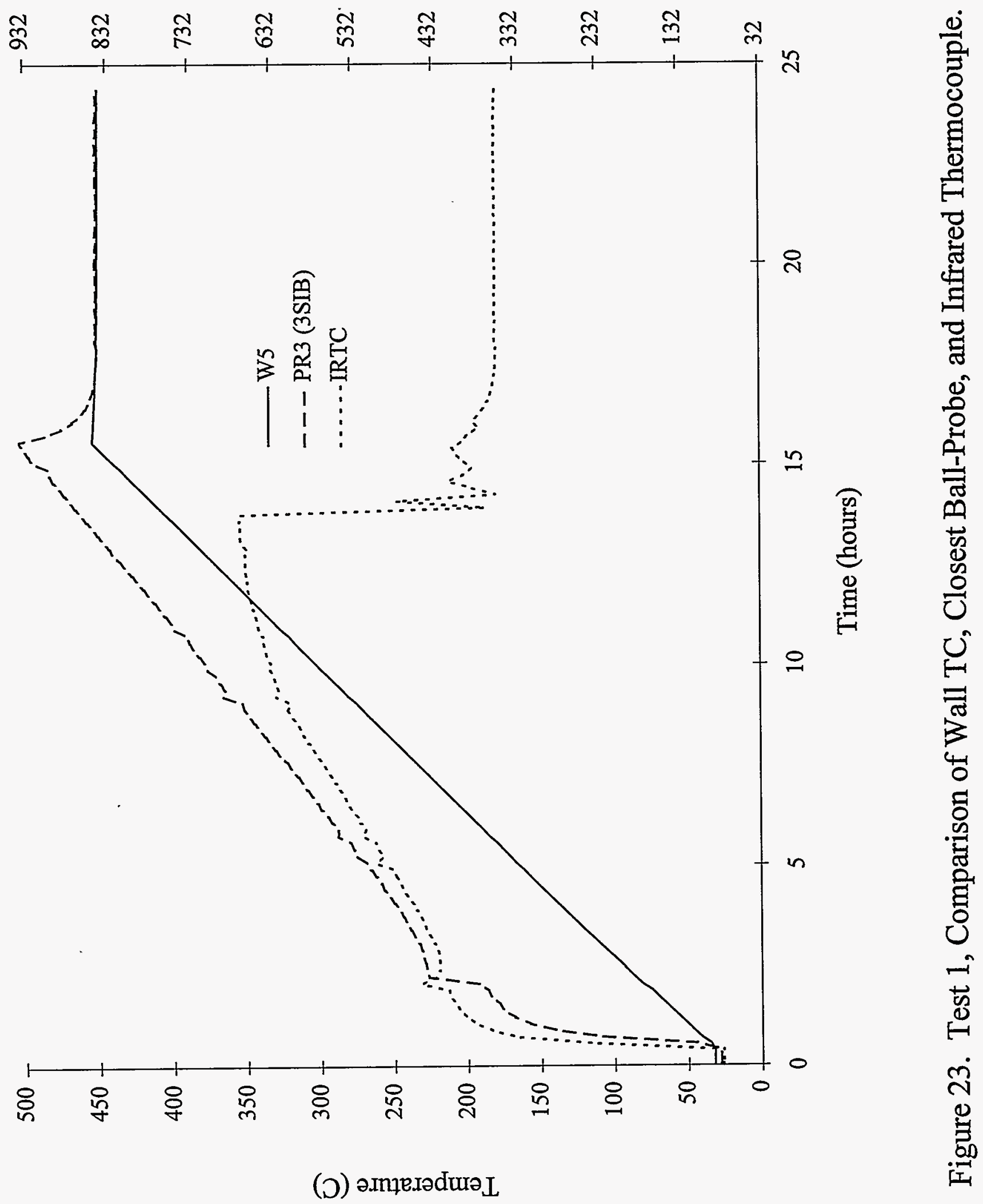




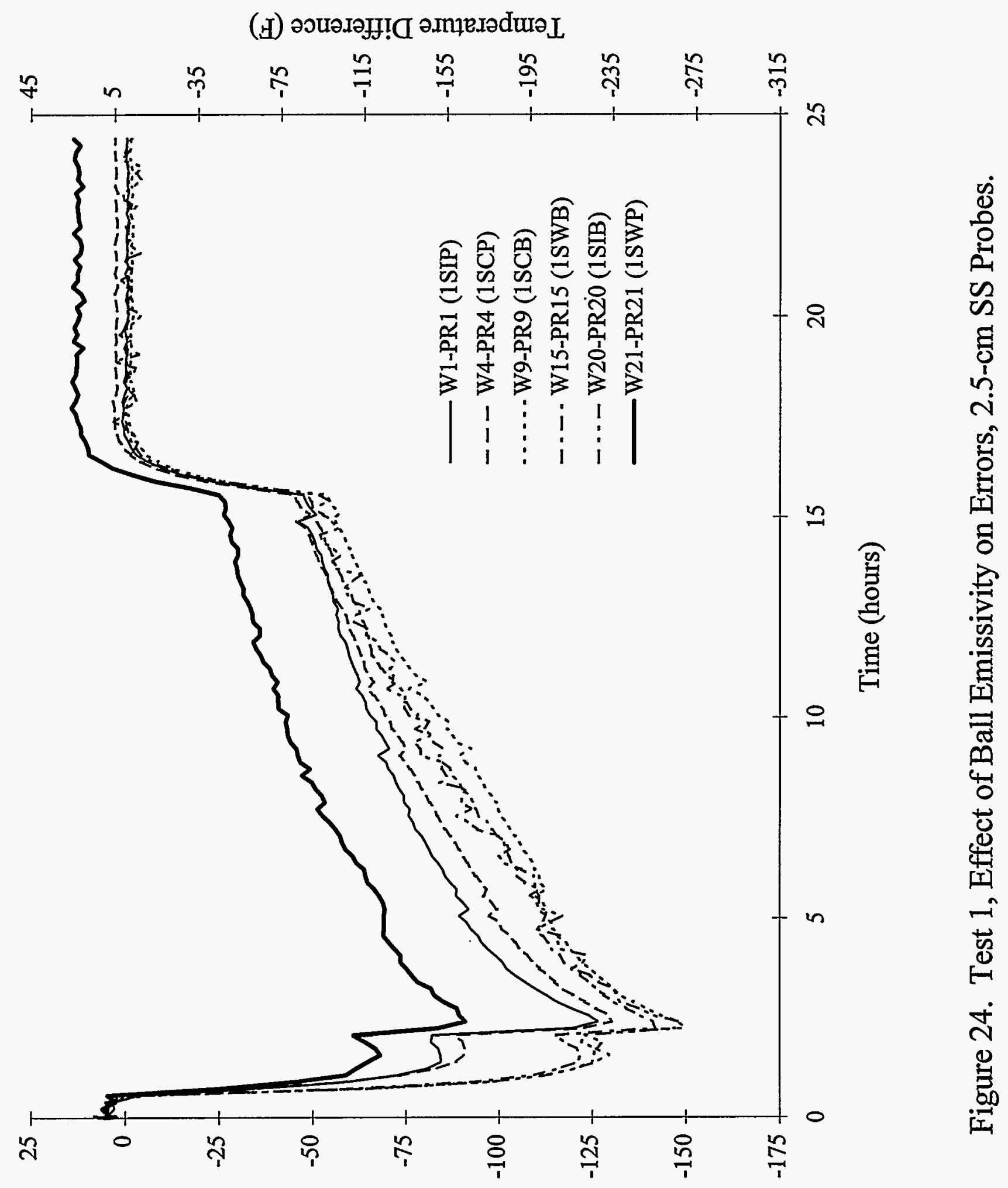

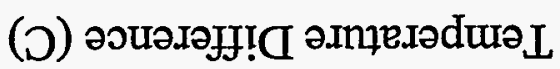




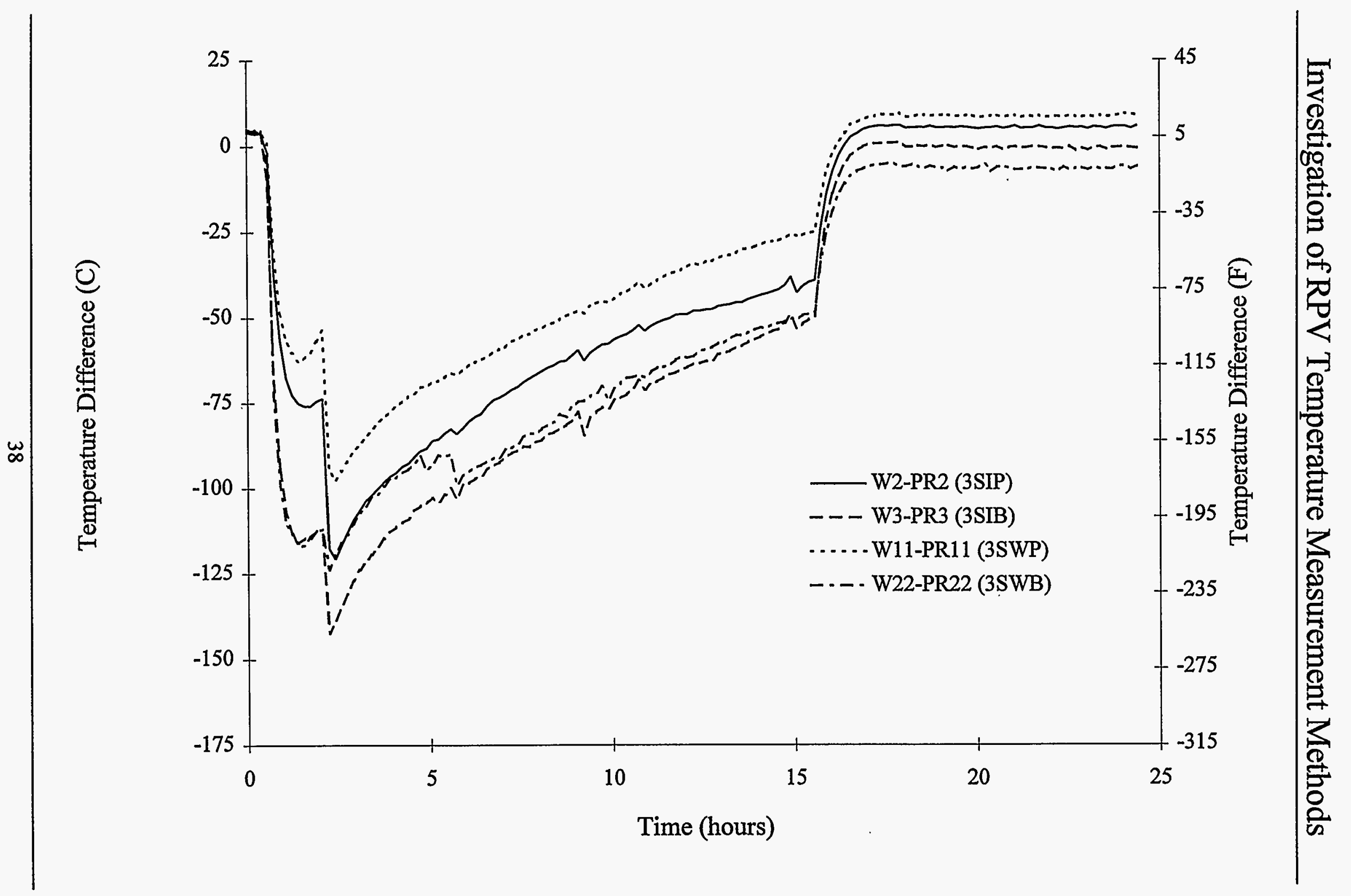

Figure 25. Test 1, Effect of Ball Emissivity on Errors, 1.9-cm SS Probes. 


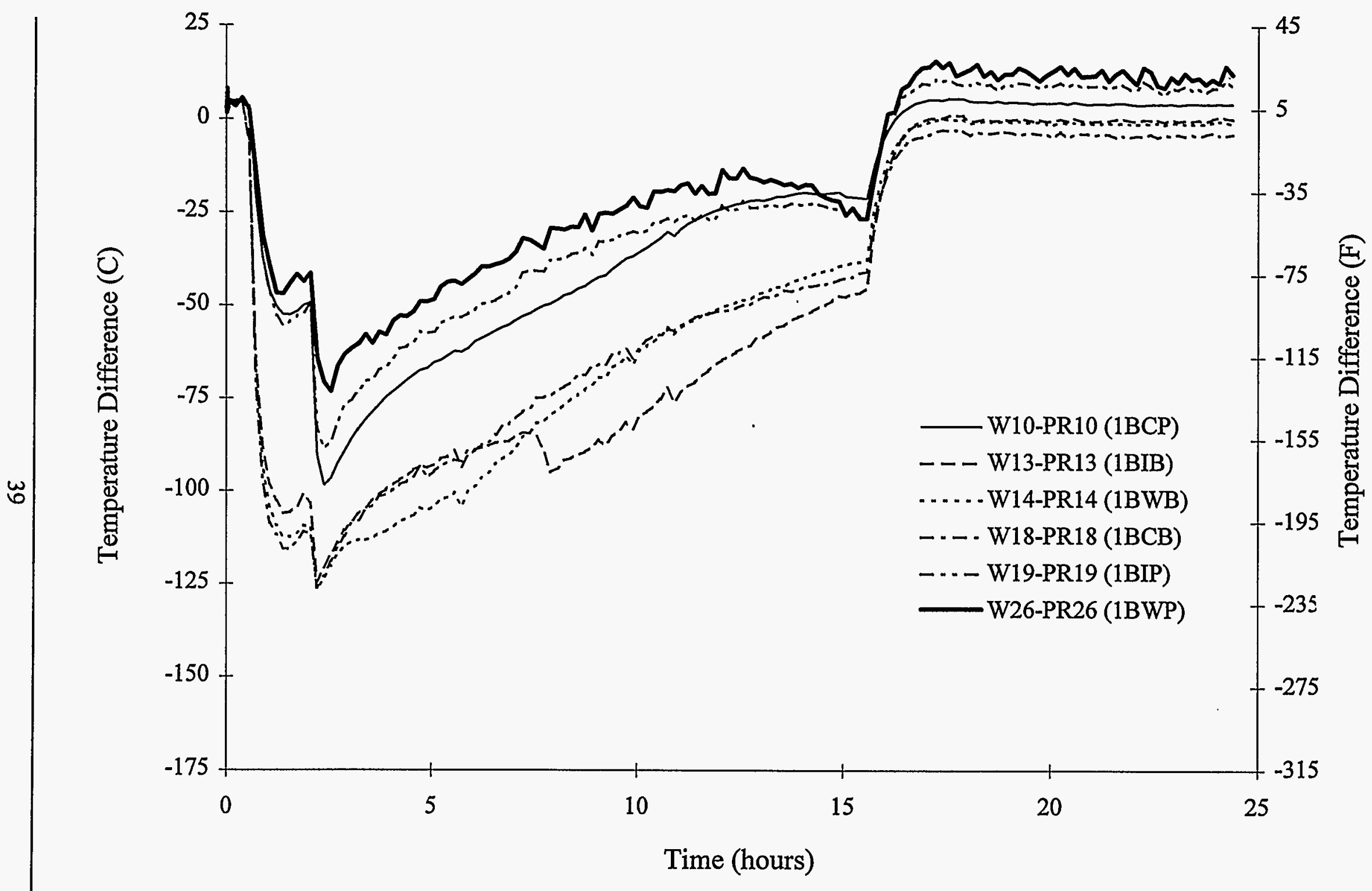

Figure 26. Test 1, Effect of Ball Emissivity on Errors, 2.5-cm Brass Probes. 


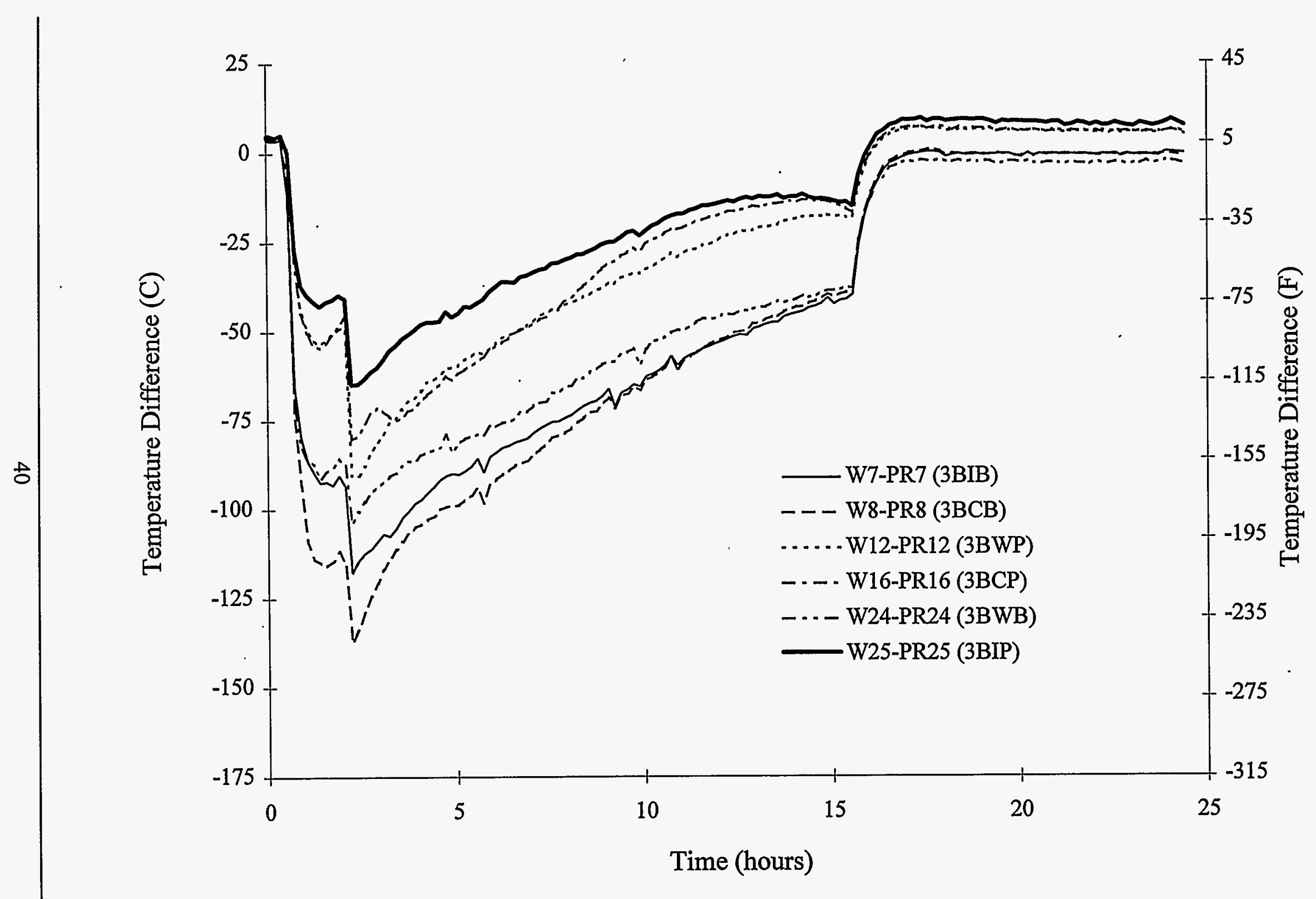

Figure 27. Test 1, Effect of Ball Emissivity on Errors, 1.9-cm Brass Probes. 


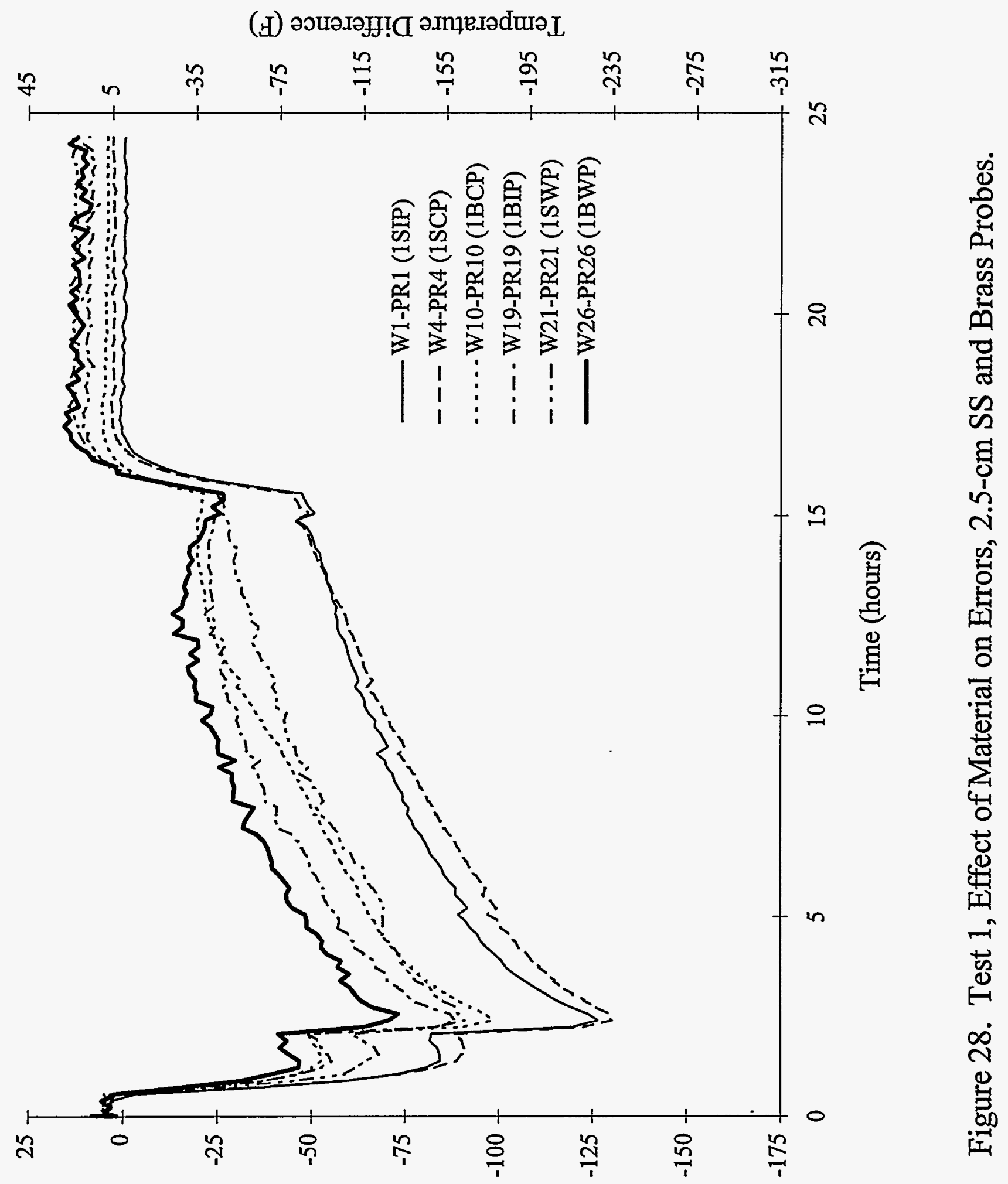

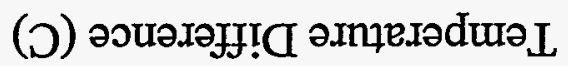




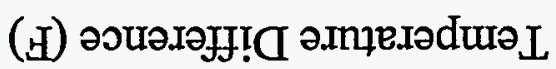
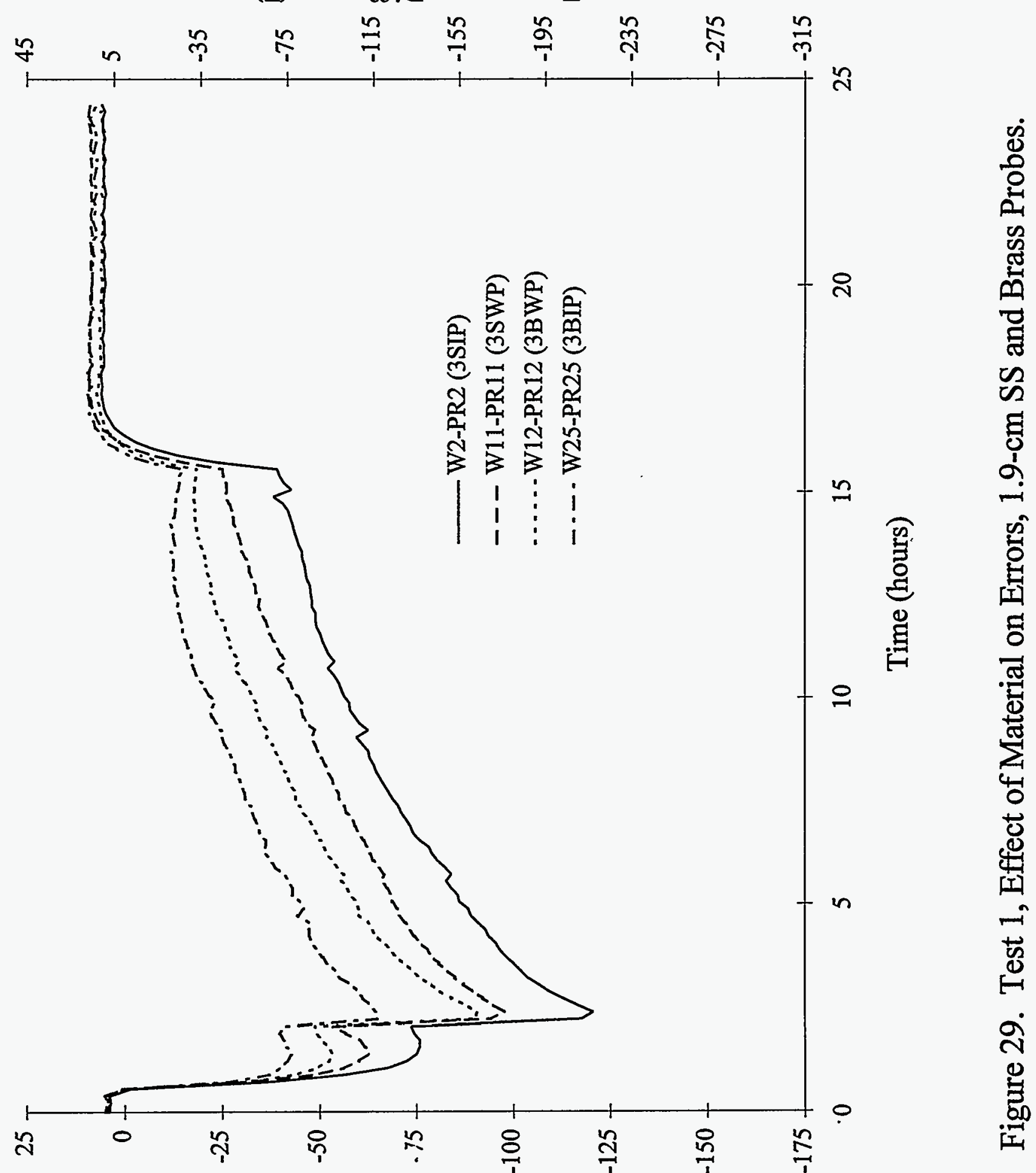

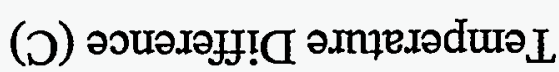




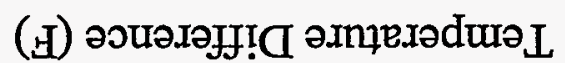
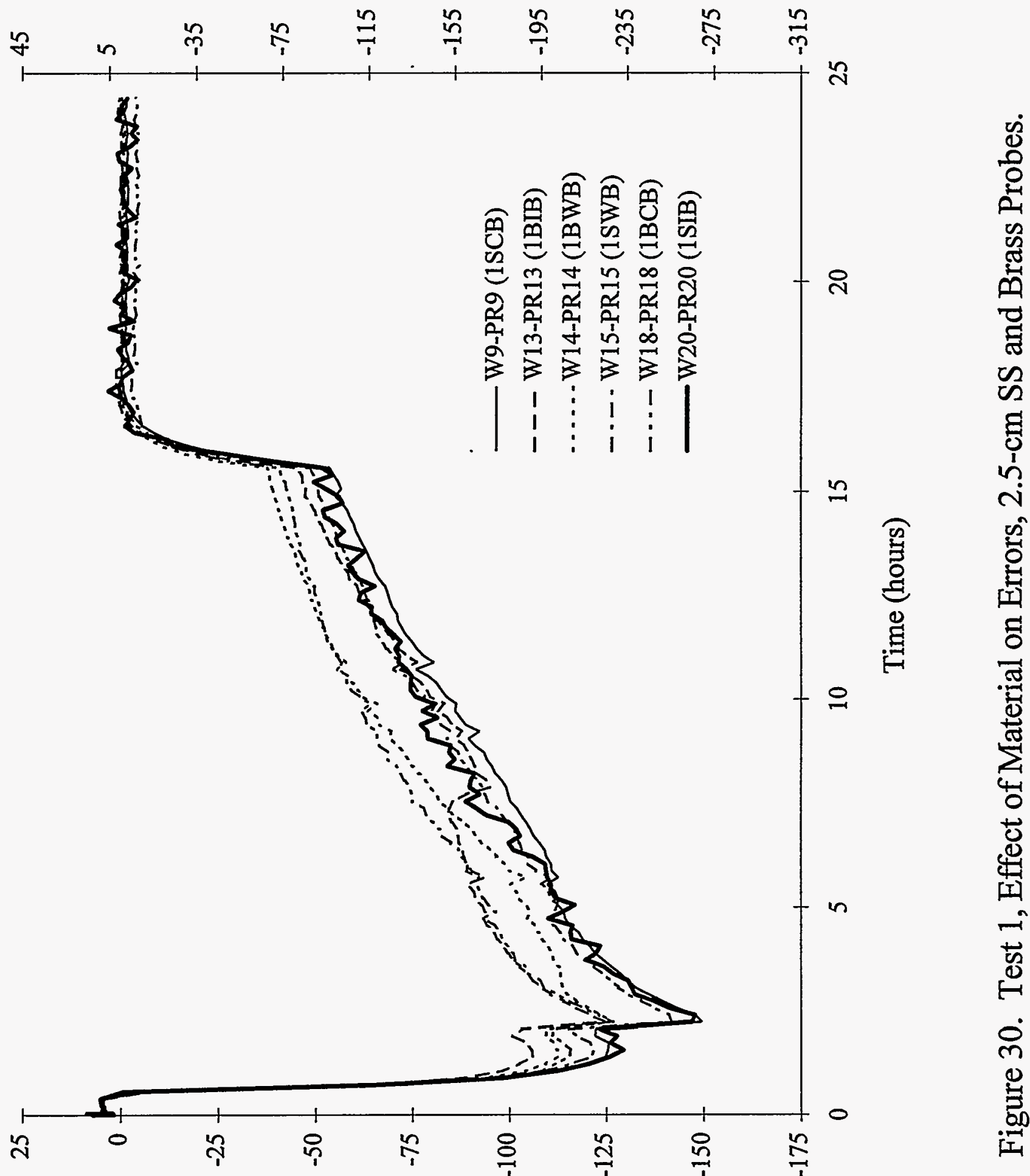

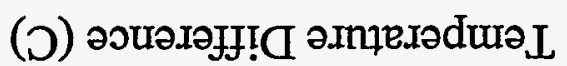




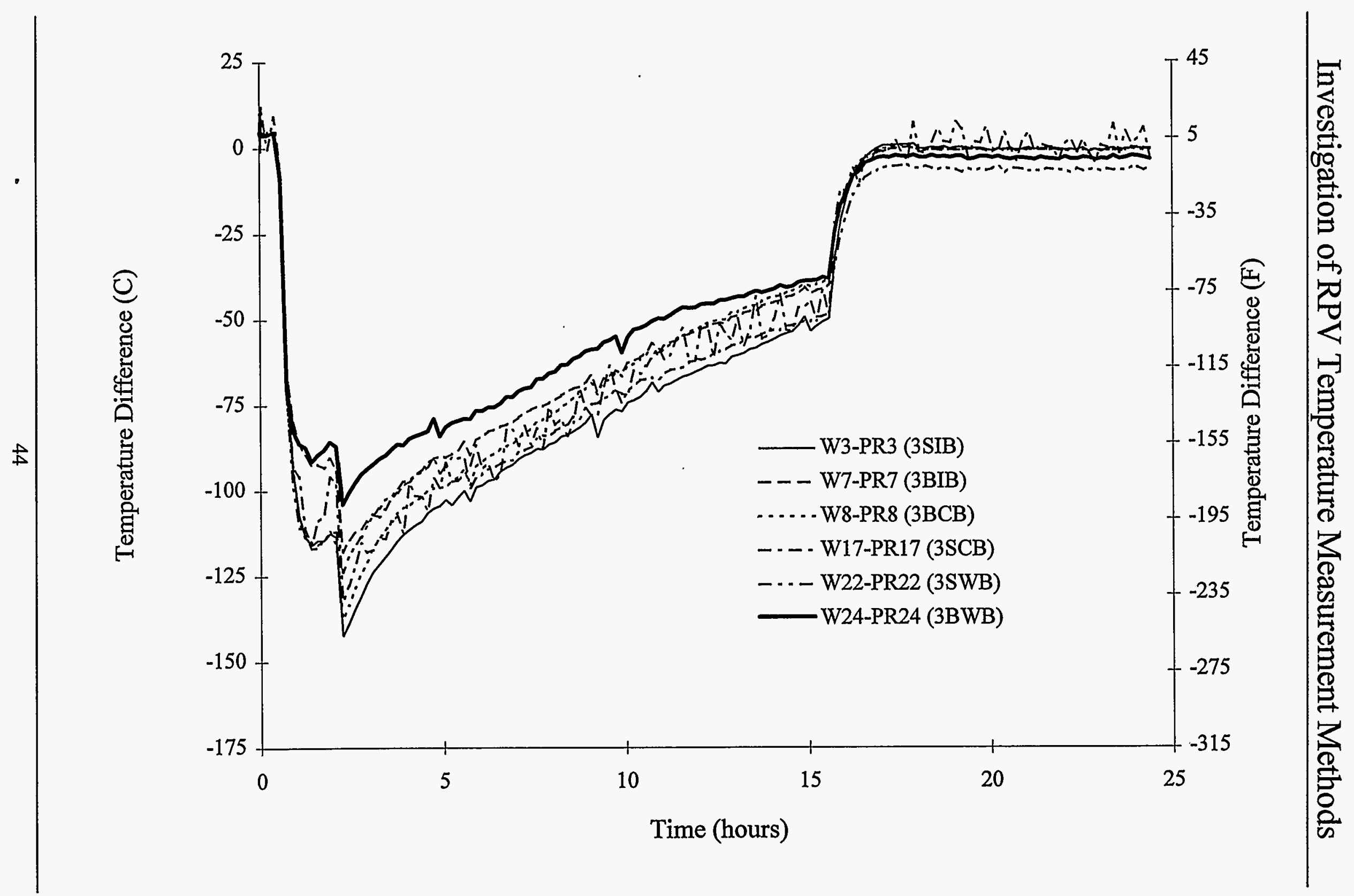

Figure 31. Test 1, Effect of Material on Errors, 1.9-cm SS and Brass Probes. 


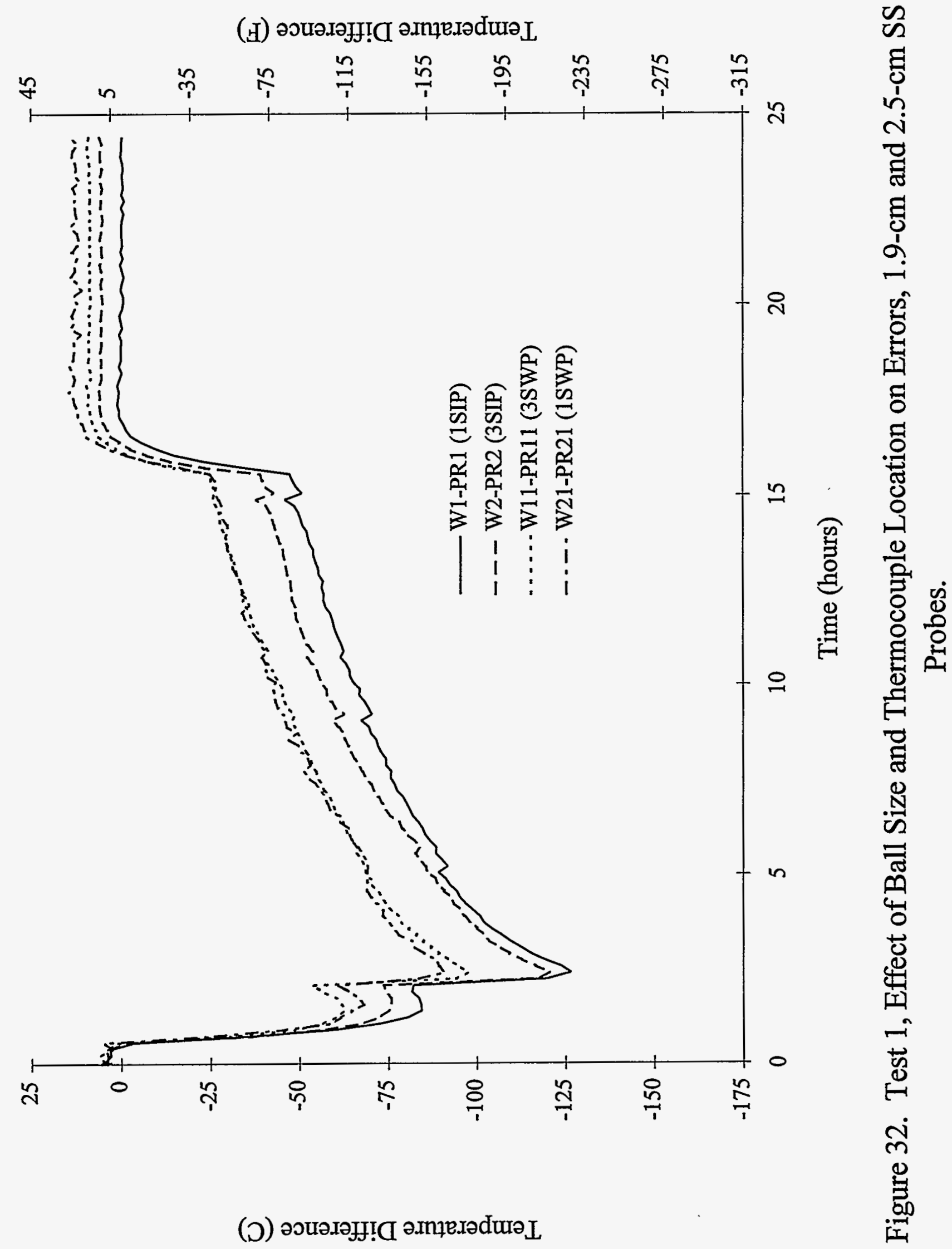




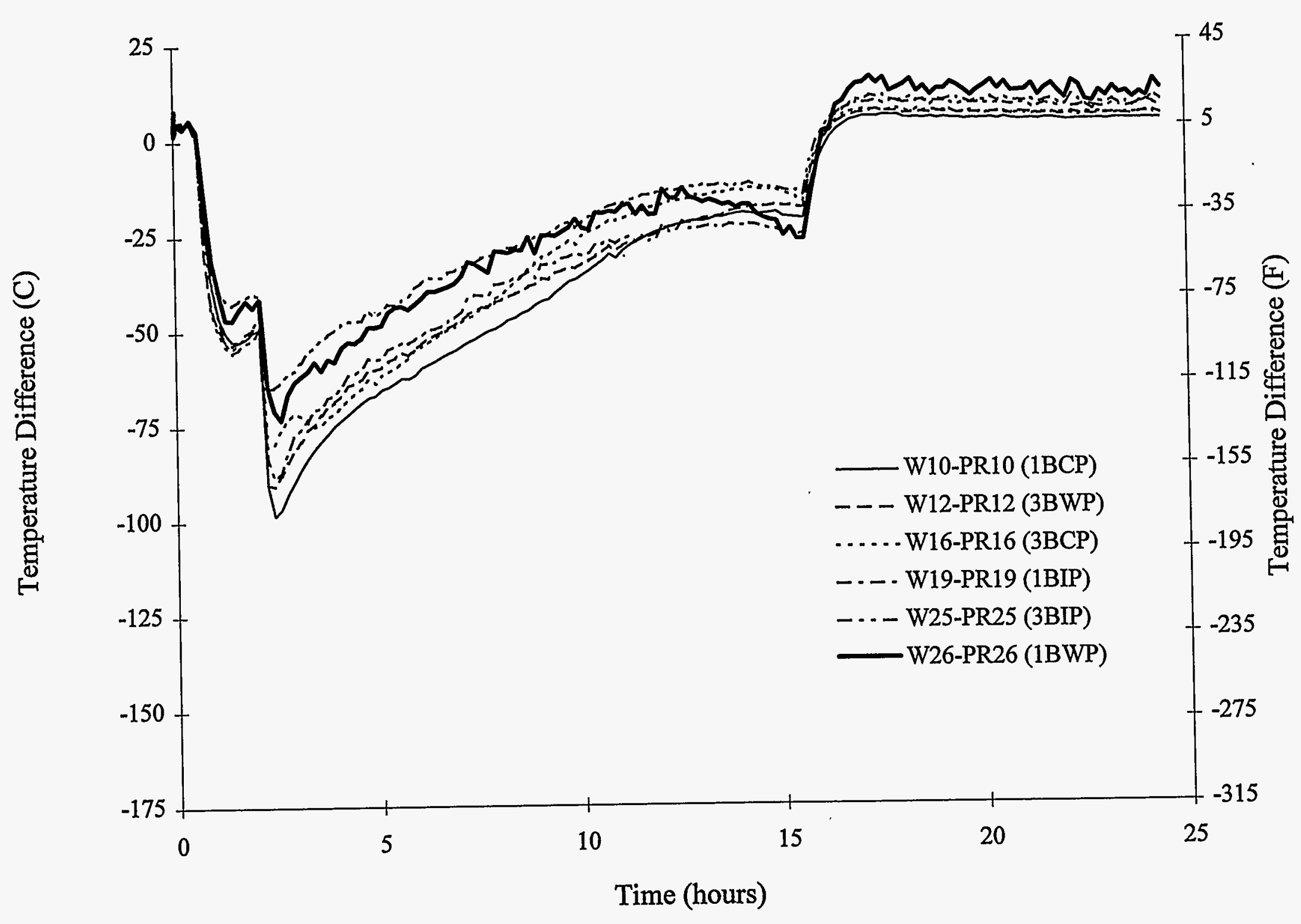

Figure 33. Test 1, Effect of Ball Size and Thermocouple Location on Errors, 1.9-cm and 2.5-cm Brass Probes. 


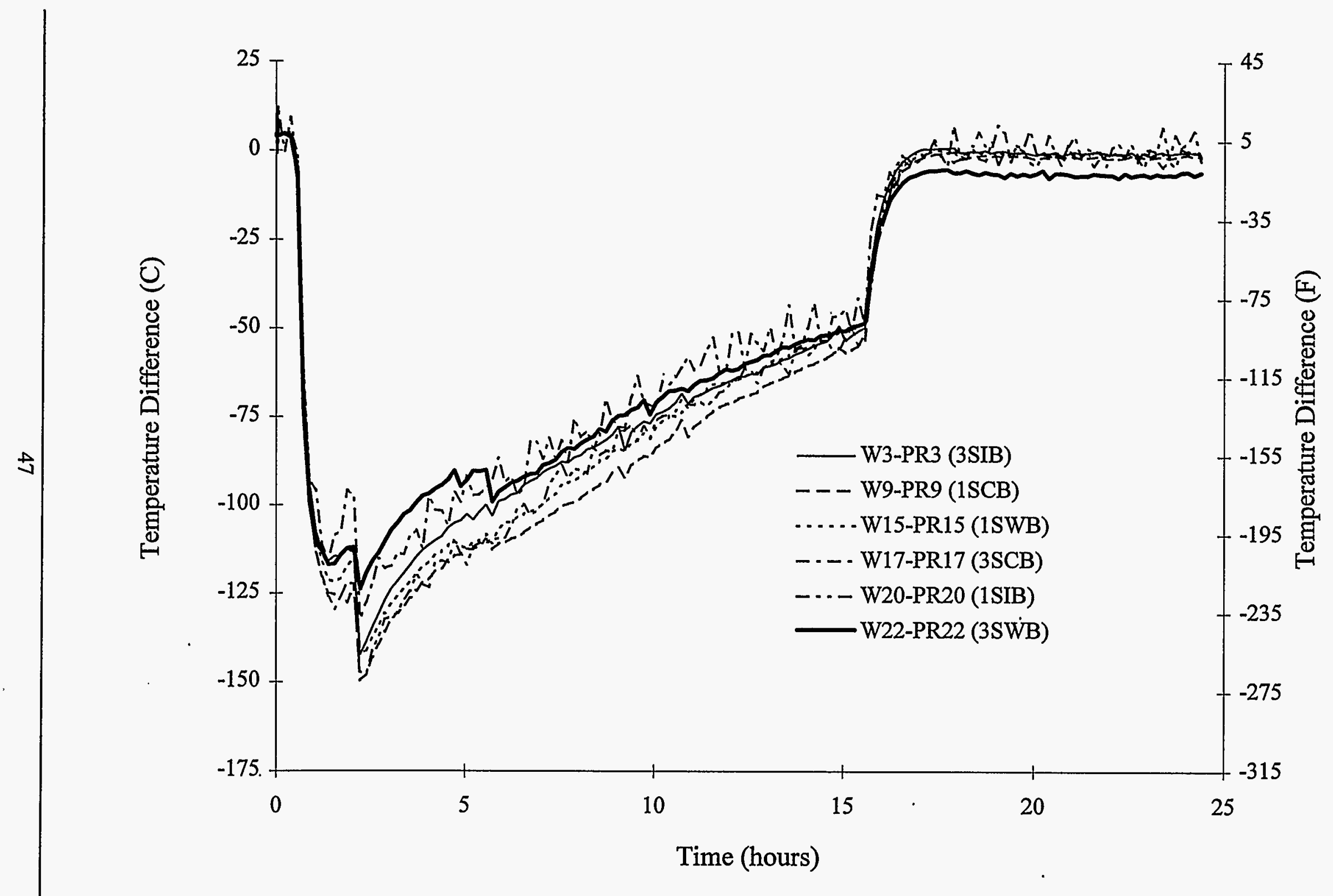

Figure 34. Test 1, Effect of Ball Size and Thermocouple Location on Errors, 1.9-cm and 2.5-cm SS Probes. 


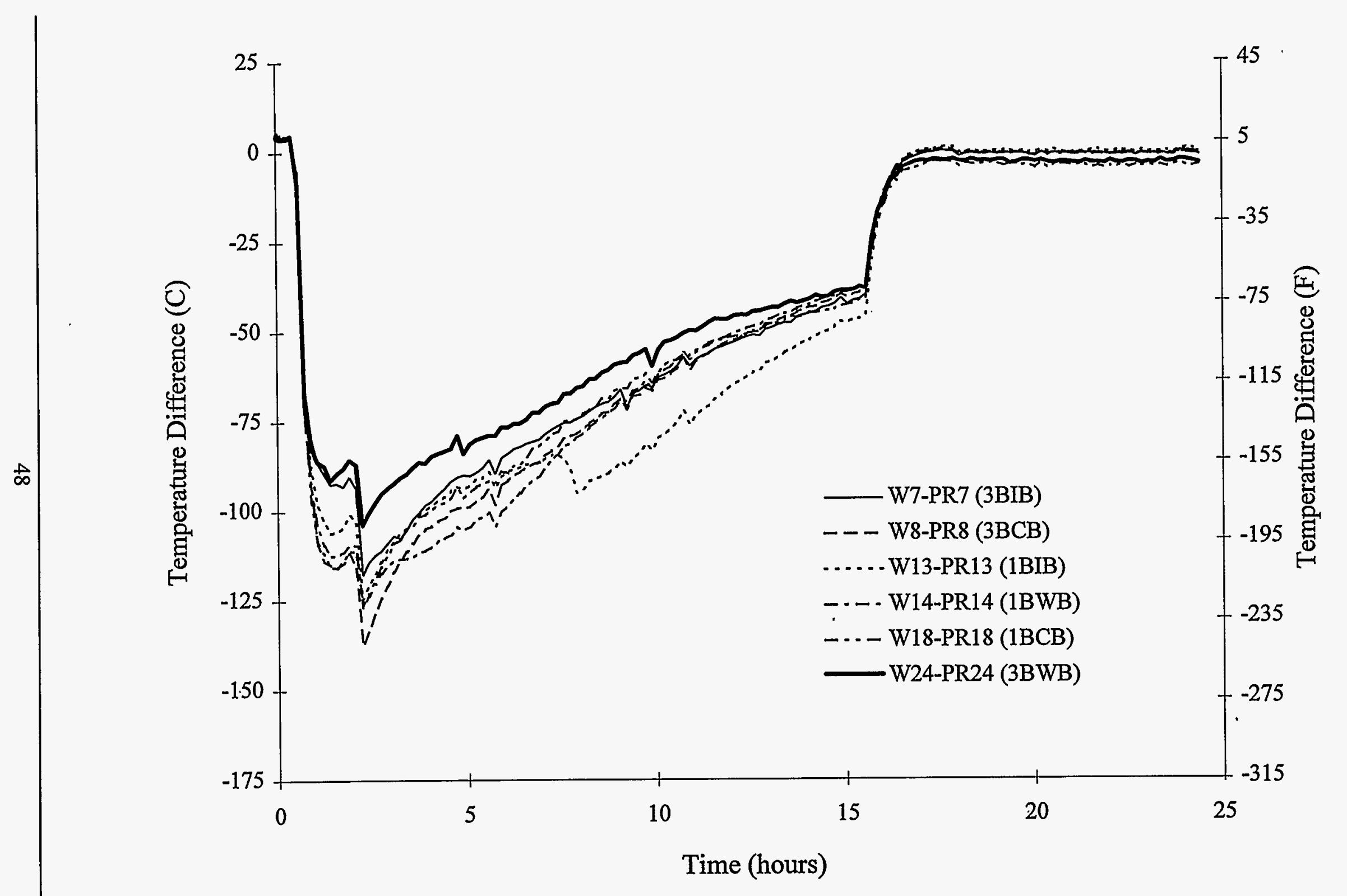

Figure 35. Test 1, Effect of Ball Size and Thermocouple Location on Errors, 1.9-cm and 2.5-cm Brass Probes. 


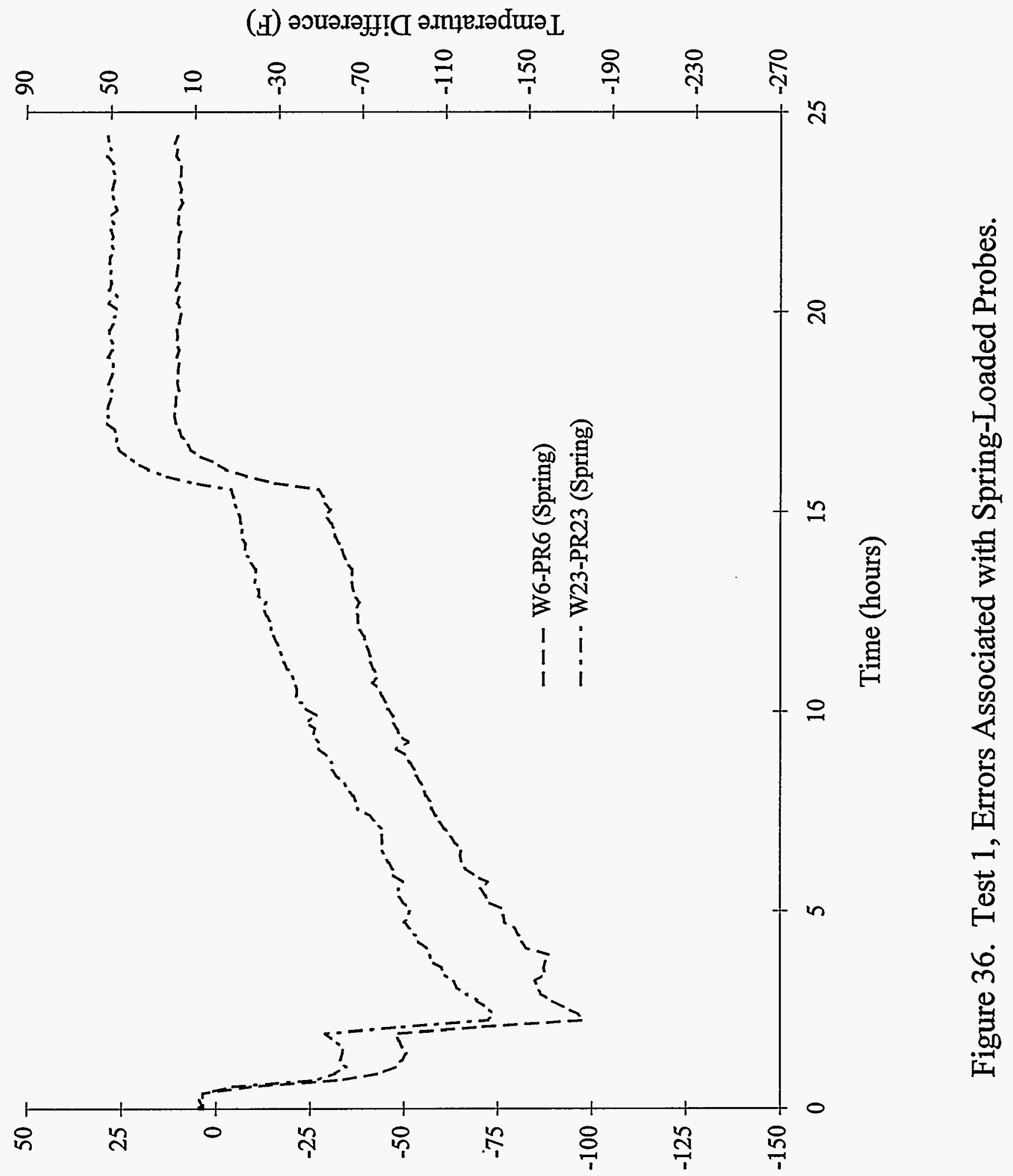

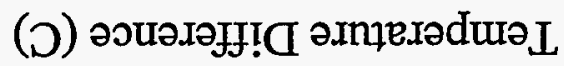




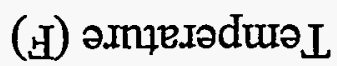

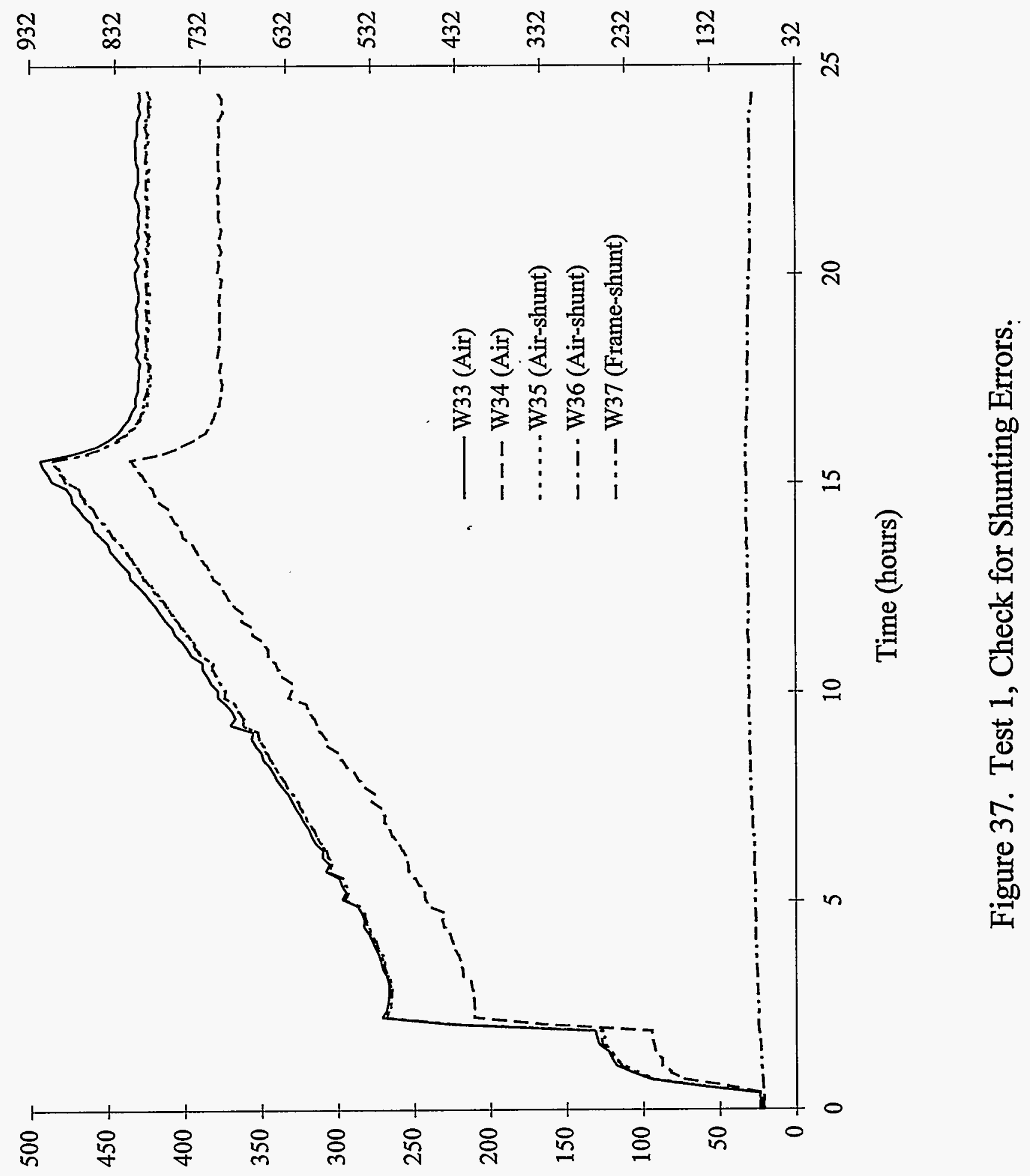

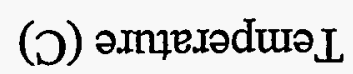




\section{Investigation of RPV Temperature Measurement Methods}

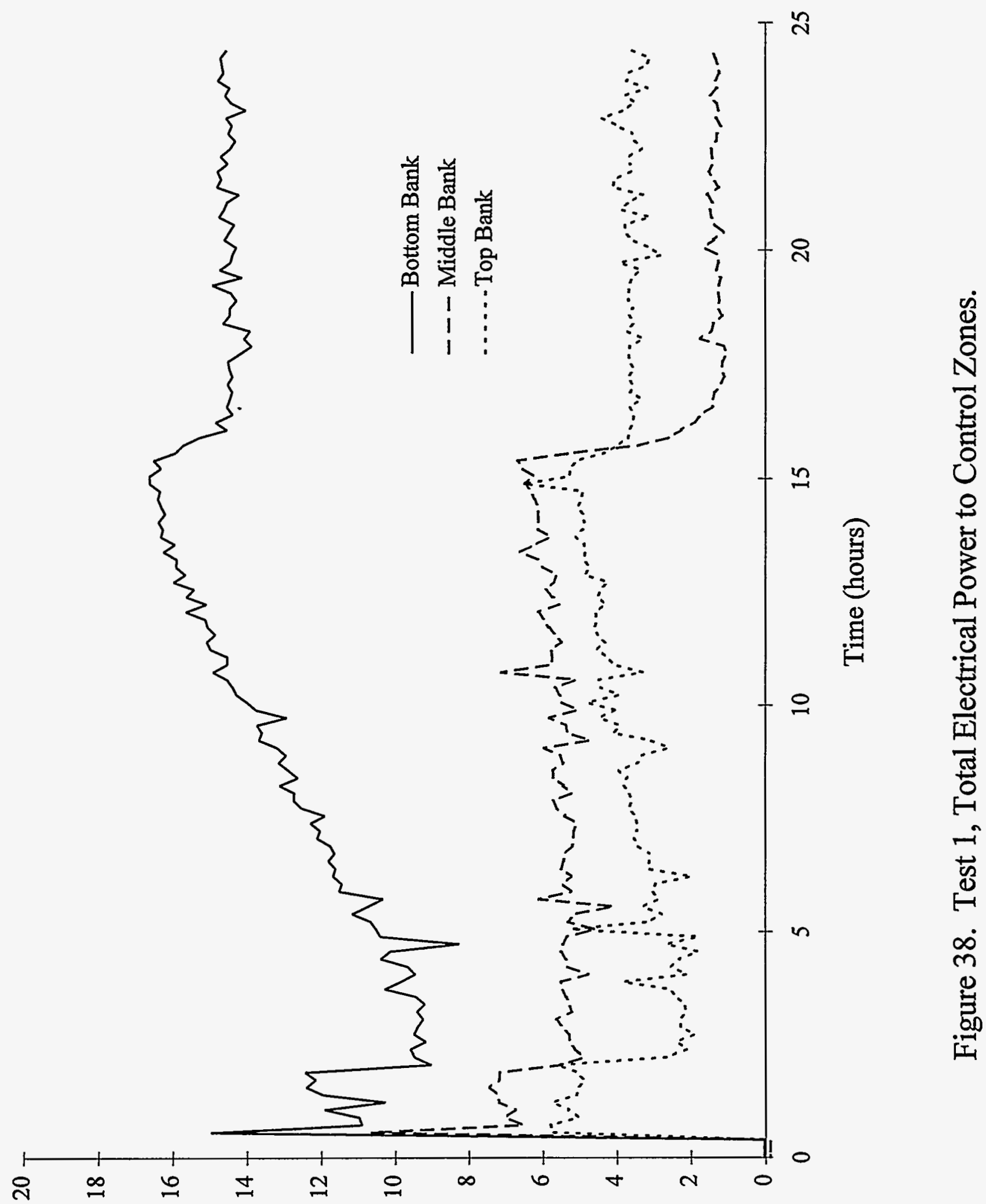

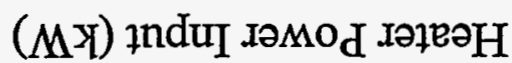




\section{Investigation of RPV Temperature Measurement Methods}

\subsubsection{Test 2 Data}

\section{Control Thermocouples}

Figure 39 shows a plot of the three control TCs, ball-probes PR4, PR14 and PR26. PR4 controlled the top heater bank, PR14 the middle heater bank, and PR26 the bottom heater bank. The probes follow a generally linear rise from ambient to $454^{\circ} \mathrm{C}\left[850^{\circ} \mathrm{F}\right]$ at a rise rate of $28^{\circ} \mathrm{C} / \mathrm{hr}$ $\left[50^{\circ} \mathrm{F} / \mathrm{hr}\right]$, but show more deviations and oscillations from a linear path than do the (spot-welded) control TCs in Test 1.

\section{Comparison of Wall and Probe Responses}

Figures 40-48 show comparisons of the wall and probe responses for all of the probe-wall TC combinations. Figures 40 and 41 show plots for pairs (e.g., W4 and PR4) of $2.5 \mathrm{~cm}$ [1 in.]diameter stainless steel ball-probes and their companion wall TCs; Figures 42 and 43 are for pairs of $1.9 \mathrm{~cm}$ [0.75 in.]-diameter SS ball-probes and their companion wall TCs; Figures 44 and 45 are for $2.5 \mathrm{~cm}$ [ 1 in.]-diameter brass ball-probes and their companion wall TCs; and Figures 46 and 47 are for $1.9 \mathrm{~cm}$ [0.75 in.]-diameter brass ball-probes. Figure 48 shows pairs of spring-loaded probes and their companion wall TCs. Several probes were not working properly during this test: PR1, PR3, and PR25. Note that all failed probes contained intrinsic TCs.

In all cases during the heat-up it can be seen that the probes read higher than their companion wall TCs at the same point in time, by a larger amount during the early stages of the heat-up, but by a lesser amount during the later stages. During the soak portion at $454^{\circ} \mathrm{C}\left[850^{\circ} \mathrm{F}\right]$, most of the probes read close to their companion wall TCs. In most cases, the probes read within about $23^{\circ} \mathrm{C}$ $\left[41^{\circ} \mathrm{F}\right]$ or $5 \%$ of the soak (i.e., annealing) temperature at the end of the soak period. As will be discussed below, it is difficult to quantify the exact error because the probe temperatures oscillated so much. However, during the heat-up, the probe errors were substantial, up to $130^{\circ} \mathrm{C}$ $\left[240^{\circ} \mathrm{F}\right]$ between 5 and 10 hours during the heat-up.

Using probes to control the heaters, as would be the case during an actual anneal, results in a nonlinear heat-up rate on the wall TCs. At low temperatures, the RPV wall temperatures lag behind the probe temperatures and the RPV wall shows actual heat-up rates less than $28^{\circ} \mathrm{C} / \mathrm{hr}$ $\left[50^{\circ} \mathrm{F} / \mathrm{hr}\right]$. During the latter part of the heat-up, close to the soak temperature $454^{\circ} \mathrm{C}\left[850^{\circ} \mathrm{F}\right]$, the RPV wall heat-up rate is actually higher than $28^{\circ} \mathrm{C} / \mathrm{hr}\left[50^{\circ} \mathrm{F} / \mathrm{hr}\right]$, up to about $36^{\circ} \mathrm{C} / \mathrm{hr}$ [ $\left.64^{\circ} \mathrm{F} / \mathrm{hr}\right]$ (see Figure 41). This may be a concern if there is a maximum specified heat-up rate threshold to preclude overstressing certain areas of the RPV. In addition, due to the faster response of the probes compared with the wall $\mathrm{TCs}$, both the probe and wall temperatures showed much higher oscillations than on Test 1.

\section{Error Plots: Differences between the Wall Thermocouples and Probes}

Figures 49-60 show plots of the difference between the wall TCs and their companion probes, i.e., the error in the probe readings. 


\section{Investigation of RPV Temperature Measurement Methods}

A typical curve goes negative soon after the heat-up begins, reaches a peak negative error between 5 and 10 hours, then slowly rises with time until the soak begins, at which time most curves approach a steady-state error close to zero. During the cool-down the errors reverse direction, becoming positive. The largest positive errors during the cool-down are less than the largest negative errors during the heat-up. In addition, a typical curve shows a much more pronounced oscillation than on Test 1 . This is due to the fast response of the ball-probes controlling the heater banks, causing the heaters to cycle on and off. The oscillations occur during the heat-up, soak, and cool-down. As with Test 1, there was a general trend for the errors to be highest/lowest in particular areas. However, the trends in Test 2 are very different from Test 1. In Test 2, the most prevalent trends were that the lowest errors were in the top third of the probes, the middle third showed the largest errors and the bottom third showed errors between the others.

\section{The Effect of Ball-Probe Emissivity (Absorptivity)}

Figures 49-52 were generated to show the effect of the ball emissivity (or absorptivity) on the error. Figure 49 shows $2.5 \mathrm{~cm}$ [1 in.]-diameter SS probes; Figure 50 shows $1.9 \mathrm{~cm}$ [0.75 in.] diameter SS probes; Figure 51 shows $2.5 \mathrm{~cm}$ [ 1 in.] diameter brass probes and Figure 52 shows $1.9 \mathrm{~cm}[0.75$ in.]-diameter brass probes.

In most cases, the polished probes had the lowest errors during the heat-up. However, during the soak and cool-down there was no consistent pattern of errors; in the majority of cases the polished probes showed the smaller error during the soak, but the blackened probes showed a smaller error during the cool-down. This behavior is similar to that in Test 1.

\section{The Effect of Ball-Probe Material}

Figures 53-56 were generated to show the differences in errors due to ball-probe material: stainless steel or brass. Figure 53 shows temperature differences between the wall TCs and 2.5 $\mathrm{cm}$ [1 in.]-diameter polished SS or brass ball-probes. Figure 54 shows temperature differences between wall TCs and $1.9 \mathrm{~cm}$ [0.75 in.]-diameter polished SS or brass ball-probes. Figure 55 shows temperature differences between wall TCs and $2.5 \mathrm{~cm}$ [1.0 in.]-diameter, black SS or brass ball-probes; and Figure 56 shows temperature differences between wall TCs and $1.9 \mathrm{~cm}$ [0.75 in.]-diameter black SS or brass ball-probes.

In the majority of cases, the brass probes, with a higher thermal conductivity, had lower errors than similar SS probes during the heat-up portion, whereas during the soak and the cool-down there was no clear distinction. This behavior is similar to that in Test 1 .

\section{The Effect of Ball Size}

Figures 57-60 show error plots associated with ball size and thermocouple location. The effect of ball size will be discussed here; the effect of TC location will be discussed in the next subsection. Figure 57 shows errors of both $1.9 \mathrm{~cm}$ [0.75 in.] and $2.5 \mathrm{~cm}$ [1.0 in.]-diameter 
polished stainless steel (SS) probes; Figure 58 shows errors of both $1.9 \mathrm{~cm}$ [0.75 in.] and $2.5 \mathrm{~cm}$ [1.0 in.]-diameter polished brass probes; Figure 59 shows errors of both $1.9 \mathrm{~cm}$ [0.75 in.] and $2.5 \mathrm{~cm}$ [1.0 in.]-diameter blackened SS probes; Figure 60 shows errors of both $1.9 \mathrm{~cm}$ [0.75 in.] and $2.5 \mathrm{~cm}$ [1.0 in.]-diameter blackened brass probes.

In almost all cases during the heat-up, soak, and cool-down the data are inconclusive. In some cases during the heat-up and cool-down the larger size ball (2.5 $\mathrm{cm}$ [1.0 in.]) probes had the lower error, in contrast to Test 1 data in which the $1.9 \mathrm{~cm}$ [0.75 in.]-diameter (smaller diameter) probes had the lowest error. It seems that if the ball probes are used to control the heaters, the ball size is not a significant factor.

\section{The Effect of Thermocouple Placement in the Ball}

Figures 57-60 show plots of the errors associated with the location of the TCs in the ball. Figure 57 shows errors of both $1.9 \mathrm{~cm}$ [0.75 in.] and $2.5 \mathrm{~cm}$ [1.0 in.]-diameter polished SS balls. Figure 58 shows errors of both $1.9 \mathrm{~cm}$ [0.75 in.] and $2.5 \mathrm{~cm}$ [1.0 in.]-diameter polished brass balls; Figure 59 for both $1.9 \mathrm{~cm}$ [0.75 in.] and $2.5 \mathrm{~cm}$ [1.0 in.]-diameter blackened SS balls; and Figure 60 for both $1.9 \mathrm{~cm}$ [0.75 in.] and $2.5 \mathrm{~cm}$ [1.0 in.]-diameter blackened brass balls.

In general, the errors associated with TCs located in the center of the ball were the lowest during the heat-up and cool-down, but there was no clear distinction during the soak. This is in contrast to Test 1 , where the TCs closest to the wall generally had the least error during the heatup. However, similar to Test 1 , Test 2 showed no clear distinction during the soak.

\section{Spring-Loaded Probes}

Figure 61 shows the errors associated with the spring-loaded probes for Test 2 . The shapes of the curves are similar to those in the ball-probe plots and the magnitude of the errors during the heat-up and cool-down is in the same range as those for the ball-probes. However, similar to Test 1 for PR23 during the soak, the error was larger than for ball-probes (about $28^{\circ} \mathrm{C}\left[50^{\circ}\right]$ ) or about $6 \%$, whereas PR6 showed less error (e.g., about $10^{\circ} \mathrm{C}\left[18^{\circ} \mathrm{F}\right]$. Similar to ball-probe responses for this test, considerable oscillations were caused by the fast response of the probes. Also, the errors during Test 2 were of the same magnitude as those in Test 1 because the two tests were run at the same heat-up rate.

\section{The "Air" Temperature and Shunting Error Thermocouples}

Figure 62 shows the response of the air temperature measurements (W33, W34, W35 and W36) and the TCs that were used to check for shunting errors (W35, W36 and W37). W35 and W36 acted as both air temperature measurements and TCs used to check for shunting. W33 W36 responded in a manner similar to a typical probe, but had larger absolute errors. W37 showed a slight temperature rise beginning at about 13 hours, but this could be accounted for by a slight increase in the mounting frame temperature, which could also explain the slight temperature drop beginning at about 24 hours. There is no obvious evidence of shunting. W35 and W36 


\section{Investigation of RPV Temperature Measurement Methods}

responded in a manner very similar to W33 and W34, also with no evidence of shunting. As with other probe plots from Test 2 , an oscillatory nature is evident.

\section{Electrical Power to Heater Zones}

Figure 63 shows a plot of the total electrical power supplied to each of the three control zones (top, middle, and bottom). In general, one can say that the bottom heater zone consumed the most power, but the plots are very oscillatory and it is difficult to determine their true shape. This is in direct contrast to the power plots in Figure 37, which are much more stable. The oscillatory nature of the plots in Figure 63 is caused by the very fast response of the control probes. Because the probes are small relative to the RPV wall, they respond quickly to heat, and cause the heaters to cycle on and off much more rapidly than in Test 1 , when RPV wall TCs controlled the heater zones. The rapid cycling of the heaters may be a reliability concern during a long test. 


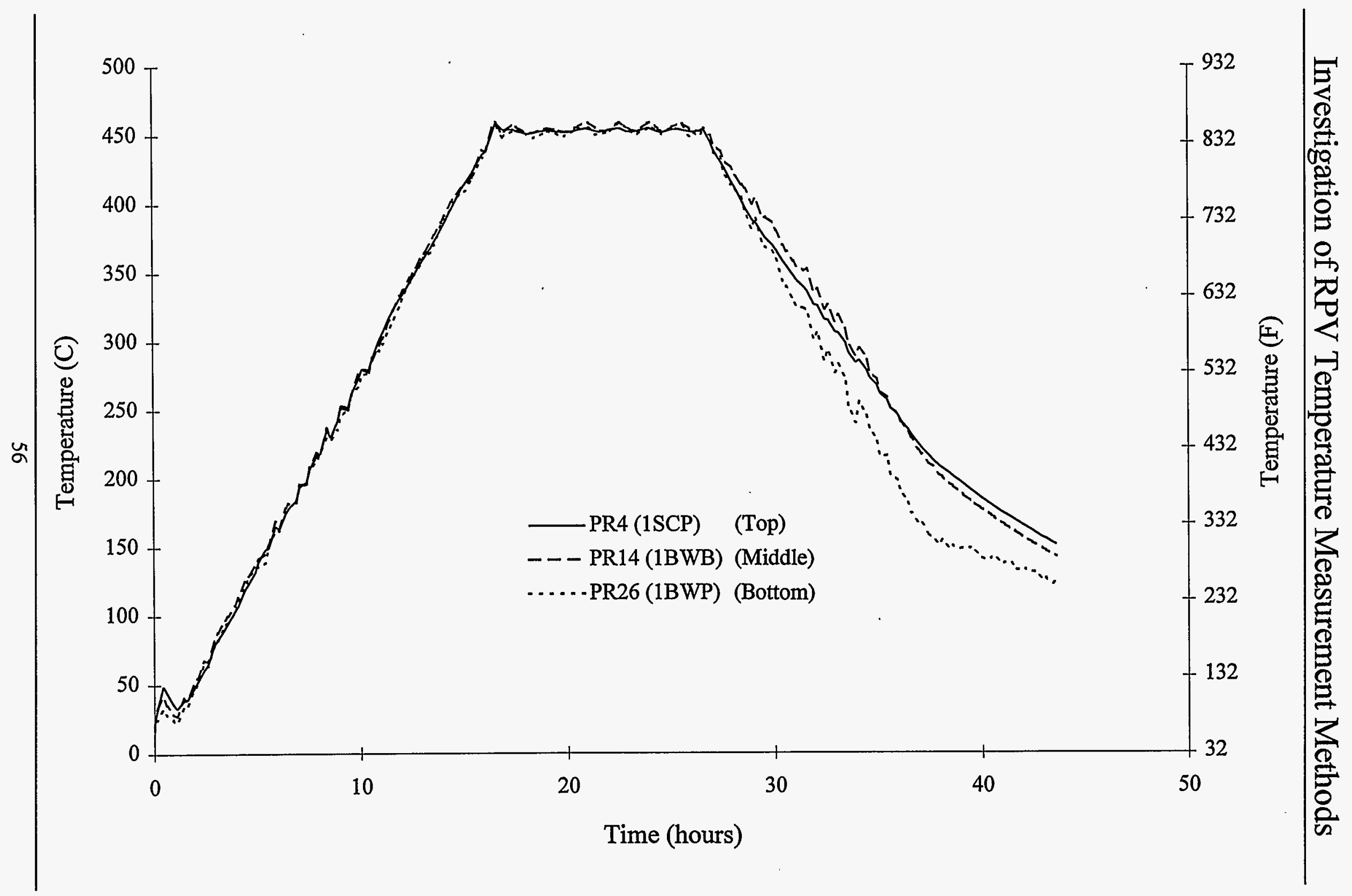

Figure 39. Test 2, Plot of Control Probes and Heat-up Rate. 


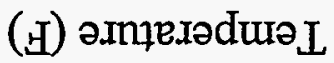
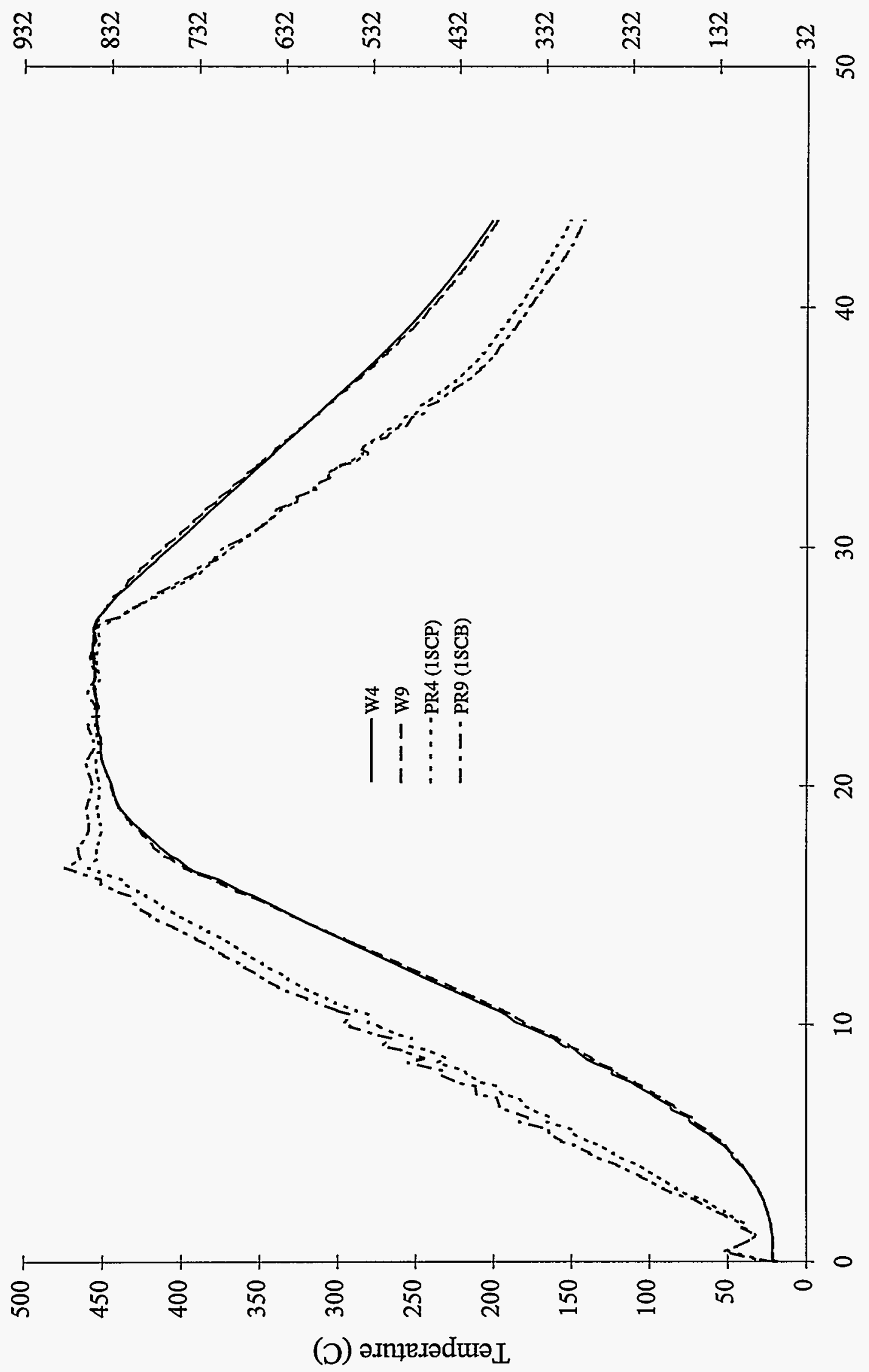


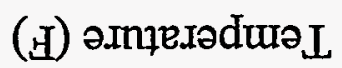
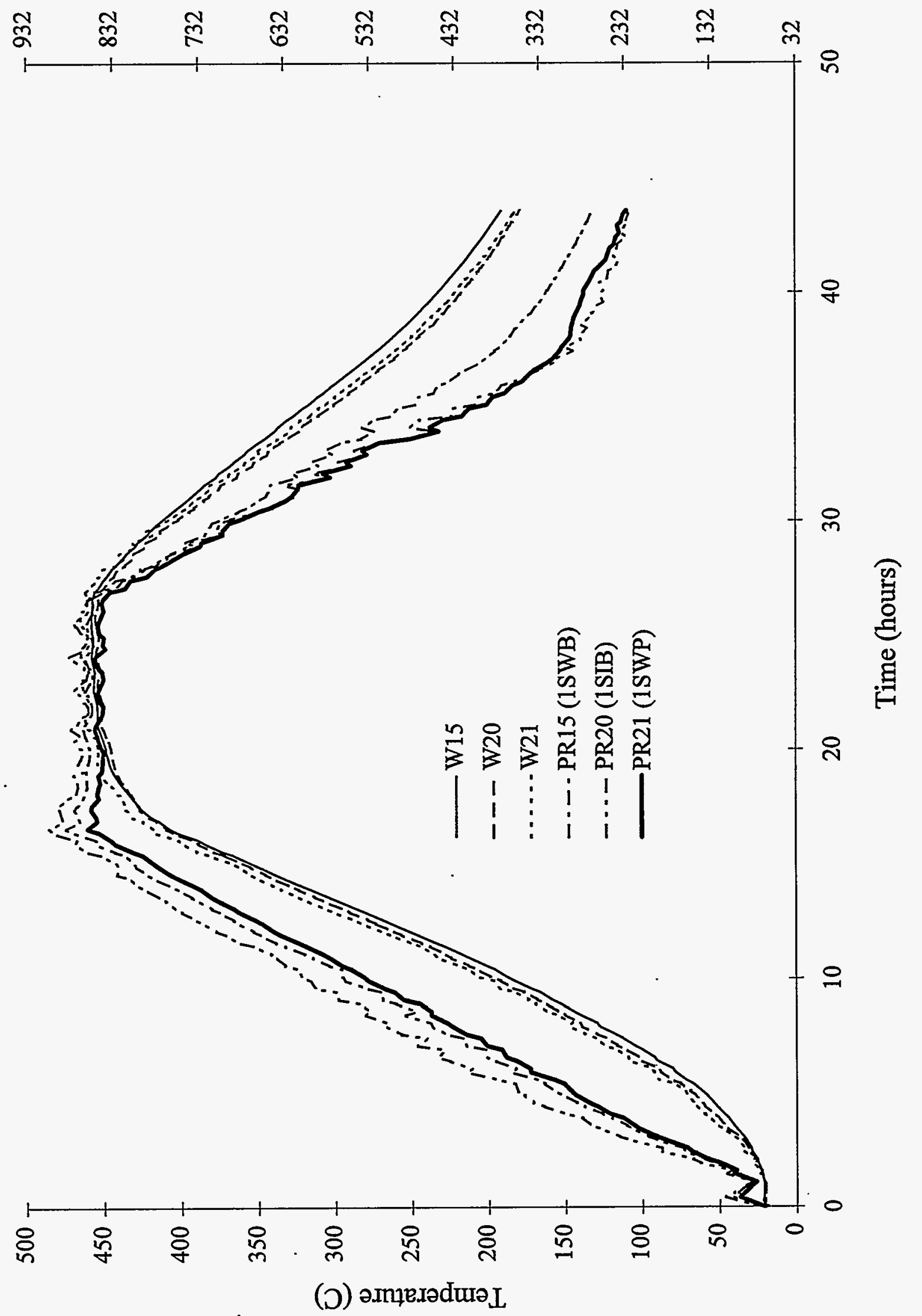


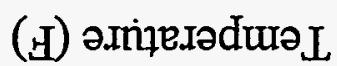
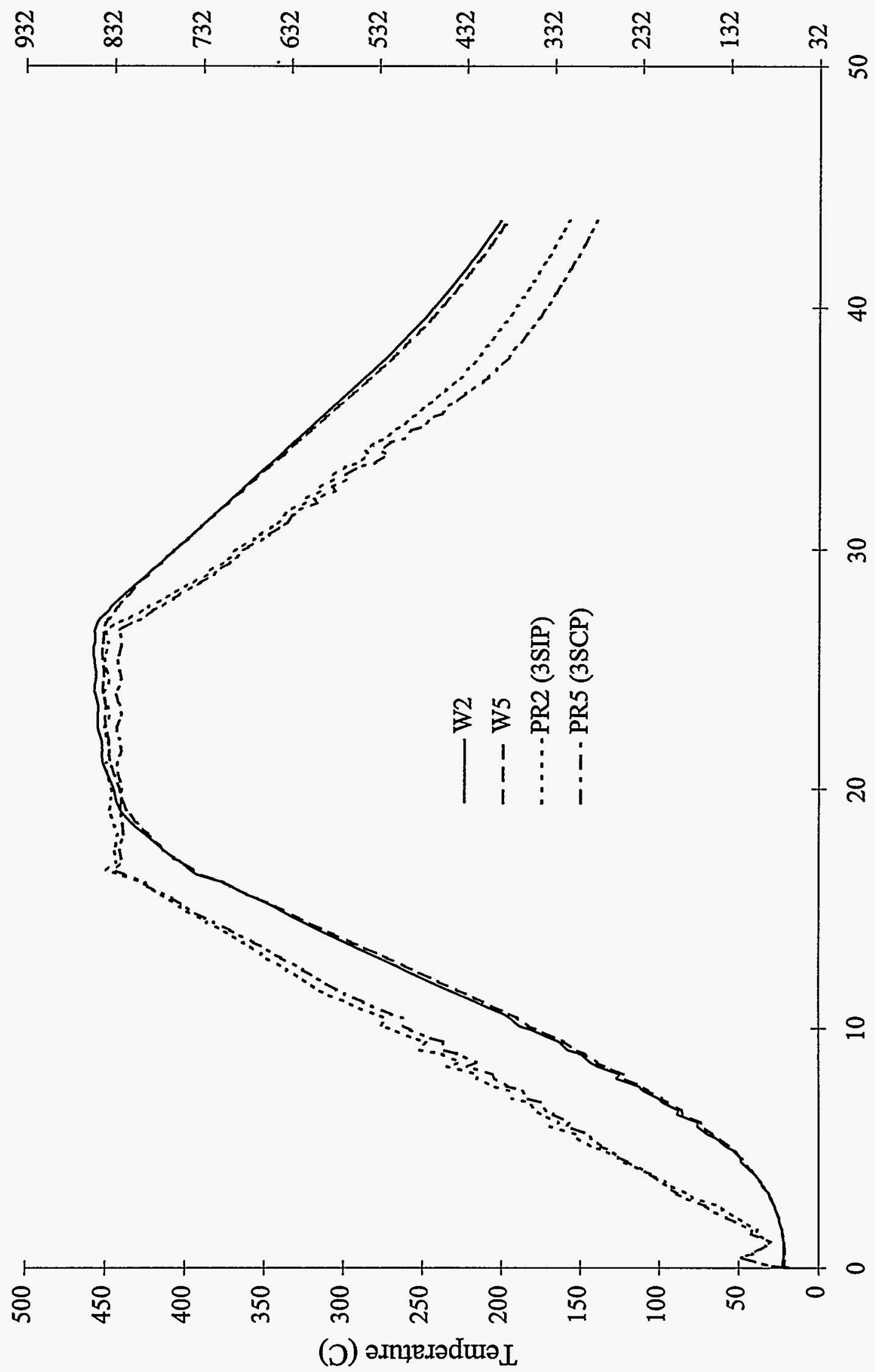

in 


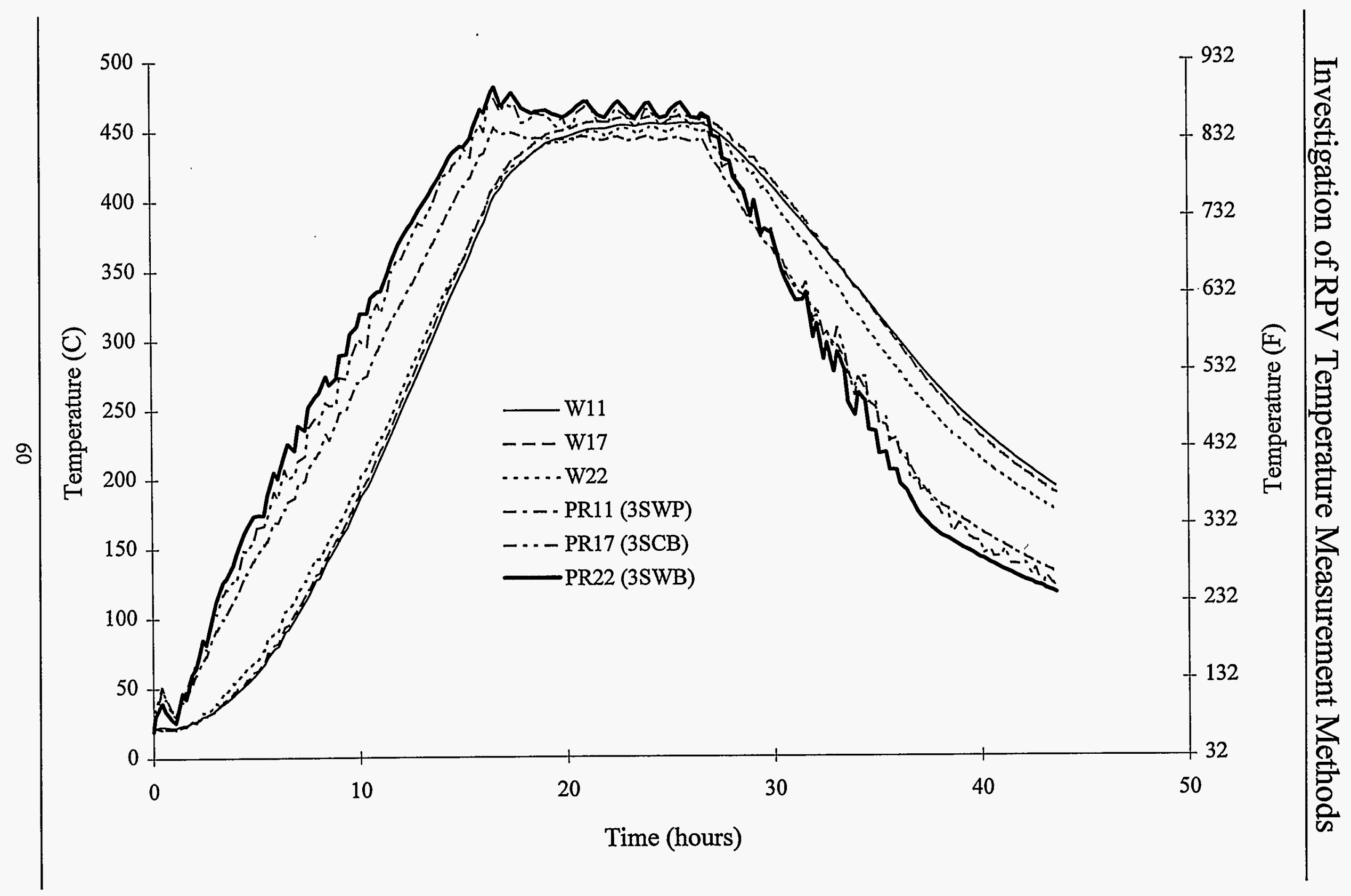

Figure 43. Test 2, Comparison of Wall TC and Probe Responses, 1.9-cm SS Probes. 


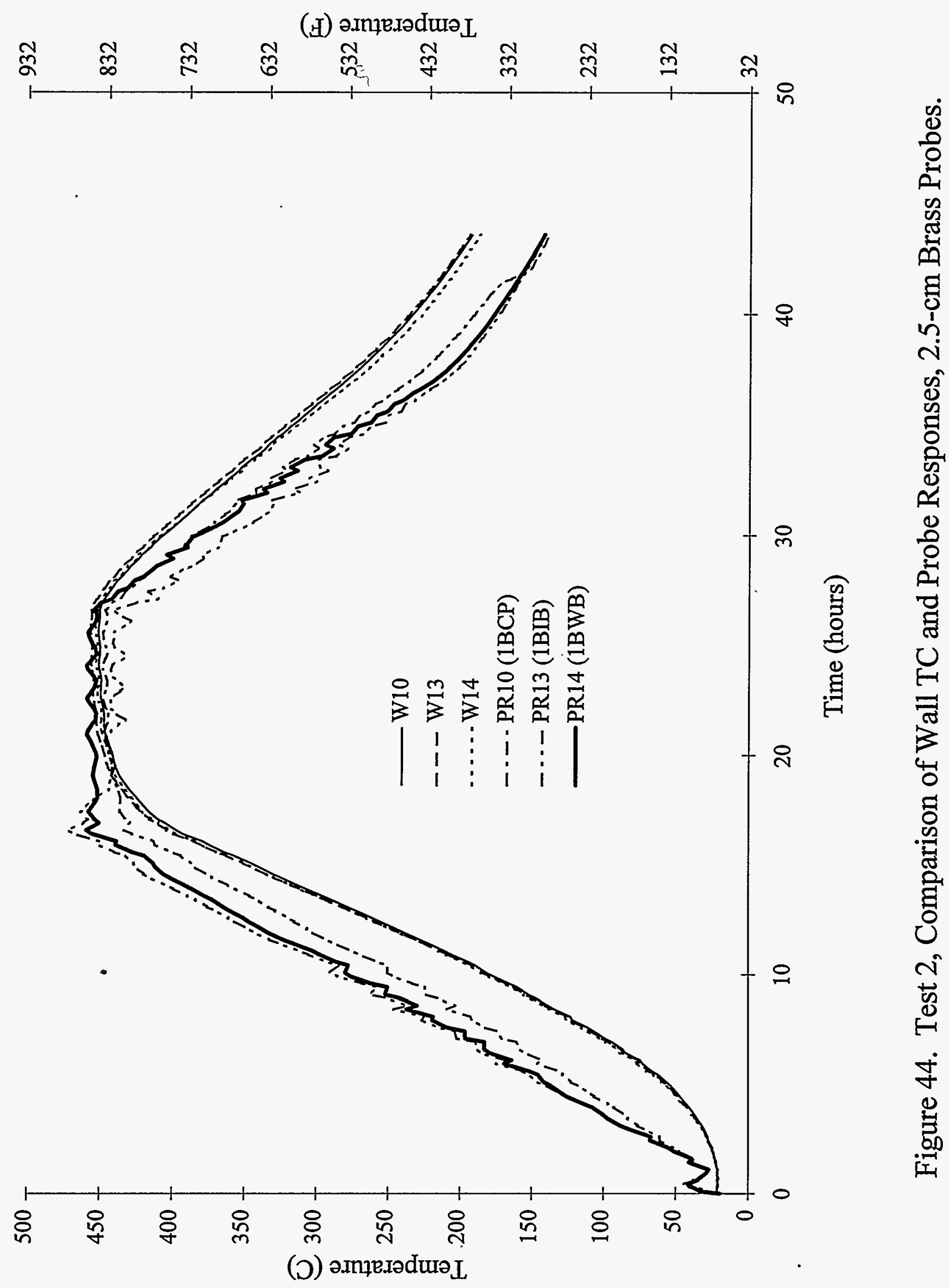




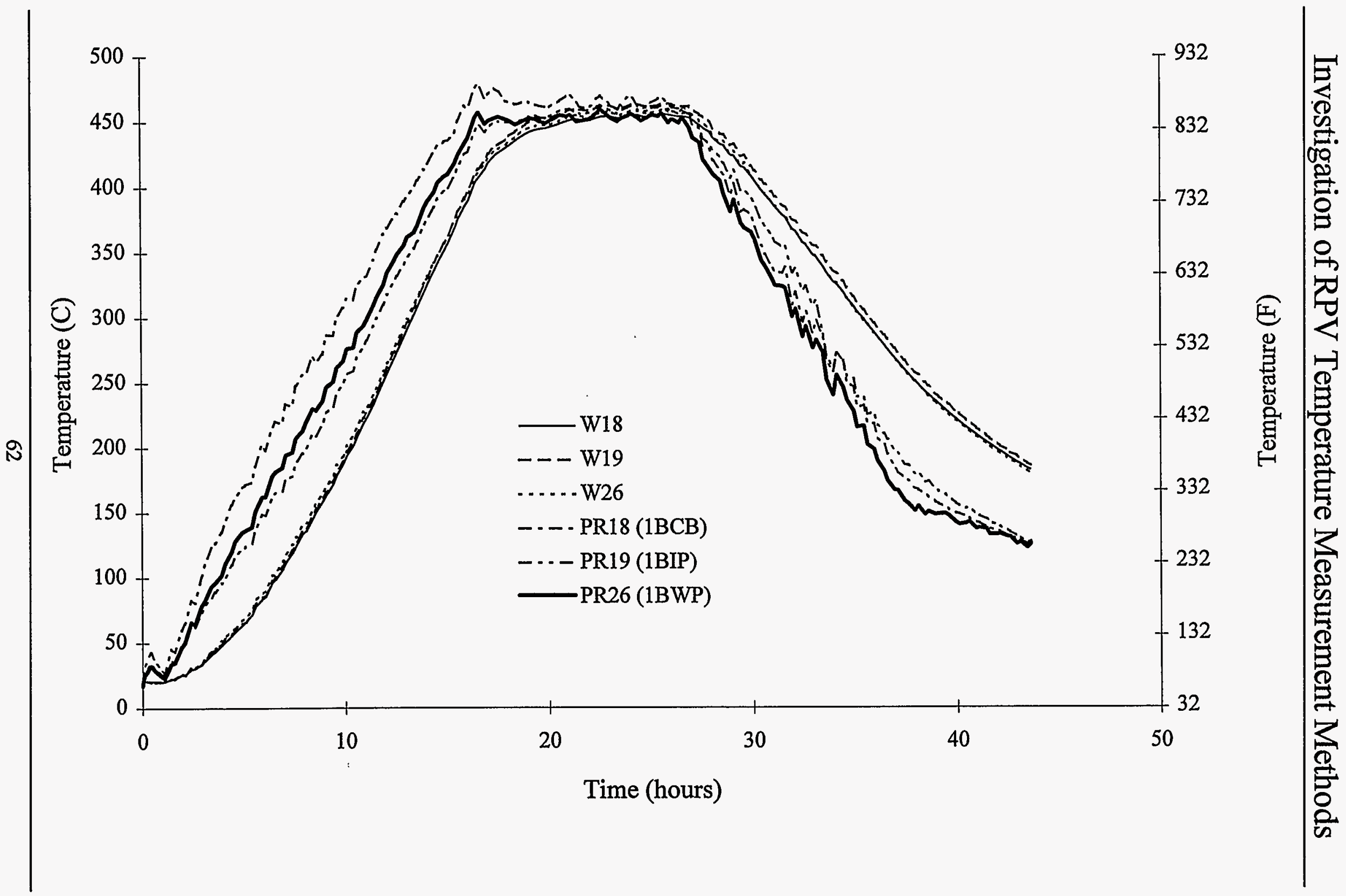

Figure 45. Test 2, Comparison of Wall TC and Probe Response, 2.5-cm Brass Probes. 


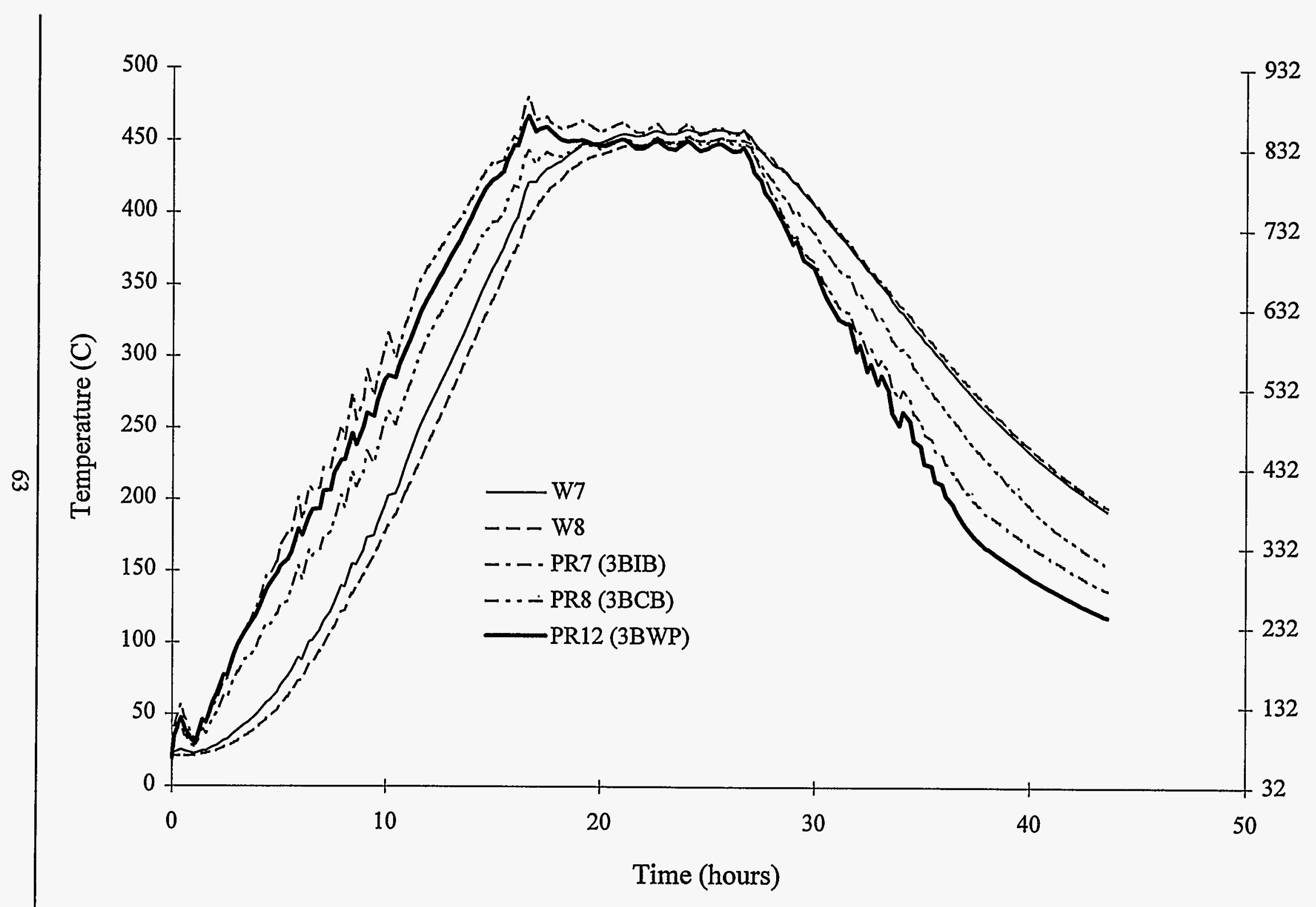

Figure 46. Test 2, Comparison of Wall TC and Probe Responses, 1.9-cm Brass Probes. 


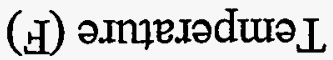

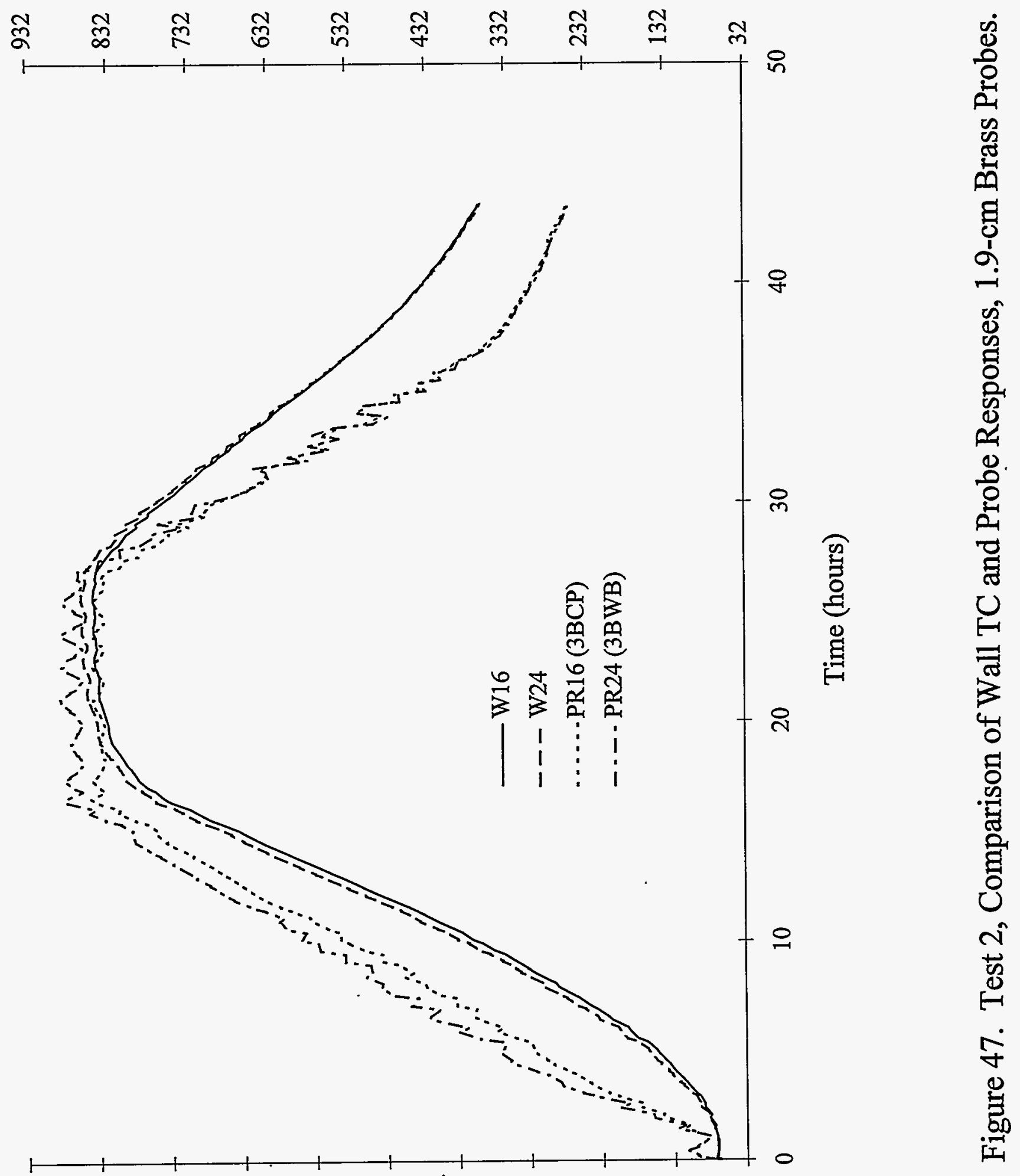

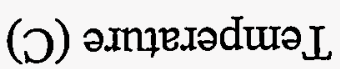




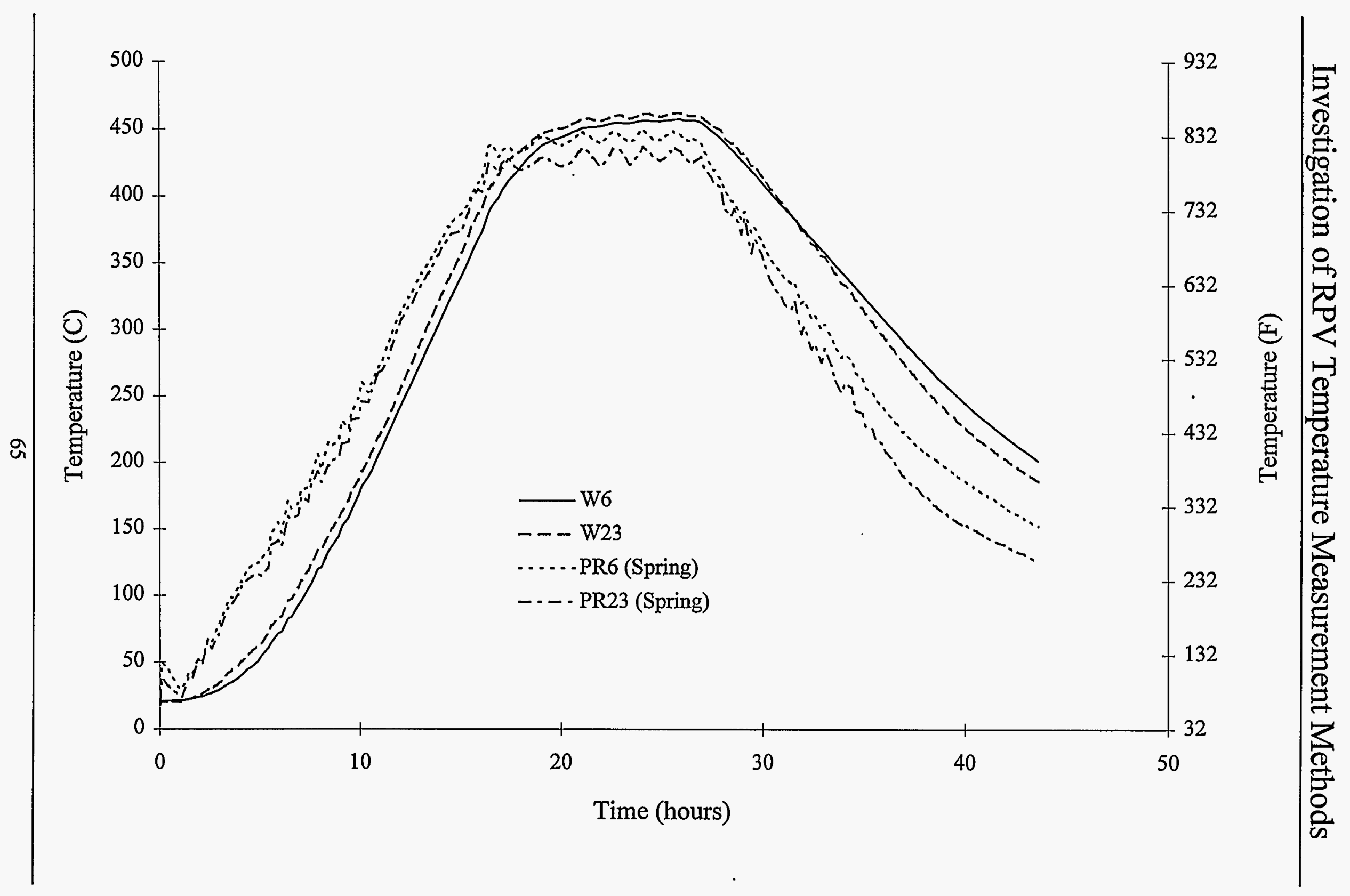

Figure 48. Test 2, Comparison of Spring-Loaded Probes and Wall TCs. 


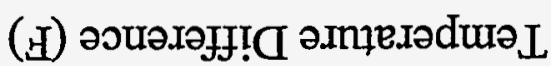

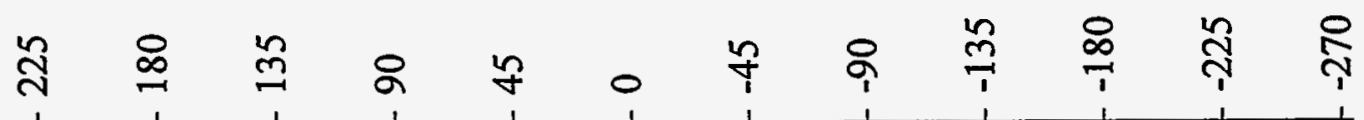
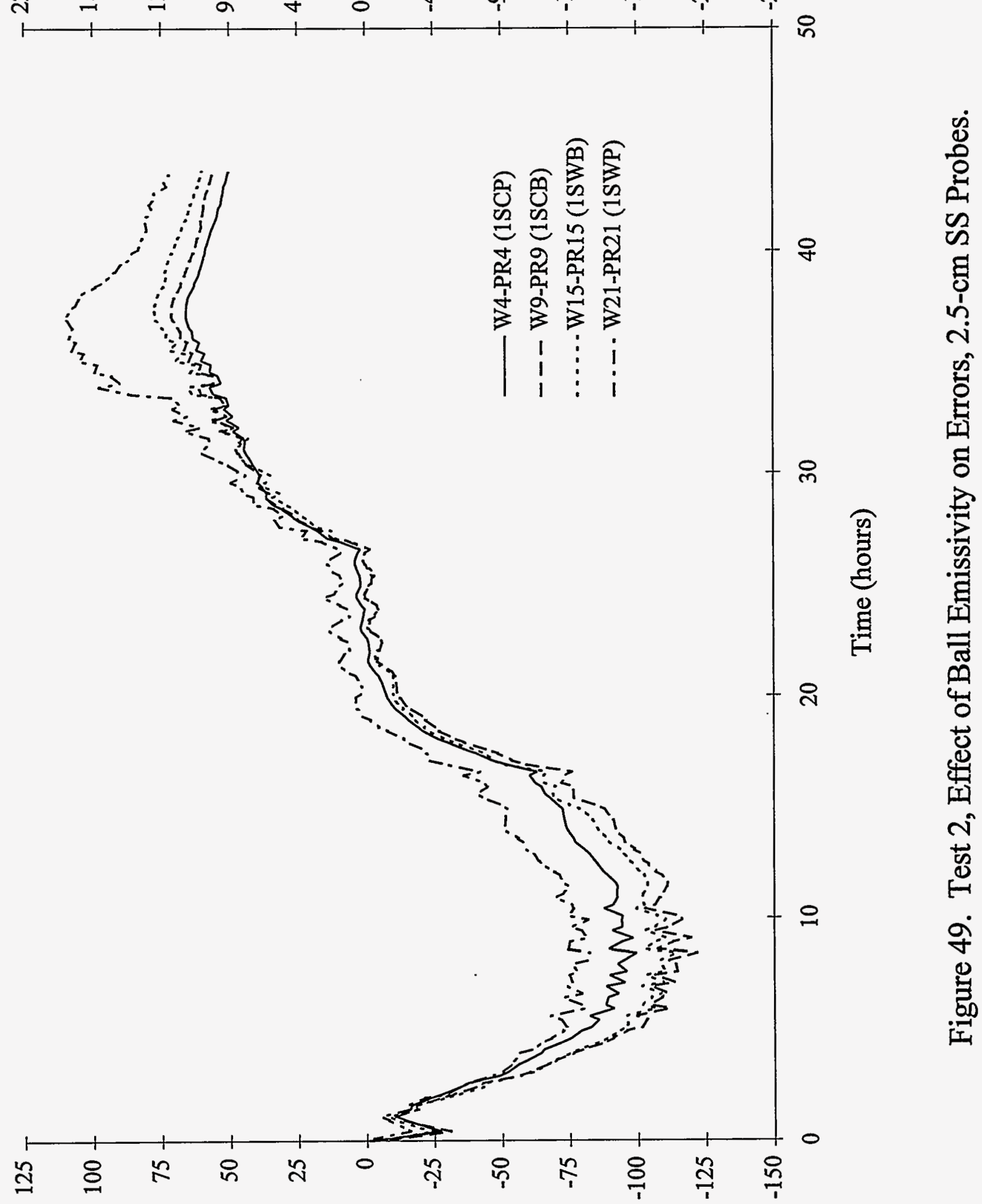

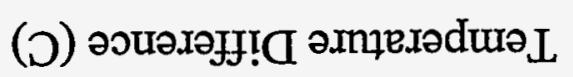




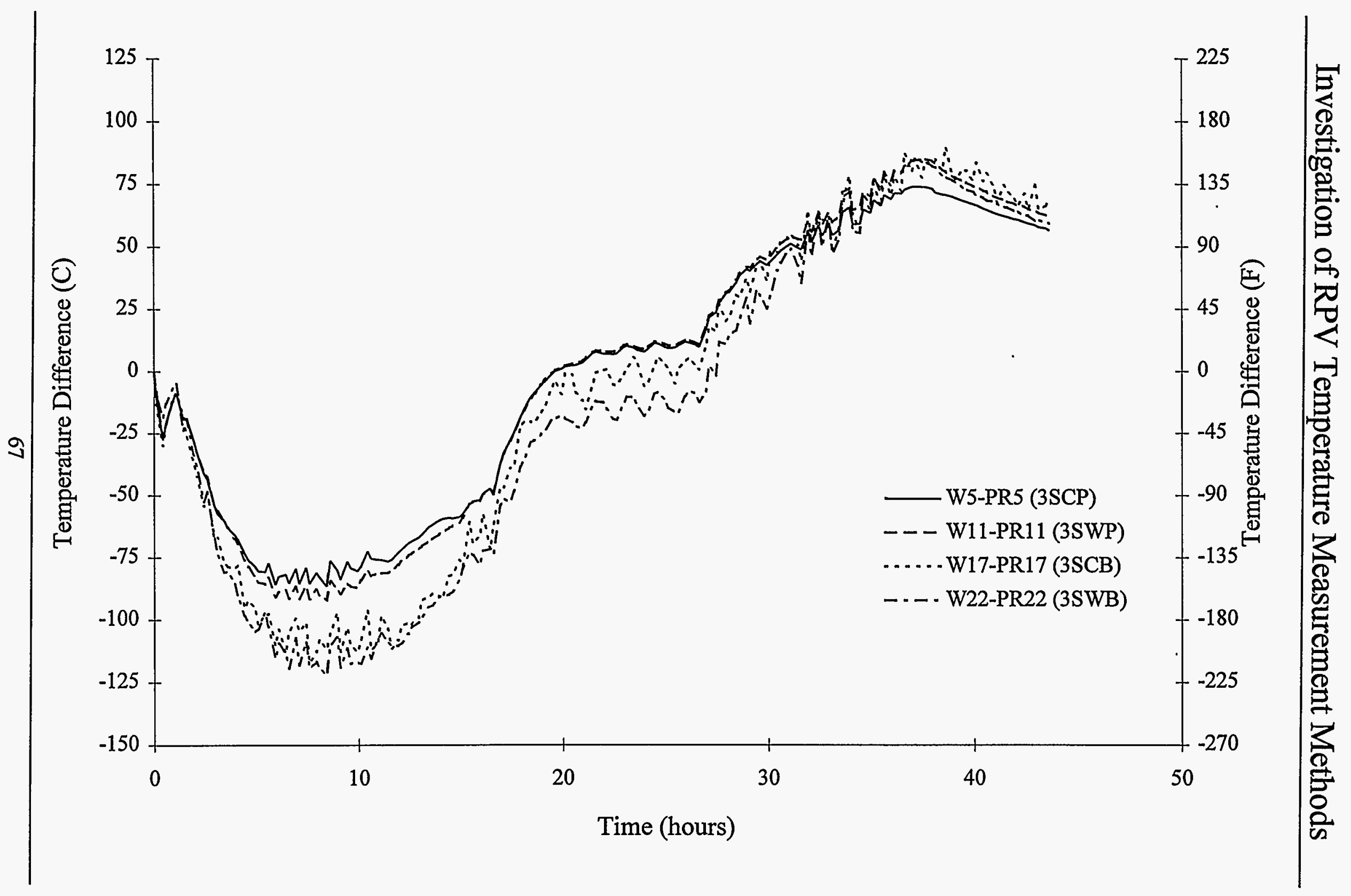

Figure 50. Test 2, Effect of Ball Emissivity on Errors, 1.9-cm SS Probes. 

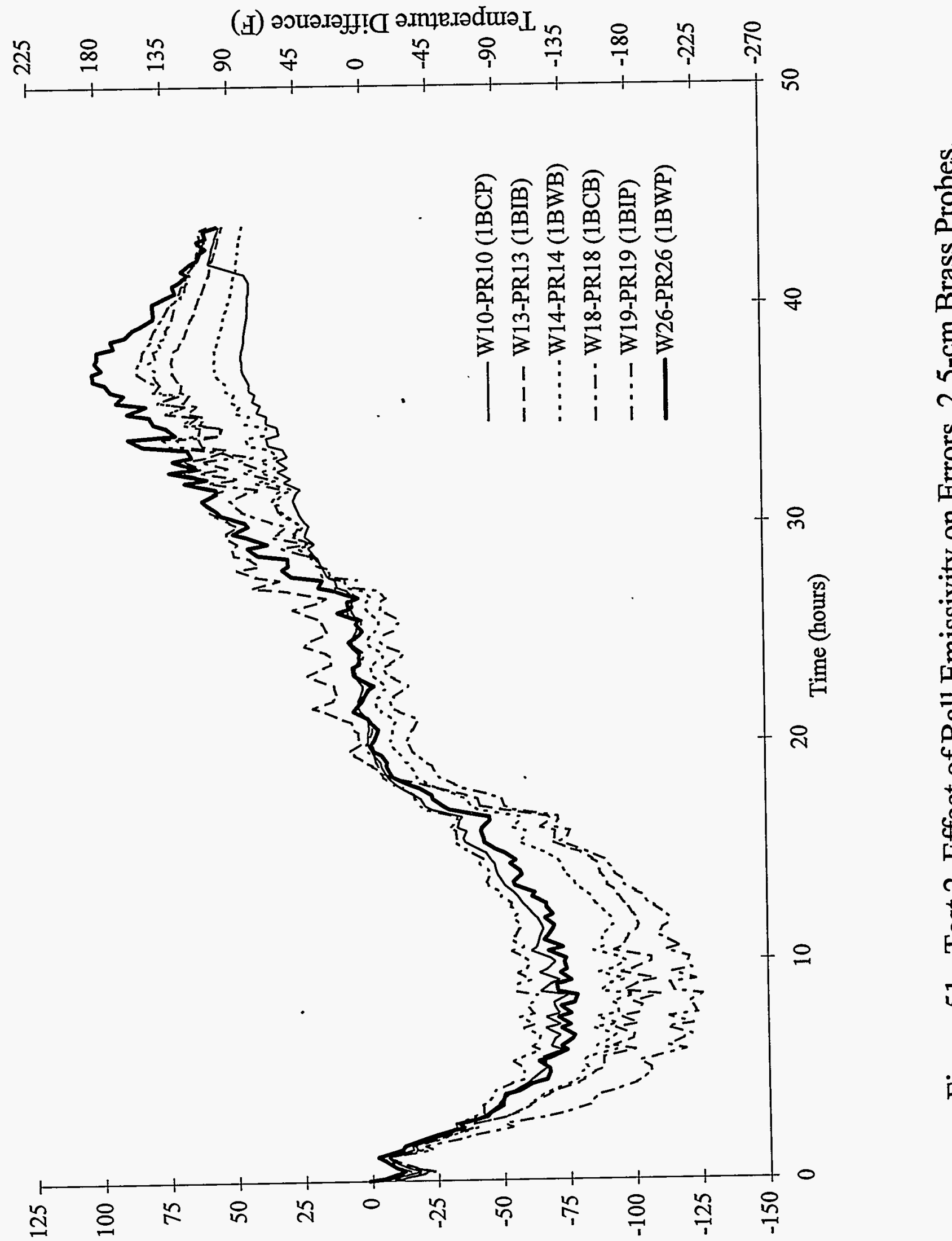

这

농

응

是

品

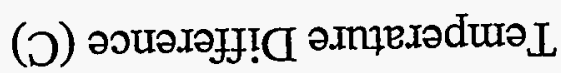




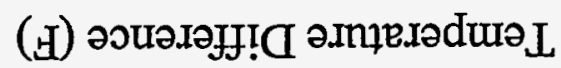

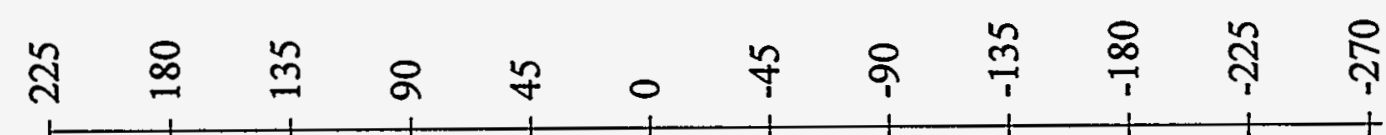

in

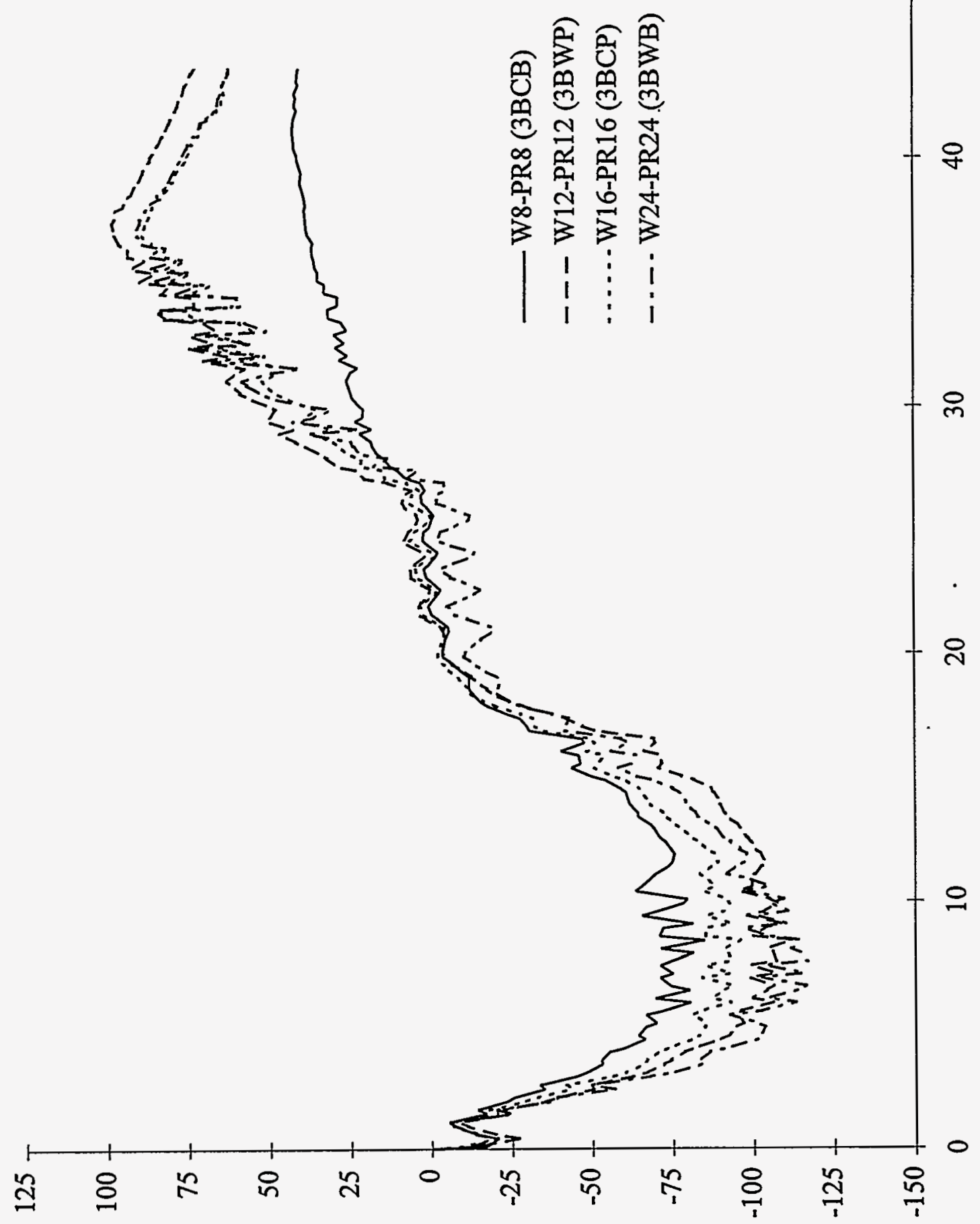

요

8

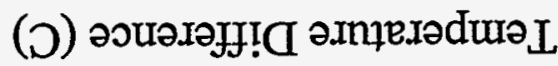




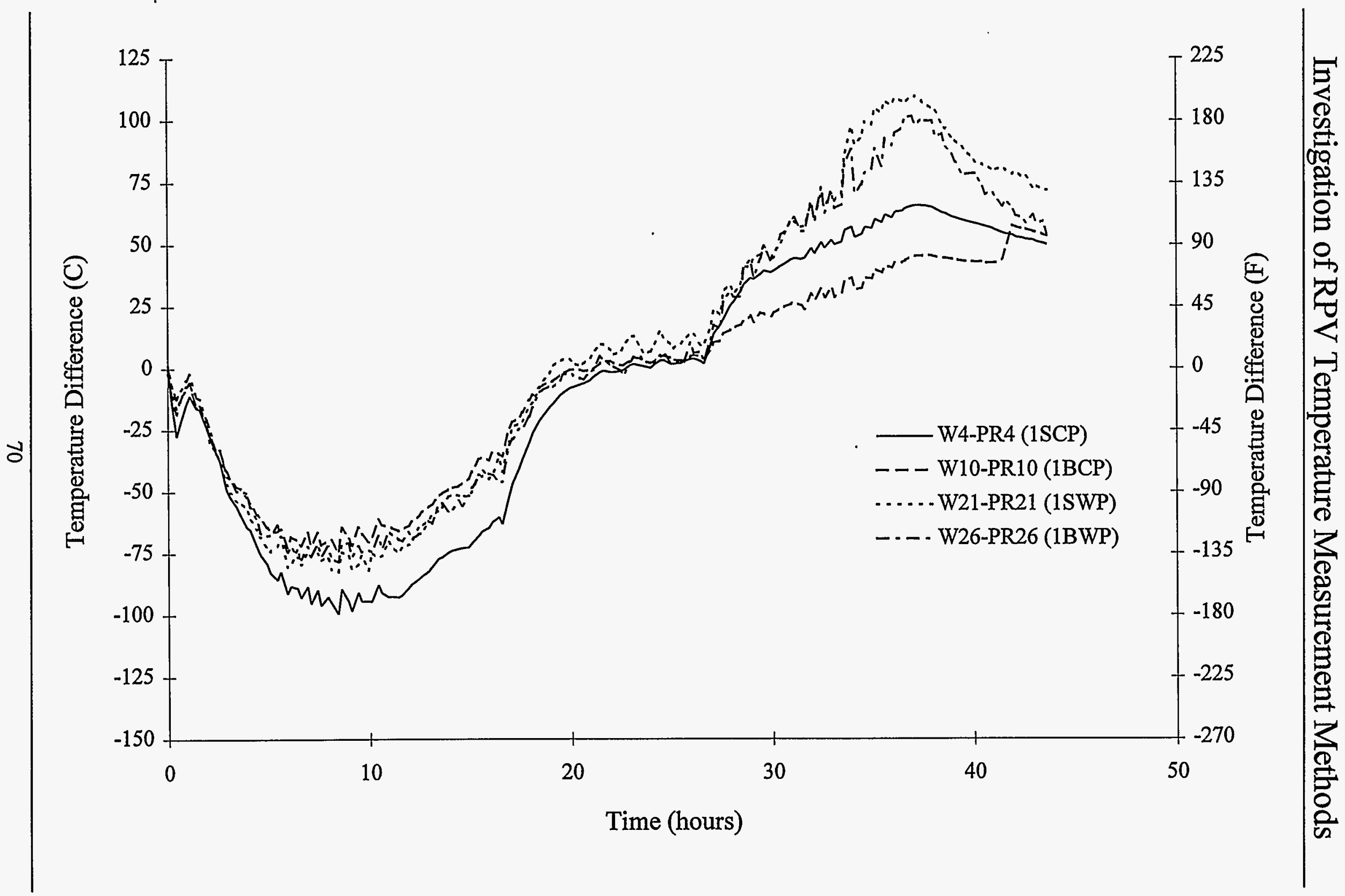

Figure 53. Test 2, Effect of Material on Errors, 2.5-cm Brass and SS Probes. 


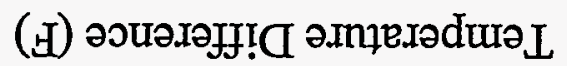

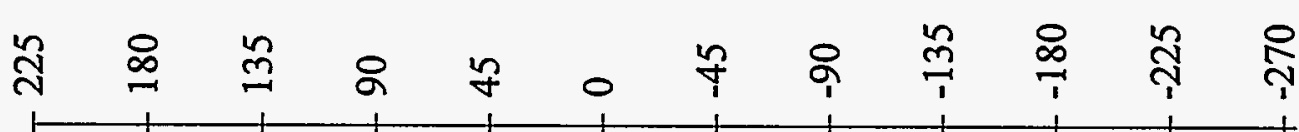

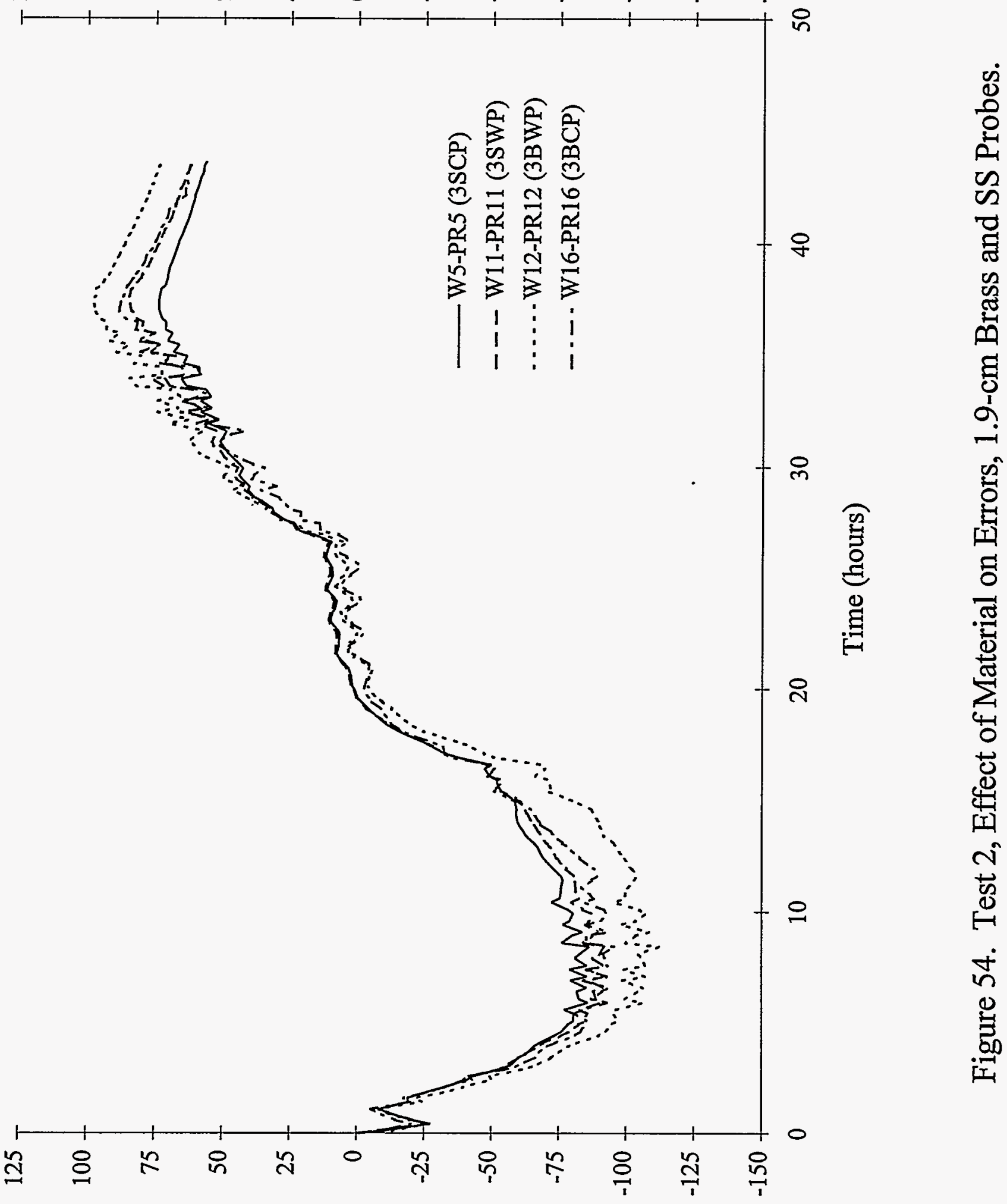

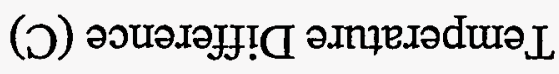




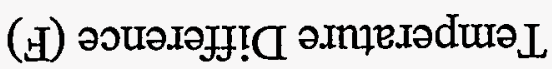

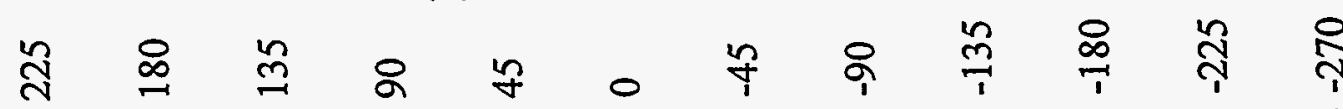

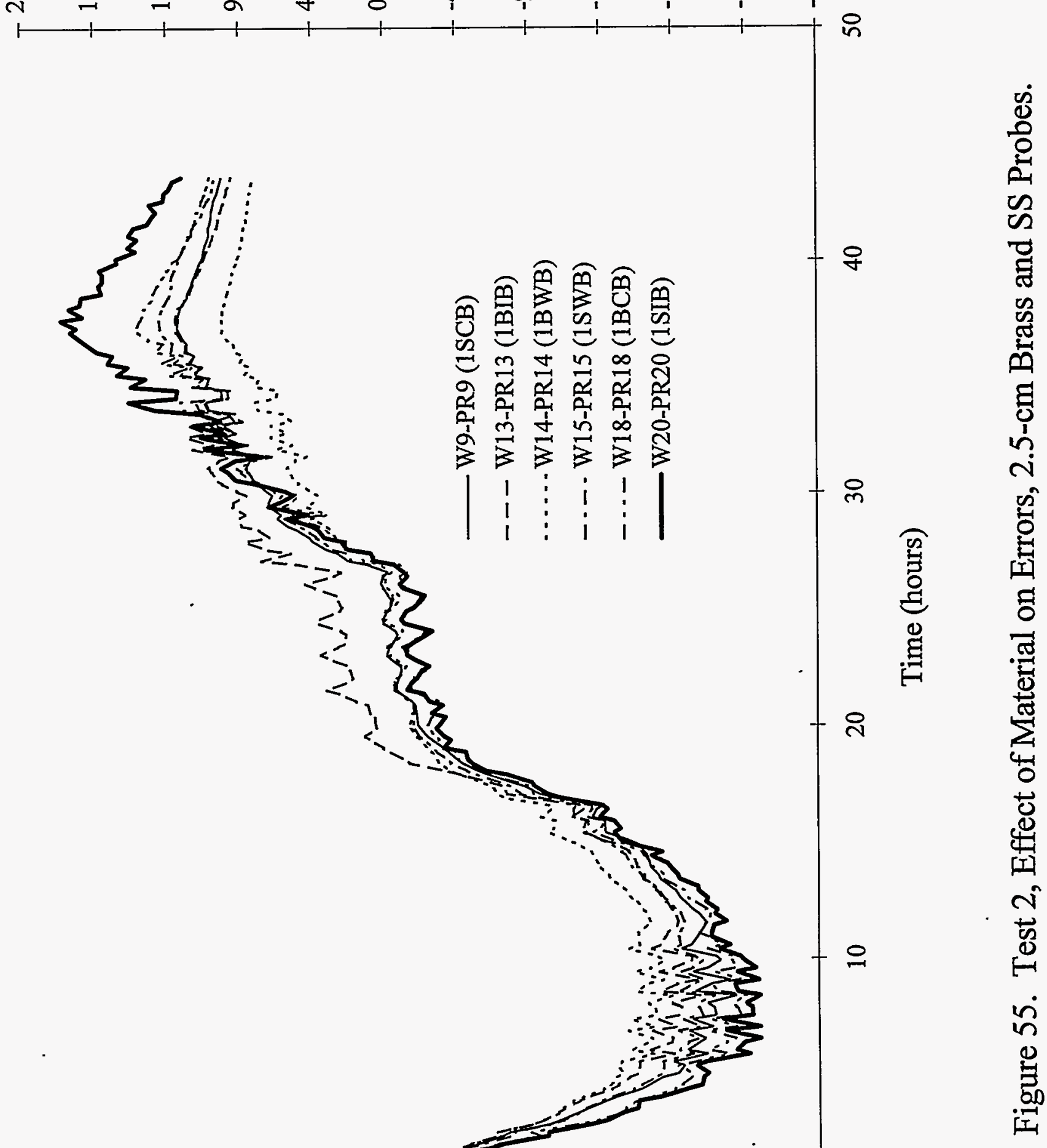

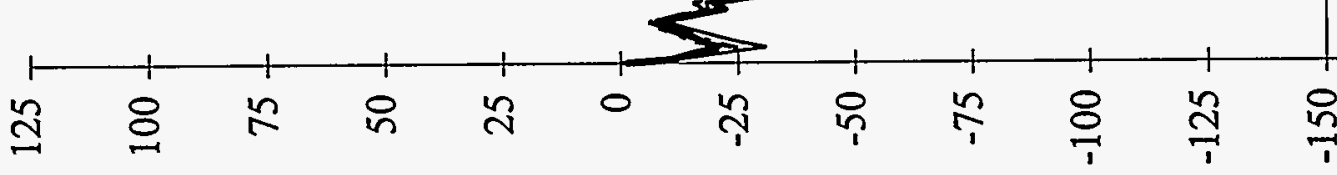

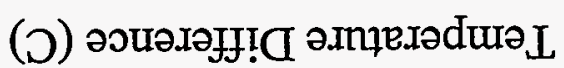




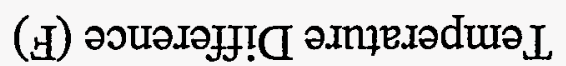
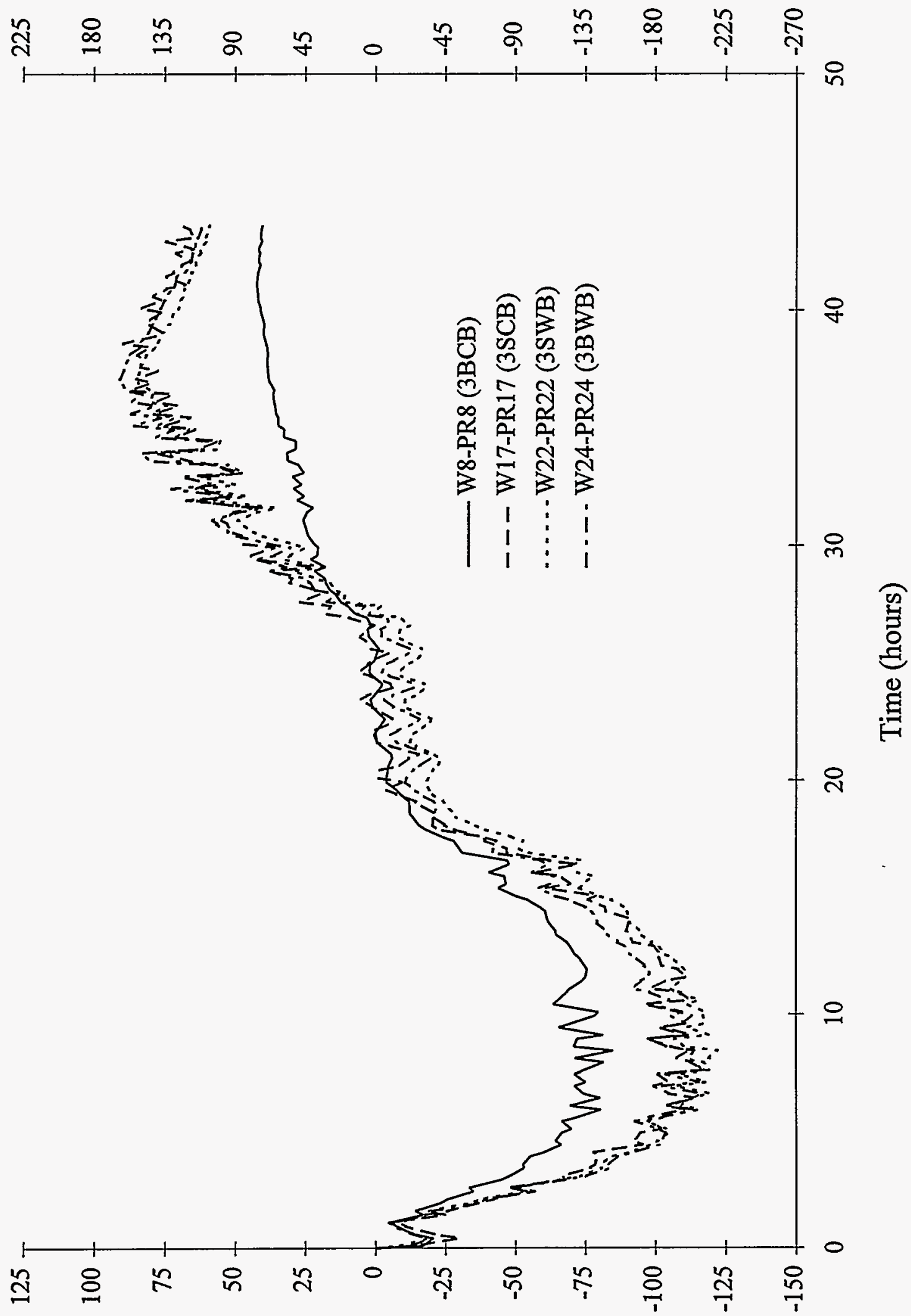

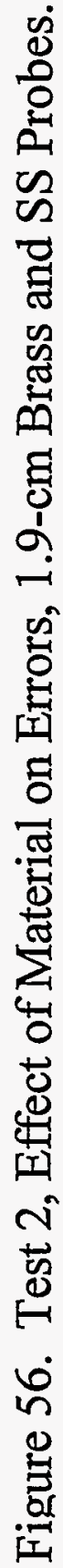

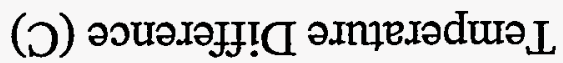




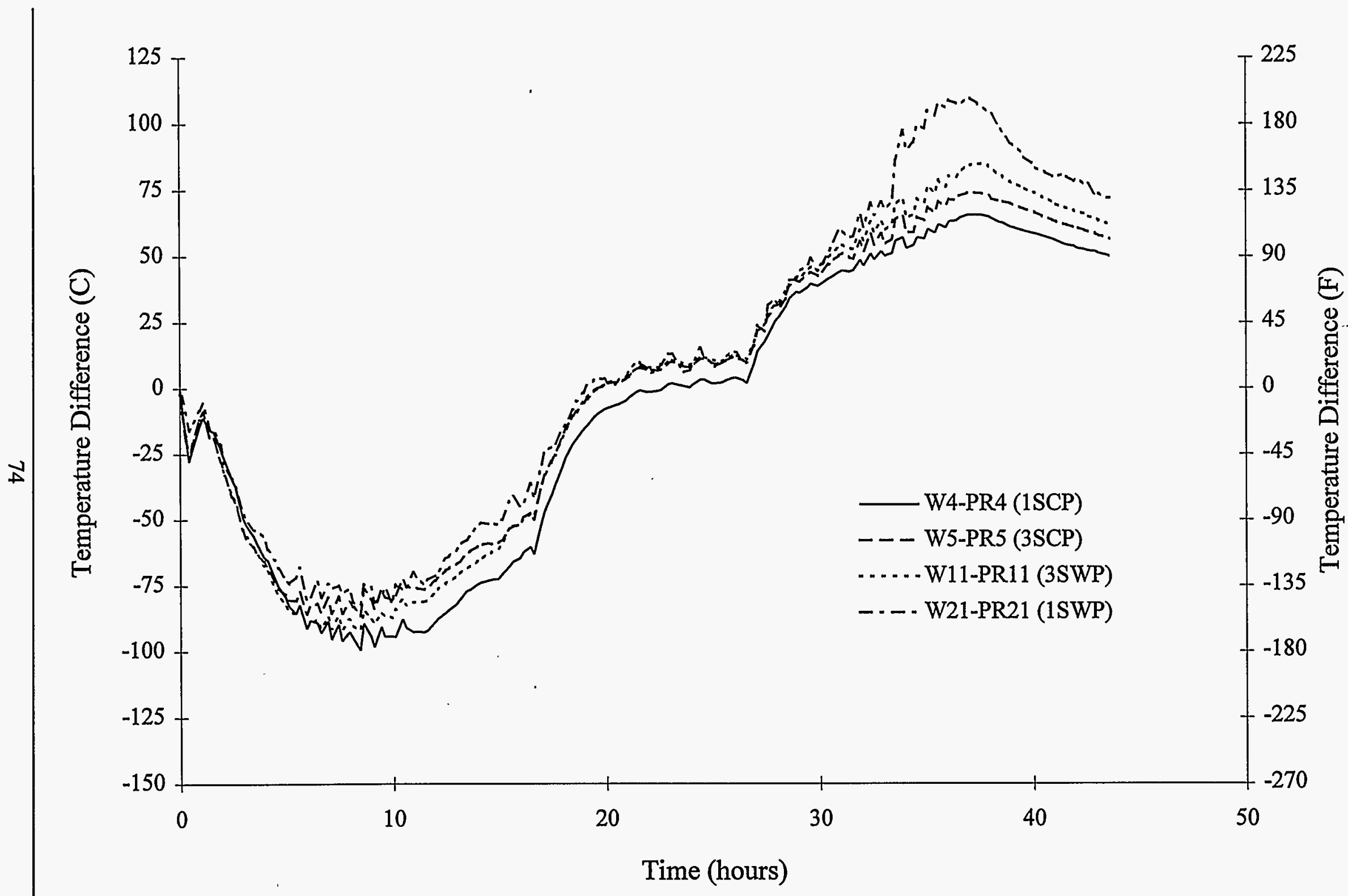

Figure 57. Test 2, Effect of Ball Size and Thermocouple Location on Errors, 1.9-cm and 2.5-cm SS Probes. 


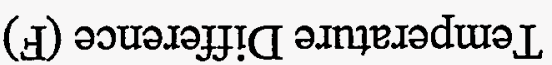
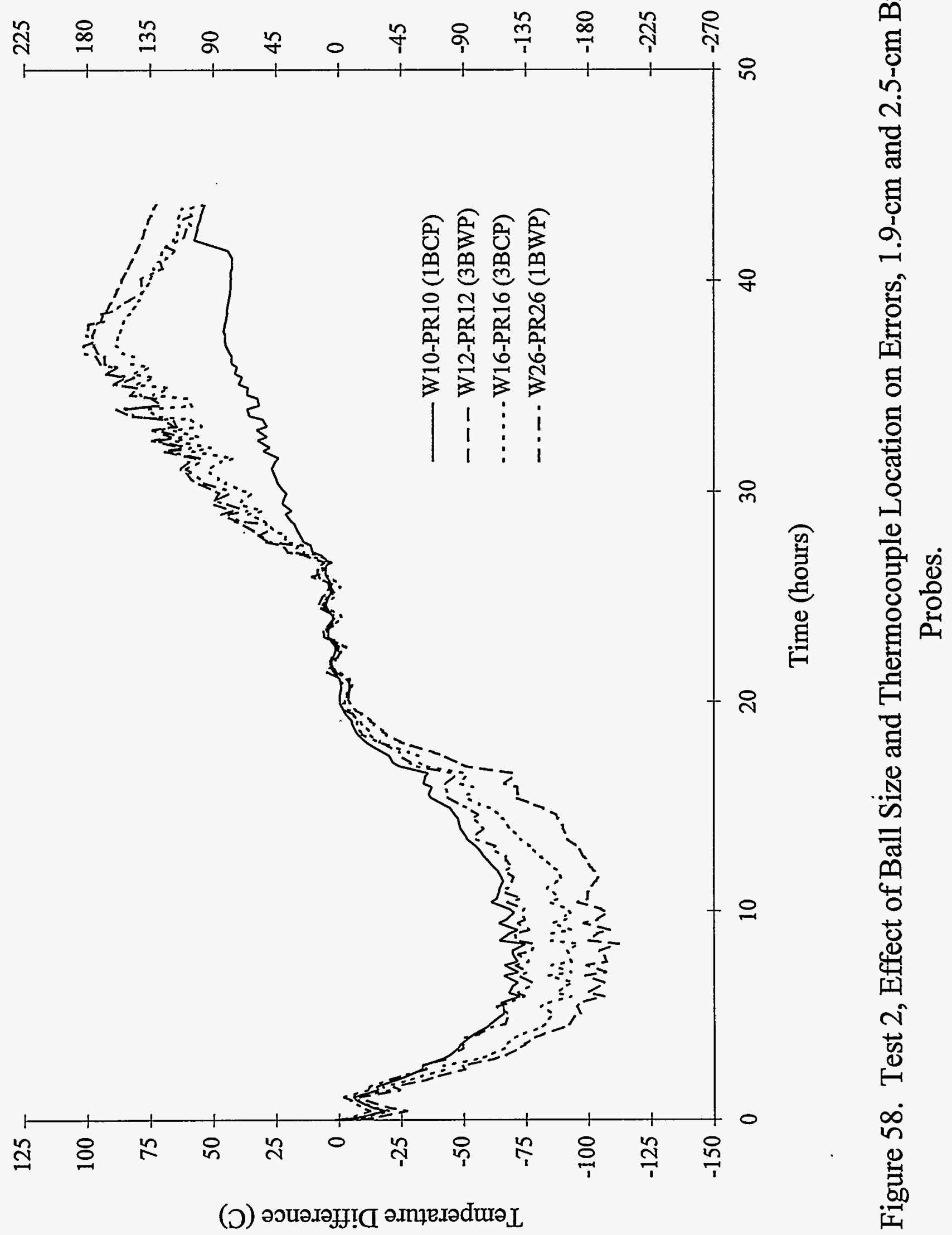

\section{in}




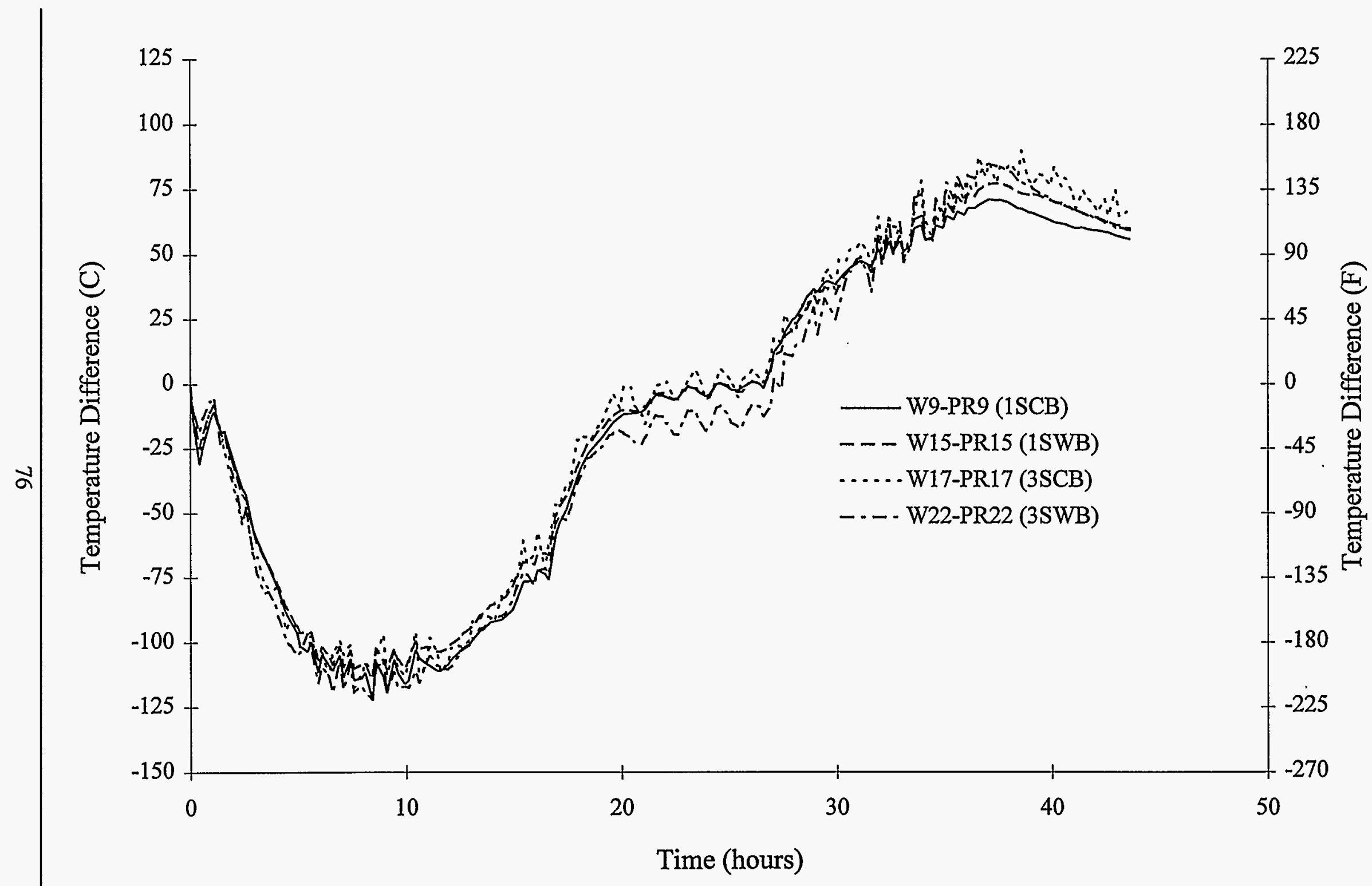

Figure 59. Test 2, Effect of Ball Size and Thermocouple Location on Errors, 1.9-cm and 2.5-cm SS Probes. 


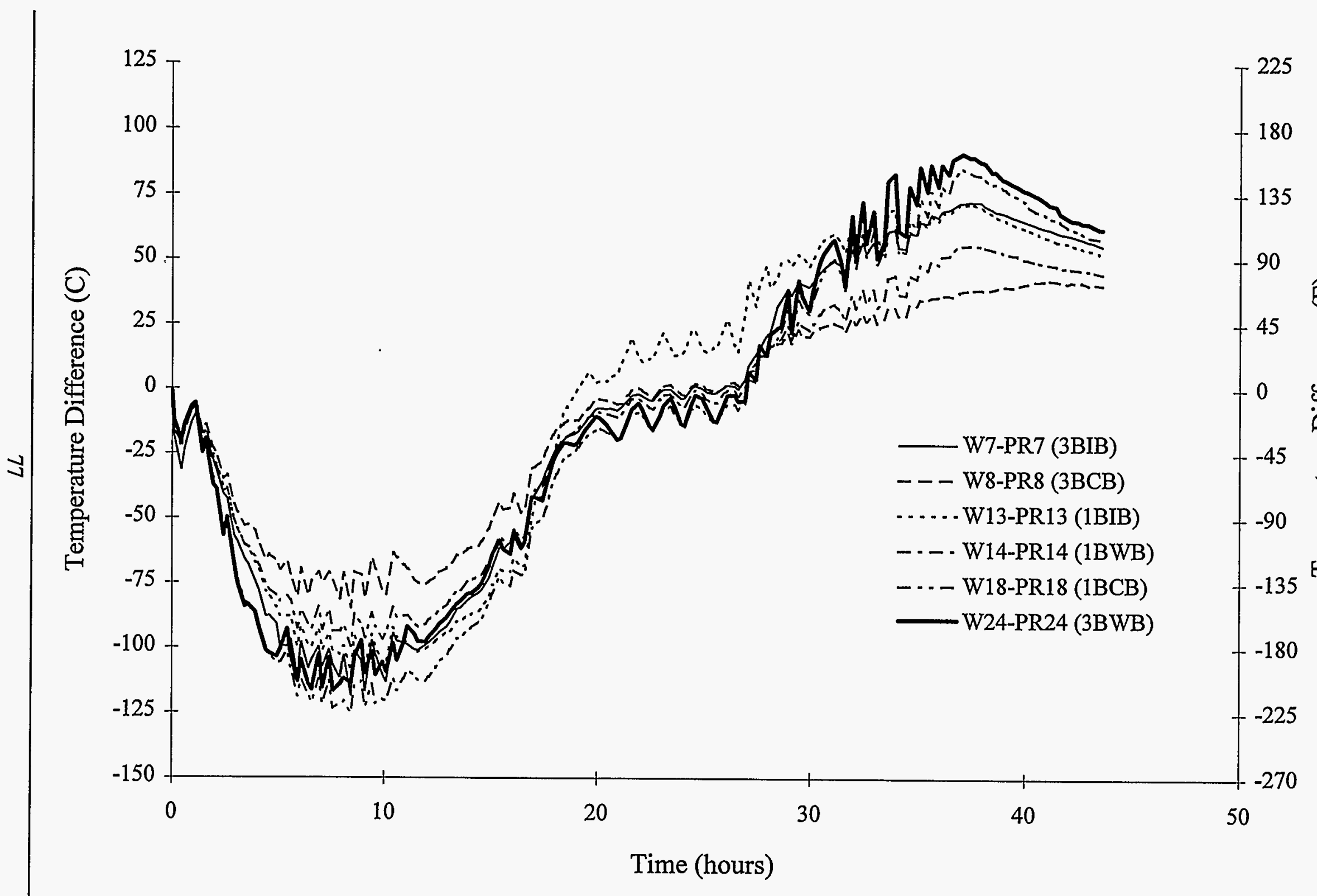

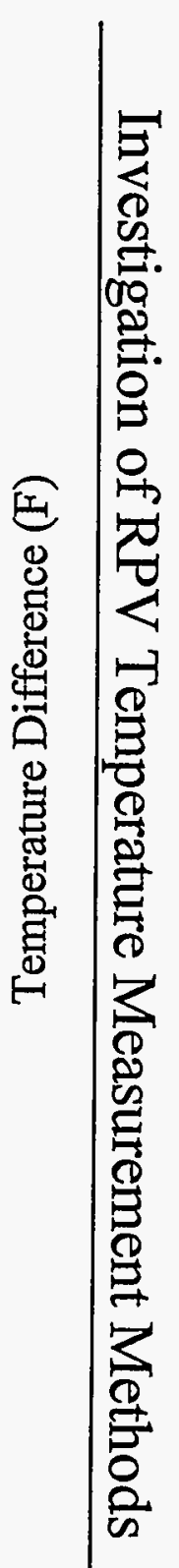

Figure 60. Test 2, Effect of Ball Size and Thermocouple Location on Errors, 1.9-cm and 2.5-cm Brass Probes. 
Investigation of RPV Temperature Measurement Methods

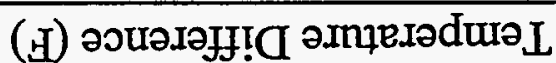

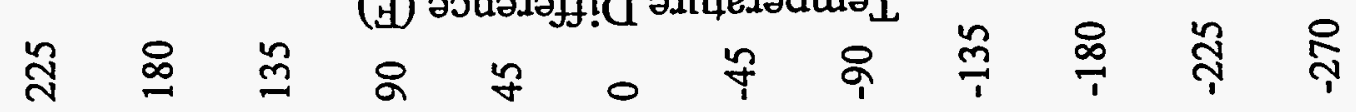
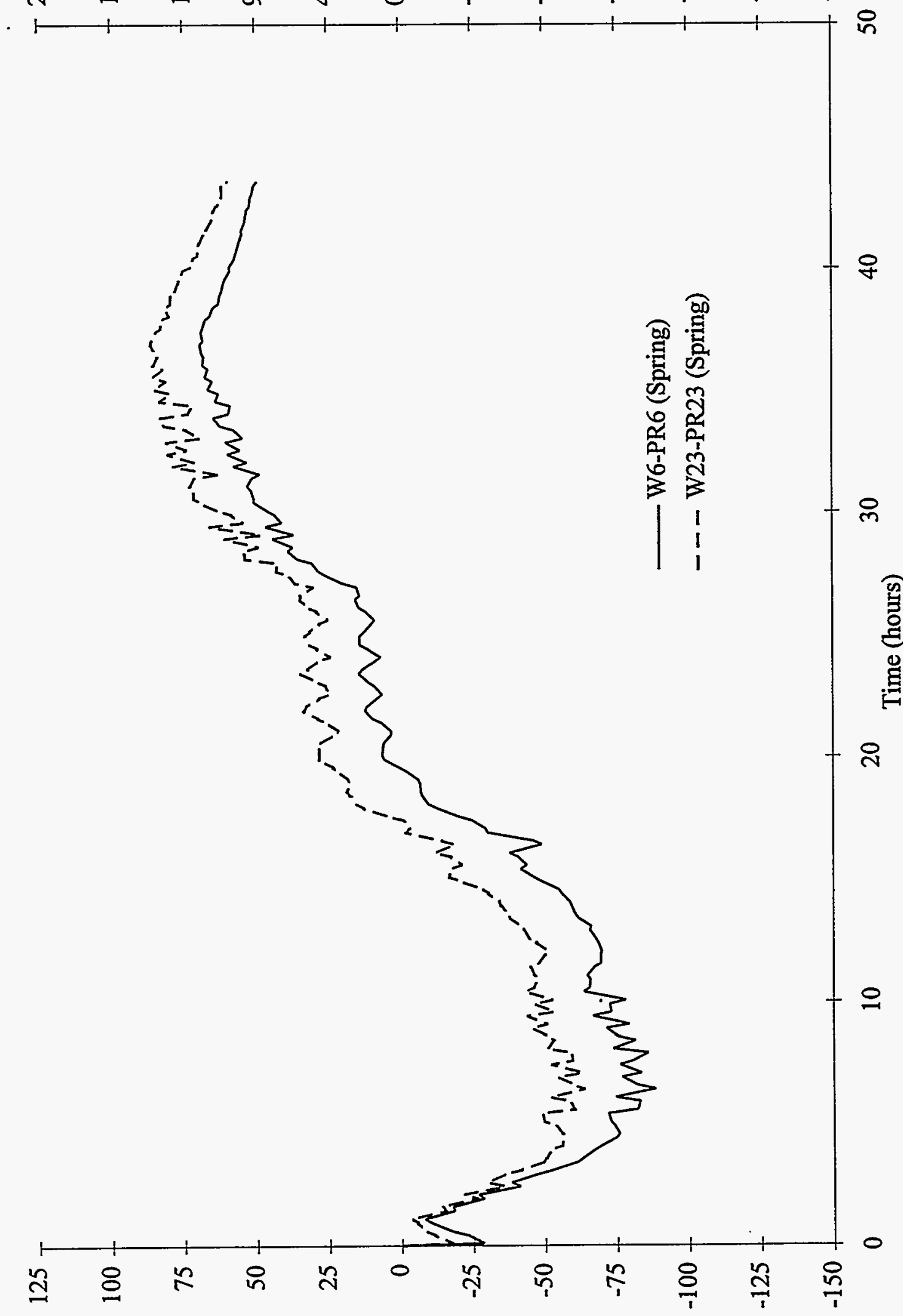

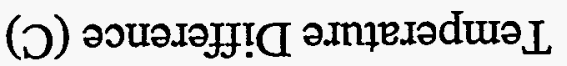




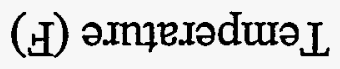

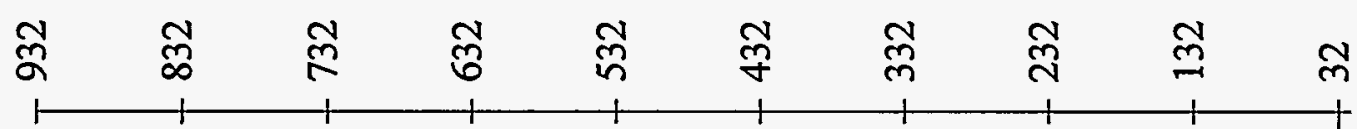

in

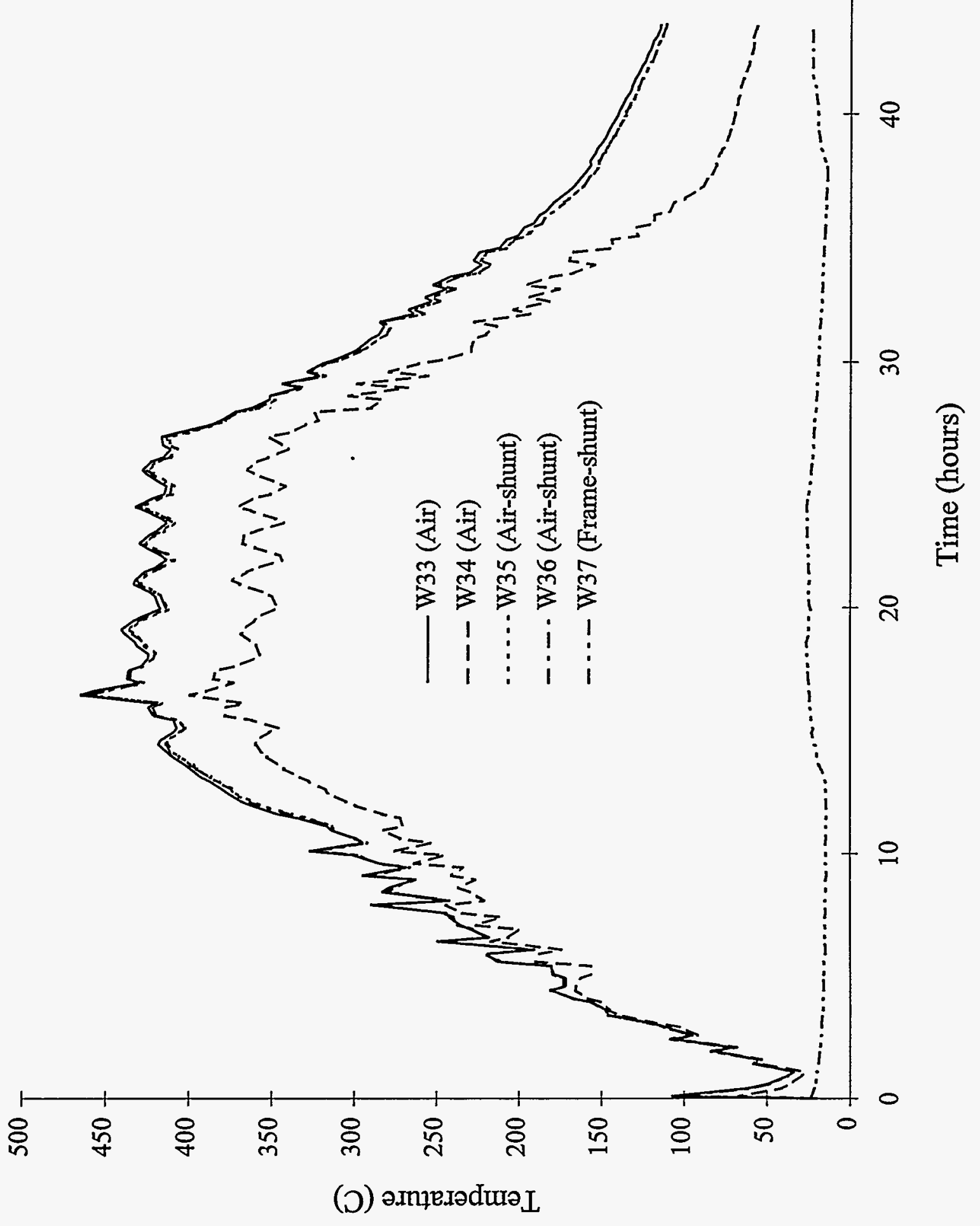

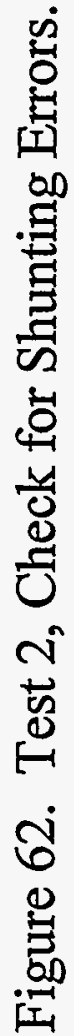




\section{Investigation of RPV Temperature Measurement Methods}
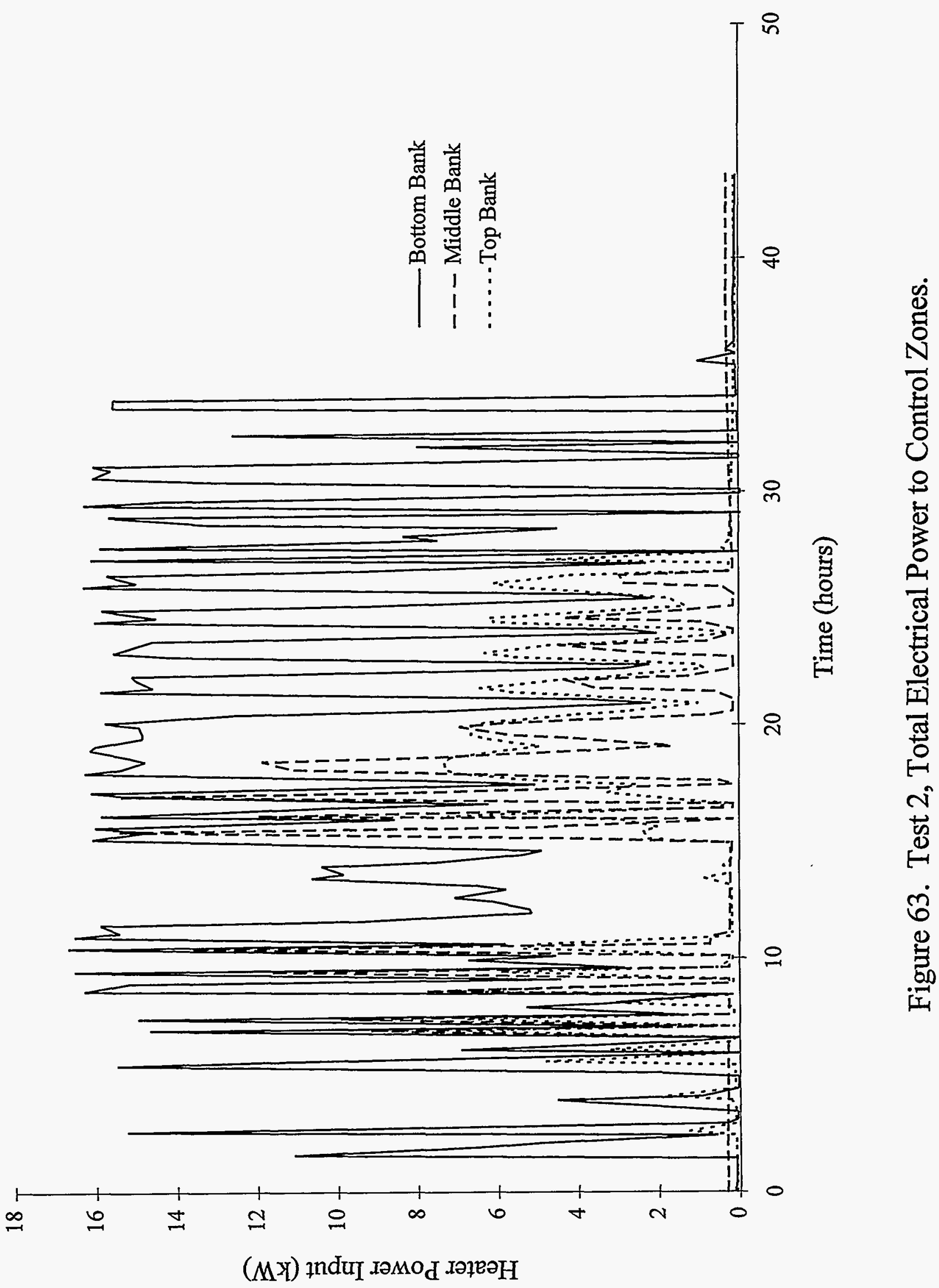


\subsubsection{Test 3 Data}

\section{Control Thermocouples}

Figure 64 shows a plot of the three control TCs, PR4, PR14, and PR26. Similar to Test 2, they show a linear rise from ambient to $454^{\circ} \mathrm{C}\left[850^{\circ} \mathrm{F}\right]$, but this time at a rise rate of $14^{\circ} \mathrm{C} / \mathrm{hr}$ $\left[25^{\circ} \mathrm{F} / \mathrm{hr}\right.$ ]. PR4 controlled the top heater bank, PR14 the middle heater bank, and PR26 the bottom heater bank.

\section{Comparison of Wall and Probe Responses}

Figures 65-73 show comparisons of the wall and probe responses for all of the probe-wall TC combinations where both the wall and probe devices were operating correctly. Probes PR1, PR3, PR13, PR19, and PR25 were malfunctioning and therefore their data were not included. All of the faulty probes used intrinsic TCs. Figures 65 and 66 show plots for pairs (e.g., W4 and PR4) of $2.5 \mathrm{~cm}$ [1 in.]-diameter stainless steel ball-probes and their companion TCs; Figures 67 and 68 for pairs of $1.9 \mathrm{~cm}$ [0.75 in.]-diameter SS ball-probes and their companion TCs; Figures 69 and 70 for $2.5 \mathrm{~cm}$ [ 1 in.]-diameter brass ball-probes and their companion TCs; and Figures 71 and 72 for $1.9 \mathrm{~cm}$ [0.75 in.]-diameter brass ball-probes. Figure 73 shows pairs of spring-loaded probes and their companion wall TCs.

In all cases during the heat-up, the probes read higher than their companion wall TCs at the same point in time, by a larger amount during the early stages of the heat-up, but by a lesser amount during the later stages of the heat-up. During the soak portion at $454^{\circ} \mathrm{C}\left[850^{\circ} \mathrm{F}\right]$, most of the probes read close to their companion wall $\mathrm{TCs}$, to within about $23^{\circ} \mathrm{C}\left[41^{\circ} \mathrm{F}\right]$ or $5 \%$ of the soak (i.e., annealing) temperature. However, during the heat-up, the probe errors were substantial, up to $90^{\circ} \mathrm{C}\left[160^{\circ} \mathrm{F}\right]$ between 5 and 10 hours during the heat-up. Note that the maximum errors during Test $3\left(90^{\circ} \mathrm{C}\left[160^{\circ} \mathrm{F}\right]\right)$ are less than those for Test $2\left(130^{\circ} \mathrm{C}\left[240^{\circ} \mathrm{F}\right]\right)$, due to the lower temperature heat-up rate $\left(14^{\circ} \mathrm{C} / \mathrm{hr}\left[25^{\circ} \mathrm{F} / \mathrm{hr}\right]\right.$ vs $\left.28^{\circ} \mathrm{C} / \mathrm{hr}\left[50^{\circ} \mathrm{F} / \mathrm{hr}\right]\right)$.

Similar to Test 2, the RPV wall temperature heat-up rate was less than $14^{\circ} \mathrm{C} / \mathrm{hr}\left[25^{\circ} \mathrm{F} / \mathrm{hr}\right]$ during the early part of the heat-up, but was faster than $14^{\circ} \mathrm{C} / \mathrm{hr}\left[25^{\circ} \mathrm{F} / \mathrm{hr}\right]$ (e.g., about $15^{\circ} \mathrm{C} / \mathrm{hr}$ $\left[27^{\circ} \mathrm{F} / \mathrm{hr}\right]$ during the later part of the heat-up.

\section{Error Plots: Differences between the Wall Thermocouples and Probes}

Figures 74-85 show plots of the difference between the wall TCs and their companion probes, i.e., the error in the probe readings.

As can be seen, a typical curve goes negative soon after the heat-up begins and drops to a maximum error between 7.5 and 15 hours, then slowly rises with time until the soak begins, at which time the most of the errors approach a steady-state value close to zero. During the cooldown the errors slowly rise to positive values, indicating the wall TCs are hotter than the probes. The magnitude of the errors is less than on Test 2 , due to the lower heat-up rate. The same as 


\section{Investigation of RPV Temperature Measurement Methods}

Test 2, but different from Test 1, the most prevalent trend was that the top third of the probes showed the lowest error, the middle third showed the most error, and the bottom third of the probes had errors in-between the others.

\section{The Effect of Ball-Probe Emissivity (Absorptivity)}

Figures 74-77 show the effect of the ball emissivity (or absorptivity) on the error. Figure 74 shows $2.5 \mathrm{~cm}$ [ 1 in.]-diameter SS probes; Figure 75 shows $1.9 \mathrm{~cm}$ [0.75 in.]-diameter SS probes; Figure 76 shows $2.5 \mathrm{~cm}$ [ 1 in.]-diameter brass probes and Figure 77 shows $1.9 \mathrm{~cm}$ [0.75 in.]diameter brass probes.

In almost all cases, the polished probes had the lowest errors during the rise, similar to Tests 1 and 2. During the soak, in about half of the cases the errors of polished probes were less than those of blackened probes, but in other cases there was no clear distinction. During the cooldown in some cases, the polished probes showed the smallest errors, but in other cases the blackened probes showed the smallest errors.

\section{The Effect of Ball-Probe Material}

Figures 78-81 show the differences in errors due to ball-probe material: stainless steel or brass. Figure 78 shows temperature differences between the wall TCs and $2.5 \mathrm{~cm}$ [1 in.]-diameter polished SS or brass ball-probes. Figure 79 shows temperature differences between wall TCs and $1.9 \mathrm{~cm}$ [0.75 in.]-diameter polished SS or brass ball-probes. Figure 80 shows temperature differences between wall TCs and $2.5 \mathrm{~cm}$ [1.0 in.]-diameter black SS or brass ball-probes, and Figure 81 shows temperature differences between wall TCs and $1.9 \mathrm{~cm}$ [0.75 in.]-diameter black SS or brass ball-probes.

In half of the cases, the brass probes, with a higher thermal conductivity, had lower errors than similar SS probes during the heat-up portion; in the remaining cases there was not clear distinction or the SS probes were slightly better. During the soak and cool-down, in slightly over half the cases, the brass probe errors were the smallest; in the remaining cases there was either no clear distinction or the SS probes were slightly better.

\section{The Effect of Ball Size}

Figures 82-85 show error plots associated with ball size and thermocouple location in the ballprobes. The effect of ball size will be discussed here; the effect of TC location will be discussed in the next subsection. Figure 82 shows errors of both $1.9 \mathrm{~cm}$ [0.75 in.] and $2.5 \mathrm{~cm}$ [1.0 in.]diameter polished stainless steel probes; Figure 83 shows errors of both $1.9 \mathrm{~cm}$ [0.75 in.] and $2.5 \mathrm{~cm}$ [1.0 in.]-diameter polished brass probes; Figure 84 shows errors of both $1.9 \mathrm{~cm}$ [0.75 in.] and $2.5 \mathrm{~cm}$ [1.0 in.]-diameter blackened SS probes; Figure 85 shows errors of both $1.9 \mathrm{~cm}$ [0.75 in.] and $2.5 \mathrm{~cm}$ [1.0 in.]-diameter blackened brass probes. 


\section{Investigation of RPV Temperature Measurement Methods}

In almost all cases during the heat-up, soak and cool-down the data are inconclusive. In some cases during the cool-down, the larger size ball (2.5 $\mathrm{cm}$ [1.0 in.]) probes had the lower error, which is consistent with Test 2 data but in contrast to Test 1 data in which the $1.9 \mathrm{~cm}$ [0.75 in.]diameter (smaller diameter) probes had the lowest error. It seems that, contrary to intuition, if the ball-probes are used to control, the ball size is not a significant factor.

\section{The Effect of Thermocouple Placement in the Ball}

Figures 82-85 show plots of the errors associated with the location of the TCs in the ball. Figure 82 shows errors of both $1.9 \mathrm{~cm}$ [0.75 in.] and $2.5 \mathrm{~cm}$ [1.0 in.]-diameter for polished SS balls for TCs located at the center and near the wall. Figure 83 shows errors of both $1.9 \mathrm{~cm}$ [0.75 in.] and $2.5 \mathrm{~cm}$ [1.0 in.]-diameter for polished brass balls; Figure 84 for both $1.9 \mathrm{~cm}$ [0.75 in.] and $2.5 \mathrm{~cm}$ [1.0 in.]-diameter blackened SS balls (center and wall TCs in balls); and Figure 85 for both $1.9 \mathrm{~cm}$ [0.75 in.] and $2.5 \mathrm{~cm}$ [1.0 in.]-diameter black brass balls (center and wall TCs in balls).

During the heat-up and soak there was no clear distinction as to which TC location showed the least errors. During the cool-down slightly more than half of the cases showed the center TC location had the lower errors.

\section{Spring-Loaded Probes}

Figure 86 shows the errors associated with the spring-loaded probes for Test 3 . The shapes of the curves are similar to those in the ball-probe plots, and the magnitude of the errors during the heat-up and cool-down is in the same range as those for the ball-probes. However, contrary to Tests 1 and 2 for PR23 during the soak, the error was smaller compared with PR6 (about $10^{\circ} \mathrm{C}$ $\left[18^{\circ} \mathrm{F}\right]$ ) or about $2 \%$. It is not known why PR6 had the highest error on this test. Similar to ballprobe responses for this test, considerable oscillations were caused by the fast response of the probes. The magnitude of the overall errors was lower for this test than for Tests 1 and 2 , due to the lower heat-up rate.

\section{The "Air" Temperature and Shunting Error Thermocouples}

Figure 87 shows the response of the air temperature measurements (W33, W34, W35 and W36) and the TCs that were used to check for shunting errors (W35, W36 and W37). W33 W36 generally responded in a manner similar to a typical probe, but had larger fluctuations. W37 showed a pattern of slight temperature fluctuations during the course of the test. For example, at the 5-hour time, W37 dropped slightly, about $14^{\circ} \mathrm{C}\left[25^{\circ} \mathrm{F}\right]$, then rose at the 19 -hour time by about the same amount. We believe this was caused by the building air conditioning system, which cycled on and off with building temperature; that in turn affected the mounting frame temperature where W37 was attached (similar behavior did not occur on Test 1, but some fluctuations were noted on Test 2). Therefore, W37 showed no evidence of shunting; neither did W35 or W36. 


\section{Investigation of RPV Temperature Measurement Methods}

\section{Electrical Power to Heater Zones}

Figure 88 shows a plot of the total electrical power supplied to each of the three control zones (top, middle and bottom). Similar to Figure 63, the power plots are very oscillatory, indicating the controllers were cycling the heater banks on and off. This was caused by the fast response of the probe control TCs. 


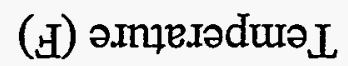
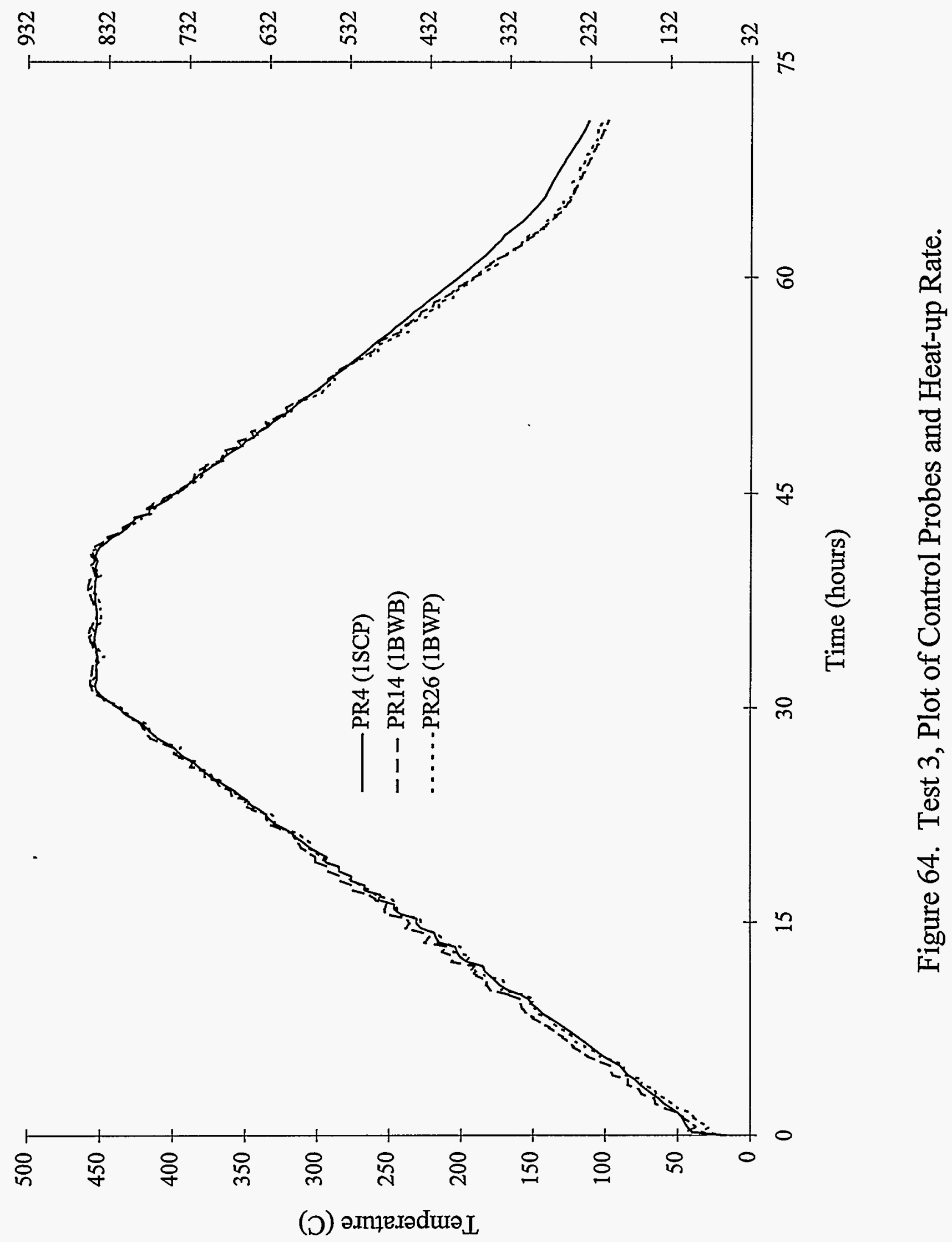


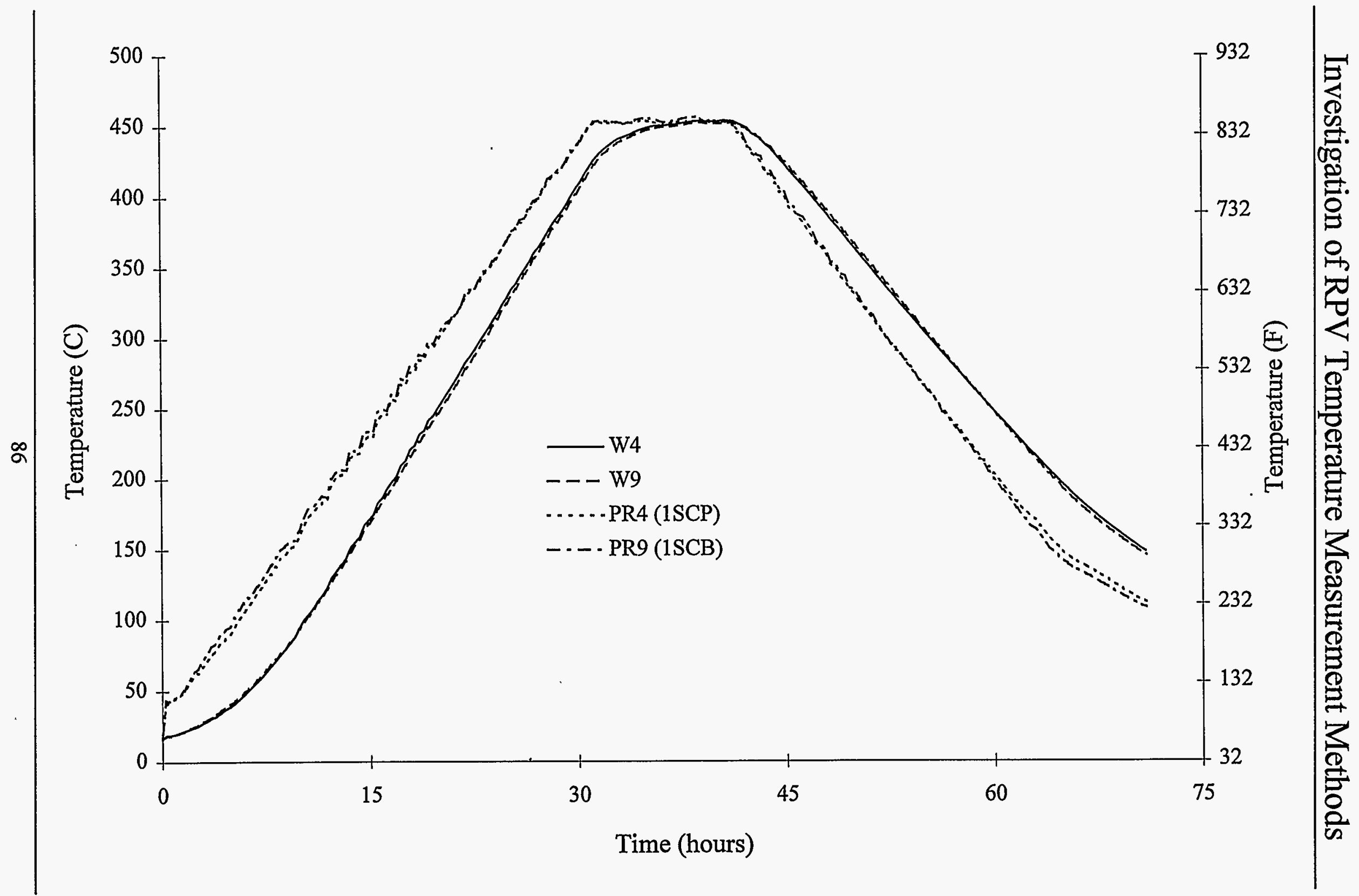

Figure 65. Test 3, Comparison of Wall TC and Probe Responses, 2.5-cm SS Probes. 


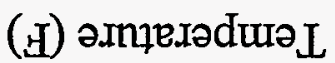
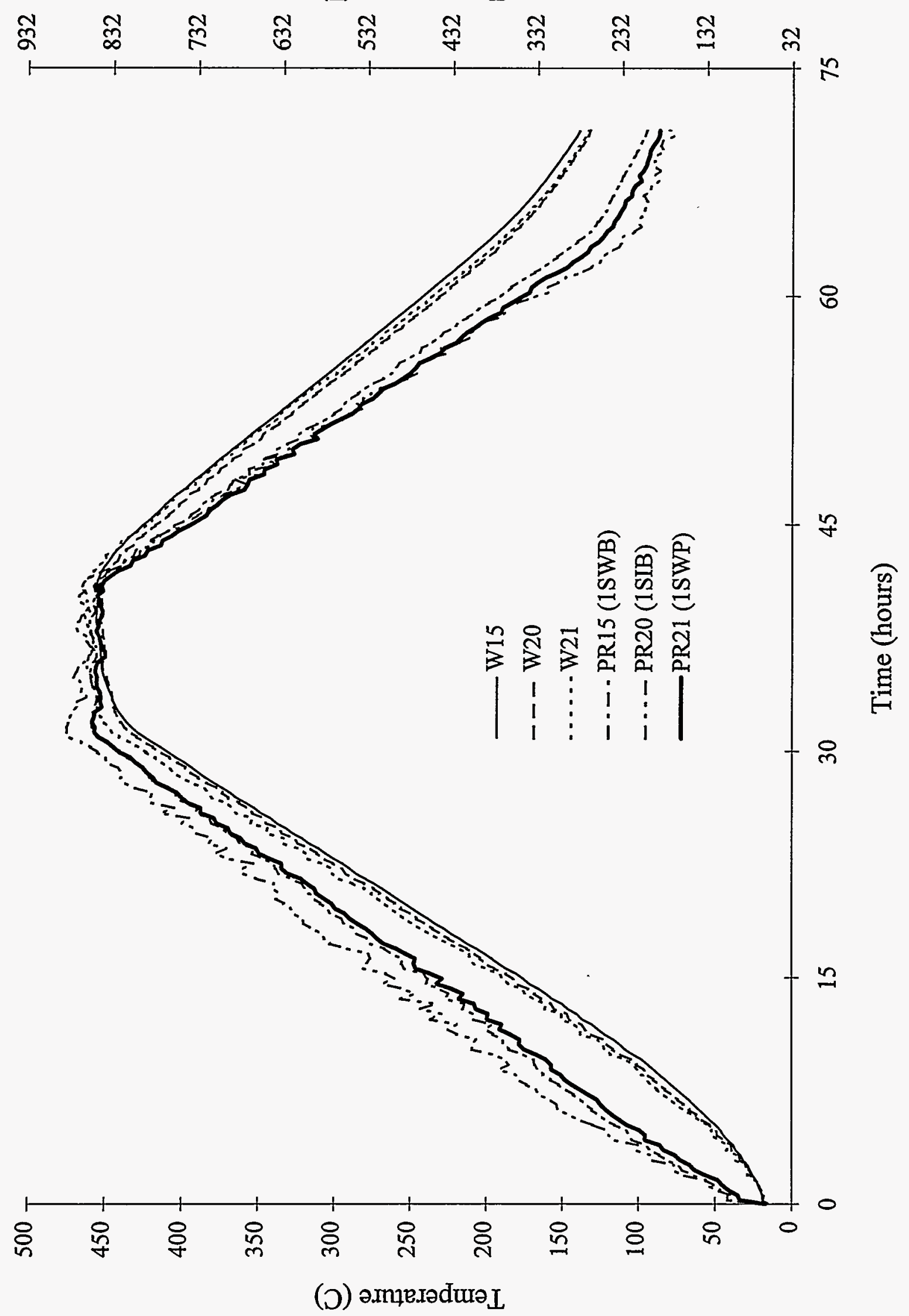

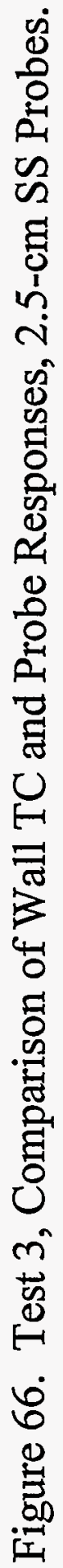




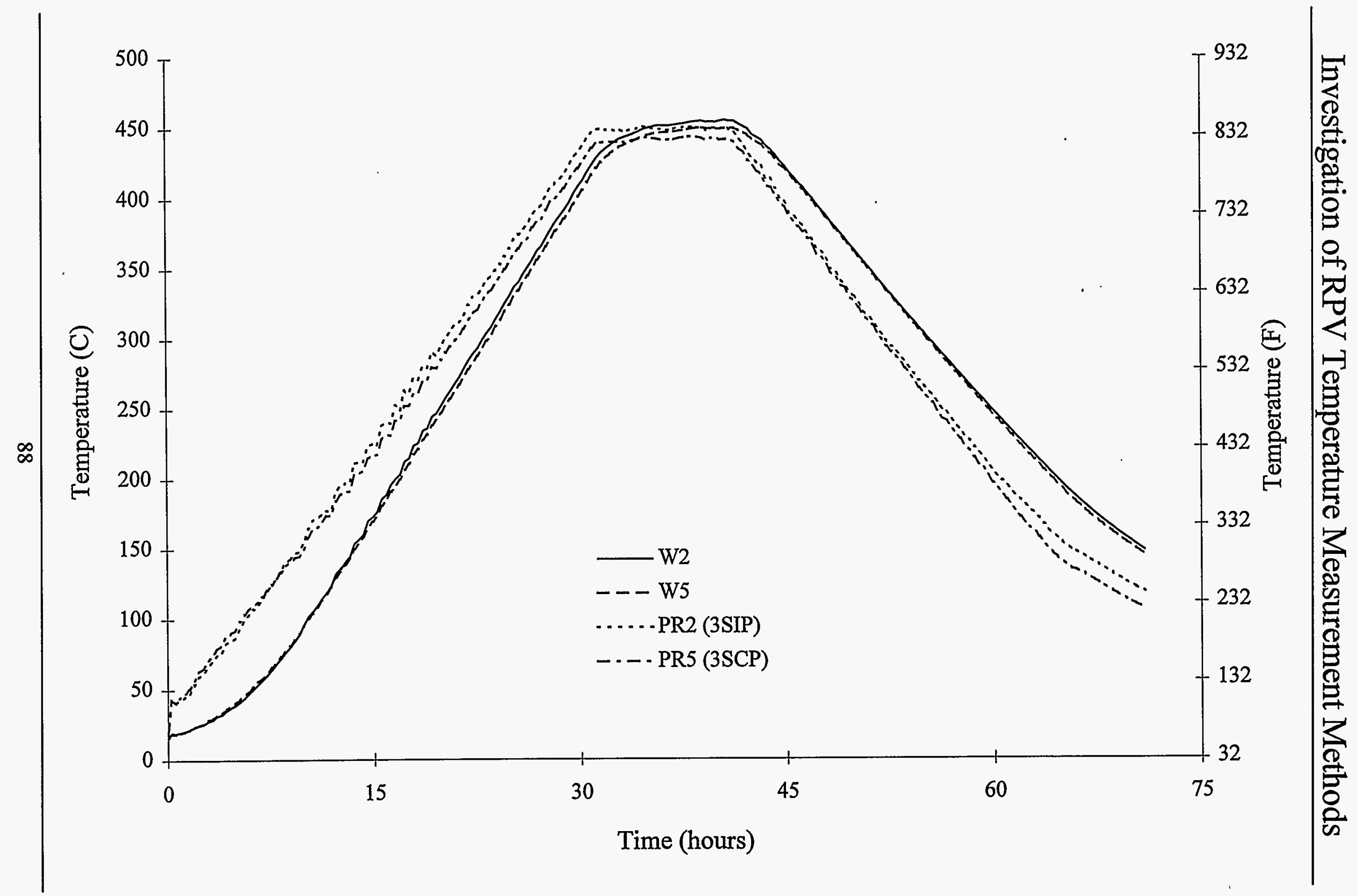

Figure 67. Test 3, Comparison of Wall TC and Probe Responses, 1.9-cm SS Probes. 


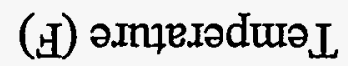

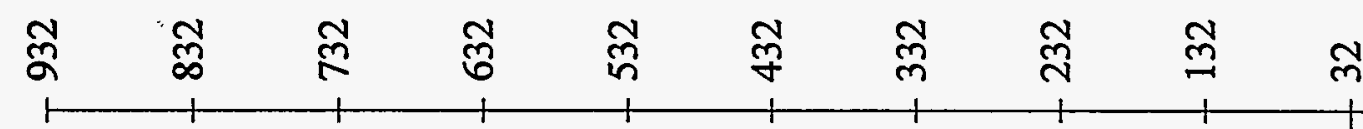

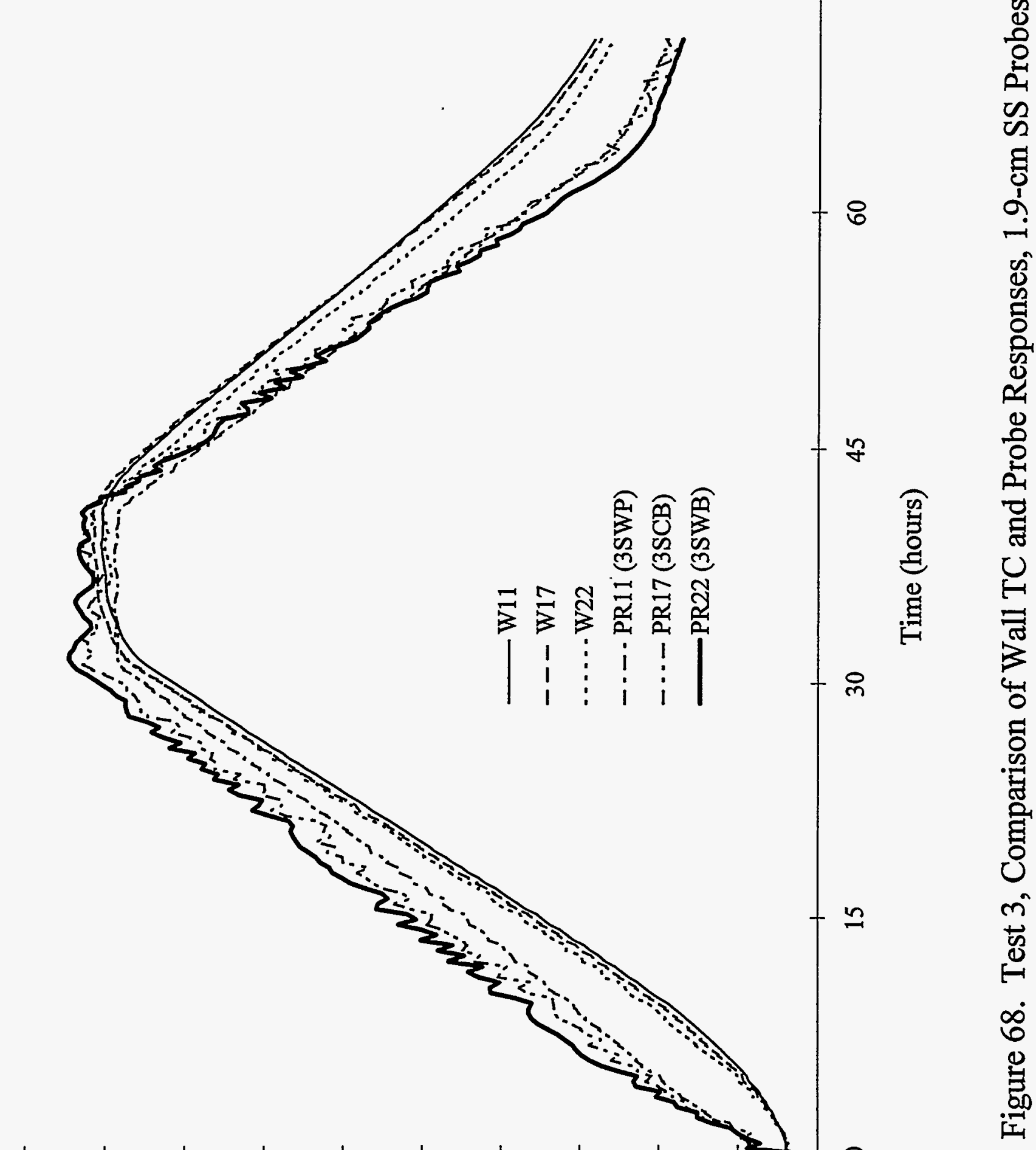

o

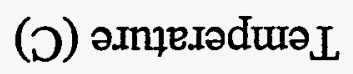




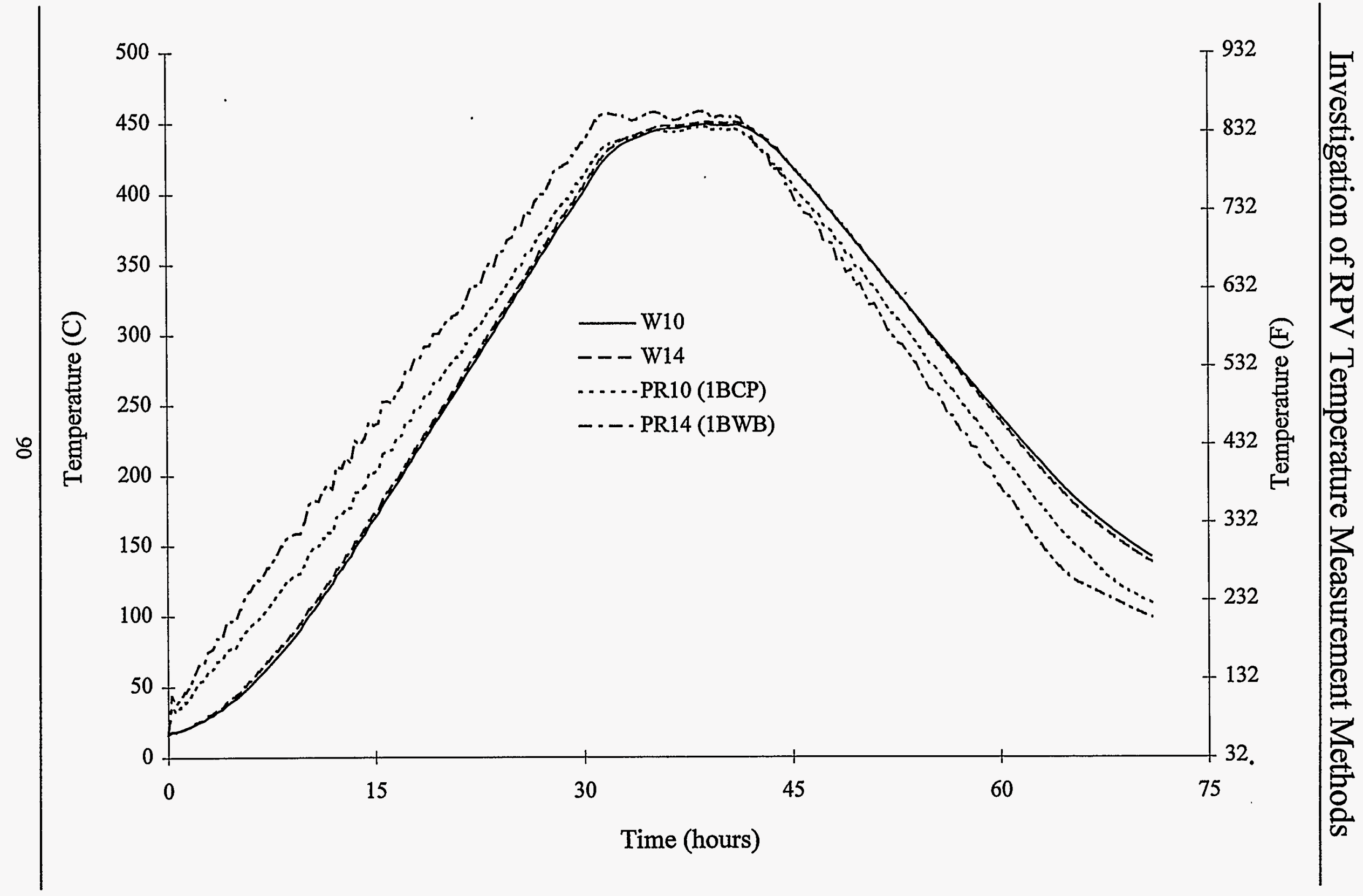

Figure 69. Test 3, Comparison of Wall TC and Probe Responses, 2.5-cm Brass Probes. 
(घ) әxпॄеıәduә $L$
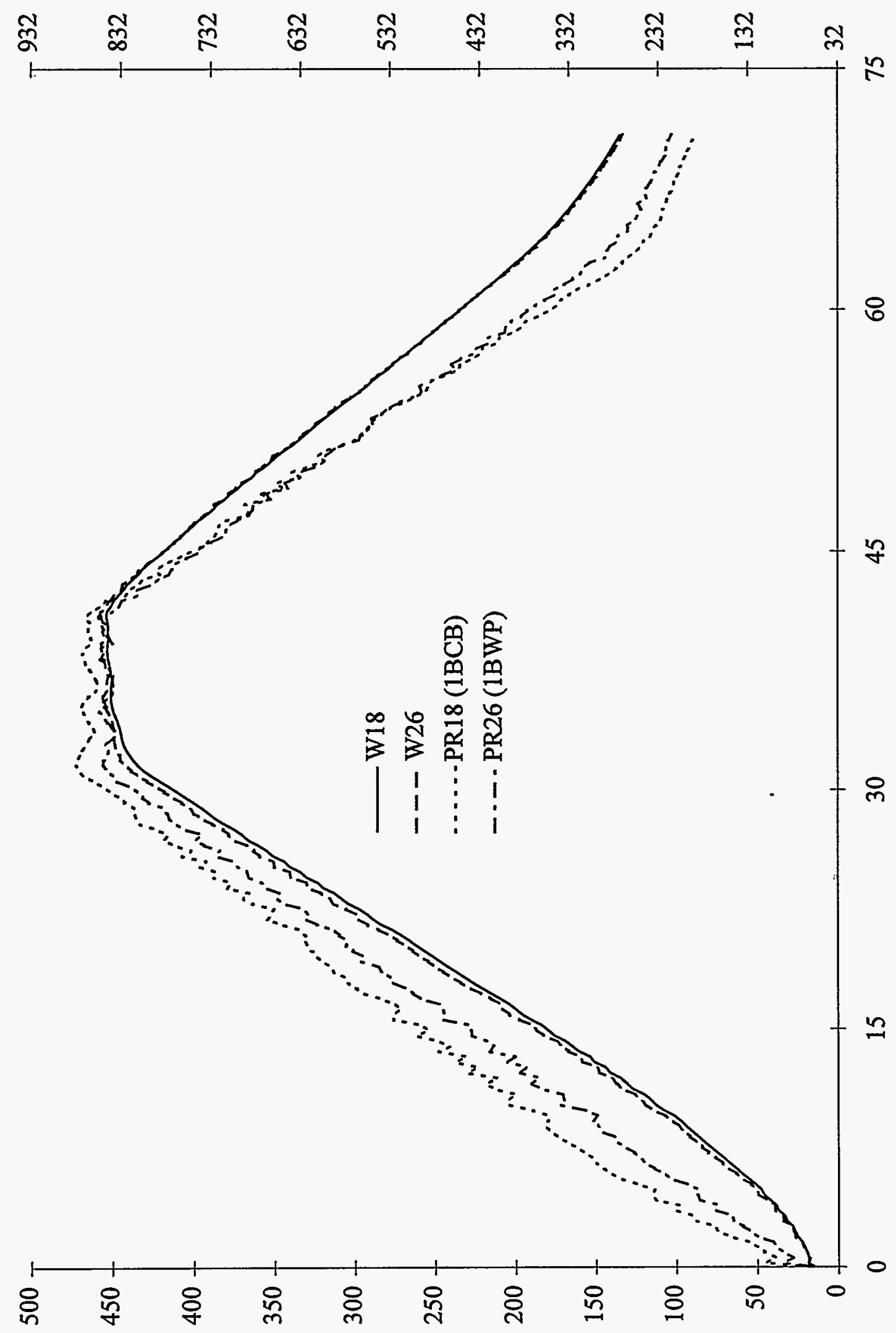

告

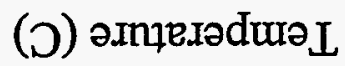




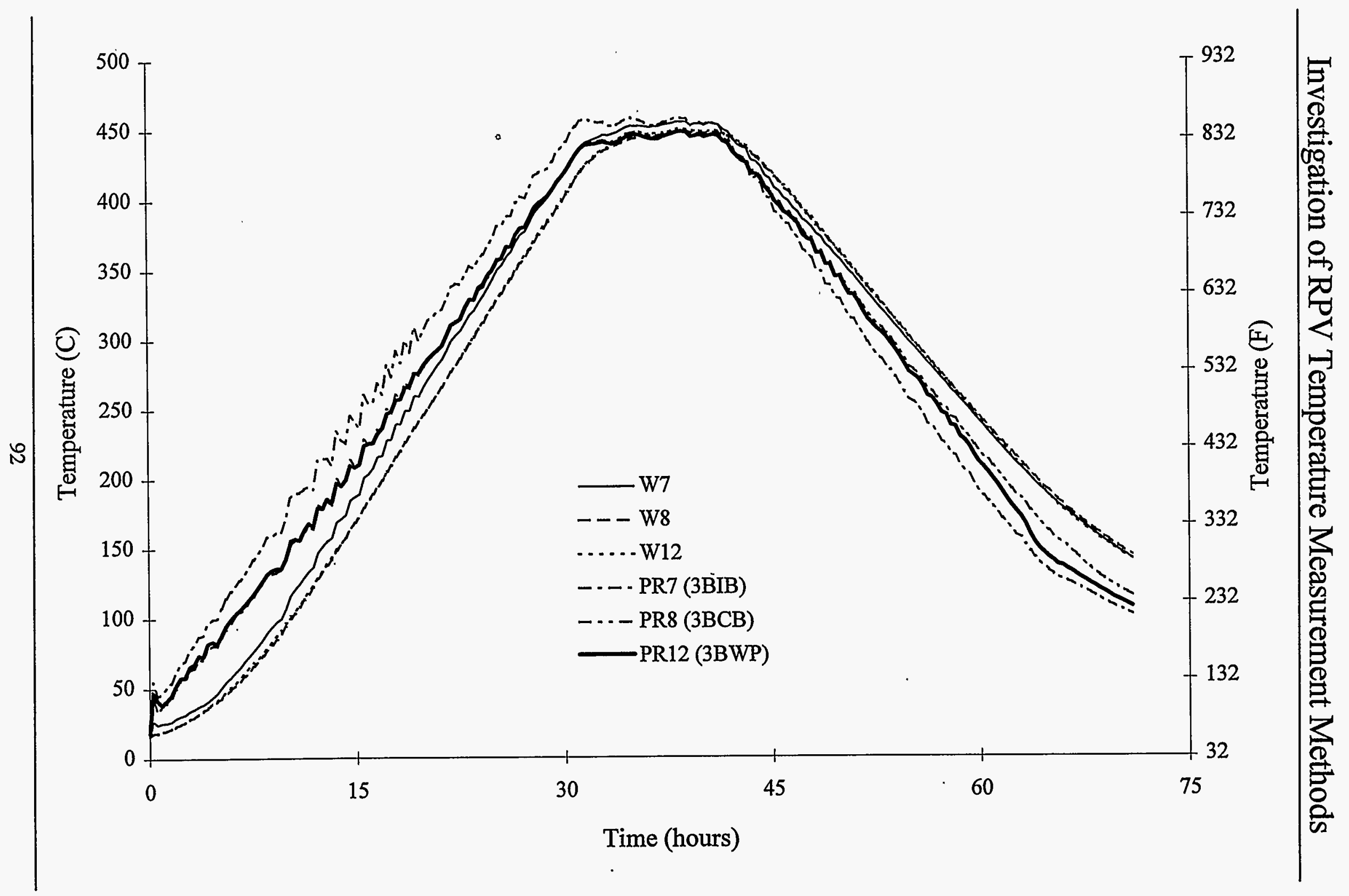

Figure 71. Test 3, Comparison of Wall TC and Probe Responses, 1.9-cm Brass Probes 


\section{Investigation of RPV Temperature Measurement Methods}

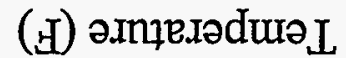
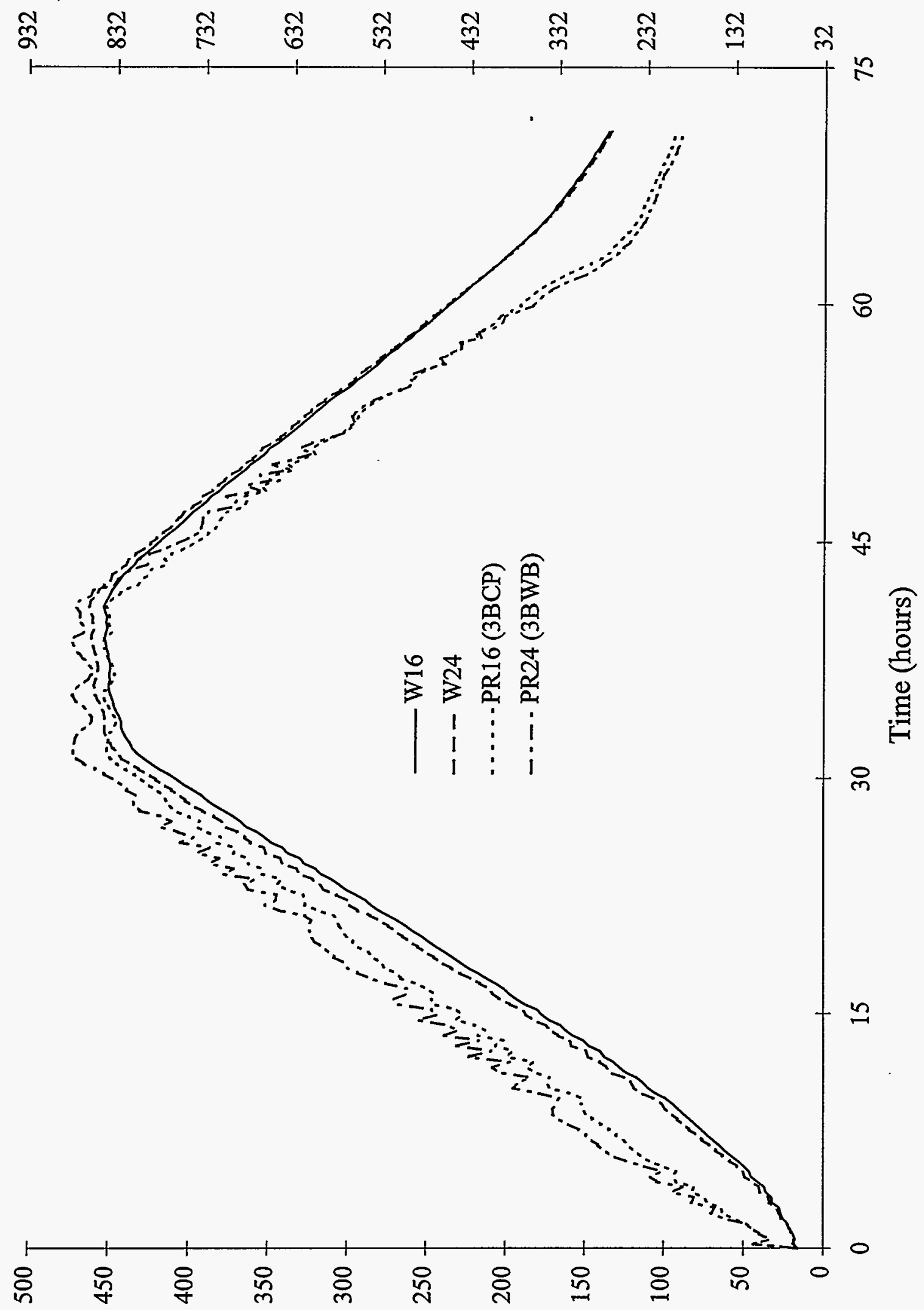

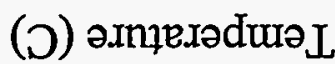




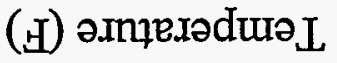
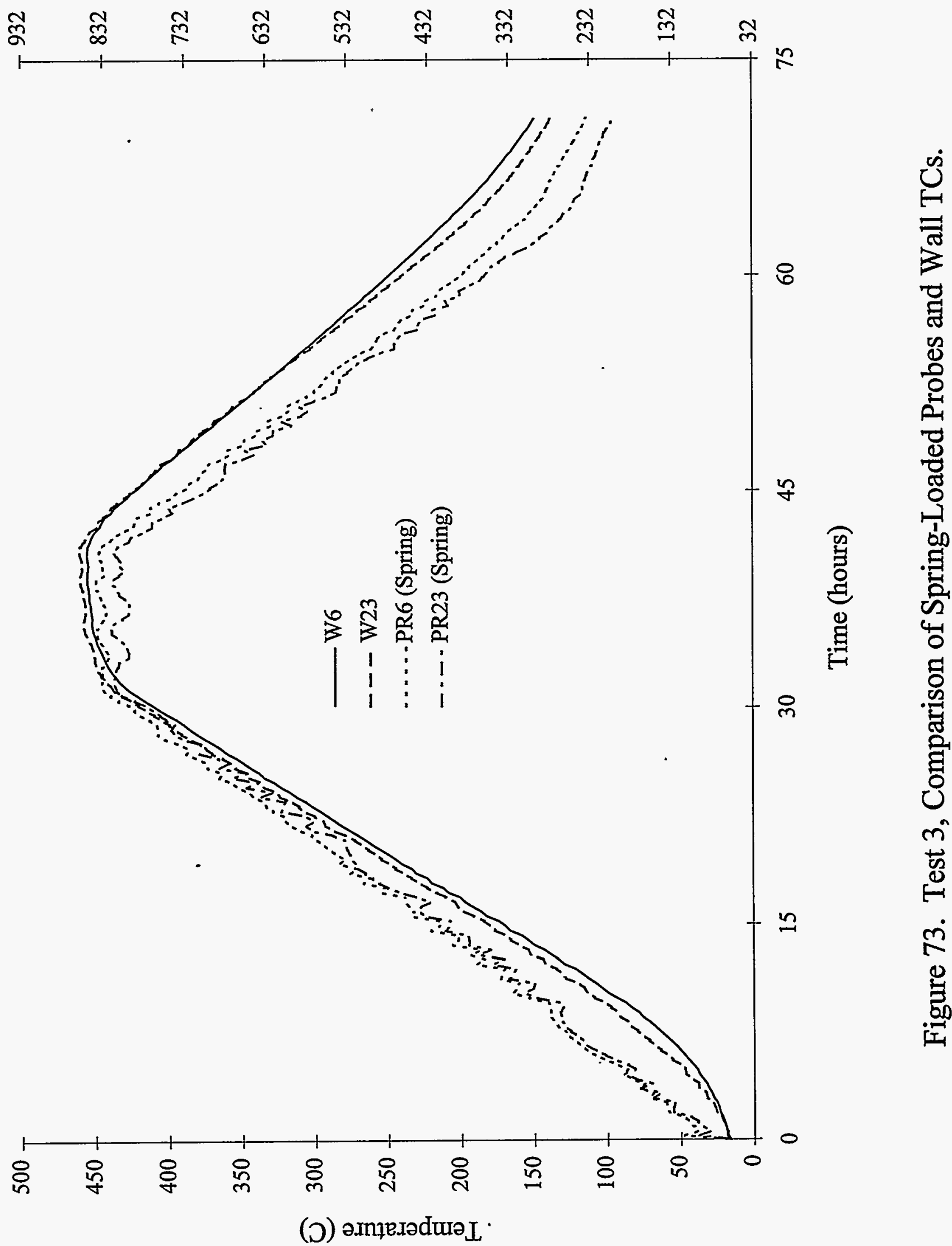


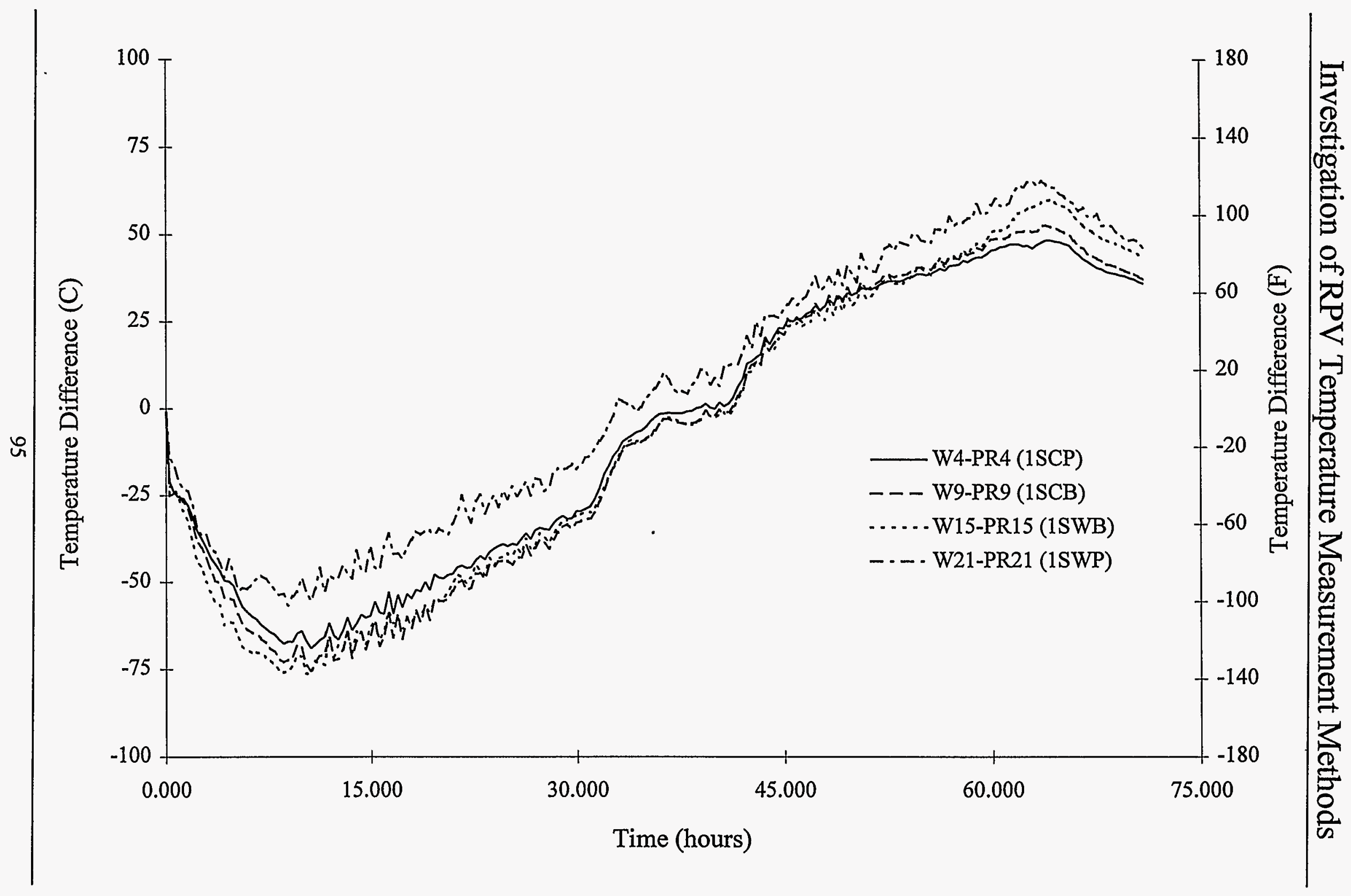

Figure 74. Test 3, Effect of Ball Emissivity on Errors, 2.5-cm SS Probes. 


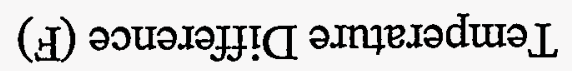

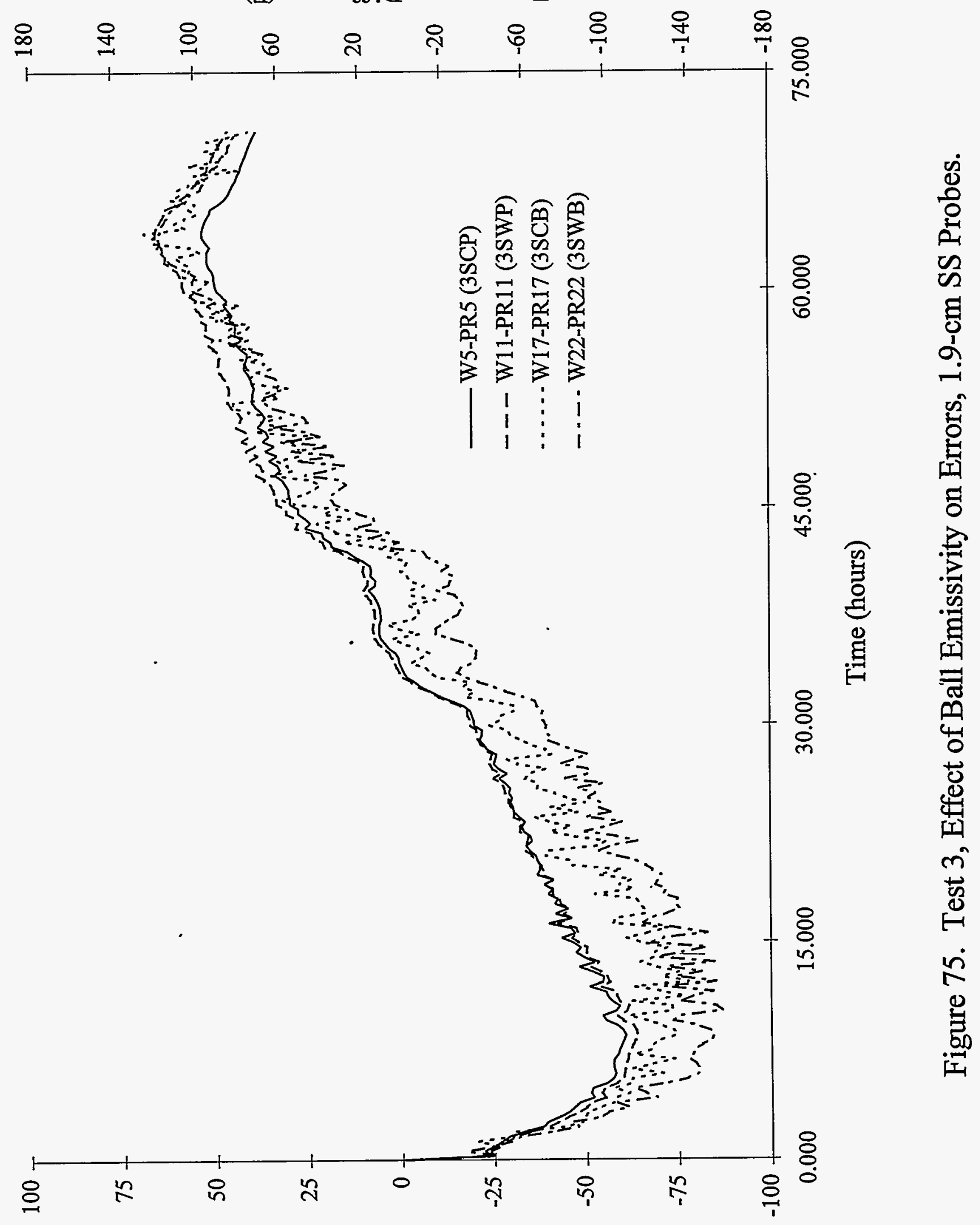

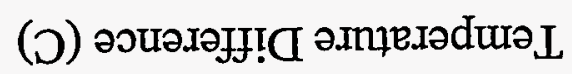




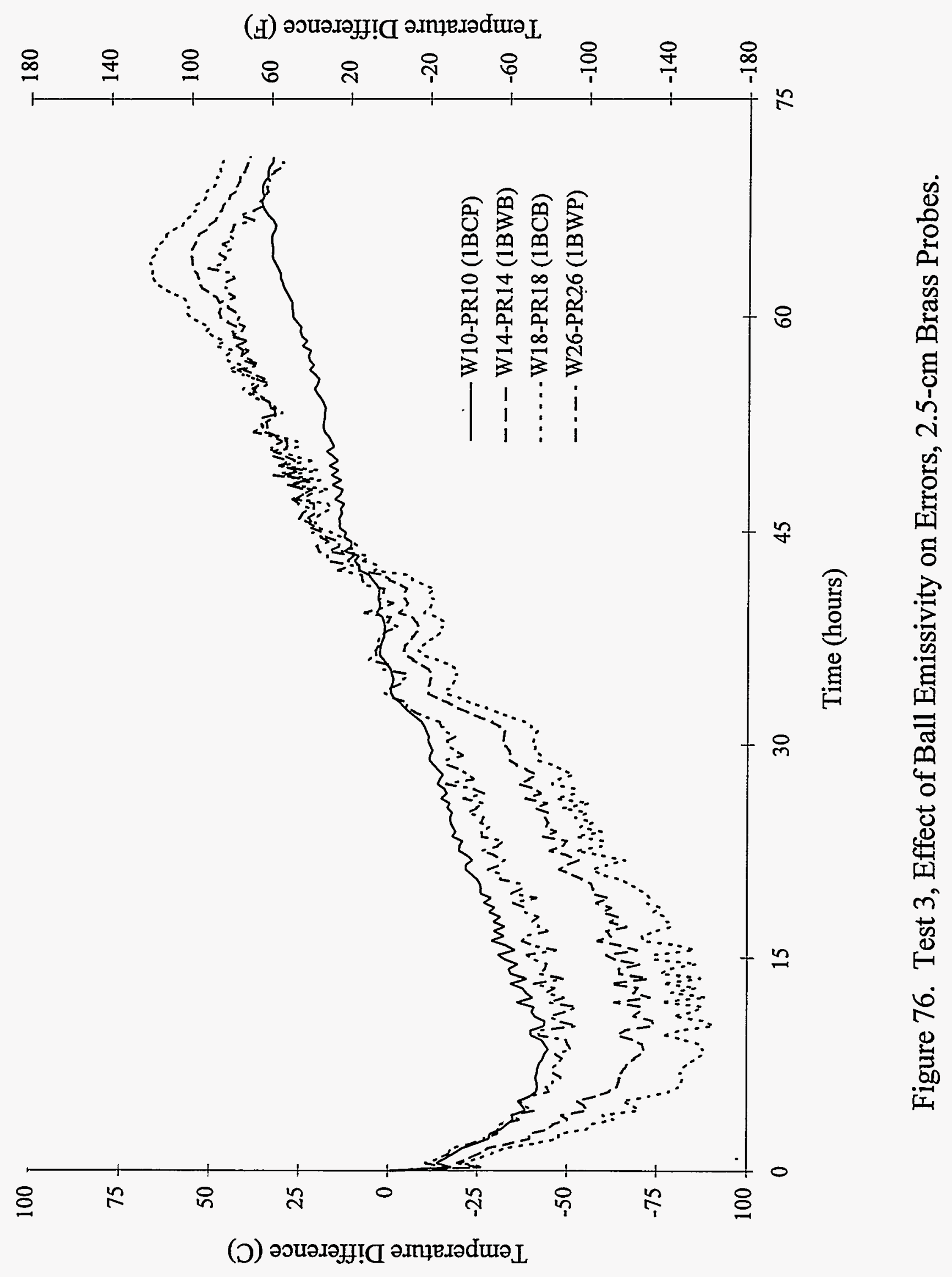




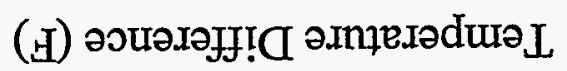
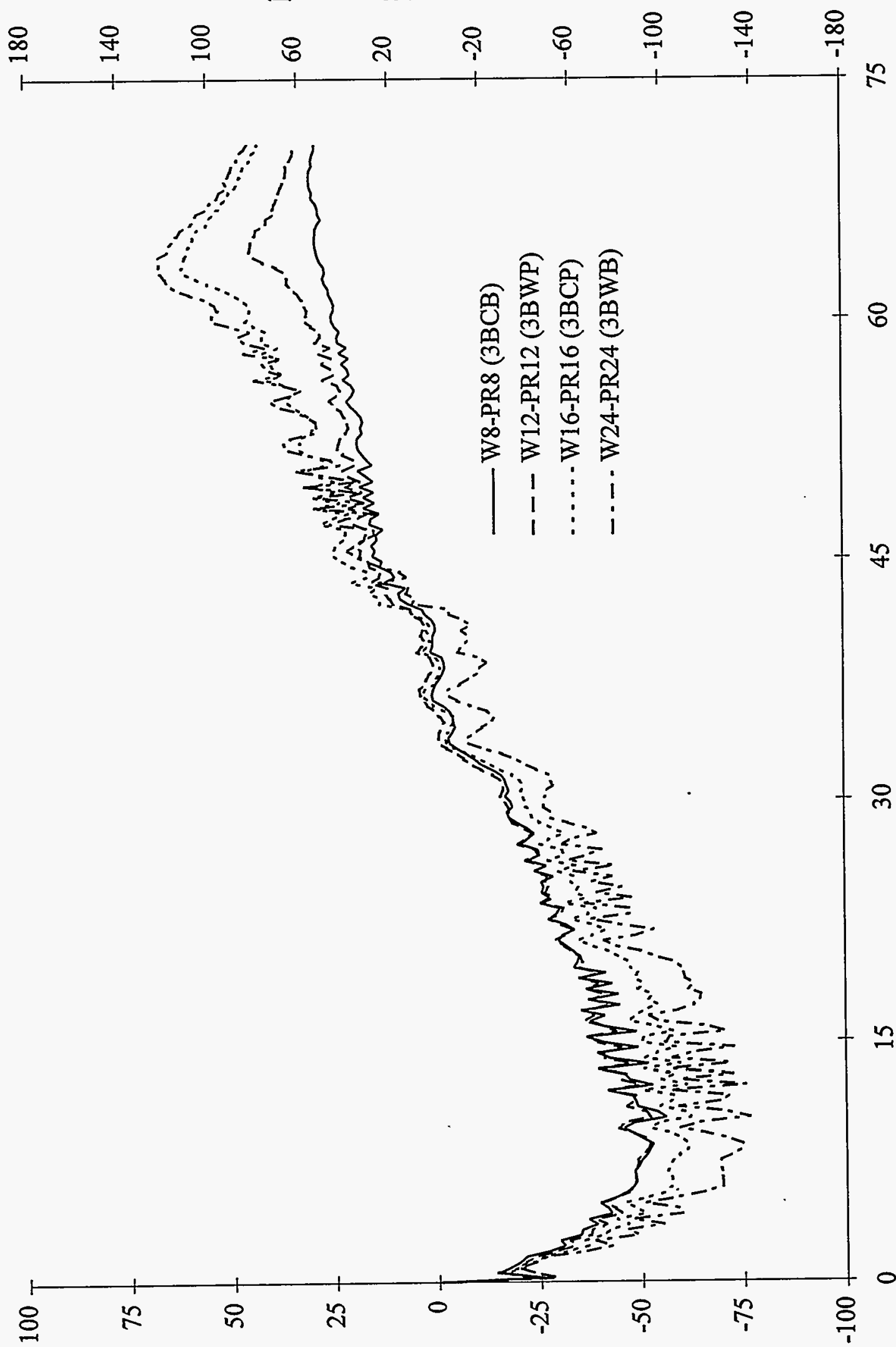

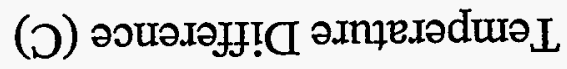




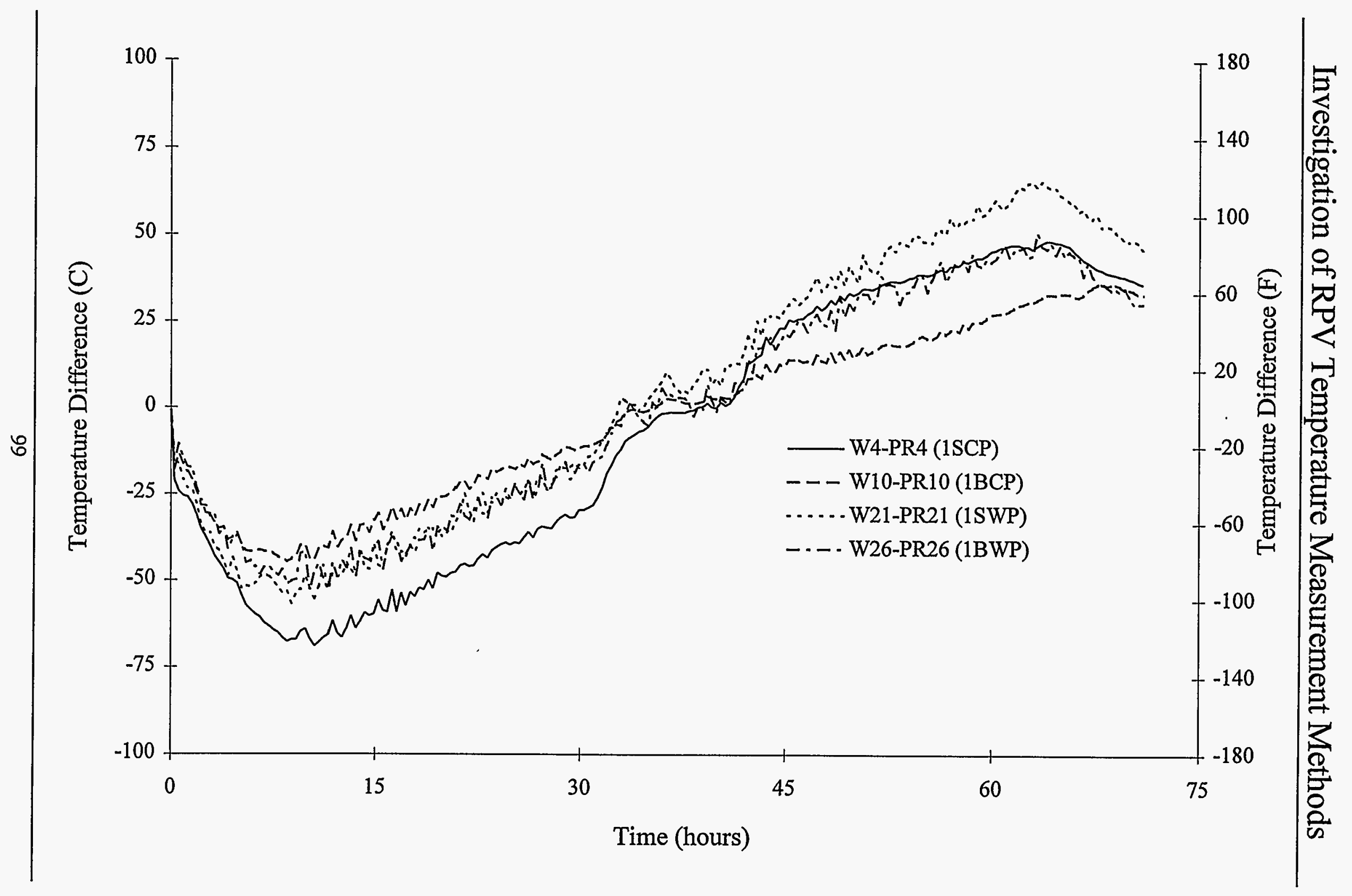

Figure 78. Test 3, Effects of Material on Errors, 2.5-cm SS and Brass Probes. 
Investigation of RPV Temperature Measurement Methods

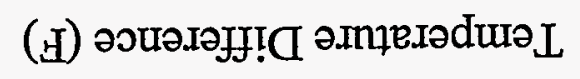
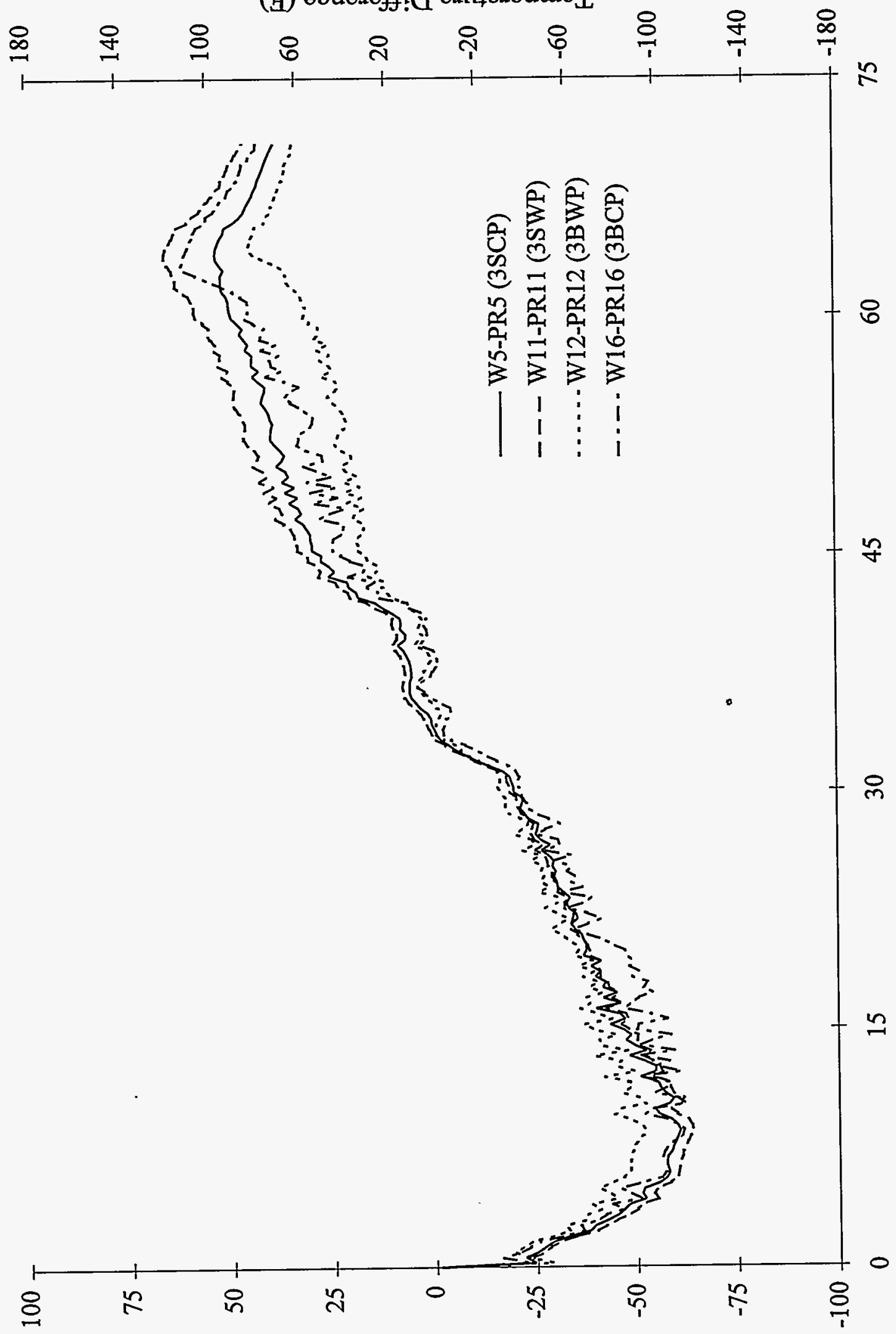

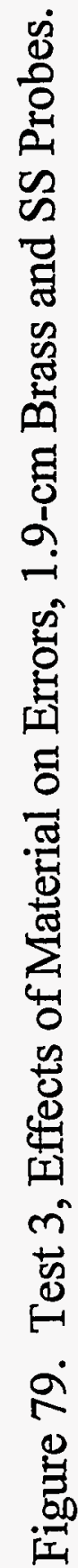

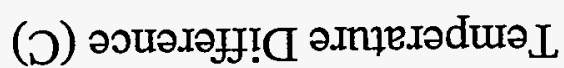




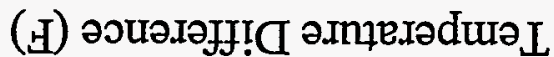
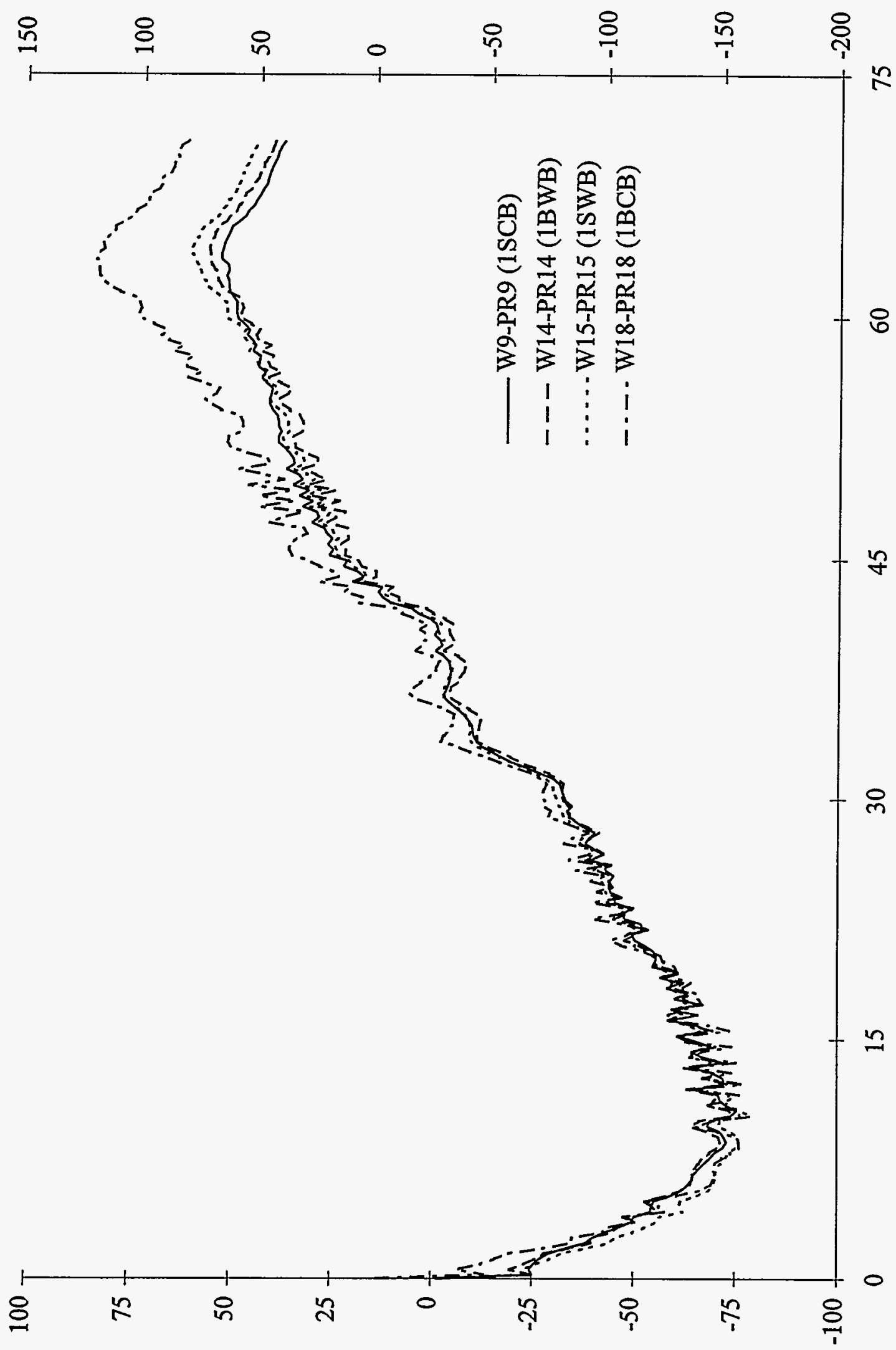
는 


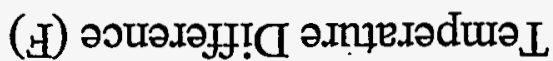
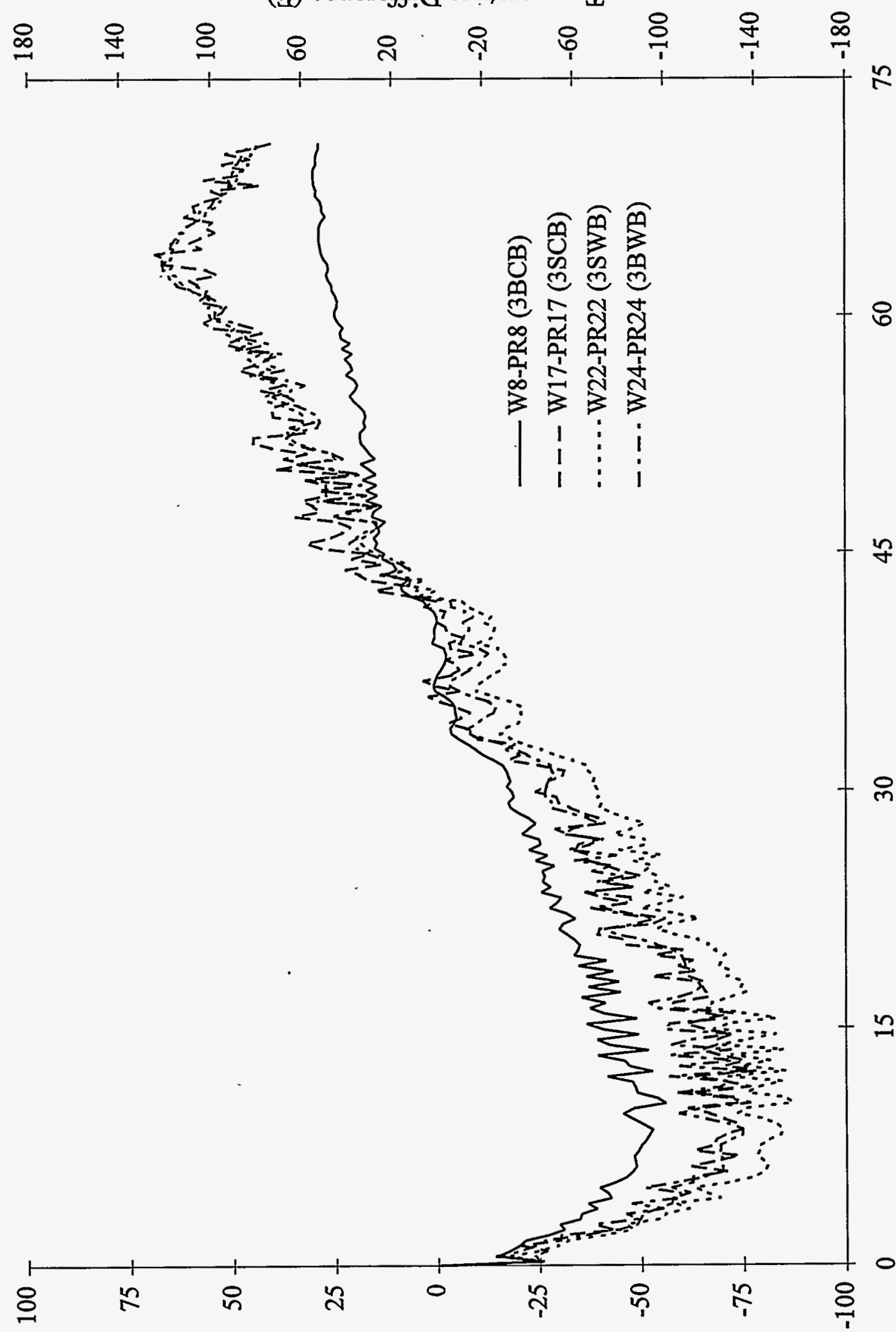

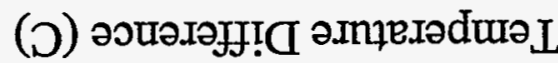




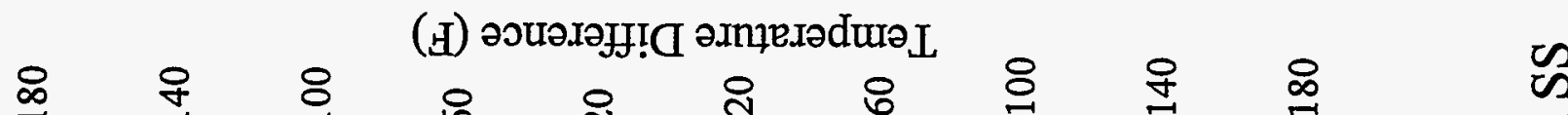
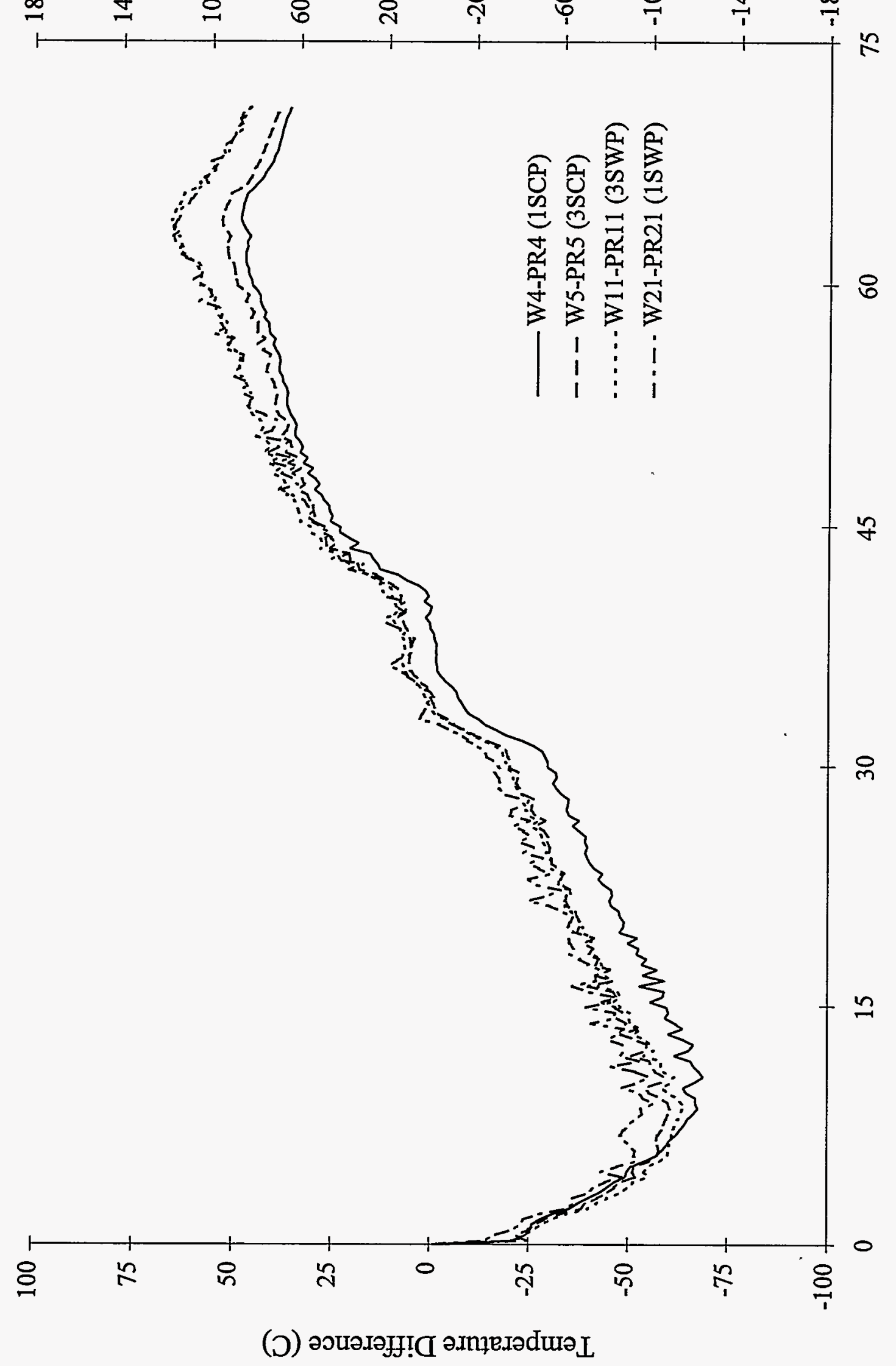


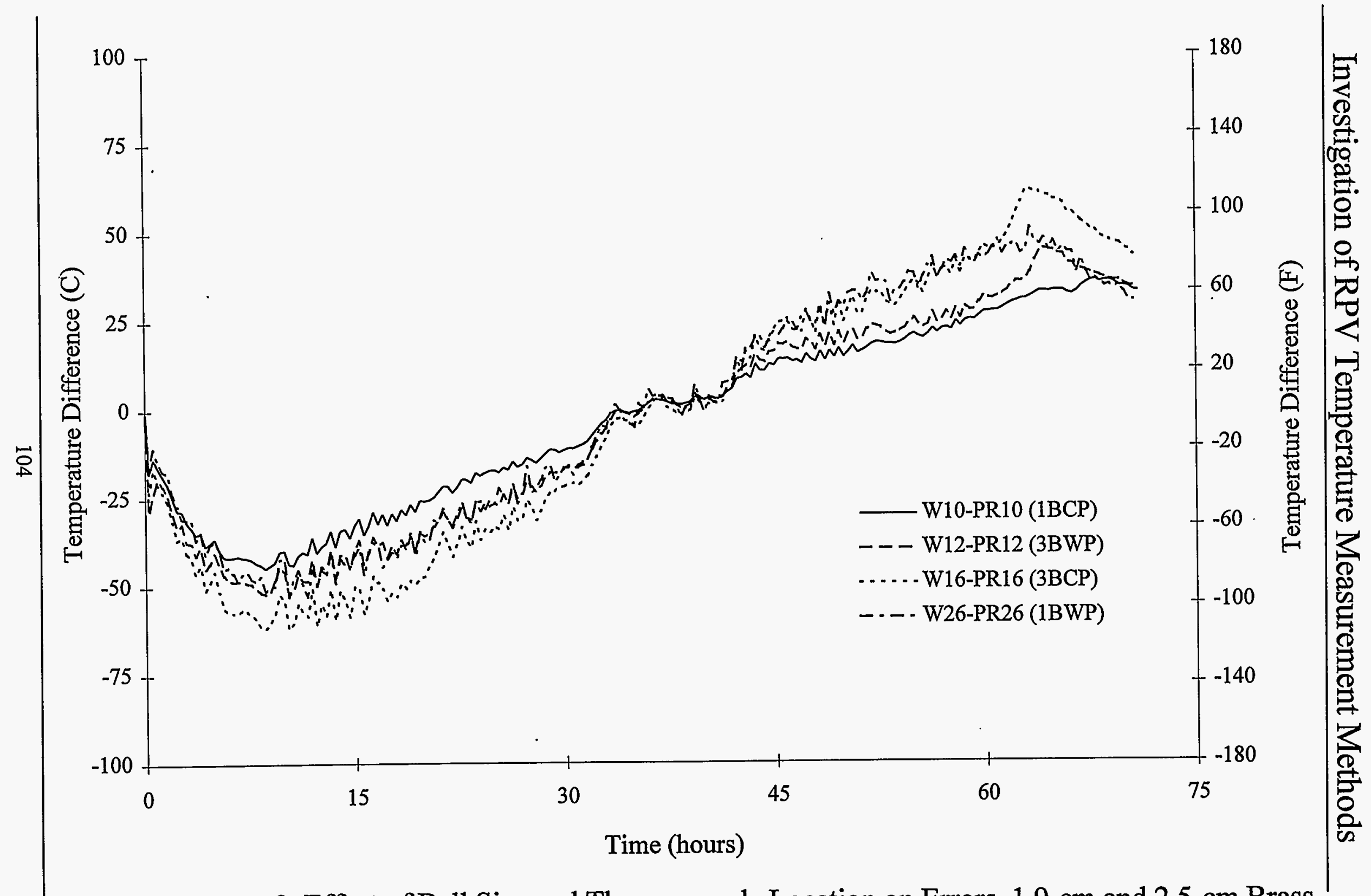

Figure 83. Test 3, Effect of Ball Size and Thermocouple Location on Errors, 1.9-cm and 2.5-cm Brass Probes. 

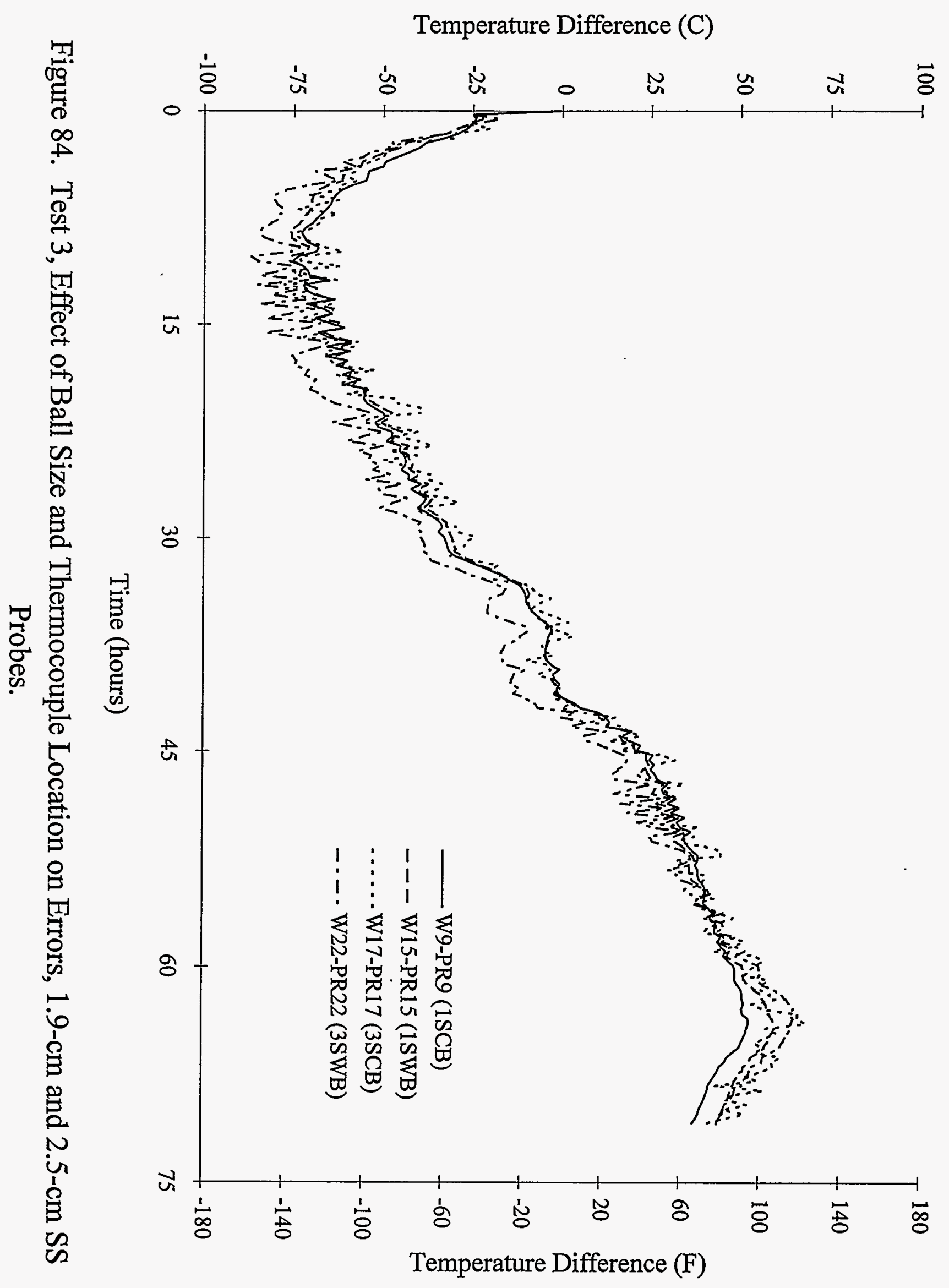

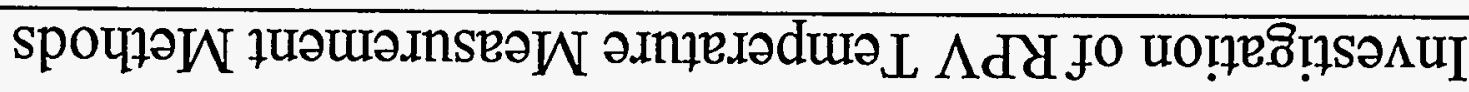




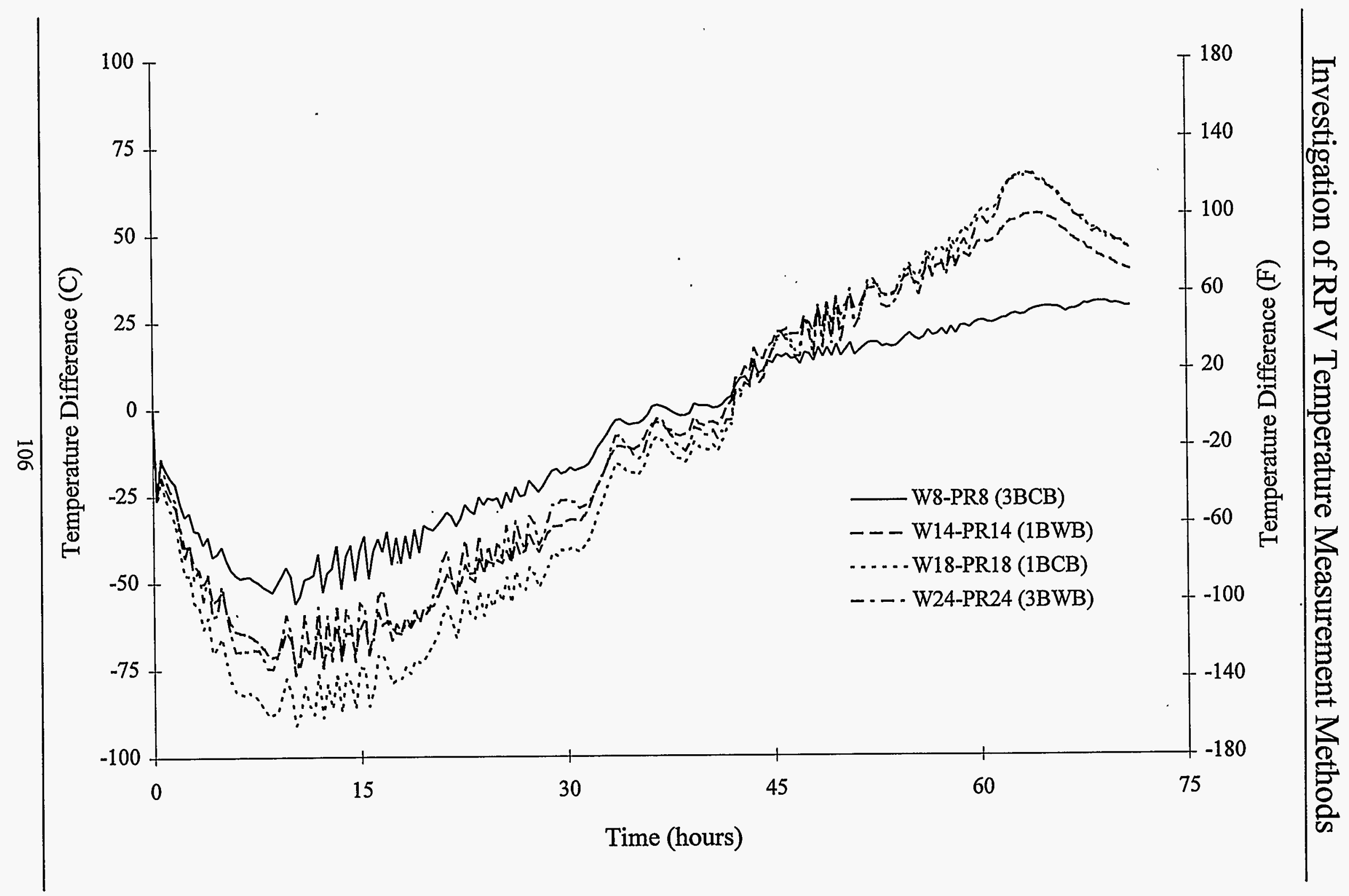

Figure 85. Test 3, Effect of Ball Size and Thermocouple Location on 1.9- $\mathrm{cm}$ and 2.5-cm Brass Probes. 


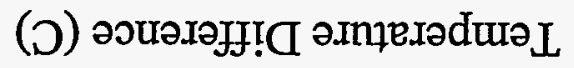

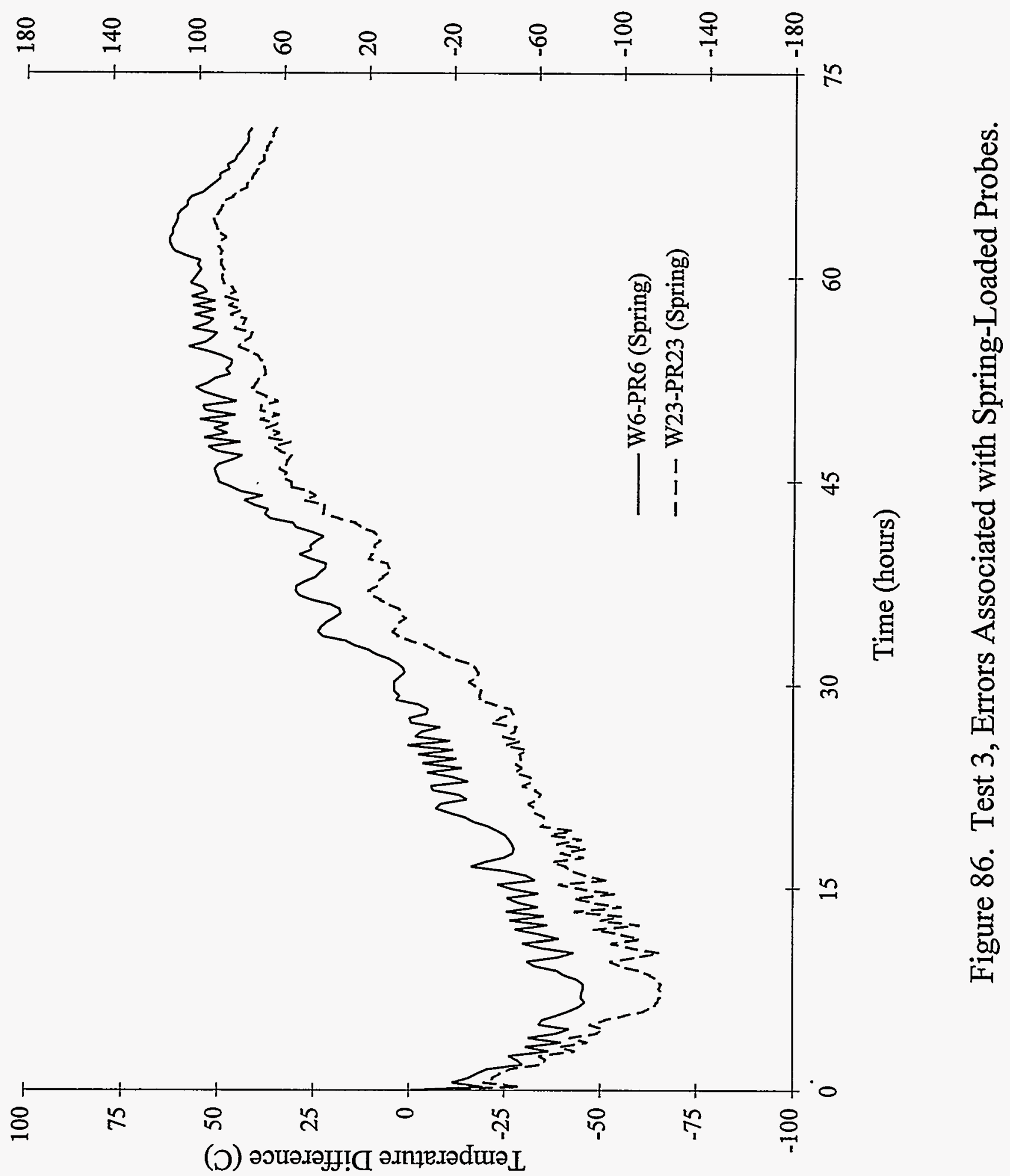




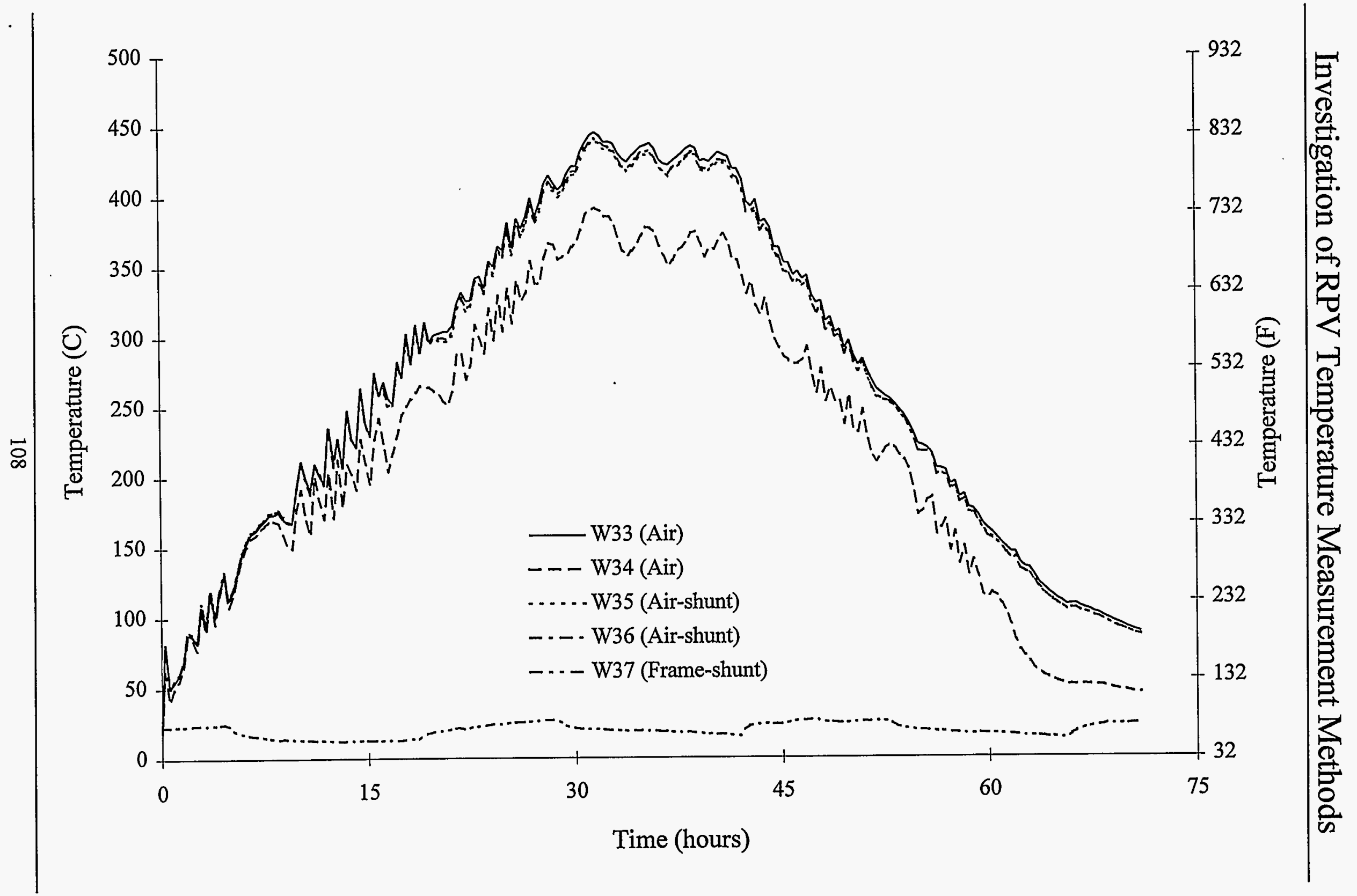

Figure 87. Test 3, Check for Shunting Errors. 


\section{Investigation of RPV Temperature Measurement Methods}

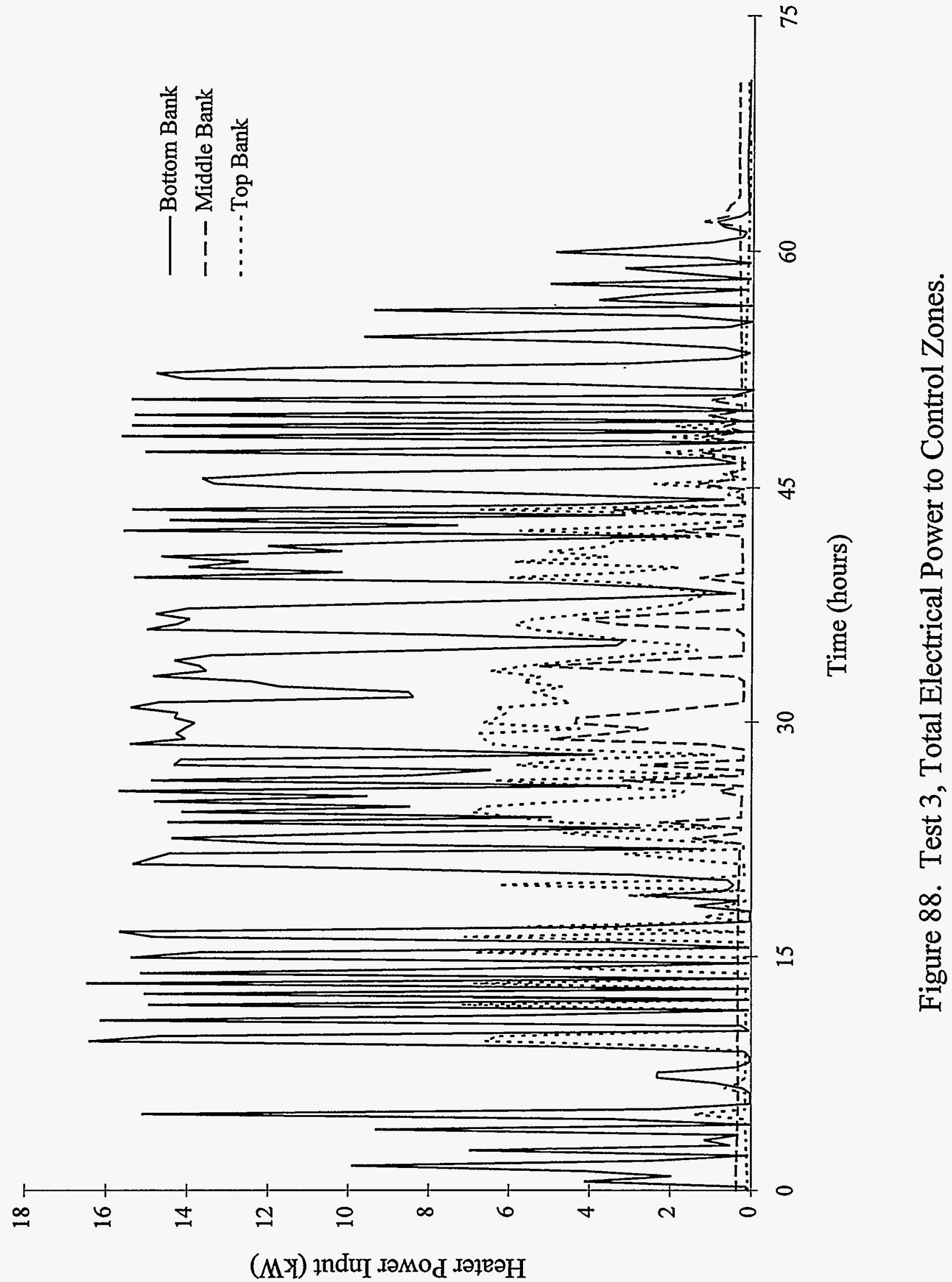




\subsection{Summary and Discussion of Results}

It is apparent from the data (and intuitively) that all of the various temperature sensors responded to the heaters much more rapidly than the massive RPV wall section unless these sensors were spot-welded to the wall.

At the soak temperature, all sensors read much the same; it was during the heat-up and cooldown that large differences occurred. Differences between the probes and the true wall temperature can be as large as $150^{\circ} \mathrm{C}\left[270^{\circ} \mathrm{F}\right]$ for the $28^{\circ} \mathrm{C} / \mathrm{hr}\left[50^{\circ} \mathrm{F} / \mathrm{hr}\right]$ heat-up rate and $90^{\circ} \mathrm{C}$ $\left[160^{\circ} \mathrm{F}\right]$ for the $14^{\circ} \mathrm{C} / \mathrm{hr}$ [ $\left.25^{\circ} \mathrm{F} / \mathrm{hr}\right]$ heat-up rate. See, for example, Figure 24 . Not only is the temperature in error but so is the heating rate. The probes in Figure 39 (Test 2) were controlling to the prescribed $28^{\circ} \mathrm{C} / \mathrm{hr}\left[50^{\circ} \mathrm{F} / \mathrm{hr}\right]$ per hour rate. The wall, however, was heating up at $36^{\circ} \mathrm{C} / \mathrm{hr}$ $\left[64^{\circ} \mathrm{F} / \mathrm{hr}\right]$ at about 18 hours (see Figure 41 ). Since the heat-up rate is set to control thermal stresses within the RPV, the faster rate may be significant.

Shunting does not appear to be a problem in this temperature range and configuration. Figures 37,62 , and 87 show that the thermocouple (W37) routed along the face of the heaters and then terminated on the cold frame of the experimental apparatus showed no noticeable error. However, in an actual anneal, the heaters may be designed to operate at a higher temperature than the heaters in this experiment. Since the probe thermocouples may be routed between the heaters and the RPV wall, shunting should be investigated as a part of the actual heater-thermocouple design (if $\mathrm{MgO}$-insulated, metal-sheathed thermocouples are used).

The experimental matrix results on the ball thermocouple probes are summarized as follows:

- Ball material: In all three tests during the heat-up, the brass ball-probes showed smaller errors than the stainless steel ball-probes. Therefore, a higher thermal conductivity is desirable. In two of the tests during the soak, there was no clear distinction as to which probe had smaller errors; during the third test's soak period, the brass probes showed slightly lower errors. During the cool-down there was no clear distinction as to which probe material showed the lower errors.

- Ball emissivity: In all three tests during the heat-up, polished ball-probes had smaller errors than blackened probes, i.e., a low emissivity is desirable. During the soak, polished probes showed slightly less error but during the cool-down there was no clear distinction.

- Ball size: On Test 1 , the smaller ball size (1.9 cm [0.75 in.]) had the lowest error during the heat-up, but on all tests the data were inconclusive during the soak. During the heat-up and cool-down in Tests 2 and 3, the larger balls $(2.5 \mathrm{~cm}$ [1.0 in.]) showed slightly lower errors.

- Location of thermocouple measuring junction within the ball: In Test 1 , the TC located closest to the wall had the lowest errors during the heat-up, but in Test 2, the 
center TC showed the lowest errors. During the soak in all three tests there was no clear distinction. During the cool-down in Tests 2 and 3 the center TCs again showed the lowest errors.

From the preceding summary, one can see that in some cases, there was a clear trend for lower errors using brass balls and polished balls. The polished balls indicated less error because of their lower absorptivity, which results in the ball being affected less by the radiative heat from the heaters. Because the polished balls were more like the stainless steel clad RPV surface than were the blackened balls, the polished balls responded more like the RPV surface, and therefore showed less error. This is a well-known problem when measuring temperature in a radiative environment. One way to reduce the errors is to use thermal radiation shielding on unshielded probes.

One of the reasons the brass balls showed lower errors is due to a lower contact resistance. Kraus and Bar-Cohen (1983) discuss thermal contact resistance and how to reduce it. The Tien correlation for nominally flat, rough surfaces in a vacuum provides qualitative guidance to assess what can be done to reduce contact resistance:

$\mathrm{h}_{\mathrm{tc}}=0.55(\mathrm{k} / \mathrm{r}) \mathrm{m}\left(\mathrm{P}_{2} / \mathrm{H}\right)^{0.85}$

where $h_{t c}$ is the thermal contact coefficient (units: $\mathrm{W} / \mathrm{m}^{2}-^{\circ} \mathrm{C}\left[\mathrm{Btu} / \mathrm{hr}-\mathrm{ft}^{2}-^{\circ} \mathrm{F}\right]$, same unit of measure as the convective heat transfer coefficient $h), k\left[2 k_{1} k_{2} /\left(k_{1}+k_{2}\right)\right]$ is an effective thermal conductivity $\left(\mathrm{W} / \mathrm{m}^{\circ}{ }^{\circ} \mathrm{C}\right.$ $\left[\mathrm{Btu} / \mathrm{hr}-\mathrm{ft}-{ }^{\circ} \mathrm{F}\right]$ ), $\mathrm{r}$ is the root-mean-square surface roughness ( $\mathrm{m}[\mathrm{ft}]$ ), $\mathrm{m}$ is the root-mean-square slope of surface asperities (peaks, dimensionless), $\mathrm{P}_{\mathrm{a}}$ is the contact pressure $\left(\mathrm{kg} / \mathrm{m}^{2}\left[\mathrm{lbf} / \mathrm{in}^{2}\right]\right.$ ), and $\mathrm{H}$ is the material hardness $\left(\mathrm{kg} / \mathrm{m}^{2}\left[\mathrm{lb} / \mathrm{f}^{2}\right]\right)$. To reduce the RPV temperature measurement probe error, one wants to increase the thermal contact coefficient to decrease the thermal contact resistance.

In the Tien correlation, Eq. [1], one can see that the thermal contact coefficient $\left(h_{t c}\right)$ is proportional to the contact pressure $\mathrm{P}_{\mathrm{a}}$, inversely proportional to the hardness $\mathrm{H}$, and depends on the thermal conductivity of the two surfaces (in this case the RPV wall and the ball probe). Writing Eq. [1] for brass and stainless steel balls, assuming the RPV wall is stainless steel and taking the ratio of the two equations, one can assess the ratio between the thermal contact coefficient of the brass ball compared with the stainless steel ball. Performing that analysis, one arrives at the following equation:

$h_{L c b} / h_{L C S S}=\left(2 k_{b} /\left[k_{b}+k_{S S}\right]\right)\left(H_{S S} / H_{b}\right)^{0.85}$

Typical values for thermal conductivity and hardness are as follows: 


\section{Investigation of RPV Temperature Measurement Methods}

Table 6: Typical Material Properties

\begin{tabular}{|c|c|c||}
\hline Material & $\begin{array}{c}\text { Thermal Conductivity } \\
\mathrm{W} / \mathrm{m}-{ }^{\circ} \mathrm{C}\left[\mathrm{Btu} / \mathrm{hr}-\mathrm{ft}-{ }^{\circ} \mathrm{F}\right]\end{array}$ & Hardness (Brinell) \\
\hline Brass & $112[65]$ & $55-180$ \\
\hline Stainless steel & $19[11]$ & $160-400$ \\
\hline
\end{tabular}

If one uses the average of the hardness values (brass $=117.5, \mathrm{SS}=280$ ) and evaluates Eq. [2], the ratio of the thermal contact coefficients of brass to SS is about 3.6, or the thermal contact coefficient of a brass ball is about 3.6 times larger than that for an SS ball. Therefore, a brass ball will produce a smaller error, which is consistent with the experimental data.

It can be easily understood why a higher thermal conductivity lowers the contact resistance, but it may not be obvious why a material with a lower hardness lowers the contact resistance. Kraus and Bar-Cohen show that (page 204) even with very low contact loads (e.g., $3.2 \times 10^{-5} \mathrm{~N}$ $\left[0.72 \times 10^{-5} \mathrm{lbf}\right]$ ), the asperities (peaks) of the surface are plastically deformed. Therefore, a probe material with lower hardness will plastically deform and increase the surface area in direct contact with the RPV surface. Because the RPV surface is weld deposited SS and rough, improving the contact area will improve the thermal contact coefficient and will reduce errors.

In summary, contact resistance between the probe and the RPV surface, and radiative coupling between the probe and the heater, are two sources contributing to probe error. Methods to reduce the probe error are as follows:

- Use radiative heat transfer shielding

- Shield the probe from radiative heat transfer from the heater

- Reduce thermal contact resistance between the probe and the RPV wall by:

- $\quad$ Using a probe material with lower hardness than that of SS

- Increasing the contact pressure of the probe to the wall

- Using a probe material with high thermal conductivity

\subsection{Thermal Model}

Because there is such a large error associated with all of the probes, a model was developed to correct probe readings to more accurately predict the actual RPV wall temperature. The model estimates were based on probe readings. The model only accounts for the radiation heat balance on the probe, wall, and heater surfaces; convection and conduction effects are neglected. As will be seen, this model applies best to the ball-probes, based on the view factors used. Great care should be exercised when using this model for other configurations. The model should be modified for the case being evaluated and convection and conduction effects should be 


\section{Investigation of RPV Temperature Measurement Methods}

considered. The main purpose of presenting this (simple) model was to show that it is possible to correct the probe readings to obtain a better estimate of the RPV wall temperature.

The heat balance leads to an expression for the rate of change of the wall temperature as a function of the probe rate, probe temperature, and wall temperature at any instant in time:

$$
\frac{d T_{w}(t)}{d t}=f\left[\frac{d T_{p}(t)}{d t}, T_{p}(t), T_{w}(t)\right]
$$

where $t$ is time, $T$ is absolute temperature and $p$ and $w$ are subscripts designating the probe and wall respectively. A predicted wall temperature for a future time, $t+\Delta t$ is:

$$
T_{w}(t+\Delta t)=T_{w}(t)+\Delta t \cdot \frac{d T_{w}(t)}{d t}
$$

The process begins at $t=0$ when $T_{w}=T_{p}$. As heating begins, the measured response of the probe, $T_{p}$ and $\left(d T_{p} / d t\right)$, and the last known value of the wall temperature are used to update the wall temperature.

The form of the function $f$ depends on the level of detail used in thermally modeling the wall. The lowest level of detail assumes the wall is backed with a perfect insulator and is constructed of a material with infinite thermal conductivity. For this case, the expression is:

$$
f\left(\frac{d T_{p}}{d t}, T_{p}, T_{w}\right)=\left[\frac{2 \cdot\left(\frac{\rho_{p} \cdot c_{p} \cdot \frac{D_{p}}{6}}{\varepsilon_{p}}\right)}{\left(\frac{2-\varepsilon_{w}}{\varepsilon_{w}}\right) \cdot \rho_{w} \cdot c_{w} \cdot L_{w}}\right] \cdot \frac{d T_{p}}{d t}+\frac{2 \cdot \sigma \cdot\left(T_{p}^{4}-T_{w}^{4}\right)}{\left(\frac{2-\varepsilon_{w}}{\varepsilon_{w}}\right) \cdot \rho_{w} \cdot c_{w} \cdot L_{w}}
$$

where $\rho, c, \varepsilon$ are density, specific heat, and surface emissivity. $\sigma$ is the Stefan-Boltzmann constant, $D_{p}$ and $L_{w}$ are the probe diameter and wall thickness.

Equation [5] is derived by writing the net heat flux from the wall and the probe surfaces as:

$$
\frac{q_{w}}{A_{w}}=J_{w}-J_{p} \cdot F_{w-p}-J_{h} \cdot F_{w-h}
$$

and 


$$
\frac{q_{p}}{A_{p}}=J_{p}-J_{w} \cdot F_{p-w}-J_{h} \cdot F_{p-h}
$$

where $q$ is the net heat flux leaving the surface, $J$ is the radiosity above the surface, $F$ is the view factor, and $A$ is the surface area. $h$ refers to the heater surface.

Using the reciprocity relation:

$$
A_{p} F_{p-w}=A_{w} F_{w-p}
$$

and noting that $A_{W} \gg A_{p}$, one arrives at the approximations:

$$
F_{w-p}=0
$$

In addition, assuming the wall and heaters can be approximated as two parallel surfaces in close proximity, one can assume:

$$
F_{w-h}=1
$$

and assuming the probe is a sphere placed between two infinitely large parallel plates:

$$
F_{p-w}=F_{p-h}=\frac{1}{2}
$$

Using the above assumptions, $J_{h}$ can be eliminated from the equations. Finally, if the definition of radiosity is inserted, one obtains the general relation:

$$
\left(\frac{2-\varepsilon_{w}}{\varepsilon_{w}}\right) \cdot \frac{q_{w}}{A_{w}}=\frac{2}{\varepsilon_{p}} \cdot \frac{q_{p}}{A_{p}}+2 \cdot \sigma \cdot\left(T_{w}^{4}-T_{p}^{4}\right)
$$

Treating the probe thermally as a lumped spherical mass with diameter $D_{p}$ gives

$$
\frac{q_{p}}{A_{p}}=-\rho_{p} \cdot c_{p}\left(\frac{D_{p}}{6}\right) \cdot \frac{d T_{p}}{d t}
$$

If the wall is treated similarly, and is further assumed to be perfectly insulated on the back side, then

$$
\frac{q_{w}}{A_{w}}=-\rho_{w} \cdot c_{w} \cdot L_{w} \cdot \frac{d T_{w}}{d t}
$$

Substitution of these two expressions into Eq. [9] and solving for $\left(d T_{w} / d t\right)$ results in Eq. [5]. 
It is worth noting, however, that with the above expressions, Eq. [9] could be solved directly for $T_{w}$, giving

$$
T_{w}=\left[\frac{\rho_{p} \cdot c_{p} \cdot D_{p}}{6 \cdot \sigma \cdot \varepsilon_{p}} \cdot \frac{d T_{p}}{d t}-\frac{\left(2-\varepsilon_{w}\right) \cdot \rho_{w} \cdot c_{w} \cdot L_{w}}{2 \cdot \sigma \cdot \varepsilon_{w}} \cdot \frac{d T_{w}}{d t}+T_{p}^{4}\right]^{\frac{1}{4}}
$$

Attractive as it may be, Eq. [12] proves to be unstable when applied to real data. The problem is caused by noise introduced in taking the time derivative of the probe readings and the calculated wall temperatures. The numerical derivative process amplifies small errors which when introduced into Eq. [10] result in large oscillations. In contrast, the methodology implied by Eq. [4] is an integration which smoothes over small errors and gives stable results. Equation [12] could perhaps be remedied by smoothing the probe data, however, in a real-time process, the integral method appears to be less complicated and just as effective.

The integral process (Eq. [4]) is applied to probe data in Figure 89. The data are taken from Test 1 and are from a 1.9-cm [0.75 in.] polished stainless steel probe (Probe 2). The calculated RPV wall section temperature is shown in the figure and can be compared with the measured RPV wall section temperature. The difference between the measurement and the calculation is also indicated.

The values used for $\varepsilon_{p}$ were 0.2 for the polished case and 0.85 for the blackened case. The blackened value (0.85) was obtained by measurements of the black paint in previous work at Sandia. The value of the RPV wall $\left(\varepsilon_{w}=0.85\right)$ was assumed because the RPV wall had been outside and had been exposed to several previous tests [Nakos et al., 1994] without being cleaned. From Kreith (1973) the values of 0.85 for "weathered" 18-8 stainless steel and 0.150.22 for polished $18-8$ stainless steel were offered.

There is a considerable degree of uncertainty in the values used for $\varepsilon_{w}(0.85)$ and $\varepsilon_{p}(0.2)$ due to the uncertain condition of the surfaces, but the value used for the blackened ball $\left(\varepsilon_{p}=0.85\right)$ is believed to be accurate. Due to the uncertainty in these values and the model's simplicity, no effort was expended to fit the experimental data by varying $\varepsilon_{p}$ and $\varepsilon_{w}$. See Appendix $B$ for more details regarding emissivity.

An additional assumption was that edge losses were neglected; this is believed to be a good assumption when probes located near the center of the RPV wall section were used. The results shown below are for PR2 and PR6. PR6 was located in the center horizontally and $29.2 \mathrm{~cm}$ [11.5 in.] below the top of the RPV; therefore, PR6 was most likely far enough away to preclude edge effects. PR2 was located $20.9 \mathrm{~cm}$ [8.2 in.] from the top and $25.4 \mathrm{~cm}$ [10.0 in.] from the right side of the RPV edge. Based on temperature contours presented in Nakos et al. (1994), it is reasonable to conclude that there are no significant edge effects present where PR2 is located. 


\section{Investigation of RPV Temperature Measurement Methods}

As can be seen in Figure 89, the correction scheme still leaves a maximum error on the order of $20^{\circ} \mathrm{C}\left[36^{\circ} \mathrm{F}\right]$. Furthermore, the error appears to be systematic. It is believed that the underestimate in the early part of the heat-up is due to the assumption of no gradient in the wall. At the higher temperatures, the assumption of no heat losses from the back side of the wall appears to be the reason for the overestimate. A limited study of modifying Eq. [11] to account for these two effects was conducted and it was found the error could be reduced, but not significantly.

The same correction scheme was applied to the spring-loaded thermocouple probe; the results are shown in Figure 90. The correction is implemented by assuming the probe ball diameter is zero in Eq. [5]. The error after the correction in this case is large and it is concluded that the simple radiation heat transfer model does not apply to a spring-loaded probe.

In Figure 91, an air probe (W33) is corrected and compared with the wall thermocouple readings directly opposite. The correction appears to be better in this case than in Figure 90; however, it is apparent a better model is needed for this type of measuring device.

Tables 7 to 9 quantify the results of variations in the ball thermocouple probe. The probe numbers are identified in Table 7 and the maximum error for each probe is listed in Table 8. Table 9 shows that the errors are reduced by applying the thermal radiation model.

There are a number of improvements that can be made and assumptions modified if one wants to use the type of correction factor methodology described above. Several of those improvements and assumptions are:

- Varying emissivity/absorptivity of RPV surface and probe

- Probe-to-RPV wall and probe-to-heater view factors (also called shape factors and configuration factors)

- Addition of conduction heat transfer in RPV wall and convective heat transfer to the probe

Appendix B provides a discussion of these items for those who are interested. 


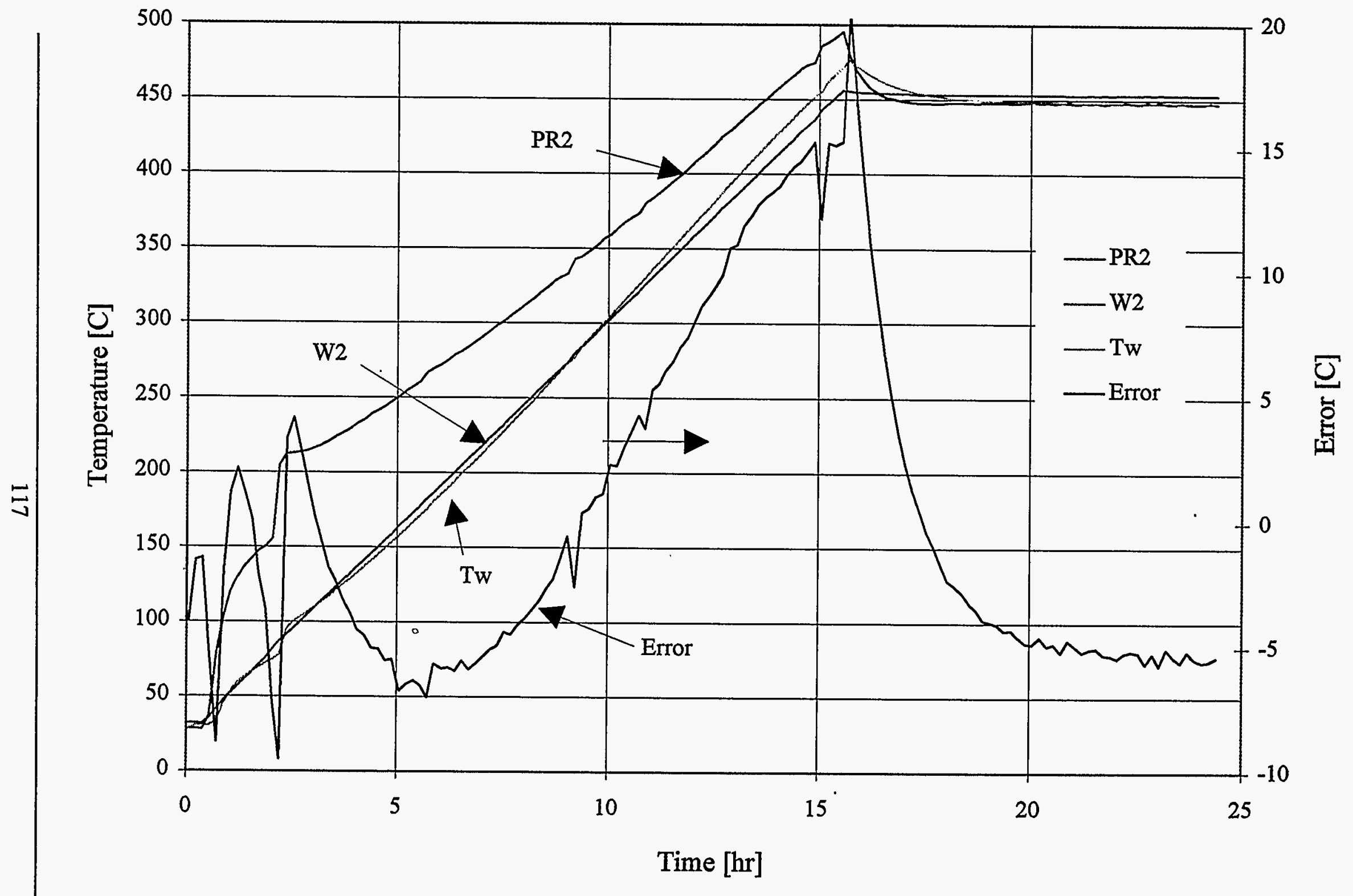

Figure 89: Test 1 Data and Corrective Model Results for a Ball-Probe 


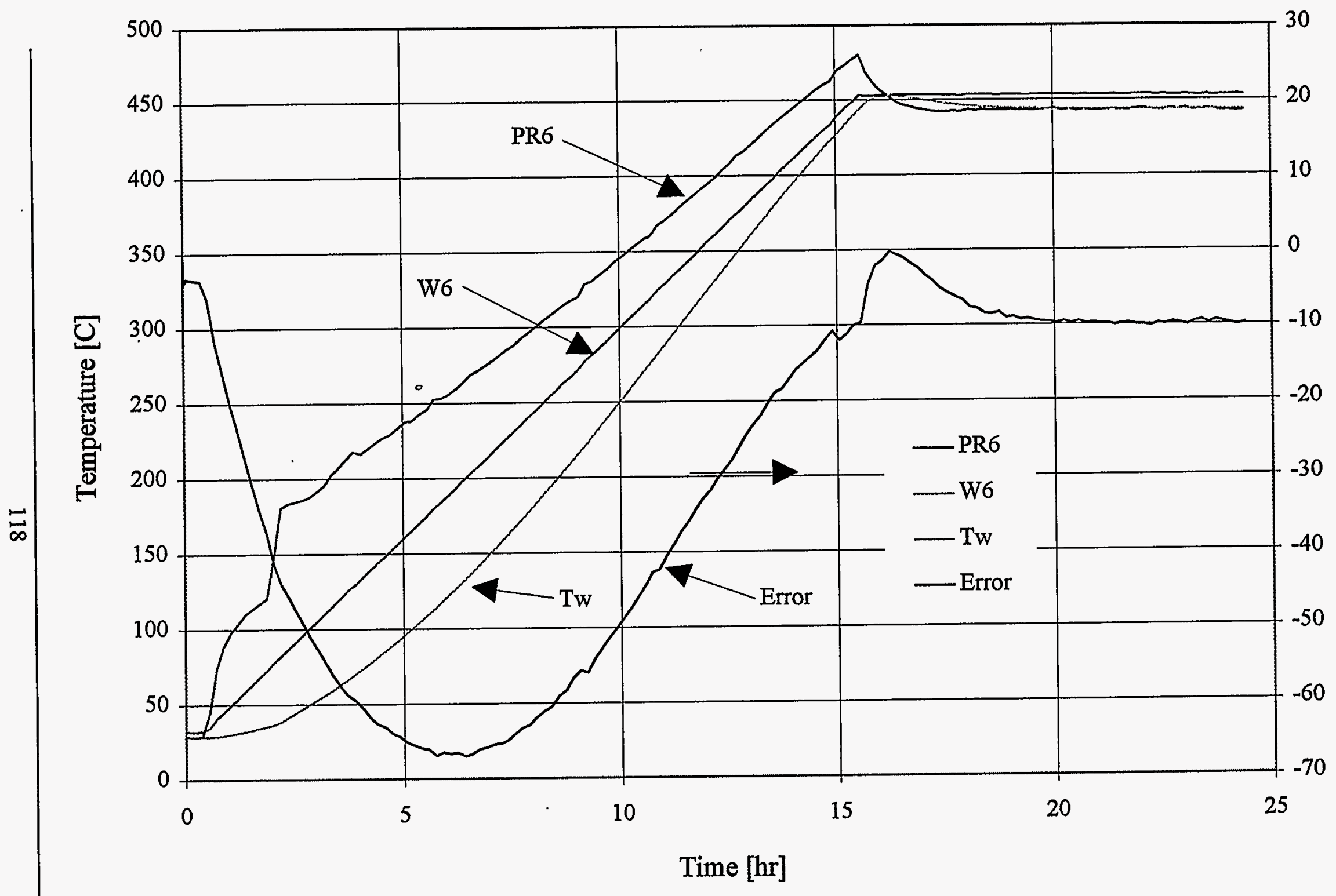

Figure 90: Test 1 Data and Corrective Model Results for a Spring-Loaded probe 


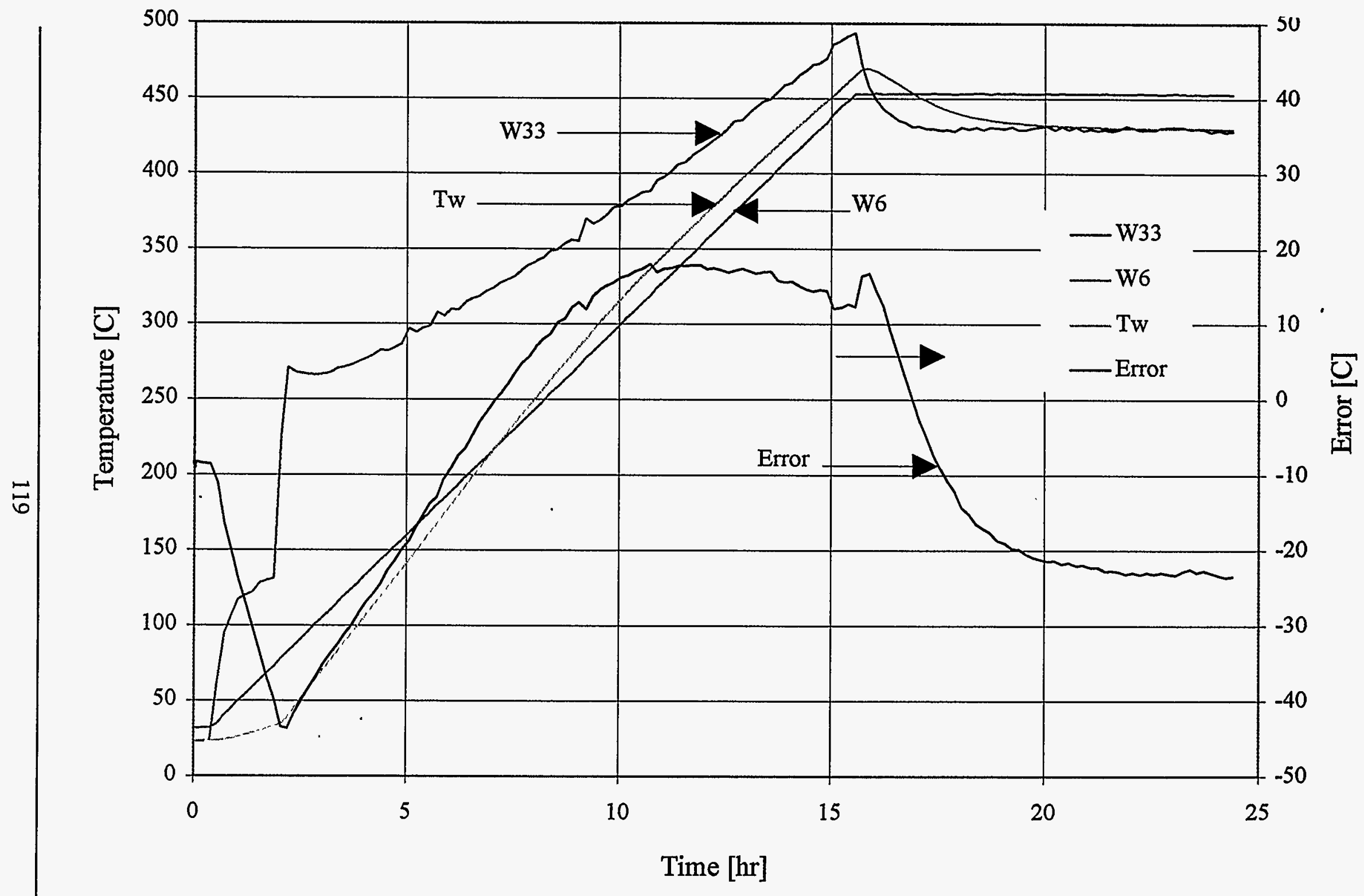

Figure 91: Test 1 Data and Corrective Model Results for an Air-Probe 


\section{Investigation of RPV Temperature Measurement Methods}

Table 7: Test Matrix Probe Identification Numbers

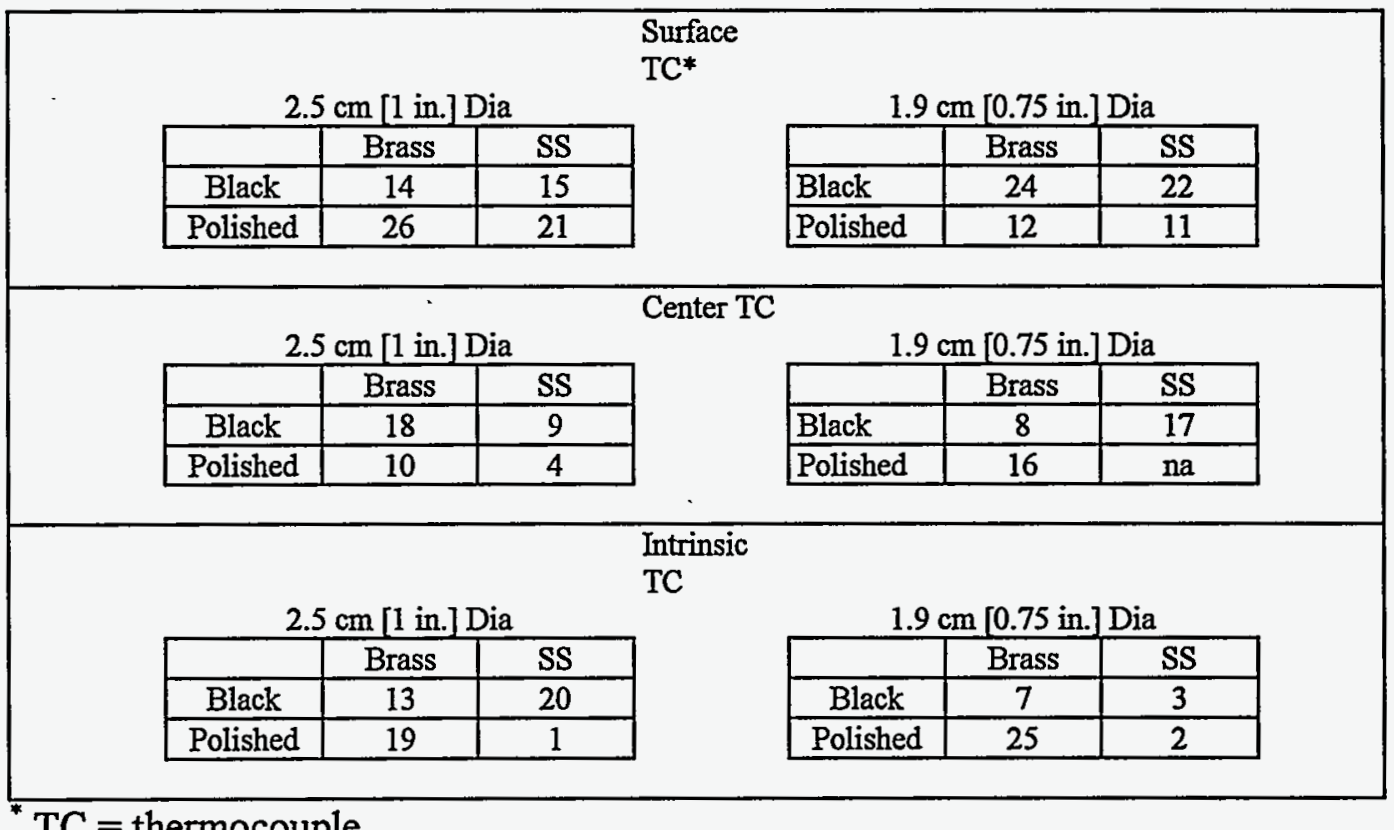

$\mathrm{TC}=$ thermocouple

\section{Table 8: Maximum Temperature Error, ${ }^{\circ} \mathrm{C}\left[{ }^{\circ} \mathrm{F}\right]$}

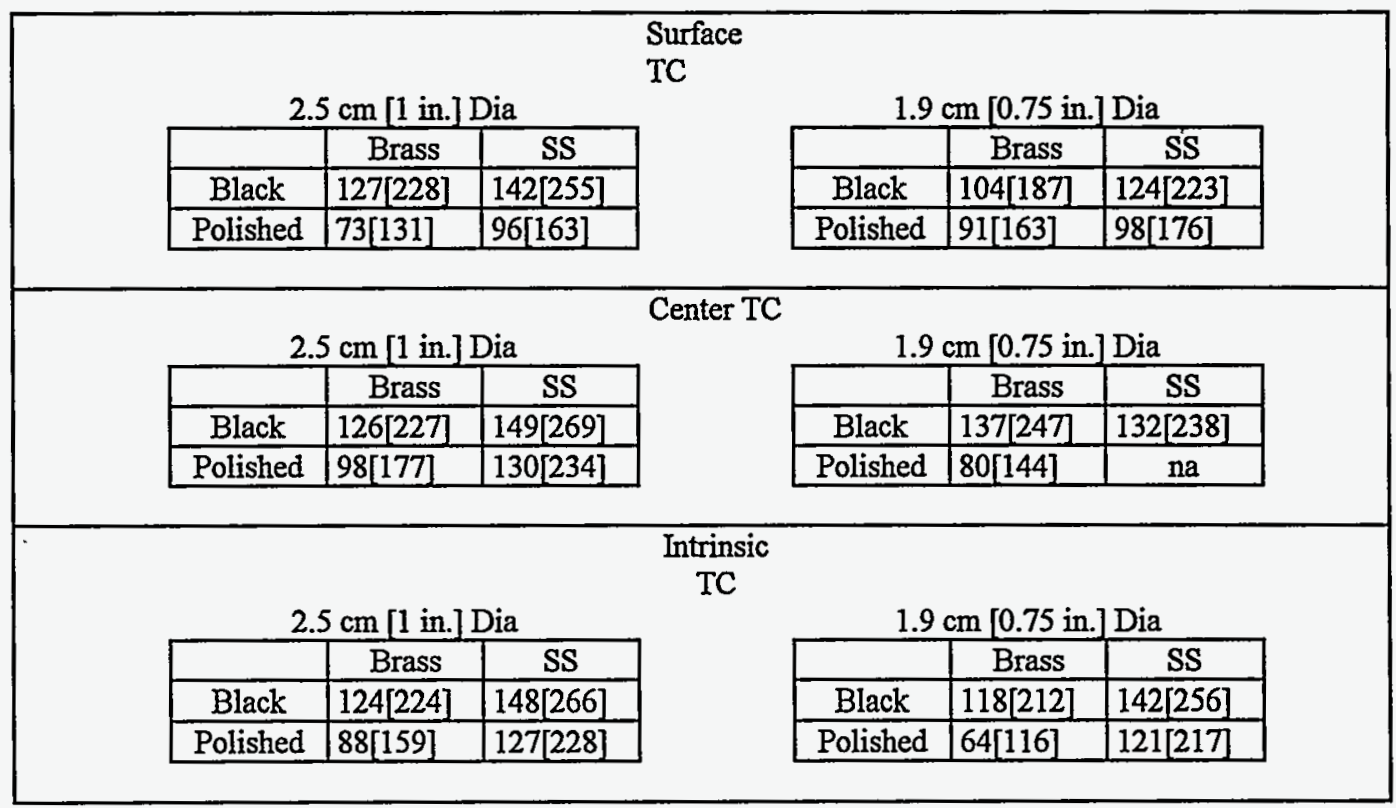




\section{Investigation of RPV Temperature Measurement Methods}

Table 9: Maximum Temperature Error after Radiation Model Correction, ${ }^{\circ} \mathrm{C}\left[{ }^{\circ} \mathrm{F}\right]$

\begin{tabular}{|c|c|c|c|c|c|c|}
\hline & & & $\begin{array}{l}\text { Surface } \\
\text { TC }\end{array}$ & & & \\
\hline & & \multicolumn{3}{|c|}{$1.9 \mathrm{~cm}[0.75 \mathrm{in}.] \mathrm{Dia}$} \\
\hline $2.5 \mathrm{~cm}$ [1 in.] Dia & Brass & SS & & & Brass & SS \\
\hline Black & $37[66]$ & $31[55]$ & & Black & $56[100]$ & $42[76]$ \\
\hline Polished & $68[122]$ & 44[79] & & Polished & $59[107]$ & $48[87]$ \\
\hline \multicolumn{4}{|r|}{ Center $\mathrm{T}$} & \multirow{2}{*}{\multicolumn{3}{|c|}{$1.9 \mathrm{~cm}[0.75 \mathrm{in}.] \mathrm{Dia}$}} \\
\hline \multicolumn{3}{|c|}{$2.5 \mathrm{~cm}$ [1 in.] Dia } & & & & \\
\hline & Brass & SS & & & Brass & SS \\
\hline Black & $40[72]$ & $31[56]$ & & Black & $37[66]$ & $43[77]$ \\
\hline Polished & $45[81]$ & $25[45]$ & & Polished & $58[105]$ & na \\
\hline \multicolumn{7}{|c|}{$\begin{array}{l}\text { Intrinsic } \\
\text { TC }\end{array}$} \\
\hline \multicolumn{3}{|c|}{$2.5 \mathrm{~cm}[1 \mathrm{in}.] \mathrm{Dia}$} & & \multicolumn{3}{|c|}{$1.9 \mathrm{~cm}[0.75 \mathrm{in}.] \mathrm{Dia}$} \\
\hline & Brass & SS & & & Brass & SS \\
\hline Black & $41[74]$ & $33[59]$ & & Black & $45[81]$ & $33[60]$ \\
\hline Polished & $58[105]$ & $26[47]$ & & Polished & $75[135]$ & $30[54]$ \\
\hline
\end{tabular}




\section{Investigation of RPV Temperature Measurement Methods}

\section{Conclusions}

The experiments investigated four temperature measurement methods: ball-probes, springloaded probes, air-suspended thermocouples, and an infrared thermocouple.

The results showed that:

- All probe designs overestimated the true RPV wall section temperature during the heat-up, and underestimated the RPV wall section temperature during the cool-down.

- Most probe designs had smaller errors during the soak portion (e.g., $\pm 5 \%$ or $\pm 23.6^{\circ} \mathrm{C}$ $\left.\left[ \pm 42.5^{\circ} \mathrm{F}\right]\right)$. This error is likely too large for a commercial anneal because a present estimate of the annealing temperature band is limited to $427^{\circ}-482^{\circ} \mathrm{C}\left[800^{\circ}-900^{\circ} \mathrm{F}\right]$.

- Probe-controlled tests showed considerable cycling of the electric heaters--this may cause excessive stress on the control system.

- Probe-controlled tests resulted in varying heat-up rates.

- Errors due to probe material, size, emissivity, and the location of the thermocouple measuring junction were studied; in general, the results show that materials with higher ball thermal conductivity (brass) and lower emissivity (polished balls) exhibit lower errors; however, it could not be determined whether ball size or TC locations within the ball had a distinguishable effect on probe errors in all cases.

- The infrared thermocouple showed errors similar to those of other probes, but failed during the first test.

A simple thermal model was developed to estimate the true temperature of an RPV wall during a thermal anneal. However, comparisons between the model and the experimental data indicate that the model must be improved in some cases. The model should not be used as is without a thorough review of the assumptions used and (perhaps) including convection and conduction effects.

We offer the following conclusions about how well the thermal model corrects the experimental data from the devices tested:

- Ball-thermocouple probe readings can be adequately corrected to RPV wall temperature with a simple radiation heat transfer model.

- Spring-loaded thermocouple probe readings cannot be adequately corrected to the RPV wall temperature with the simple radiation heat transfer model. 


\section{Investigation of RPV Temperature Measurement Methods}

- Air-suspended thermocouple readings also cannot be adequately corrected to RPV wall temperature with the simple radiation heat transfer model. 


\section{Investigation of RPV Temperature Measurement Methods}

\section{Suggestions for Further Investigations}

The present set of experiments showed that the main source of probe measurement error is insufficient thermal coupling between the wall and the probe, and excessive thermal (i.e., radiative) coupling between the probe and the heater. Therefore, the following suggestions are offered to improve the probe design and reduce the error:

- Investigate thermal radiation shielding designs, a well-known error reduction method, for the spring-loaded probes.

- Investigate other methods with closer probe surface contact with the RPV wall.

- Investigate methods that seek to establish an isothermal boundary layer between the RPV wall and a probe, and measure the temperature of the air boundary layer.

The following tests are desirable to ensure proper probe operation during actual anneals:

- Investigate exact designs that are proposed for the DOE-sponsored annealing demonstration projects.

- Determine the maximum temperature at which the heaters in an actual anneal will operate, then determine if thermocouple routing could cause shunting in that configuration.

- Investigate methods to ensure that the high radiation environment present in an operating reactor does not affect probe operation.

- Investigate commercially available and inexpensive thermocouple probes that may be used with at most slight modifications.

- Investigate noncontact temperature measurement schemes that are similar to, but more robust than, the $\mathrm{Ir} / \mathrm{tc}^{\text {}}$.

This work can be used in DOE's annealing demonstration projects (ADPs) at Marble Hill and Midland to design more accurate probes. It can also be used by utilities that intend to perform an anneal on an operating plant. 


\section{References}

Cole, N.M., and T. Friderichs. 1991. 'Report on the Annealing of the Novovoronezh Unit 3 Reactor Vessel in the USSR," U.S. Nuclear Regulatory Commission, NUREG/CR-5760, MPR Associates, Alexandria, VA.

Kraus, A.D., and A. Bar-Cohen. 1983. Thermal Analyses and Control of Electronic Equipment, Hemisphere Publishing, McGraw-Hill, New York.

Kreith, F., 1973. Principles of Heat Transfer, 3rd ed., Intext, New York, p. 237.

Nakos, J.T., S.T. Rosinski, and R.U. Acton. 1994. "1-Dimensional Simulation of Thermal Annealing in a Commercial Nuclear Power Plant Reactor Pressure Vessel Wall Section," SAND94-0135, Sandia National Laboratories, Albuquerque, NM.

Tien, C.L., 1968. "A Correlation for Thermal Contact Conductance of Nominally Flat Surfaces in a Vacuum,"Proc. 7th Conf. on Thermal Conductivity, National Bureau of Standards, Gaithersburg, MD., pp. 755-759, November 1967. Published in National Bureau of Standards Special Publication 302. 


\section{Appendix A: Data on Shunting}

Several of the authors of this report have examined shunting of metal-sheathed thermocouples in the past. A large fire test facility is maintained by Sandia National Laboratories. Pool fires as

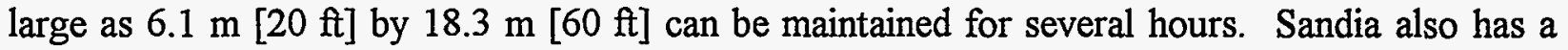
large radiant heat facility where arrays of linear quartz lamps can be powered with up to $5 \mathrm{MW}$ of electrical energy. In both facilities, long runs of sheathed thermocouples that traverse a spectrum of temperatures are very common.

Figure Al shows a schematic of an experimental setup designed to examine thermocouple shunting (insulation breakdown). This experiment was performed at the Radiant Heat Facility. Five identical, sheathed thermocouples were placed in a stainless steel cylinder. One thermocouple (TC5) terminated inside the cylinder and read the temperature of thermocouple sheaths TC1-TC4. Two thermocouples were routed through the cylinder with $6.1 \mathrm{~m}[20 \mathrm{ft}]$ of their length coiled inside the cylinder. Two other thermocouples were routed through the cylinder with only $1.2 \mathrm{~m}$ [4 $\mathrm{ft}$ ] of their length inside the cylinder. All four of the measuring junctions of these thermocouples terminated in an ice bath outside the stainless steel cylinder. Finally, one thermocouple measured the ice bath temperature (see Table A1). The cylinder was heated to $1010^{\circ} \mathrm{C}\left[1850^{\circ} \mathrm{F}\right]$. The results of this test are shown in Figure A2. All TCs except TC5 should have read the ice bath temperature, $0^{\circ} \mathrm{C}\left[32^{\circ} \mathrm{F}\right]$. At a sheath temperature (TC5) of about $1000^{\circ} \mathrm{F}$, TCs 1-4 begin to exhibit shunting errors. The errors rose to a maximum of about $21^{\circ} \mathrm{C}\left[70^{\circ} \mathrm{F}\right]$ at 58 minutes, then dropped when the sheath temperature was purposely lowered, then rose again when the sheath temperature was raised. The data show that TCs with the longest length $(6.1 \mathrm{~m}$ [20 ft]) inside the cylinder (TC2 and TC3) had the largest error; conversely, those with the shortest length inside the cylinder $(1.2 \mathrm{~m}[4 \mathrm{ft}])$ had the smallest error. Also, both TCs with the shortest distance $(1.2 \mathrm{~m} \mathrm{[4} \mathrm{ft}])$ from the cylinder to the ice bath (TC3 and TC4) had lower errors than TCs 1 and 2, which had the longest distance $(6.1 \mathrm{~m}[20 \mathrm{ft}])$ from the cylinder to the ice bath. 


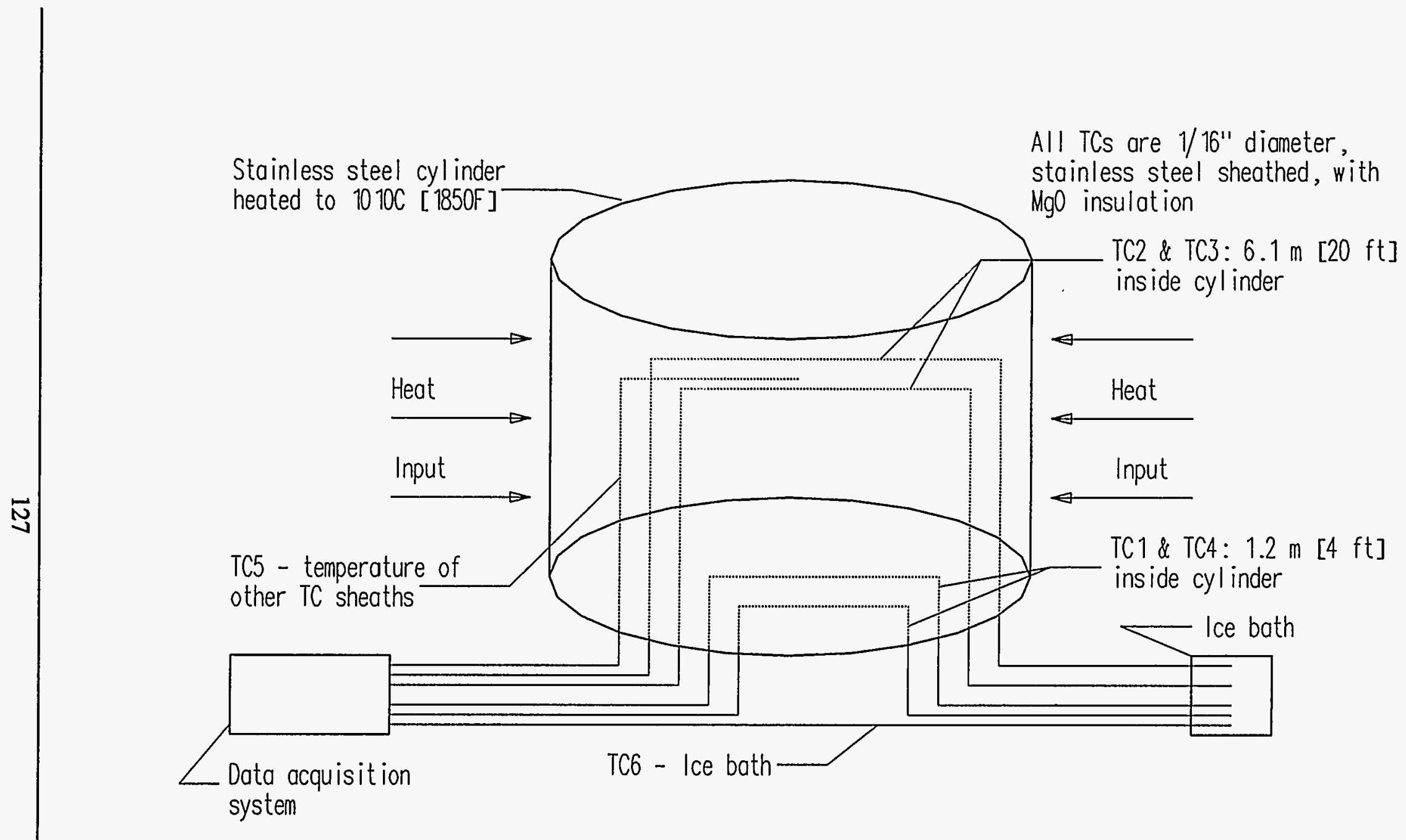

Figure A1. Thermocouple Shunting Experiment. 


\section{Table A1: Thermocouple Locations in Shunting Experiment}

\begin{tabular}{|c|c|c|c|}
\hline Thermocouple & $\begin{array}{c}\text { Location of Measuring } \\
\text { Junction }\end{array}$ & Length Inside Cylinder & $\begin{array}{c}\text { Length from Cylinder } \\
\text { to Ice Bath }\end{array}$ \\
\hline $\mathrm{TC} 1$ & Ice bath & $1.2 \mathrm{~m}[4 \mathrm{ft}]$ & $6.1 \mathrm{~m}[20 \mathrm{ft}]$ \\
\hline $\mathrm{TC} 2$ & Ice bath & $6.1 \mathrm{~m}[20 \mathrm{ft}]$ & $6.1 \mathrm{~m}[20 \mathrm{ft}]$ \\
\hline $\mathrm{TC} 3$ & Ice bath & $6.1 \mathrm{~m}[20 \mathrm{ft}]$ & $1.2 \mathrm{~m}[4 \mathrm{ft}]$ \\
\hline $\mathrm{TC} 4$ & Ice bath & $1.2 \mathrm{~m}[4 \mathrm{ft}]$ & $1.2 \mathrm{~m}[4 \mathrm{ft}]$ \\
\hline $\mathrm{TC5}$ & $\begin{array}{c}\text { Sheath inside } \\
\text { cylinder }\end{array}$ & - & - \\
\hline $\mathrm{TC6}$ & Ice bath & None & - \\
\hline
\end{tabular}

Other investigators (McDearman, Googe, and Shepard, 1989; Burnett and Gentry, 1984) have looked at the shunting problem and developed models that predict the errors if a number of variables are known:

- thermocouple type

- sheath diameter

- insulation type, e.g., magnesium oxide

- electrical resistivity of insulation

- temperatures along thermocouple path length and length of those temperature zones

Some of the parameters that have been found to influence shunting errors are

- thermocouple diameter

- insulation type

- higher temperatures

- manufacturer 


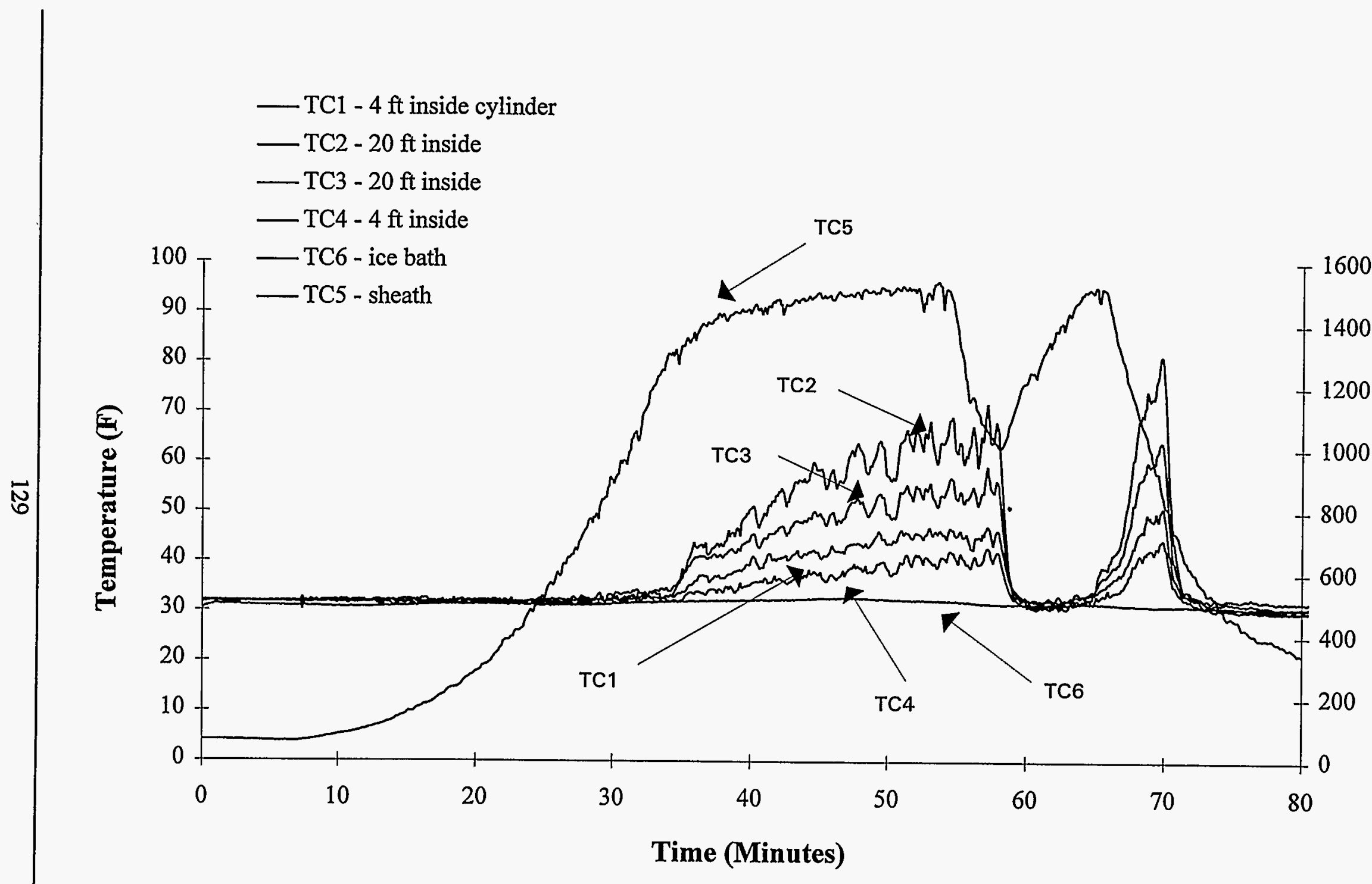

Figure A2. Results of Sheathed Thermocouple Shunting Experiments. 


\section{Investigation of RPV Temperature Measurement Methods}

\section{A.1 References}

McDearman, J.R., J.M. Googe, and R.L. Shepard, 1989. "A Three-Wire Insulator Shunting Model for High Temperature Thermocouple Errors," IEEE Trans. Ind. Elec. Control Instrum. Vol. IECI-18(4) pp. 137-144.

Burnett, P., and P.J. Gentry, 1984. "Insulation Degradation Errors in Long, Metal Sheathed Thermocouples: Calculations and Measurements," Inst. Chem. Eng. Symp. Ser. Vol. 86, pp. 933950. 


\section{Investigation of RPV Temperature Measurement Methods}

\section{Appendix B: Thermal Model Enhancements}

As indicated at the end of Section 4.4, there are several enhancements that can be made to the thermal model. Also, certain assumptions related to surface emissivity (absorptivity) and view (shape or configuration) factors will be discussed. This appendix is intended for those who wish to use the correction factor model, but wish to modify it to suit their situation and improve it to make the correction factors more accurate.

\section{B.1. Surface Emissivity}

Surface emissivity and absorptivity are often used interchangeably without explanation. Strictly speaking, emissivity and absorptivity are not equal unless a number of conditions are met, see for example Siegel and Howell (1972), page 65. Most of the conditions are concerned with directional dependencies and whether the surface is diffuse (i.e., not shiny). Measuring absorptivity is more difficult than measuring emissivity, and most often the assumption used is that the emissivity equals the absorptivity. This will be the case here. This is a good assumption for the blackened balls and the "weathered" RPV surface; it may not be as good for the polished (brass or SS) balls. However, it is difficult to improve these values because there are no accurate data. In fact, as will be shown below, the variability of reported emissivities is large. The two surfaces where emissivities are needed are the ball-probe and the RPV wall. The RPV wall will be discussed first.

The RPV wall is made of A533B steel with a stainless steel cladding. The cladding is weld deposited onto the base metal and the surface is rough (see Figure 8). As shipped from EPRI, the RPV section was dirty but not rusted. The surface was cleaned with a solvent to remove the loose dirt, but the resulting surface was not shiny. After the first series of tests with this RPV wall section, the surface was further oxidized; one may call it "weathered." Table B-1 shows emissivity values reported in various heat transfer texts. As can be seen, the variability is quite large: from a low of 0.16 for Type 310 polished SS to 0.9 for Type 310 oxidized SS. In addition, emissivities vary a large amount even when they are described the same, e.g., "polished" or "smooth" values range from a low of 0.16 to a high of 0.39 (a $144 \%$ increase over the low value). For "weathered," "after heating," or "oxidized" stainless steels, the values range from a low of 0.44 to a high of 0.90 (a $105 \%$ increase over the low value).

From the analyst's point of view, the large variability of emissivity makes the job of obtaining accurate results very difficult, unless accurate emissivity values can be obtained (e.g., by in situ measurements) for the case being considered. The same kind of variability would likely occur for the polished balls (either brass or SS). However, this would not be a problem with the blackened balls because the balls were painted with the high-emissivity black paint (Pyromark Black) which has been extensively characterized in previous experimental work at Sandia. In fact, it is sometimes more desirable to paint a test specimen with a paint like Pyromark Black in situations where the primary mode of heat transfer is radiative and the surface properties (e.g., emissivity) are not well known, to reduce analytical uncertainties. 
Table B-1: Emissivity Values

\begin{tabular}{|c|c|c|}
\hline Source of Information & $\begin{array}{c}\text { Emissivity or Absorptivity } \\
\text { Values }\end{array}$ & Comments \\
\hline Heat Transfer, by Frank & $\begin{array}{l}\text { Emissivity values } \\
\text { (assumed to be total } \\
\text { emissivity) } \\
\text { 1) } 0.18-0.22 \\
\text { 2) } 0.85\end{array}$ & $\begin{array}{l}\text { 1) } 18-8 \mathrm{SS} \text {, polished, } 38^{\circ}-538^{\circ} \mathrm{C}\left[100^{\circ}-1000^{\circ} \mathrm{F}\right] \\
\text { 2) } 18-8 \mathrm{SS} \text {, weathered, } 38^{\circ}-538^{\circ} \mathrm{C}\left[100^{\circ}-1000^{\circ} \mathrm{F}\right]\end{array}$ \\
\hline $\begin{array}{l}\text { Thermal Radiation Heat } \\
\text { Transfer, by R. Siegel and } \\
\text { J.R. Howell }\end{array}$ & $\begin{array}{l}\text { Normal-total emissivity } \\
\text { values: } \\
\text { 1) } 0.19-0.20 \\
\text { 2) } 0.19-0.22 \\
\text { 3) } 0.16 \\
\text { 4) } 0.39 \\
\text { 5) } 0.24-0.31 \\
\end{array}$ & $\begin{array}{l}\text { 1) Inconel } \mathrm{X} \text {, polished, } 149^{\circ}-482^{\circ} \mathrm{C}\left[300^{\circ}-900^{\circ} \mathrm{F}\right] \\
\text { 2) Inconel } \mathrm{B} \text {, polished, } 149^{\circ}-482^{\circ} \mathrm{C}\left[300^{\circ}-900^{\circ} \mathrm{F}\right] \\
\text { 3) Type } 301 \text {, polished, } 24^{\circ} \mathrm{C}\left[75^{\circ} \mathrm{F}\right] \\
\text { 4) Type } 310 \text {, smooth, } 815^{\circ} \mathrm{C}\left[1500^{\circ} \mathrm{F}\right] \\
\text { 5) Type } 316 \text {, polished, } 204^{\circ}-1038^{\circ} \mathrm{C}\left[400^{\circ}-1900^{\circ} \mathrm{F}\right]\end{array}$ \\
\hline $\begin{array}{l}\text { Thermal Radiation Heat } \\
\text { Transfer, by R. Siegel and } \\
\text { J.R Howell }\end{array}$ & $\begin{array}{l}\text { Normal-total absorptivity } \\
\text { value: } \\
0.37\end{array}$ & Type 301, polished \\
\hline Heat Transfer, by B. & $\begin{array}{l}\text { Normal-total emissivity } \\
\text { values: } \\
\text { 1) } 0.074 \\
\text { 2) } 0.44 \\
\text { 3) } 0.90\end{array}$ & $\begin{array}{l}\text { 1) Polished SS at } 100^{\circ} \mathrm{C}\left[212^{\circ} \mathrm{F}\right] \\
\text { 2) Type } 304 \text {, after heating, at } 216^{\circ} \mathrm{C}\left[420^{\circ} \mathrm{F}\right] \\
\text { 3) Type } 310 \text {, oxidized, at } 216^{\circ} \mathrm{C}\left[420^{\circ} \mathrm{F}\right]\end{array}$ \\
\hline
\end{tabular}

From the above, one should be very careful to use realistic emissivity values when applying the radiative correction factor model to actual situations, and should consider performing in situ measurements to confirm the assumed values.

\section{B.2. View Factors}

In Eq. [8] of Section 4.4, it was assumed that the physical configuration was that of two infinitely long parallel plates. For that configuration, view factors from the spherical ball-probe to the wall $\left(F_{p-w}\right)$ and from the probe to the heater $\left(F_{p-h}\right)$ were the same and equal to $1 / 2$. The location of the probe in relation to the plates does not affect the value of the view factor in this case. More precise view factors can be obtained by noting that the setup is really closer to a pair of finite parallel (183 cm [72 in.] x $183 \mathrm{~cm}$ [72 in.]) plates (almost flat and parallel). In this case, one should use the view factor relation from a sphere (radius $r$ ) to a rectangle (L1 by L2), where the sphere center is placed $d$ above rectangular corner $(r<d)$ :

$F(d, L 1, L 2)=(1 / 4 \pi) \arctan \left[\left(1 /\left\{(d / L 1)^{2}+(d / L 2)^{2}+(d / L 1)^{2}(d / L 2)^{2}\right\}\right)^{0.5}\right]$ 


\section{Investigation of RPV Temperature Measurement Methods}

In this case the distance $\mathrm{d}$ is $25 \mathrm{~cm}$ [10 in], $\mathrm{L} 1$ and $\mathrm{L} 2$ are $91.5 \mathrm{~cm}$ [36 in] x $91.5 \mathrm{~cm}$ [36 in]. The ball-probe diameters are $2.54 \mathrm{~cm} \mathrm{[1} \mathrm{in]} \mathrm{and} 1.91 \mathrm{~cm} \mathrm{[0.75} \mathrm{in].} \mathrm{To} \mathrm{obtain} \mathrm{the} \mathrm{entire} \mathrm{view} \mathrm{factor,} \mathrm{one}$ needs to use Eq. [B-1] four times, for each quarter of the RPV wall (remember that Eq. [B-1] applies to the case of a sphere to a corner of a rectangle). Therefore, the total view factor from the probe to the heater may be expressed as:

$F_{p-h}=F\left(x_{p}, y_{p} 10-\mathrm{dia} / 2\right)+F\left(x_{p}, 72-y_{p}, 10-\mathrm{dia} / 2\right)+F\left(72-x_{p}, y_{p}, 10-\mathrm{dia} / 2\right)+F\left(72-x_{p}, 72-y_{p}, 10-\mathrm{dia} / 2\right)$

and

$F_{p-w}=F\left(x_{p}, y_{p}, \operatorname{dia} / 2\right)+F\left(x_{p}, 72-y_{p}, \operatorname{dia} / 2\right)+F\left(72-x_{p}, y_{p}, \operatorname{dia} / 2\right)+F\left(72-x_{p}, 72-y_{p}, \operatorname{dia} / 2\right)$

where 'dia' is the ball diameter and $x_{p}$ and $y_{p}$ are the probe coordinates (all values in inches). Using a ball diameter of $2.54 \mathrm{~cm}$ [1 in.], one can calculate the view factors as follows:

$F_{p-h}=0.364$, and $F_{p-w}=0.492$

Before one uses these modified view factors, the enclosure equations (see Section 4.4, Eqs. [6] and [7]) have to be rewritten to include another surface: the insulation filling the gap between the heater and the RPV wall:

$q_{w} / A_{w}=J_{w}-J_{w} F_{w-w}-J_{p} F_{w-p}-J_{h} F_{w-h}-J_{i} F_{w-i}$

$q_{p} / A_{p}=J_{p}-J_{\psi} F_{p-w}-J_{p} F_{p-p}-J_{h} F_{p-h}-J_{j} F_{p-i}$

$q_{i} / A_{i}=J_{i}-J_{w} F_{i-w}-J_{p} F_{i-p}-J_{h} F_{i-h}-J_{j} F_{i-i}$

where the subscript ' $i$ ' refers to the insulation in the gap between the heater and the RPV wall. A similar equation can be written for the heater, but it is not needed. Assuming $F_{w-w}=F_{p-p}=0$, also that $F_{w-p} \approx F_{h-p} \approx F_{i-p} \approx 0$, and the insulation is adiabatic $\left(q_{i}=0\right)$, one can reduce Eqs. [B-5] - [B-7] to the following:

$q_{w} / A_{w}=J_{w}-J_{h} F_{w h}-J_{i} F_{w-i}$

$q_{p} / A_{p}=J_{p}-J_{w} F_{p-w}-J_{h} F_{p-h}-J_{i} F_{p-i}$

$0=J_{i}-J_{w} F_{i-w}-J_{h} F_{i-h}-J_{i} F_{i-i}$

Equations [B-8] - [B-10] can be reduced to a single equation with $J_{w}$ and $J_{p}$ using the following method:

- Solve equation [B-10] for $J_{i}$,

- Substitute $J_{i}$ into [B-8] and [B-9],

- Solve both [B-8] and [B-9] for $J_{h}$,

- Set [B-8] and [B-9] equal to find the relation between $q_{w} / A_{w}$ and $q_{p} / A_{p}$. 
Once the algebra is done, the final solution is the same as that for the case of two infinitely parallel plates, Eq. [10] in Section 4.4. Therefore, the assumption of $F_{p-w}=F_{p-h}=1 / 2$ is a good assumption, as long as the gap is assumed to be adiabatic. Should the assumption in the gap be changed to include a finite heat transfer, the results would change. A more challenging application would be two concentric cylinders, the case of an actual anneal.

Finally, the actual values used only apply to the ball-probes and are not the same for the spring-loaded or air-suspended probes, which are more like cylinders with hemispherical tips. This is one reason why the model worked best for the ball-probes. Therefore, one should be careful to review the assumptions made in the analysis before using the model. This is especially the case if a spherical shape is not used for the measurement probe.

\section{B.3. Conduction and Convection Heat Loss Terms}

\section{Conduction}

In Section 4.4, Eq. [11] can be modified to account for temperature gradient in the RPV wall section and a finite amount of heat loss off the back (unheated) side. Equation [11] is a simplified version of the overall heat balance on the wall. It assumes there is no temperature gradient in the RPV wall, i.e., it is isothermal. One could modify the heat balance to take into account the fact that there is a finite wall temperature gradient.

Second, it was assumed that the unheated side boundary condition was adiabatic, i.e., a perfect insulator. In reality, there is a finite heat loss off the unheated side of the PRV wall. Therefore, Eq. [11] could be modified to account for this effect. If insulation were placed directly on the RPV wall, one would need to account for the insulation resistance and convection off the cool side of the insulation. If there was an air gap between the RPV wall and the insulation, the thermal resistance of the air gap would have to be included.

\section{Convection}

Equations [10] and [11] show the heat balance on the ball-probe and the wall. Both equations neglect convective heat transfer, because it is assumed to be a small contributor to the total. One may enhance the model by adding a convective heat gain/loss term to Eqs. [10] and [11]. For example, for the ball-probe, Eq. [10] could be modified in the following way:

$q_{p} / A_{p}+h_{p}\left(T_{p}-T_{q}\right)=-p_{p} \cdot c_{p} \cdot\left(D_{p} / 6\right) \cdot d T_{p} / d t$

where $T_{a}$ is the air temperature flowing by the ball-probe. Using the assumption that the air temperature is equal to the wall temperature, it was possible to estimate a convective heat transfer coefficient $h$. During the heat-up, the probe temperature is higher than the wall temperature, so there is a net heat loss by convection from the probe. A similar term could be added to Eq. [11]. 


\section{Investigation of RPV Temperature Measurement Methods}

For the probe, there is also a contact resistance term which may be of significant magnitude (see Section 4.3). However, this may be difficult to estimate accurately.

When modifying the radiation-only model, one should be careful about sign conventions used. In Eqs. [10] and [11], it was assumed that heat loss from the probe was positive, thus the negative sign in those equations. The same sign convention should be used if convection and conduction terms are added to the model.

If one chooses to add conduction or convection terms, an assessment of their magnitude should be made. If they are of negligible magnitude, then the radiation-only model should be used and the model tuned by varying the emissivitities and adding a contact resistance term to the probe heat balance.

Several of these enhancements were used to try to improve the results, and in fact the results can be improved if the constants (emissivity, heat transfer coefficient $h$, etc.) are varied to fit the data. However, because most of the heat transfer was by radiation, and the surface properties of the RPV and balls (except painted balls) were so poorly known, we did not feel confident in providing a detailed model with all the enhancements when there was so much uncertainty in the parameters used in the simple model.

\section{B.4. Summary}

In summary:

- Surface emissivity values for the stainless steel cladding on the RPV and the unpainted brass and stainless steel balls were not accurately known (i.e., inaccuracy $<10 \%$ ).

- If shapes other than spheres are used for the RPV temperature measurement probes, one should recalculate the view factors.

- One can very likely enhance the correction factor model by including conduction and convection heat loss/gain terms in Eqs. [10] and [11] of Section 4.4, but only if one can accurately assess the emissivity values used in the radiative calculations. Otherwise one may obtain results with false confidence. 


\section{Investigation of RPV Temperature Measurement Methods}

\section{B.5 References}

Gebhart, Benjamin, 1971. Heat Transfer, 2nd ed., McGraw-Hill, New York.

Kreith, Frank, 1973. Principles of Heat Transfer, 3rd ed. Intext, New York.

Siegel, Robert, and John R. Howell, 1972. Thermal Radiation Heat Transfer, McGraw-Hill, New York. 


\section{DISTRIBUTION}

\section{Department of Energy}

Sterling Franks, III

U.S. Department of Energy, NE-451

19901 Germantown Road

Germantown, MD 20852

Dennis Harrison

U.S. Department of Energy, NE-451

19901 Germantown Road

Germantown, MD 20852

John Warren

U.S. Department of Energy, NE-451

19901 Germantown Road

Germantown, MD 20852

Duli Agarwal

U.S. Department of Energy, NE-451

19901 Germantown Road

Germantown, MD 20852

Nuclear Regulatory Commission

Ed Hackett

U.S. Nuclear Regulatory Commission MS OWFN7D4

Washington, D.C. 20555

Debra Jackson

U.S. Regulatory Commission

MS OWFN11F23

Washington, D.C. 20555

Shah Malik

U.S. Nuclear Regulatory Commission MS T10-E10

Washington, D.C. 20555

Mike Mayfield

U.S. Nuclear Regulatory Commission 5650 Nicholson Lane, M.S. 217C NL/S Rockville, MD 20852
Al Taboada

U.S. Nuclear Regulatory Commission 5650 Nicholson Lane, M.S. 217C NL/S

Rockville, MD 20852

Keith Wichman

U.S. Nuclear Regulatory Commission 11555 Rockville Pike, M.S. 7D4

Rockville, MD 20852

EPRI

Larry Becker

EPRI Component Reliability Center 1300 Harris Boulevard

Charlotte, NC 28262

John Carey

Electric Power Research Institute

3412 Hillview Avenue

Palo Alto, CA 94303

Robert Carter

EPRI Component Reliability Center 1300 Harris Boulevard

Charlotte, NC 28262

Stan Rosinski

EPRI Component Reliability Center 1300 Harris Boulevard

Charlotte, NC 28262

NEI

Kurt Cozens

Nuclear Energy Institute

1776 Eye Street, N.W., Suite 300

Washington, D.C. 20006-2496

National Labs

William Pennell (2 copies)

Oak Ridge National Laboratory

Post Office Box 2008

Oak Ridge, TN 37831 
Randy Nanstad

Oak Ridge National Laboratory

Post Office Box 2008

Oak Ridge, TN 37831

Mikhail Sokolov

Oak Ridge National Laboratory

Post Office Box 2008

Oak Ridge, TN 37831

NSSS Vendors

Dave Ayers

ABB Combustion Engineering

1000 Prospect Hill Road

Windsor, CT 06095-0500

P. Hijeck

ABB Combustion Engineering

1000 Prospect Hill Road

Windsor, CT 06095-0500

E. A. Siegel

ABB Combustion Engineering 1000 Prospect Hill Road

Windsor, CT 06095-0500

H. W. Behnke

Framatome Technologies

3315 Old Forest Road

Post Office Box 10935

Lynchburg, VA 24506-0935

Dave Darling

Framatome Technologies

3315 Old Forest Road

Post Office Box 10935

Lynchburg, VA 24506-0935

Larry Stanek

Framatome Technologies

3315 Old Forest Road

Post Office Box 10935

Lynchburg, VA 24506-0935
David Howell

Westinghouse Electric Company

Post Office Box 355

Pittsburgh, PA 15230-0355

Dave Roarty

Westinghouse Electric Corporation

P.O. Box 355

Pittsburgh, PA 15230

Rick Rishel

Westinghouse Electric Company

Post Office Box 355

Pittsburgh, PA 15230-0355

Don Seeger (2 copies)

Westinghouse Electric Corporation

P.O. Box 355

Madison, PA 15230-0355

R. Edward Kothmann

Science \& Technology Center

Westinghouse Electric Corporation

1310 Beulah Road

Pittsburgh, PA 15235

Lee Tunon-Sanjur

Westinghouse Electric Corporation

P.O. Box 355

Pittsburgh, PA 15230-0355

$\underline{\text { Utilities }}$

T. Satyan Sharma

American Electric Power

One Riverside Plaza

Columbus, $\mathrm{OH} 43216$

Mike Melton

Arizona Public Service Company

411 North Central Ave.

Station 1796

Phoenix, AZ 85072 
Barth Doroshuk

Baltimore Gas \& Electric

Calvert Cliffs

Route 4 South

Lusby, MD 20657

Robert Hardies

Calvert Cliffs Nuclear Power Plant

1650 Calvert Cliffs Parkway

Lusby, MD 20657

Charles H. Griffin

Carolina Power \& Light

P.O. Box 1551

Raleigh, NC 27602-1551

Alex G. Panagos

Commonwealth Edison Company

Suite 400

1400 Opus Place

Downers Grove, IL 60515

Russell J. Tamminga

Commonwealth Edison Company

Suite 400

1400 Opus Place

Downers Grove, IL 60515

Bill Beckius

Consumers Power Company

Palisades Station

27780 Blue Star Highway

Covert, MI 49085

Thomas Buczwinski

Consumers Power Company

Palisades Station

27780 Blue Star Highway

Covert, MI 49085

Jack Hanson

Consumers Power Company

Palisades Nuclear Plant

27780 Blue Star Hwy

Covert, MI 49043
Greg Robison

Duke Power Company, EC09F

422 South Church Street

P.O. Box 1006

Charlotte, NC 28201-1006

Jeff Gilreath

Duke Power Company

526 South Church Street, MC EC09O

Post Office Box 1006

Charlotte, NC 28201

Greg Kammerdeiner

Director, Materials and Standards

Duquesne Light Company

Beaver Valley

P.O. Box 184

Shippingport, PA 15077

Ted Huminski

Duquesne Light Company

Beaver Valley

P.O. Box 184

Shippingport, PA 15077

Dan Fouts

Entergy Operations

Arkansas Nuclear One, Unit 1

P.O. Box 137G

Highway 64 West, GSB-3WEST

Russelville, AK 72801

Karen Head

Entergy Operations

Arkansas Nuclear One, Unit 2

P.O. Box 137G

Highway 64 West, GSB-3WEST

Russelville, AK 72801

Jai S. Brihmadesam

Entergy Operations

1340 Echelon Parkway

Jackson, MS 39213 
Steve Collard

Florida Power \& Light

700 Universe Boulevard

P.O. Box 14000

Juno Beach, FL 33408

Vince Roppel

Crystal River Nuclear Plant

Florida Power Corporation

P.O. Box 1240

Crystal River, FL 34429

Dave Miskiewicz

Florida Power Corporation

P.O. Box 14042, MAC C2M

St. Petersburg, FL 33733-4042

Terry Sides

Southern Nuclear Operating Co.

P.O. Box 1295

Birmingham, AL 35201-1295

Robin Dyle

Southern Nuclear Operating Co.

P.O. Box 1295

Birmingham, AL 35201-1295

George L. Lehmann

GPU Nuclear

100 Interpace Parkway

Parsippany, NJ 07054

Chung He Chen

GPU Nuclear

100 Interpace Parkway

Parsippany, NJ 07054

Chris Freer

Indiana Michigan Power

D.C. Cook Nuclear Power Plant

1 Cook Place

Bridgeman, MI 49106
Matthew L. Paquette

Northeast Utilities

P.O. Box 270

Hartford, CT 06141

J. Haseltine

Northeast Utilities

Connecticut Yankee Atomic Power

Haddam Neck Plant

362 Injun Hollow Road

East Hampton, Conn. 06424

Marcus Guinn

Omaha Public Power District

Energy Plaza

444 S. 16th Street Mall

Omaha, NE 68102

Kevin Holthaus

Omaha Public Power District

Energy Plaza

444 S. 16th Street Mall

Omaha, NE 68102

Phil Brashear

Pacific Gas and Electric Co.

333 Market

San Francisco, CA 94177

Mike Sullivan

Pacific Gas \& Electric Company

3400 Crow Canyon Road

San Ramon, CA 94583

Mahesh R. Danak

Public Service Electric \& Gas Co.

Hope Creek Power Station

P.O. Box 236

Hancocks Bridge, NJ 08038 
Ron Jaquin

Rochester Gas \& Electric Corp.

89 East Avenue

Rochester, NY 14649-0001

Keith Reeser

Southern California Edison

Mail Drop X345

23 Parkers Street

Irvine, CA 92718

Dana R. Couch

Tennessee Valley Authority

1101 Market St. LP 4F

Chattanooga, TN 37402

John Harrell

Virginia Power Company

Innsbrook Technical Center, M/S IN3SW

5000 Dominion Blvd.

Glen Allen, VA 23060

Joe Hegner

Virginia Power Company

Innsbrook Technical Center, M/S IN2E

5000 Dominion Blvd.

Glen Allen, VA 23060

James R. Pfefferle, P.E.

Wisconsin Electric Power Co.

P.O. Box 2046

Melwaukee, WI 53201

Ronda Fergusson

Wisconsin Public Service Corp.

700 N. Adams

P.O. Box 19002

Green Bay, WI 54307

Chuck Tomes

Wisconsin Public Service Corp.

600 N. Adams

Green Bay, WI 54302
International

Albert Fabry

SCK-CEN

Boeretang 200

B-2400, Mol

Belgium

Milan Brumovský

Nuclear Research Institute Řež plc

25068 Řež

Czech Republic

L. Myrddin Davies

176 Cumnor Hill

Oxford Oxon OX2 9PJ

England

Tapio M. Planman

VTT Manufacturing Technology

P.O. Box 1704

VTT FIN-02044

Finland

Matti Valo

VTT Manufacturing Technology

P.O. Box 17042

VTT FIN-02044

Finland

Ludwig Stumpfrock

Staatliche Materialprüfungsanstalt

Pfaffenwaldring 32

70569 Stuttgart

Germany

Leonid Sapojnikov

Director General

MOHT-OTJIG RM Ltd.

5, b.4, Potapovsky per.,

Centre, Moscow,

101000 
Sergei V. Selsky (2 copies)

Head of Department

D. Sci. Engineering

109088, Moscow

Sharikopodshipnikovskaya st., 4 NPO CNIITMASH

A. Nossovsky

D. Sci. Engineering 109088, Moscow

Sharikopodshipnikovskaya st., 4 NPO CNIITMASH

Sergei C. Morozov

VNIIAES

Ferganskaya St. 25

Moscow, Russia

Michael F. Rogov

GIDROPRESS

Ozdzhowikidze 21

Podolsk, Russia

\section{Others}

Ray Art

ASME, Suite 906

1828 L. Street N.W.

Washington, D.C. 20036-5104

Russ Acton

11519 Baldwin Ave. NE

Albuquerque, NM 87112

Russ Cipolla

APTECH Engineering Services

1282 Reamwood Avenue

Sunnyvale, CA 94089

Tim Griesbach

ATI Consulting

2010 Crow Canyon Place, Suite 140

San Ramon, CA 94583

William Server

ATI Consulting 2010 Crow Canyon Place, Suite 140

San Ramon, CA 94583
Bill Hopkins

Bechtel Power Corporation 9801 Washingtonian Blvd.

Gaithersburg, MD 29878-5356

Glenn Campbell (2 copies)

Cooperheat

1021 Centennial Ave.

Piscataway, NJ 08854

Mike Sciascia (2 copies)

Cooperheat

1021 Centennial Ave.

Piscataway, NJ 08854

Ed Bird

MPR Associates

320 King Street

Alexandria, VA 22314-3238

Noman Cole

MPR Associates

320 King Street

Alexandria, VA 22314-3238

Tom Friderichs

MPR Associates

320 King Street

Alexandria, VA 22314-3238

Nick Marrone

MPR Associates

320 King Street

Alexandria, VA 22314-3238

Robert Steele

MPR Associates

320 King Street

Alexandria, VA 22314-3238

Alex Zarechnak

MPR Associates

320 King Street

Alexandria, VA 22314-3238 
Internal

MS 0736 Nestor Ortiz (6400)

MS 0507 Kathleen McCaughey (9700)

MS 0835 Bruce Bainbridge (1513)

MS 0653 Bobby Strait (3522)

MS 1139 T.Y. Chu (6423)

MS 0741 Ajoy Moonka (6471)

MS 0741 John Clauss (6471)

MS $0741 \mathrm{Jim}$ Nakos (6471) - 10 copies

MS 0741 Gary Rochau (6471)

MS 1135 Jaime Moya (9735)

MS 1135 Walt Gill (9735)

MS 1135 Bill Jacoby (9735)

MS 1135 Jerry Meloche (9735)

MS 1135 David J. Sais (9735)

MS 1135 Dave Schulze (9735)

MS 0899 Technical Library (4414) 5 copies

MS 0619 Print Media (12615)

MS 0100 Document Processing for DOE/OSTI (7613-2) - 2 copies

MS 9018 Central Tech. Files (8523-2) 